\title{
The global justice movement and struggles over knowledge
}

Sky Croeser

This thesis is presented for the degree of Doctor of Philosophy of the University of Western Australia

School of Social and Cultural Studies

Discipline of Political Science and International Relations 


\section{Abstract:}

This dissertation argues that knowledge is a vital site of contestation for the global justice movement. In shaping scientific and technological developments actors alter political, economic, and social systems, just as these in turn alter knowledge systems. Struggles over knowledge are therefore vital to the work of the global justice movement. This thesis is elaborated through examination of two case studies: the opposition to genetically-modified crops in India, and the digital liberties movement. The former exemplifies some of the ways in which movements in the Global South have struggled over knowledge by calling for an end to the theft of their biodiversity and for traditional knowledge systems to be accorded legitimacy. The emerging digital liberties movement, based predominantly but not exclusively in the Global North, addresses attempts by government and business elites to (re)gain control over information and communications technologies. These attempts create threats to the ability of the global justice movement to organise and communicate. Both of these movements make vital and parallel contributions to the global justice movement's attempts to build a more democratic and diverse world.

Examination of these contributions extends the existing literature in three important respects. Firstly, it demonstrates the vital role that struggles over knowledge play in the global justice movement by exploring commonalities in the analysis and work of movements previously seen as disparate. Secondly, it argues for the value of a complex conceptualisation of the way in which movements, groups, and individuals relate and contribute to the global justice movement. Thirdly, it provides a critical analysis of the emergence of the digital liberties movement, and adds to existing work on the Indian opposition to genetically modified crops. 


\section{Table of Contents}

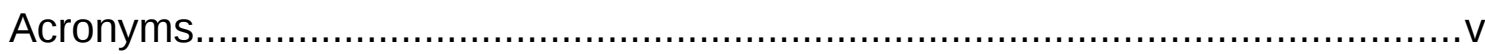

Acknowledgements............................................................................

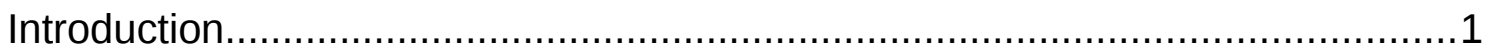

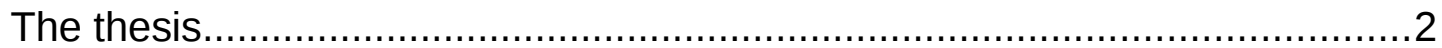

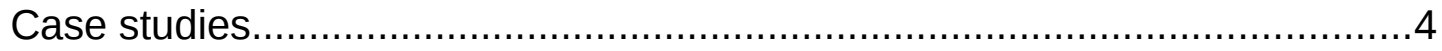

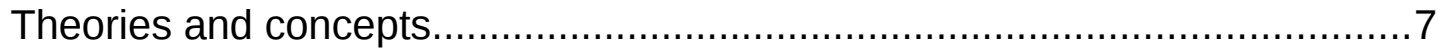

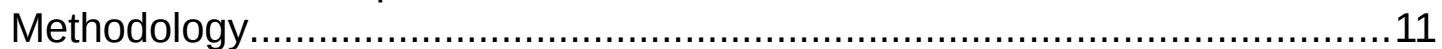

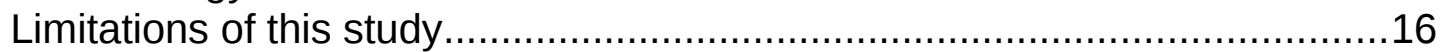

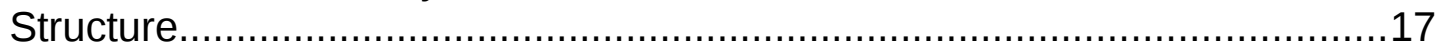

Chapter One

Neoliberalism, the global justice movement and struggles over knowledge......20

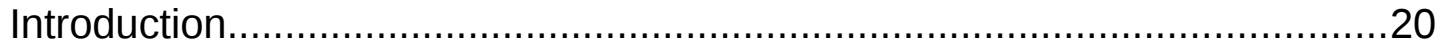

Section one: knowledge and power.......................................................22

Section two: the Information Age and neoliberal globalisation.......................28

Section three: the global justice movement and knowledge systems.............34

The emergence of the global justice movement.......................................35

The global justice movement and knowledge systems...........................45

Section four: the ongoing struggle to control knowledge..........................52

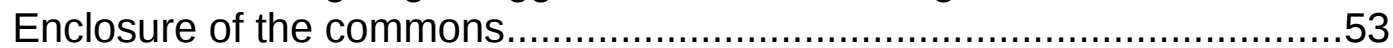

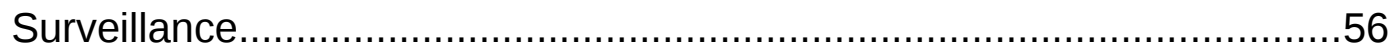

Resistance to peer-produced knowledge...........................................57

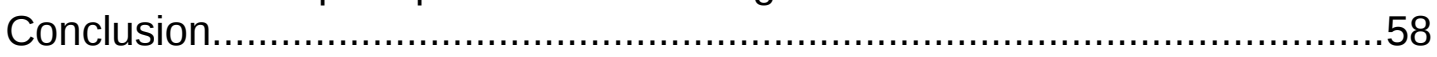

\section{Chapter Two}

Opposition to genetically modified crops in India: who knows best when it

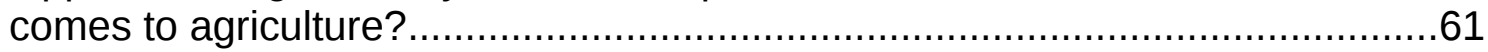

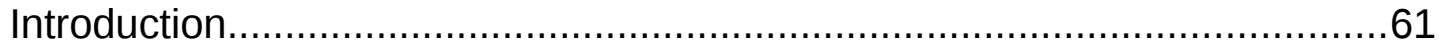

Section one: the opposition to genetically modified crops in India.................64

Section two: "there is no resistance without alternatives"..............................79

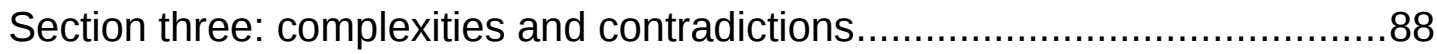

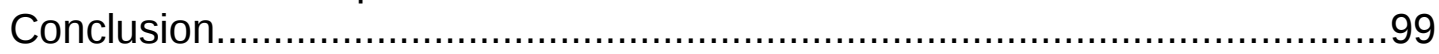

\section{Chapter Three}

The digital liberties movement: the digital is political...................................102

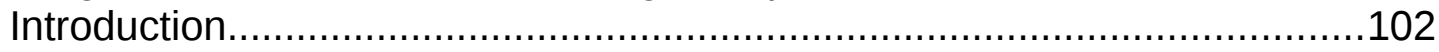

Section one: defining the digital liberties movement.................................104

Section two: (re)taking the digital......................................................111

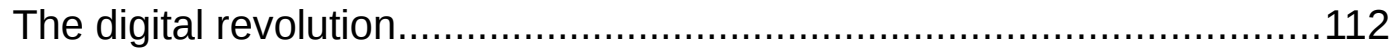

The relationship between the real and the virtual..............................113

Shifts in knowledge production.......................................................116

(Re)gaining control over information and communications technologies 116

National security, law and order, and surveillance .................................118

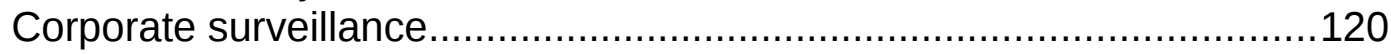

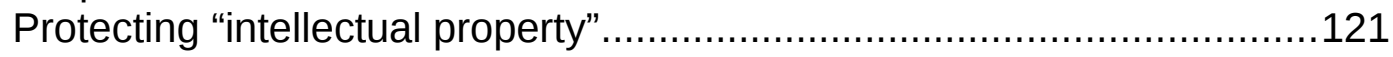

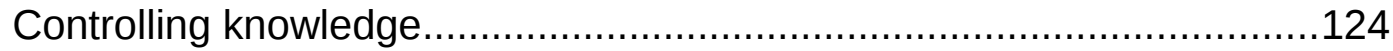

Section three: the emergence of the digital liberties movement.................126

Roots in previous movements and communities...............................126

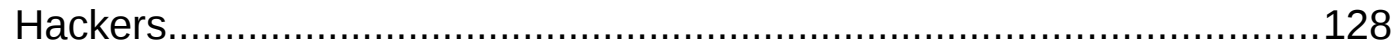


The free/libre and open source software movement.........................130

Landmarks in the emergence of the digital liberties movement..............135

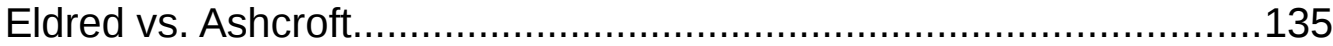

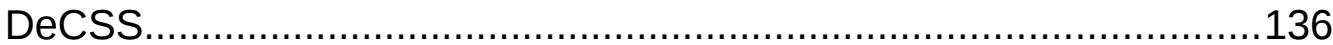

Diebold Election Systems vs. the Internet...................................137

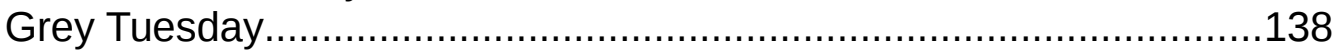

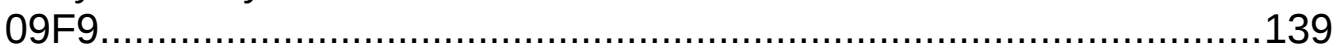

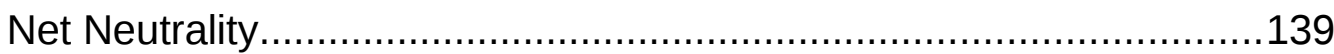

Anti-Clean Feed activism in Australia.........................................141

Pirate Bay trial........................................................................... 142

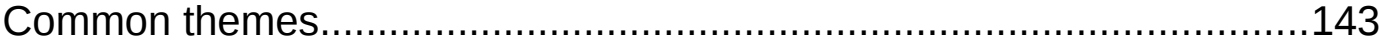

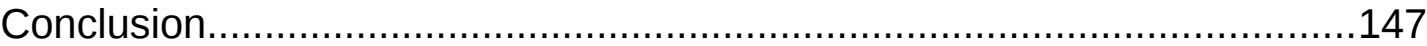

Chapter Four

The global justice movement and struggles over knowledge......................149

Introduction................................................................................. 149

Section one: mapping the movements..............................................151

The Indian opposition to genetically modified crops and the global justice

movement......................................................................................... 151

The digital liberties movement and the global justice movement............160

Section two: struggles over knowledge and contributions to the global justice

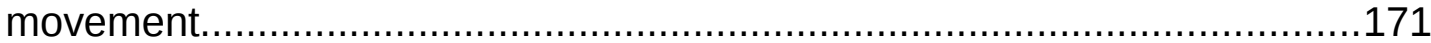

Democratic control over key technologies.......................................172

Peer-based knowledge systems.................................................178

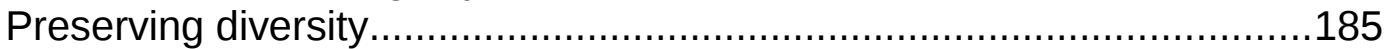

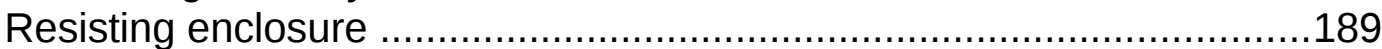

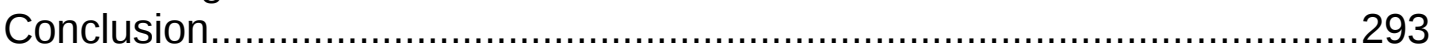

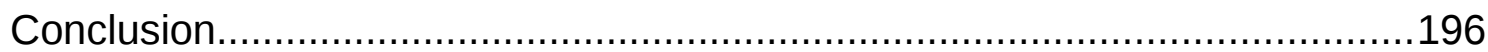

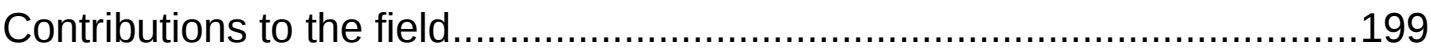

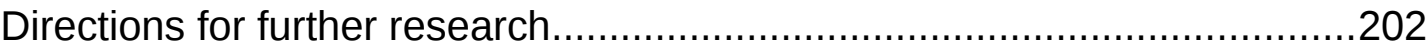

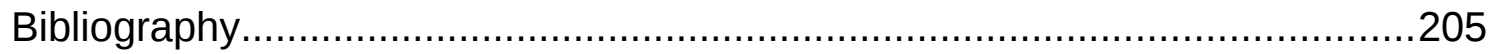





\section{Acronyms}

$\begin{array}{ll}\text { CCTV } & \text { Closed circuit television } \\ \text { DLM } & \text { Digital liberties movement } \\ \text { DMCA } & \text { Digital Millennium Copyright Act } \\ \text { DRM } & \text { Digital rights management } \\ \text { EFF } & \text { Electronic Frontier Foundation } \\ \text { ESG } & \text { Environment Support Group } \\ \text { FFII } & \text { Foundation for a Free Information Infrastructure } \\ \text { F/LOSS } & \text { Free/libre and open source software } \\ \text { FSF } & \text { Free Software Foundation } \\ \text { GATT } & \text { General Agreement on Tariffs and Trade } \\ \text { GEAC } & \text { Genetic Engineering Approval Committee } \\ \text { GJM } & \text { Global justice movement } \\ \text { GM } & \text { Genetically modified/genetic modification } \\ \text { GMO } & \text { Genetically modified organism } \\ \text { GNU } & \text { GNU's Not Unix } \\ \text { GPL } & \text { General Public License } \\ \text { GREEN Foundation } & \text { Genetic Research, Ecology, Energy, and Nutrition } \\ & \text { Foundation } \\ \text { ICRA } & \text { Institute for Cultural Research and Action } \\ \text { ICTS } & \text { Information and communication technologies } \\ \text { IMF } & \text { International Monetary Fund } \\ \text { IP } & \text { Intellectual property } \\ \text { IPR } & \text { Intellectual property rights } \\ \text { ISP } & \text { Internet service provider } \\ \text { KRRS } & \text { Karnataka Rajya Raitha Sangha (Karnataka State } \\ & \text { Farmers' Association) } \\ \text { MNC } & \text { Multinational corporation } \\ \text { MPAA } & \text { Motion Picture Association of America } \\ \text { NGO } & \text { Non-governmental organisation } \\ \text { NSM } & \text { New social movement } \\ \text { PGA } & \text { People's Global Action } \\ \text { RFID } & \text { Radio frequency identification } \\ \text { RIAA } & \text { Recording Industry Association of America } \\ \text { TRIPS } & \text { Agreement on Trade-Related Aspects of Intellectual } \\ & \text { Property Rights } \\ \text { TSMO } & \text { Transnational social movement organisation } \\ \text { WIPO } & \text { World Intellectual Property Organization } \\ \text { WSF } & \text { World Social Forum } \\ \text { WTO } & \text { World Trade Organization } \\ & \end{array}$




\section{Acknowledgements}

First and foremost, thanks go to my primary supervisor, Dr. Chen Jie. He has continually challenged my ideas and helped me to think more deeply about the issues addressed in this dissertation. I am tremendously grateful for his unflagging support, encouragement, and humour throughout my candidature, and couldn't have wished for a better supervisor.

Thanks also go to the staff of UWA's Discipline of Political Science and International Relations for their help and support over the years, particularly to my secondary supervisor, Roderic Pitty, for his helpful suggestions and to Linley Hill for her encouragement and her almost-magical ability to find the right forms.

Participation in conferences and fieldwork has enriched this project and allowed me to gain valuable experience and feedback on my work. The Dean's Postgraduate Travel Award facilitated my attendance at the 2005 International Society for Third Sector Research conference in Bangkok. The Patrick O'Brien Political Science Graduate Internship Award allowed me to spend several weeks working with the GREEN Foundation and Janastu in Bangalore in 2007. Thanks go to the sponsors of these awards, as well as to the organisations that hosted me. Thanks also go to the anonymous reviewers and conference audiences who provided me with feedback on papers presented at the 2005 ISTR conference, the 2008 and 2009 Australian Political Studies Association conferences, and on my article in the 2007 edition of Agenda.

My research would have been much poorer had I not had the opportunity to talk to activists in India and Sweden, and at the Karachi and Nairobi World Social Forums. I can't begin to thank everyone who helped me by discussing their work, their lives, and their ideas. Special thanks, however, must go to Akshay and Suresh Heblikar, Prasad, Hari Ram, TB Dinesh, Kavita Philip, Ravi Srinivasan, Raheema Begum, Chukki Nanjundaswamy, and Shyla and HP Dwarakanath. 
I would not be who I am, and this dissertation would not be what it is, had it not been for my family. I cannot count the ways in which I am indebted to them: for the discussions about politics and ethics, the games of tá $\beta \lambda_{1}$ with my grandfather, the stern talks and dolmades from my grandmother, the proofreading, the support and, most of all, for the love. Many thanks to the collection of Croesers, especially Eve, Roselt and Kyle, and to the full set of Gregoriadises: 'Apyupú, 'Avtúvnc, Strati, Lorraine, Cassandra, Nastassia, and Byron.

Many friends and loved ones have sustained me throughout this project. They have debated important ideas with me, proofread, made tea, and provided much-needed support in a thousand ways, large and small. Special thanks go to Jason Sharbanee, Nathalie Latter, Kale Dyer, Jarrad Robb, Lisa Max, Elizabeth Przywolnik, Tim Highfield, Jessica McLeod, Filip Wijkström, Chloe Britton, Jamie Bainbridge, Jess Porter, Ben Griffin, and Balram and Jyothi Choudhary (and their family).

Many thanks go to my colleagues at the Bluestocking Institute: Shae Garwood, Christalla Yakinthou, Liza Beinart, and Kate Riddell. They have been there for every step of this journey, and have shown me the way forward whenever I was lost.

Lev Lafayette, David Glance, and Cameron Patrick have helped to provide me with laptops at various points throughout my candidature. Clearly, dissertations are hard on laptops as well as on candidates, and I am very grateful for their assistance.

This dissertation was written on laptops running Ubuntu, Open Office, Firefox, and Zotero. I am grateful to the communities that create and maintain these programs, as well as to other users of the forums who have answered my questions and helped me to get everything running smoothly. 


\section{Introduction}

In 1999, thousands of activists turned out to protest against the World Trade Organization (WTO) Ministerial Conference in Seattle in a series of events that the left heralded as the "coming out party" for a global movement (Burbach $2001,99)$. These protests represented only a tiny proportion of the global justice movement (GJM), built on many years of organising throughout the world (and particularly in the Global South ${ }^{1}$ ). Until the 1999 protests in Seattle, there was a growing sense among sections of both the right- and the left-wing in the Global North that neoliberal capitalism had defeated all comers. With the collapse of state socialism as a viable alternative for much of the world and the end of the Cold War, neoliberal globalisation seemed to have no serious competitors, and "[a]s far as the powerful were concerned, there was no opposition to capitalism, no alternative to the 'free' market" (Notes from Nowhere 2003e, 500). On the left, many argued that the identity politics of the 1970s and following decades had fractured opposition to capitalism to the point where it had become useless. Anticapitalist protests of the late twentieth and early twenty-first centuries changed this, leading to a flurry of excitement about a new web of global activism, a movement that brought struggles from around the world together into an overlapping and interconnected movement of movements. Other developments, especially the World Social Forum (WSF) of 2001 and those that followed, have strengthened the sense that a global resistance to neoliberal capitalism has emerged, a unified (if multiplicitous) commitment to building alternatives.

The obstacles faced by those attempting to challenge capitalism's current incarnation are significant, although the recent global financial crisis has gone some way towards weakening the idea that neoliberal globalisation is the pinnacle of economic, social, and political organisation. Political elites around the world have begun to argue, as Australian Prime Minister Kevin Rudd has,

1 Use of the terms 'Global North' and 'Global South' to designate broad global divisions of wealth and power is not ideal, and does not map perfectly onto the geopolitical realities of the world. However, these terms are preferable to the alternatives and are therefore used throughout this analysis. 
that "the great neo-liberal experiment of the past 30 years has failed" (2009). However, the power structures and institutions built up over previous decades are unlikely to disappear overnight, and it is doubtful whether the more sceptical language being employed by centrists such as Rudd and Obama towards neoliberalism will translate into deep structural change. Insofar as such change is allowed and promoted by political elites, it is likely to be in large part a result of pressure by social movements and other actors outside the political and economic establishment. The GJM is likely, therefore, to remain one of the primary actors in the search to find alternatives to neoliberal globalisation.

\section{The thesis}

The thesis of this dissertation is that knowledge-including that embodied in science and technology-is a vital site of contestation in the struggle between actors working to strengthen neoliberal capitalism and those within the GJM. Both neoliberal capitalism and the resistance to it rely on information and communications technologies (ICTs) and related technologies, although in different ways. In shaping scientific and technological developments, and the way in which these developments are understood and approached, actors alter political, economic, and social systems, just as these systems alter the course of scientific and technological change. The view that science and technology can be and are shaped by forces other than their own internal logic is not a new one: what is new here is the argument that knowledge is a vital battleground in the struggle to shape globalisation.

This dissertation is particularly concerned with the contest between neoliberal capitalism and the GJM, which can also be seen as a struggle between two forms of globalisation: globalisation from above, and globalisation from below. Falk defines globalisation from above as, "reflecting the collaboration between leading states and the main agents of capital formation". In opposition to this, globalisation from below, "consists of an array of transnational social forces animated by environmental concerns, human rights, hostility to patriarchy, and a vision of human community based on the unity of diverse cultures seeking an end to poverty, oppression, humiliation, and collective violence" (Falk 1993, 39). 
I will argue throughout this thesis that struggles over knowledge are part of elites' efforts to further globalisation from above, and activists' efforts to bring about globalisation from below.

Struggles over knowledge take multiple forms, ranging from attempts to reconfigure particular technologies through to attempts to change how we understand and control the production of knowledge itself. These forms are interrelated. To take what may seem like a trivial example, the debate over whether computer owners should be able to copy copyrighted material on CDs and DVDs is linked to much broader debates over whether information can be owned in the same way as physical property, and the extent to which amateur cultural production should be considered legitimate and valuable. Similarly, attempts to implement technologies that would allow companies to prevent replanting of patented seeds bring up questions about the role of communities in the Global South in developing agricultural biodiversity and the institutional possibilities for recognising this role. Struggles over knowledge therefore involve complex relationships between contests over particular technologies and much deeper questions regarding control over the production and dissemination of knowledge.

This thesis examines existing attempts that are underway by movements throughout the world to (re)gain democratic control over knowledge. Although such concerns may seem post-materialist in the extreme, movements in the Global South have been among the first to take up the banner by calling for an end to the theft of their biodiversity and for indigenous knowledge systems to be accorded legitimacy. There are also other strands of activism contributing to the GJM, including the DLM, which have begun to address threats to the ability of those working towards globalisation from below to organise and communicate. These threats come primarily from governments and corporations, and are spurred on by different motivations, primarily national security in the case of the former (as part of the United States' "War on Terror" and control of information flow within and over the borders of undemocratic states like China and Burma), and, in the case of the latter, in order to prevent piracy of copyrighted material. Currently, the efforts of activists engaged in struggles over knowledge remain 
disconnected and largely unrecognised. If the GJM is to have any chance of achieving its goals, these struggles must gain a higher priority and connect up with each other. This thesis makes a novel contribution to the study of political struggle by bringing attention to the common analysis and goals of movements previously seen as disparate.

\section{Case studies}

The first case that I will discuss is the movement against genetically modified (GM) crops in Karnataka, India, with occasional reference to anti-GM activism in other parts of India. This movement has connections to other activists and groups opposing GM crops within India and in other countries, including Navdanya, a group founded by Vandana Shiva. However, the movement in Karnataka is relatively self-contained, and has unique characteristics not shared by other anti-GM movements. Most prominent of these is the domination of the movement by the Karnataka Rajya Raitha Sangha (Karnataka State Farmers' Association, KRRS) and the resulting discourse that places opposition to GM crops within a Gandhian framework, centring the producer rather than the consumer or environmental issues. In light of the focus in this dissertation on the struggle over globalisation, Karnataka's juxtaposition of the booming ICT, biotechnology, and business process outsourcing industries based in Bangalore $^{2}$ and the anti-GM movement is a microcosm of the larger struggle between different visions of globalisation.

This movement is also particularly useful for my analysis because it highlights the complex way in which the GJM is constituted from struggles throughout the world. As I will argue in Chapter Four, the Indian opposition to GM crops has an iconic role within the GJM. However, closer examination of the relationship between the Indian movement and the GJM destabilises any notion that the former is simply a part of the GJM. This case study demonstrates that even movements considered to form the core of the GJM may have a fragile and tenuous relationship with the broader GJM, as the Indian movement does. Examination of this relationship allows a better understanding of the GJM as

2 As of 2008/2009, there are efforts underway to relocate much of this work to Mysore, as Bangalore's infrastructure has been strained by the growth of these industries. 
built from and through a diverse range of overlapping struggles, rather than as a movement with a clearly defined core and peripheral membership.

At first, my research on the Indian opposition to GM crops focused predominantly on those who were directly involved in protests, lobbying, research, or other activities aimed at preventing the entry into and spread of GM crops in India. The KRRS has received widespread coverage within India, and some coverage overseas, for its anti-GM protests, particularly the destruction of test fields of Bt cotton in the late 1990s. Other organisations, including Greenpeace India and the Environmental Support Group (ESG), have been involved in researching and publicising GM issues as well as lobbying state and federal governments. Professionals, particularly academics, journalists, and lawyers have played a significant role in the opposition to GM crops, both through their work and through outside activism. A wide range of individuals and organisations play a role in the movement's attempts to convince institutions, farmers, and consumers of the need to ban or avoid the use of GM crops.

Over time it became clear that this work, and these actors, constituted only a small part of the anti-GM crop movement's activities and participants. MD Nanjundaswamy, the late leader of the KRRS, has written that "there is no sense in dividing resistance and alternatives, since none of them can take place without the other" (1998b, 157). Although the most visible section of the KRRS and other groups' activities are well-publicised direct actions, the vast majority of the work carried out by movement participants is not a direct opposition to GM crops, but rather the promotion of sustainable, organic, low-input farming, and the use of indigenous seed varieties. Groups such as the Institute for Cultural Research and Action (ICRA), the Genetic Research, Ecology, Energy, and Nutrition (GREEN) Foundation, and small-scale farmers' organic produce groups relate their promotion of organic farming to the resistance to GM crops, and are understood by others to be a part of this struggle. The movement opposing GM crops is, therefore, also in large part a movement promoting organic, sustainable farming. In doing so, movement participants are contesting claims that the technologies of the Green Revolution and biotechnology are the only way to feed India's growing population, questioning the scientific basis of 
these claims and calling for indigenous and appropriate technologies and knowledge systems to be recognised as legitimate.

Like the Indian movement, the digital liberties movement (DLM) involves a complex web of actors and links together issues that at first glance do not seem directly related. Movement participants make connections between the use of proprietary software, government controls on and surveillance of the Internet, copyright law and digital rights management, linking them through a frame that opposes restrictions on the free flow of digital information. As is the case with the Indian movement, participants match their opposition (in this case, to these restrictions) with an inventive exploration of alternatives, including creative commons licenses $^{3}$, Free/Libre and Open Source Software (F/LOSS), and community-run wireless networks. Movement participants are often informed by the ideals of liberalism, libertarianism and anarchism, and the freedom to exchange and build upon existing knowledge and cultural content is seen as an important aspect of a free society.

However, unlike in the case of the Indian movement, the DLM is not strongly rooted in a particular geographic place. While the movement in Karnataka draws on experiences and ideas from other areas, it is strongly informed by the historic, cultural, and political context of southern India. On the other hand, although the DLM is informed and shaped by the particularities of place (most notably the United States), it is rooted in online spaces and built on and through online cultures and communities. Virtual space is not the same as geographical space, but it shares many of the same characteristics-including its increasing interlinkage with other places and spaces. For this reason I have not drawn the bounds around a particular geographical section of the DLM, but rather have focused on its online presence.

My interest in the DLM is twofold. Firstly, because it is not conventionally seen as holding a position of importance within the GJM, it allows further exploration of how the GJM is constituted. Although the DLM is far less prominent than the

These licenses allow content creators to easily modify the copyright provisions on their work, such as by allowing non-commercial uses. 
Indian anti-GM movement within the GJM, it nevertheless makes vital contributions to the GJM's work. This demonstrates, once again, the importance of diverse and decentralised struggles to furthering the GJM's attempts to reshape globalisation. Secondly, I believe that the DLM is one of the most important social movements to have emerged over recent decades because the issues which the DLM is addressing are central to the structure and work of the GJM. It is therefore vital that the DLM receives increased attention within social movement scholarship.

\section{Theories and concepts}

This thesis draws and builds on the significant literature that attempts to theorise social movements, which includes the literature which focuses specifically on new social movements (NSMs) and transnational social movements. This thesis draws on both the European, or new social movements, approach, and the North American perspective, sometimes split into political process and resource mobilisation theories. In doing so, I have been mindful of several critiques of this body of work. The first of these critiques notes the inward-looking nature of a significant proportion of the social movement literature. Flacks argues that there is a large and ever-expanding body of work that scholars of social movements feel the need to relate to, work within or synthesise, but that this work is currently more concerned with "establishing, critiquing, or refining 'paradigms'" than with creating theory that is relevant outside the body of literature itself (2005, 7-8). Flacks recognises the value of social movement scholarship, but also argues that there are important reasons to critique the amount of time and energy that scholars of social movements are devoting to the critique of new social movement and North American theoretical perspectives. The most important of these is the decreasing relevance of this body of work to activists themselves (Flacks 2005). This critique has also been voiced by others, including Cox and Nilson (2000), particularly as it relates to the relevance of social movement literature to activists. 
A second important critique of the social movement literature is its focus on activism in the Global North, which has been voiced by a number of scholars including Foweraker (1995) and Cox and Nilson (2000). Increasingly, the focus on Europe and America is shifting in social movement scholarship, with more work looking at movements in the Global South. This is particularly case with the literature on transnational social movements, and edited collections on both social movements generally and transnational social movements in particular increasingly include a more diverse range of case studies (cf. Richter, Berking \& Müller-Schmid 2006; Meyer, Whittier \& Robnett 2002), moving beyond the literature's previous focus on the North. There remains a tendency, however, to treat Southern movements as exotic or in some ways fundamentally different from Northern movements, which continue to define the norm in social movement studies. In examining the movement against GM crops in India, I have attempted to avoid romanticising the movement or its participants.

In order to avoid either taking for granted the assumptions of literature based on empirical studies of Northern movements or allowing the reification of existing social movement scholarship paradigms to dominate my analysis, I have been guided in this work by the concerns voiced by activists. This does not mean a rejection of valuable work done by previous scholars of social movements and transnational social movements. On the contrary, concepts developed over previous decades of work form the backbone of the study. The first and most important contribution which I draw upon is the social movement literature's establishment of "social movements" as distinct phenomena. The novelty and importance of this contribution, as well as the complexity of social movements as a conceptual entity, is sometimes overlooked now that the term has gained widespread acceptance.

Defining and mapping social movements continues to be a complicated task. Charles Tilly defines a social movement as "a sustained, organized public effort making collective claims on target authorities" that uses a particular repertoire of tactics on behalf of a group of people that claim to be worthy, united, numerous, and committed (2004, 3-4). To this, other notable scholars in the field have also noted the presence of network structures (della Porta \& Diani 1999, 159) and 
collective identity (della Porta \& Diani 1999, 24) as defining features of social movements. Transnational social movements are those that are "linked across country boundaries that have the capacity to generate coordinated and sustained social mobilisation in more than one country to publicly influence social change" (Khagram, Riker, \& Sikkink 2002, 8), as the GJM is. Social movements are not static: they are fluid networks of individuals and organisations who come together for movement activities and may participate only rarely. While this gives adequate grounds for deciding what is a movement and what is not (for example, a single non-governmental organisation, or NGO, is not a social movement, while a collection of NGOs and individuals may be), it leaves many issues unresolved.

The most pressing of these is the question of where to draw the boundaries around any particular movement. Is an individual a movement participant if they come to a single protest? Are feminist peace activists part of the feminist movement or the anti-war movement? Are radical feminists and liberal feminists part of the same movement? Which movements are part of the GJM? Social movements are not just fluid, they are decidedly messy. They frequently overlap, and have blurry borders. When it comes to defining the movements in this dissertation, I have taken the defining characteristics described above as a starting point. I consider actors to be part of the same movement if they have a shared frame of analysis and a common discourse, and if they are connected through formal or informal networks and activities. At the same time, I have attempted to retain a sense of the movement concerned as heterogeneous and fluid.

The literature on framing has also provided valuable concepts for understanding how and why inter- and intra-movement coalitions are built. Building on a concept initially applied to social movements by Goffman (1974), Benford and Snow's (cf. Snow et al. 1986; Snow and Benford 1988) work on collective action frames has been a valuable addition to the field of social movement studies. Benford and Snow define collective action frames as "action-oriented sets of beliefs and meanings that inspire and legitimate the activities and campaigns of a social movement organization" $(2000,614)$, which can also be applied to 
social movement participants more generally. Benford and Snow emphasise that collective action frames are not pre-existing, but rather are a result of "interactive, discursive processes" (2000, 615). The alignment, or lack of alignment, of frames within and between movements plays an important role in explaining the relationship between each of the case-study movements and the GJM as a whole.

Finally, I have drawn on the injunctions by both Cox and Nilsen $(2000,430)$ and Flacks (2005) to recognise activists as playing a role as theorists. The challenge here is not so much to bring together the political process, resource mobilisation and new social movement traditions, but to find the ways in which the insights of these traditions can be combined with the work and priorities of movement scholars. Such an effort also benefits from Gramsci's analysis of the role of organic intellectuals, as set out in The Modern Prince (1967). The work of Naomi Klein, Amory Starr, Subcomandante Marcos, MD Nanjundaswamy, as well as collectives such as Crimethinc, the Midnight Notes Collective and Notes from Nowhere, provides a vital insight into how activists themselves conceive of and theorise the movements which they are involved in. Similarly, my work on the DLM has drawn extensively on work by academic-activists such as Lawrence Lessig, Yochai Benkler, and James Boyle. These bodies of work should not only be the subject of study, analysed as movement texts, but should also be acknowledged as a source of useful frameworks in the attempt to understand social movements, as it is in the case of academic-activists such as Naomi Klein and Amory Starr. These writers frequently draw on a large body of first-hand experience and take part in theoretical discussions in both face-toface contexts and online. This is because for the most part, circulation of information must be accompanied by circulation of analysis—on web pages this can become one-sided, but in email "especially in the usual form of mailing lists and conferences, access is free and all sides have the possibility of articulating their own position". These lists "constitute a kind of alternative, oppositional community of discussion and debate" (Cleaver 1999, 11). Arguably, the need to develop relevant and empirically-validated theory is all the more urgent when it relates to one's life project, as is the case with activists' work. 
As well as drawing extensively on social movement literature, this dissertation relies heavily on the extensive work surrounding the relationship between knowledge and political and economic power. This body of work is extensive, and stretches from the realms of science and technology studies to literature that attempts to theorise the Information Age. Science and technology studies are built on the concept of "technoscience", which links science and technology within a single matrix and situates this matrix within the context of other social and cultural power structures. This framework has primarily been developed by Haraway (1997) and Latour and Woolgar (1986). The work of Haraway, Woolgar, Latour, and others in the field explores the multiple interstices of power that shape the production of knowledge, and the way in which scientific paradigms are imbricated with the maintenance or transformation of political and economic power. The literature on the Information Age is, to an extent, built on this earlier work. Manuel Castells' seminal three volume work, The Information Age, is an expansive discussion of what he sees as a fundamental transformation of the capitalist mode of production (and, hence, of social and political life) tied to the ICT revolution. Taken together, this body of literature allows connections to be built between the contemporary form of global capitalism and knowledge as embodied in science, technology, and the flow of information.

\section{Methodology}

This thesis relies heavily on primary source material in various forms. During 2006, I spent three months in Karnataka interviewing activists, journalists, academics, and opponents of the anti-GM movement. Interviews were semistructured, with questions tailored to the particular position of the interviewee within the movement. Initially, academics studying the movement were contacted, and further interview subjects were contacted by a process of snowball sampling. There were several biases involved in this process, particularly a tendency towards interview subjects who were perceived by others to be in leadership positions within the movement, and towards those who spoke English. I repeatedly requested that I be introduced to those at the grassroots level of the movement, and those likely to be marginalised within the 
movement, but my contact with these movement participants remained somewhat limited. I have therefore attempted to balance the material gathered from movement participants with critical perspectives from outside the movement, including those of academics, journalists, critics of the movement, and farmers who know of but are not (or are no longer) involved in the movement.

During my period of fieldwork, I had the opportunity to observe movement activities, including recruitment drives, meetings, and protests. The majority of my time in this regard was spent with the KRRS, but I also attended events and meetings held by other organisations, including the ESG. In 2007, I spent a further five weeks in Bangalore working with the GREEN Foundation, a NGO involved in promoting domestic crop biodiversity and sustainable, organic, farming. Field observations have been further supplemented by access to movement publications, including websites, press releases, brochures, minutes, emails, training manuals, and books produced by actors within the movement.

As well as the primary sources for the Indian opposition to GM crops, there is a significant body of secondary literature that discusses the movement within the context of the emergence of farmers' movements in India. Much of this literature focuses on the KRRS, and falls within the work by scholars such as Muzaffar Assadi, Gail Omvedt, and Tom Brass, on the farmers' movements that came to prominence in India during the 1980s, and conceptualises the opposition to GM crops primarily either within the broader framework of farmers' struggles to attain economic concessions from urban elites, or as part of a shift towards a style of protest associated with NSMs. Other work on the Indian movement has conceptualised it as part of a new kind of transnational activism, positioning it within the framework of emerging coalitions of farmers and other global justice activists (cf. Featherstone 2003). The work on this movement is also contextualised within the literature on the anti-GM movement in India, much of which is based on organisations in Northern India. The literature on biopiracy is also relevant to the discussion of this movement. These bodies of secondary literature provide a multifaceted understanding of the movement against GM crops in India, highlighting different aspects of participants' work and history. 
Research on the DLM has relied primarily on online sources, many of which can be seen as the digital analogue of activities that would be conducted offline in more traditional movements. Recruitment, dialogue, and even protests all happen online to a far greater degree than offline. Online spaces, including discussion forums, blogs (particularly their comments sections), and even webcomics, have become sites for not only putting forward the movement's perspectives but also holding meetings, organising, and recruiting. Movement publications, including academic-activists' books, are readily accessible online, and I have relied on several key websites as portals to this information. This material has been supplemented by an extensive interview carried out with a prominent member of the Swedish piratpartiet, the first political party in the world to campaign on these issues.

My research has also been supplemented at times by use of Wikipedia. In part, this is because it would be hypocritical to advocate for peer-produced knowledge sources, as I do, while refusing to acknowledge my own use of them. Many researchers use Wikipedia as a starting point for their research, much as they would use any other encyclopaedia, either to acquaint themselves with the background to issues they are unfamiliar with or to find more reputable resources. In addition to these uses, academic responses to Wikipedia are shifting. Some authors are now comfortable citing Wikipedia, as well as using it for background information. Lisa Spiro (2008) has carried out a preliminary analysis of Wikipedia use in the humanities and social sciences, finding that while Wikipedia citations make up only a tiny proportion of citations in these fields, the number of citations is increasing. Spiro also cites Matt Kirschenbaum's discussion of his choice to use Wikipedia. Kirschenbaum (2008, xvii) argues that while Wikipedia should be used with caution, it is frequently the best source for up-to-date information on rapidly-changing areas, including information technology. Similarly, Kate Milberry and Gabriella Coleman, leading researchers in studies of Internet-based activism, note the usefulness of Wikipedia in researching areas that have not yet reached the academic arena. Milberry (2009) writes on her blog: 
When nobody was writing on wikis, social software, copyleft, crowd sourcing or free software, Wikipedia had the most comprehensive definitions. Unlike an online dictionary reference, Wikipedia also contains history, controversies, (often academic) citations and links out to key people and websites. Researching the development and use of internet technology for social justice activism, I typically find that Wikipedia has the most useful, if not the only, information l'm looking for.

Coleman, in the comments following this post, notes that while there are no academic sources for her area of research, Wikipedia "has an overflowing list of handy references". Following the guidance of authors such as Kirschenbaum, Milberry, and Coleman, I have approached the use of Wikipedia and other online sources with caution, but have not avoided them. At times, I have used these sources much as one would use data obtained through participant observation and interviews. In other instances, however, it has been necessary to turn to material on Wikipedia, blogs, or other online sources in order to understand, analyse, and explain new technological developments or aspects of activism that have not been covered in academic literature. Whenever I have done so, it has been done critically and in an attempt to access the most relevant and up-to-date material available.

Little secondary literature exists on the DLM, in part because of its relatively recent emergence. The many differences between this movement and traditional (and even new) social movements have led to a significant lack of recognition of (or possibly interest in) the movement within the mainstream of social movement scholarship. There are, however, a number of historical accounts of movements that have fed into the DLM, notably Bruce Sterling's (1992) account of the early days of the Electronic Frontier Foundation (EFF), The Hacker Crackdown, and various histories of the F/LOSS movement (cf. Moody 2001; Torvalds \& Diamond 2001). There is also a growing body of work addressing the issues raised by the movement, including Lawrence Lessig's (2004) Free Culture and James Boyle's (2008) The Public Domain, that peripherally cover digital liberties activism as part of a wider discussion of the perspectives and actors involved in the struggle over control of the flow of 
information online. It is hoped that this thesis will go some way towards bringing together this scattered work and pointing out directions for further research into the movement.

This dissertation has also benefited in a more general sense from my attendance at several events of importance to the movements studied. Most notable of these were two WSFs, the 2006 WSF in Karachi, Pakistan, and the 2007 WSF in Nairobi, Kenya. WSFs are the largest gatherings of participants in the GJM, a space in which activists gather to debate analysis and strategies, and build connections. The WSF is an excellent place to take the pulse of the movement, full of chaos and the many contradictions that run through today's global web of activism. In addition to my participation in these WSFs, in 2007 I attended a seminar on food security in Bangalore which brought together practitioners, activists, and academics interested in sustainable agriculture, many of whom I had met during my earlier trip to Bangalore. While only one session was explicitly directed at GM issues, the opposition to GM crops was a recurring theme throughout the formal and informal sections of the seminar. Finally, my attendance at Barcamp Bangalore 5 in 2007 gave me a new perspective on activism in India, allowing me to meet many people who were attempting to combine their technical expertise with a concern with social justice. In their own way, each of these events allowed me to gain a better picture of connections within and between movements.

Ethically, there were two main issues that needed to be addressed with regard to this research. The first issue relates to the power dynamic between the researcher and the subjects of research. This is particularly a concern with regard to participants in the Indian movement, many of whom are not literate or do not read English and therefore will not be able to access, let alone comment on, the way in which I analyse and present their activism. To an extent this was compensated for by giving a full explanation to all interviewees of what the material would be used for, answering any questions they had about me, my work, and my background, and maintaining contact with those with regular access to the Internet. I have attempted to make my work available for those who are interested and have access to the Internet: I discuss my research and 
invite comments on my blog, have posted edited extracts of interviews (with the permission of interviewees), and have the full text of all publications available for download and comment. Two of my publications have been in spaces accessed by both researchers and activists: a working paper was published in the proceedings of the 2006 International Society for Third-Sector Research (ISTR) Conference, which was attended by those from the NGO sector as well as academics, and a paper on the Indian movement was published in a 2007 special on biopolitics in Agenda, a South African feminist journal aimed at both academics and activists. In most cases, there will be a huge gulf between the power of social scientists to shape the representations of those they study and the power of those studied to contest the way in which they are presented. However, to the extent possible I have attempted to lessen this gulf.

Secondly, participant-observer research opens up questions of bias. Academics can never hope to be truly objective-we are always affected by our lifeexperiences, and whether we consciously intend it or not our work may be used to bolster some of the world's existing power structures and some of the struggles against them. I am white, a fledgling academic (with all the privileges that come with the position, including a scholarship and funded international travel), a storyteller, a member of several online communities, a Linux user (and propagandist), and an advocate of appropriate technology. My many overlapping selves have informed my prejudices and my affinities, and I have tried to bear them in mind and test them. Without the passion we bring to research from the world outside our offices our work would be much drier, irrelevant to the struggles that flow through our lives. However, our work would be stagnant without the desire to push ourselves and learn more, to question our existing beliefs.

\section{Limitations of this study}

As I have noted throughout the text, there are a number of difficulties involved in studying social movements. One of the most significant limitations of this research lies in the difficulty of identifying and reaching a representative crosssection of movement participants. Despite attempts to ensure that participants 
from the most marginalised sections of society were represented in my study of the Indian movement against GM crops, their voices have often been overwhelmed by those of movement leaders. The difficulty posed by language barriers was the most significant factor here, but it was compounded by the gatekeeping function played by movement leaders and by my own lack of familiarity and social ties to the communities involved. It was easier to access the opinions of a more representative range of participants within the DLM, in large part because of their involvement in online forums and their visibility through blogs and other social media. Nevertheless, even in this case the perspectives of movement leaders tend to eclipse those of other participants.

Secondly, this research has been hampered by my limited ability to access Southern academic or activist literature related to the movements described. In part, this is because of my limited language skills: I do not speak any Indian languages. Many Indian texts were also only available to me during my stay in India. Where possible I have attempted to seek out perspectives from the South in order to balance the bias in much of the relevant bodies of literature towards Northern voices and groups. Studies of social movements continue to have a lamentable bias towards events that occur in the Global North (particularly in Europe and the United States), and the field is dominated by academics from these areas. Similarly, even the literature on the Indian movement discussed in Chapter Two is dominated by Northern academics, and Chapter Three is largely bare of perspectives from the Global South. Women have been similarly underrepresented. It is difficult to tell whether I could have done more to include marginalised voices: the limitations of the literature itself, the availability of material, and my inability to speak languages other than English have all played a role in confounding my attempts to provide a wider range of perspectives.

\section{Structure}

The first chapter lays out the theoretical and historical background of the thesis, addressing the development of both neoliberal globalisation and the antiglobalisation movement. It explores the links between the ICT revolution, changes to the capitalist mode of production, and the emergence of the GJM. 
The argument put forward in this chapter is that science, technology, and the flow of information are all aspects of knowledge, and are fundamentally tied to the process of globalisation from above, being used both to legitimate neoliberal globalisation and to facilitate the flows of information that sustain it. However, at the same time, the ICT revolution has been vital to the emergence of the GJM's struggle for globalisation from below. Struggles over knowledge are vital to the GJM for three reasons. Firstly, the Internet and other technologies of the Information Age play a vital role in allowing the GJM to maintain a decentralised structure constituted from a diverse range of struggles. Secondly, ICTs play an important role in GJM activists' strategic toolbox. Thirdly, localised, democratic, and peer-based knowledge systems empower GJM activists by investing their arguments with authority.

The second chapter discusses the Indian movement against GM crops, focusing on activism in the state of Karnataka. Often, participants in this movement and others like it are romanticised and presented as farmers struggling to maintain their traditional way of life. This chapter argues that participants in the anti-GM movement are rational actors engaging in the same dialogues as movement participants elsewhere, attempting to redefine the structures of the contemporary world rather than return to an Arcadian past. It outlines the various complexities within the movement, including intramovement struggles and the contradictions between rhetoric and reality. A vital part of this struggle has been the attempt to delegitimise the science used by corporations and governments to support the spread of GM seeds in India, and to gain legitimacy for indigenous and grassroots knowledge. Participants in the movement also contest corporations' attempts to patent life by placing legal and technological restrictions on seeds, asserting that it should not be possible to own either living beings or thousands of years of farmers' collective efforts. This movement is an active part of the global debate over how knowledge is produced and legitimised, and who should have access to it.

The third chapter discusses emerging digital rights activism. This chapter establishes that there are grounds for considering the DLM to be a coherent movement. It discusses the historical antecedents to the DLM, the demographic 
involved in the movement, and the ideologies that inform it. This chapter puts forward the argument that the issues this movement is addressing have a relevance beyond the narrow field in which they have received attention. Issues of government surveillance and corporate control of the Internet and computer software have been discussed at length by those who are part of online communities with a technological focus, as well as by academics such as Yochai Benkler and Lawrence Lessig, who write on the implications of these challenges for legislation. However, these issues have not diffused to the wider scholarship on social movements, and have not received the attention that they deserve within the activist community.

The fourth chapter synthesises the two case studies in the context of the argument put forward in Chapter One. This chapter discusses the connections and disjunctures between each of the movements studied here and the broader GJM. It outlines several possible reasons why the DLM has failed to make significant connections with other movements within the broader web of global activism, including the personal histories of digital liberties activists and the ideologies and discourses that tend to inform the movement. It also outlines both the successes and failures the Indian anti-GM movement has had in building links with other movements. This chapter argues that there are compelling reasons to pay more attention to this aspect of the work of movements in the Global South, as well as to address the disconnect between the DLM and more traditional movements.

The Conclusion will review the dissertation and present contributions to the field, which include arguing for the importance of struggles over knowledge to the GJM, expanding existing research on the case-study movements, and arguing that a more nuanced approach to the study of the GJM's structure is necessary. 


\section{Chapter One}

\section{Neoliberalism, the global justice movement and struggles over knowledge}

\section{Introduction}

This chapter provides the conceptual and historical background for the thesis by introducing two sites of contestation: knowledge and globalisation. The struggle over globalisation gained widespread visibility in the Global North in 1999, when thousands of people protested outside the WTO Ministerial Meeting in Seattle. This was the first manifestation of the GJM to gain attention within the mainstream media. However, struggles between global elites and activists over the shape of globalisation were underway before Seattle, and have continued since. This struggle takes many forms, and is tightly interwoven with struggles over knowledge. Knowledge-as embodied in different systems of science, technology, and information flows-affects the processes of globalisation, and is simultaneously a site of contestation, shaped by political, social, and economic systems.

Section one provides a critical framework for understanding knowledge as a contested space. It argues that science and technology, and knowledge more broadly, should be understood as essentially contested and contestable areas. There is significant evidence that science and technology not only shape, but are shaped by, other systems of power, including political, economic, and social structures. The paths of scientific research and technological development have been influenced by their development within particular historical periods and places, and science and technology are, far from being unbiased, used to legitimise and provide logistical support for particular power structures. Science and technology are also part of broader systems of knowledge, playing a crucial role in the ways in which knowledge is produced, legitimised, accessed, and disseminated. These aspects of knowledge systems are inherently political, both in terms of how they overlap with and are shaped by other power structures and in terms of their effects. 
Section two discusses the contemporary character of global capitalism, and the interaction between neoliberalism and knowledge. I argue that in light of the growing power and ubiquity of Information Age science and technology, it is more important than ever to pay attention to the interaction between knowledge and politics. Scientific narratives have been mobilised to support the neoliberal project, and to delegitimise opponents of neoliberalism, while ICTs have played a crucial role in the recent restructuring of capitalism. However, these narratives and technologies could have, and could yet, take alternative pathways-their current incarnations are in part a result of the political and economic context in which they have developed.

Section three discusses the GJM, which has grown from the amalgamation of other movements around the world, as well as the emergence of new movements, and which now poses a challenge to neoliberalism. In this section, I argue that the way in which we understand science, the shape of particular technologies, and the framing of particular groups as legitimate or illegitimate producers of knowledge are vital to the GJM. GJM participants rely heavily on the use of ICTS, both for their everyday activities and for their organisational inspiration. Movement participants also need to be recognised as legitimate speakers in order to achieve their goals; participants cannot assume that their knowledge - their analysis of the situation, their critiques, and their proposals for alternatives-will always be accepted as valid. In order for this to happen, the movement needs to contest the top-down, universal model of knowledge production, and gain acceptance for grassroots, embedded, and embodied knowledge.

Section four emphasises ongoing struggles over knowledge, looking at some of the recent attempts by elites to (re)gain control over key technologies, and to maintain their control over the production of knowledge. These attempts have taken multiple forms, including what has been termed a second enclosure of the commons, attempts to develop or retool ICTs for the purpose of surveillance, and the denigration of projects that are based on peer-produced knowledge. These struggles weave together legal, technological and cultural strategies. 


\section{Section one: knowledge and power}

Knowledge, as a concept, is slippery. It is used to encapsulate "formal systems of ideas" (Swidler \& Aditi 1994, 306), but also "content" (such as music and films), information, technologies and science (Stehr \& Weiler 2008, 3-4). This section outlines the relationship between these different aspects of knowledge, arguing for knowledge to be seen as a number of overlapping systems rather than as a series of discrete, self-contained and self-determining components. Additionally, science, technology, content and information have political ${ }^{4}$ implications, and the ways in which they are produced and accessed are shaped by political considerations.

There are a number of different bodies of literature that have developed critical theories of knowledge, including standpoint theories (Harding 1991), those identified with the new sociology of knowledge (Swidler \& Aditi 1994) and the new sociology of science (Bauchspies, Croissant \& Restivo 2006, 11-12), as well as literature on the social shaping of technology (MacKenzie \& Wajcman 1999), on technoscience (Latour 1987; Latour \& Woolgar 1986), on technofeminism (Haraway 1997; Wajcman 2004), and on actor-network theory (Law \& Hassard 1999). These bodies of literature blend into each other, and share a central argument: that science and technology have political effects and are shaped by the context in which they develop and by power structures, and that knowledge is constituted through complex and overlapping systems. The following discussion draws on insights from a number of these fields in order to outline the relationship between knowledge and power.

To begin with, it is necessary to examine the separation of science and technology. "Technology" is a term that is usually used to refer to human-made, material artefacts, and often also to "the social processes and knowledge accompanying their development and use" (Sclove 1995, 245 n. 4). Science, on the other hand, is seen as a far loftier pursuit: the search for knowledge, and ideally a search for "pure knowledge as a self-justifying end in itself" (Midgeley $1989,12)$. However, over the last three decades a number of researchers and philosophers have complicated this division. Latour and Woolgar's ethnographic study of Laboratory Life in the Salk Institute provided evidence that "one cannot

\footnotetext{
4 I use "political" in the sense of being imbued with power relations, rather than in the narrower
} sense of relating to the formal structures of government. 
take for granted the difference between "material" equipment and "intellectual" components of laboratory activity: the same set of intellectual components can be shown to become incorporated as a piece of furniture a few years later" $(1986,238)$. The technological artefacts of the laboratory are material incarnations of currently-accepted scientific thought, and at the same time shape the direction of scientific research and determine which data are accepted as scientific fact. Latour developed the concept of technoscience ${ }^{5}$ as a way of bringing together the messy continuity of practice that is usually tidied away and presented as "science and technology" (Bauchspies, Croissant \& Restivo 2006, 7). Science and technology are not separate, but rather mutually constitute each other.

It is also necessary to understand science and technology as part of systems, rather than in isolation. Arnold Pacey $(1983,6)$ argues that technologies are often thought of as only specific machines, or systems of machines, linked with the knowledge and skills needed to operate them. However, to properly understand the role that technology plays in our lives we need to also include the cultural and organisational aspects that surround the technical aspects of particular technologies. Wajcman adopts a similar analysis, examining the ways in which technological innovation builds on previous technology, "not in the form of separate, isolated devices but as part of a whole, as part of a system", which is in turn integrated with other systems. The development of technological artefacts ranging from fridges and microwaves to ballistic missiles is shaped not just by the demands of the tasks they are meant to achieve, but also by existing infrastructure, prevailing political ideologies such as the contemporary construction of gender, as well as by other systems (Wajcman 2004, 34-38). These systems overlap and constitute each other.

Critical theories of science and technology, and of knowledge more generally, argue for a rethinking of the frequent division made between the realms of science and technology and of politics, society, culture, and economics. Frequently, science and technology are discussed as if their development is shaped entirely according to their own internal, entirely rational and fact-based,

5 Donna Haraway has also discussed technoscience extensively, expanding and complicating Latour's use of the concept and arguing that "Technoscience extravagantly overshoots the distinction between science and technology as well as those between nature and society, subjects and objects, and the natural and the artifactual" $(1997,3)$. 
logic. A diagram from Wellington Grey's webcomic (1997) that was widely circulated on the Internet illustrates this perspective admirably, contrasting the scientific method with religion:

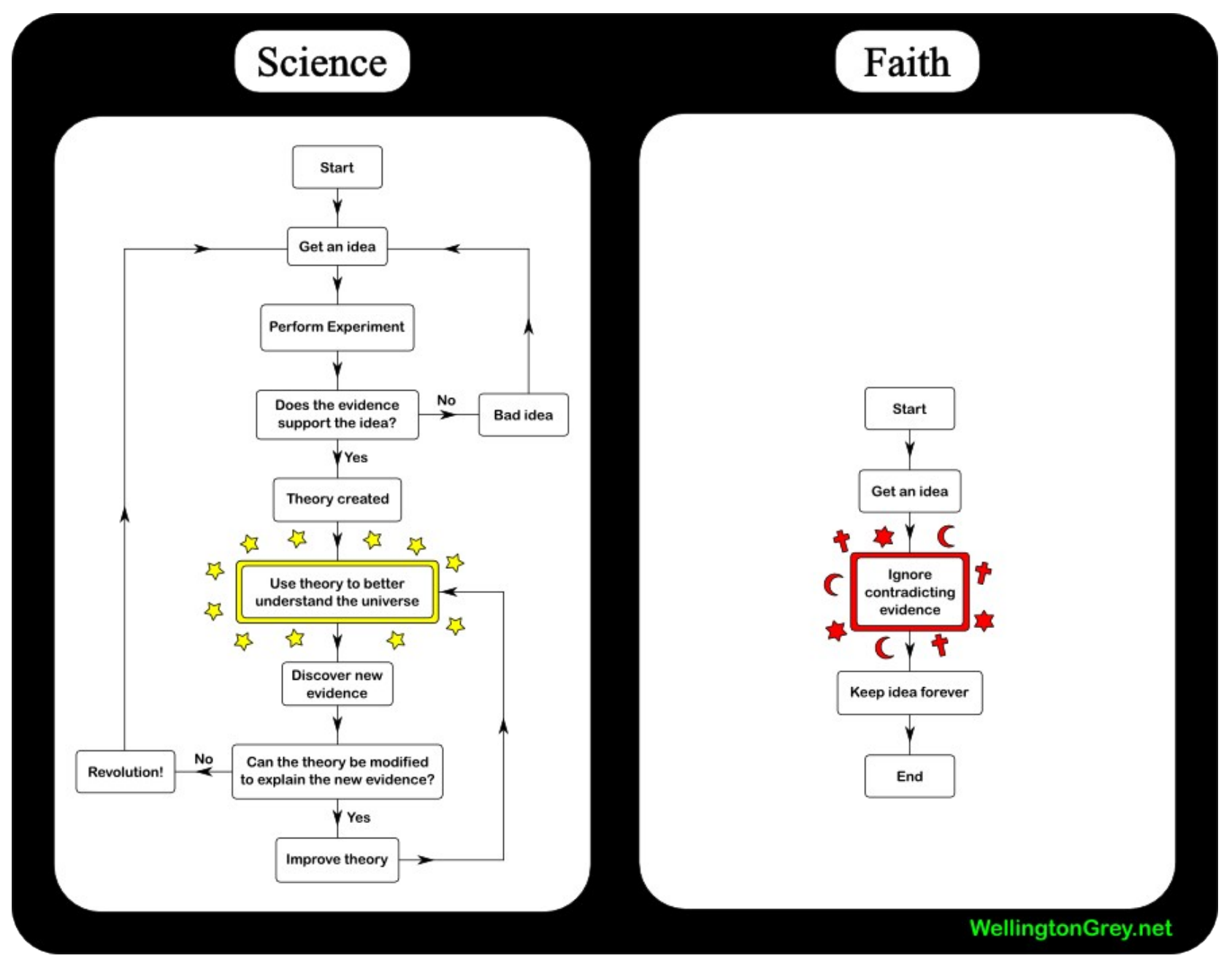

This idealised model of science is notable both for the rigid division it makes between facts and values and for the questions and issues that it excludes. There is no recognition in this model of political pressures, economic constraints, or social influences on scientific research. Science is portrayed as pure discovery, in which scientists come closer to an objective truth with every step. Similarly, technological development is often seen as "self-propelling, moving forward along a singular path without human intervention. [...] There are no social choices, as technology has only one path, which is intrinsically determined, and there is no point in blocking the road down which technology proceeds, as it is always for the good" (Kleinman 2005, 5). This model is reinforced by those who see scientific rationality in a negative light, but 
nevertheless beholden to its own internal principles rather than outside forcesfor these critics, the best that can be hoped for is to put limits on the reach of science and technology into the lifeworld (Feenberg 1999). However, despite the popular acceptance of this idealised model of scientific discovery, there is a significant body of work that refutes it.

A number of writers have shown that social, political, and economic forces all shape the path of scientific and technological change. At the most fundamental level, Kuhn argued in The Structure of Scientific Revolutions (1970) that shifts in scientific paradigms are social as much as scientific, revolutions rather than part of "a continuous or cumulative pursuit of truth," as previous philosophers had characterised science (Hård \& Jamison 2005, 258). Postmodernism, feminism, environmentalism and postcolonialism have each offered critiques of the idealised model of an apolitical science propelled by an internal, universally applicable rationality.

There is also a wealth of research that documents the various forces that influence the development of particular scientific systems and technological artefacts. Emily Martin's (1991) work on The Egg and the Sperm provides a classic study of the way in which social structures, in this case gender, influence scientific research. Martin argues that the conventional understanding of human conception as a matter of active sperm and passive ova was shaped and perpetuated by gender stereotypes. Even when researchers uncovered evidence that challenged this understanding their model of conception remained bound by a gendered understanding of the role ova and sperm played in fertilisation. The idea that matrices of power such as race, wealth, political structures or gender can influence the path of scientific and technological change is therefore neither novel nor particularly controversial in many disciplines. However, it is important to emphasise this point because the argument put forward here relies on an understanding of knowledge as a site of power and contestation, shaped by other power structures.

Scientific and technological change is, however, shaped not just by existing power structures but also by users once particular artefacts and systems become generally accessible. The French government's Teletel network, for 
example, was initially meant to be a medium for disseminating official information effectively. Users then hacked the system to expand from a information-access system to one that had capabilities for person-to-person communication. Subsequently the network became known as a medium for sex chat, and those running it responded by promoting it with sexualised advertisements (Rheingold 1994, 229-234). Very quickly, users significantly reshaped not only the content carried on the network, but the very way in which it worked. There are countless other examples of the creative rethinking of technological systems by their users, from the many cases discussed in Hård and Jamison's (2005) Hubris and Hybrids through to skateboarders' use of urban architecture as a space for play rather than shopping or work. These examples complicate the vision of technological artefacts as the outcomes of scientific discoveries, and of a sharp divide between scientists as active and users as passive in the process of technological development. These examples show that systems of knowledge are shaped by outside forces and interests during and after their implementation, as well as during their development.

The contestability and multiplicity of knowledge is further illustrated by the existence of alternative paths of development that are either aborted or follow a parallel but subordinated path alongside dominant modes. Indigenous knowledge systems relating to agriculture or medicine are prime examples of this. For example, traditional Indian agriculture continues to be practised and developed by a significant proportion of farmers at the same time as Green Revolution agriculture dominates institutional and commercial thinking in India. While the proprietary model of software development dominates the desktop market, other sections of the software industry are dominated by F/LOSS. Examples abound of other ways of doing research, other ways of knowing, other processes for technological change. The continued existence of subordinated systems such as these highlights the contingent nature of dominant systems by offering models of alternatives that could have been more influential. They also offer starting-points for imagining change to existing systems.

Throughout this thesis, I refer to peer-based knowledge systems as alternatives to dominant modes of knowledge production. Grassroots knowledge, which can 
be thought of as part of the spectrum of peer-based knowledge systems, are usually seen as those built from the practices and experiences of everyday life, and rooted in specific locations. Grassroots knowledge is often discussed in terms of indigenous agricultural or medicinal systems, although community-level knowledge and "informal knowledge" in the Global North (Swidler \& Aditi 1994, 321-322) have also been understood as part of this paradigm. While grassroots knowledge is often contrasted with more hierarchical forms of knowledge, the distinction between grassroots and hierarchical knowledge systems is not always clear-cut. Grassroots knowledge systems often include elements of hierarchy, such as increased legitimacy for those who hold certain roles within the community or differing value placed on contributions according to the gender, age, or other aspects of the contributor's identity. Some systems, such as the academic peer-review system, include elements of openness, decentralisation, and democratic principles while simultaneously excluding certain groups and perspectives and placing barriers to contributions. In discussing peer-based knowledge production, then, there must be recognition that peer-based knowledge systems differ in their details, and may take many different forms. The relevant forms of peer-based knowledge production will be discussed in more detail in the following chapters.

Many aspects of contemporary knowledge systems actively reinforce social, political, and economic inequalities. One way to understand this relationship is through substantivist perspectives on science and technology, which are those that see these systems and artefacts as imbued with particular values, a classic example being McLuhan's (1994) declaration that the medium is the message. Feenberg (1999) argues that substantivist perspectives share similarities with technological determinism, in which science and technology are viewed as homogeneous and autonomous. However, work by scholars such as Sclove (1999) emphasises the particularity of technological systems, seeing technologies as carrying certain values but at the same time being contestable and multiplicitous. Sclove (1999) provides a well thought-out and comprehensive discussion of the many ways in which technologies shape our lives, ranging from the way in which furniture design and placement affects people's sense of personal space and their interactions with each other right through to the implications of particular technologies for different models of 
democracy. He argues that various technologies play a role in producing undemocratic outcomes, as well as reinforcing disadvantage among marginalised groups within society, including women, children, and people with disabilities, but suggests that ultimately technology can be shaped by, and in ways that further, democratic concerns.

While Sclove's work focuses on the effects that technological systems have on social structures and behaviours, other work has looked at the way in which dominant scientific paradigms shape the structures through which we think about the world. For example, Darwin's theory of evolution was twisted into the social darwinism used by Herbert Spencer and Francis Galton to justify eugenics and racism. Science and technology do not determine society, and society does not fully script the course of technology change-rather, a complex pattern of interaction affects the shape of both (Castells 2000a, 5). It is therefore both possible and necessary to understand systems of knowledge as part of power structures while simultaneously being mutable, a site for resistance as well as domination.

\section{Section two: the Information Age and neoliberal globalisation}

Arguably, the need to consider the power of different systems of knowledge has acquired a new urgency in the wake of the ICT revolution and the restructuring of capitalism. Manuel Castells argues that during the 1970s, a "converging set of technologies in micro-electronics, computing (machines and software), telecommunications/ broadcasting, and opto-electronics" came together and reinforced each others' effects (2000a, 29) [emphasis in original], drastically changing our ability to communicate and manage information. Castells includes biotechnologies in this set of technologies,

not only because genetic engineering is focused on the decoding, manipulation, and eventual reprogramming of the information codes of living matter, but also because biology, electronics, and informatics seem to be converging and interacting in their applications, in their materials and, more fundamentally, in their conceptual approach (2000a, 29). 
These technologies have had wide-ranging effects on society, economics and culture. They have changed the way in which we produce and access content, making it trivial to share vast amounts of information. They have also been linked to changes in the contemporary capitalist system. Castells argues that ICTs have led to a "new, informational mode of development [in which] the source of productivity lies in the technology of knowledge generation, information processing, and symbol communication" (2000a, 16-17). This informational mode of development is linked to, but distinct from, the capitalist restructuring that has accompanied it $(2000 \mathrm{a}, 14)$. The argument that changes to capitalism have been caused by ICTs alone is not convincing, but they have certainly played a role in accelerating the development of neoliberal capitalism.

The emergence of neoliberal capitalism has been associated with many changes. For the purposes of this discussion, it is sufficient to note two major differences between contemporary capitalism and the capitalism of previous eras. The first change that is relevant here has been to the scope of capitalism; whereas previously capitalism was international, today it is global, affecting all parts of the world, albeit in different ways (Burbach 2001, 33). The global nature of contemporary capitalism means that people throughout the world are being affected by interrelated processes, although the effects are uneven. Whether one lives in a global city or a village in a rural area, life has been and continues to be changed fundamentally by the processes of economic globalisation. This has played a role in facilitating the emergence of the GJM, as we will discuss below.

A second change worth noting is that while Fukuyama (1992) and various political leaders have put forward the claim that western liberal democracy has triumphed, the role of the nation-state has changed and democracy has, arguably, been further constrained by the increasing power of international financial institutions and multinational corporations (MNCs). While it is tempting to see this as a straightforward process in which states cede power to the interests of capital, the situation is more complicated. Burbach writes that "[t]he determinant feature of the current epoch is the supersession of the nation state as the organizing principle of capitalism, and with it, of the inter-state system as 
the framework of capitalist development" $(2001,45)$. However, others see the role of the state as changing, rather than being superseded.

Government responses to the global financial crisis, which have included nationalisation of financial institutions in some cases, would seem to confirm this. Additionally, while to some extent national governments may be constrained by international institutions and the demands of capital, they exert power over their own citizens and other states through the requirements that these institutions place on national policies, and through rhetoric about to the need to remain competitive in the global economy. There is a strong case for the argument that states could, and should, play a role in buffering their citizens from the negative effects of economic globalisation. Neoliberalism, therefore, is both global and transnational, but it does not entirely efface national boundaries or the importance of the nation state. One of the implications of this is that resistance to the dominant world system is directed towards MNCs and international financial institutions as well as nation-states.

A number of factors have played a role in changes to the form of capitalism over previous decades. David Harvey, for example, has argued that neoliberal ideology was spread through the capture of the media, corporations, educational institutions, and political parties, as well as by the co-option of social movements calling for increased individual freedom (2005, 40-41). In addition to these processes, and interlinked with them, the ICT revolution of the 1970s played an important role. While the restructuring of capitalism may have been possible without ICTs, it would have taken on a vastly different form. ICTS have played a role in the establishment of international financial institutions, the increasing international flows of capital, finance, and trade, and the development of a global elite. The International Monetary Fund (IMF) has acknowledged the key role that ICTs played in this process. Its 2005 report on the World Economic Outlook noted that "[t]he recent bout of financial globalization is partly associated with the decline in information processing and dissemination costs that have fostered cross-border trade in an expanding variety of financial instruments through decreased transaction costs" (IMF in Youngs 2007, 11). Just-in-time manufacturing and global shipping may seem to be inherently material processes, but they also require information management 
on a scale that was not possible several decades ago. The speed, as well as the nature, of capitalist restructuring has also been affected by the ICT revolution. Bae argues that ICTs have combined with the globalization of finance and production to produce "synergies that have accelerated changes in the world economy" $(2003,87)$, increasing the pace of economic globalisation. Neoliberal globalisation has grown with, and been shaped by, the ICT revolution.

As well as the logistical support that ICTs provide to neoliberal capitalism, capitalism is shored up by the ideologies that are built up around science and technology, in particular the taken-for-granted assertion that capitalism is the foundation of scientific and technological progress, the only political and economic system that supports innovations. There are a number of variations of this claim: one of the most significant contemporary versions is that the current capitalist system allows scientists and technological innovators to pursue their work not only by allowing corporations to provide funding for the "vast apparatus required to splice their genes or smash their atoms", but also by opening up "the prospect of getting intellectual property rights on their results, so adding the fortune of follow-up exploitation to the fame of initial discovery" as a vital incentive (Shipman 2002, 192). These claims depend in part upon an effacement or devaluation of other visions of knowledge, such as traditional knowledge systems and the appropriate technology movement.

References to the mutually supportive relationship between capitalism, particularly in its current incarnation, and science and technology also depend in large part on an implicit substantivist view of scientific and technological development as inherently progressive and predominantly positive. The claim that capitalism is essential to scientific progress is only useful if science is invoked as the protagonist of the story. This is a story of the science that created high-yielding agriculture, cured polio, and (to move from the 1950s to the 2000s) will develop nanotechnology and sustainable energy that will allow everyone to have a western lifestyle while simultaneously preventing the harms of climate change and other forms of environmental degradation. 
Capitalism's supposedly symbiotic relationship with scientific progress is also framed within a wider claim that capitalism has demonstrated its superiority over other systems through a process of evolutionary competition. Shipman argues that,

Today's institutions and ideas survive and thrive because they outperformed the alternatives. To still be around, they have to be the best around. Any superior approach would, by now, have stepped in and stolen the show. So the clamour for change is actually a call to turn the clock back to solutions that were tried and found wanting several centuries ago. Globalization is a product of this Darwinian, 'retainedbecause-judged-relevant' logic $(2002,200)$.

By this logic, neoliberalism and economic globalisation are the outcome of evolutionary processes, the pinnacle of the competition between different political systems. Other systems of knowledge are pushed to the side or, more often, ignored completely, as are the political outcomes and systems that may be produced by these systems.

There are two important points to note here. The first is that none of these myths are, in all likelihood, essential to the neoliberal project. Neoliberalism harnesses many stories to its wagon, including narratives of gender and race, as well as those discussed above. Further, while neoliberalism provides an ideological justification for economic globalisation, both the threat and the use of force also play a role in its spread; economic globalisation is not built on ideology alone. Within nations, even democracies, police forces and armies have been deployed to subdue dissent (Fernandez 2008), while the United States government has repeatedly shown its willingness to intervene overseas in order to further its foreign policy agenda, from its military actions in Iraq between 2003 and the present to its involvement in the failed 2002 coup against President Chavez in Venezuela (Vulliamy 2002). Therefore, attempts to undermine claims relating to science and technology put forward by proponents of neoliberalism are unlikely to cause any great weakening of neoliberal capitalism. However, these myths do not only shore up neoliberalism-they also act to silence dissent by discrediting alternatives as unrealistic, unscientific, or a 
sign of Luddite tendencies. Undermining the general acceptance of the narratives that surround the relationship between capitalism and "scientific progress" may therefore be an important step for those proposing alternatives to economic globalisation.

Secondly, if, as was argued in the previous section, knowledge systems are developed by the economic, political, and social power structures that surround and run through them, it is not only the narratives that surround knowledge systems that are shaped and used by proponents of neoliberalism. From the development and design of particular technological artefacts through to the fundamental structure of science itself, contemporary knowledge systems have been shaped by the context in which they have emerged. This idea can be explored through counterfactual thought experiments, systems that exist as subordinate alternatives, and examinations of the forces that influenced the development of particular ICTs. Existing alternatives, such as the Cuban biotechnology for the people (Mola et al. 2006) or the tiered Internet proposed by companies in the United States discussed below, provide visions of alternatives that might have been, or might one day become, dominant. Castells has written extensively on how American culture and political structures have influenced the milieux of innovation surrounding ICTs (2000a), and the various influences on Internet culture, including academia and the US counter-cultural movement of the late 1960s and 1970s (2001). It is vital to bear this in mind when we discuss the politics of knowledge-remembering that knowledge systems can (and do) exist in forms other than those that are currently dominant opens the space available for dissent, and for imagining other futures.

This is particularly important in light of the far-reaching changes that have accompanied the informational mode of development and the rise of neoliberalism. As Castells notes, humans are now more tightly tied to our productive technologies than ever before, as there is "a close relationship between the social processes of creating and manipulating symbols (the culture of society) and the capacity to produce and distribute goods and services (the productive forces)" (2000a, 31). These developments are hailed by some as first steps into a new (and better) phase of human existence. Techno-utopians such as Kevin Kelly and Nicholas Negroponte see ICTs as able to "empower the 
individual, enhance personal freedom, and radically reduce the power of the nation-state" (Barbrook \& Cameron 1995). Proponents of neoliberal globalisation explicitly or implicitly claim that the changes wrought by economic globalisation and the knowledge systems linked to it are both beneficial and inevitable (Shipman 2002; Friedman 2000 \& 2005; Brown 2006). For others, these developments are a cause for concern. The combination of systems which stretch from the sub-molecular level of genetic engineering to global effects such as climate change, and a neoliberal globalisation that affects all corners of the world, has come under fire from a number of unexpected directions. One of the most significant of these is the movement of movements that made its début in Seattle in 1999: the global justice movement.

\section{Section three: the global justice movement and knowledge systems}

The first part of this section discusses the background to the emergence of the GJM, including its roots in the NSMs of the 1960s and 1970s and in movements from the Global South. While in part the GJM can be seen as a reaction to the effects of neoliberal globalisation, it is primarily defined through its incorporation of a wide variety of struggles addressing different facets of global justice, and through a commitment to sustainability and democracy, as well as a desire to reform or radically alter capitalism. It is also defined through the value placed on diversity within the movement, not only as a goal to aim for in the contest over globalisation, but also as a defining feature of the movement itself. The second part of this section discusses the importance of knowledge systems to the work and structure of the GJM. Firstly, these systems are important because the very structure of the GJM, particularly its decentralised nature and its ability to incorporate diversity, is inextricably tied to the democratic potential of ICTs. Secondly, knowledge systems are important because ICTs have become vital parts of GJM activists' toolbox. Thirdly, knowledge is important because activists' ability to gain legitimacy for their analysis relies on the acceptance of non-elites as producers of authoritative knowledge. 


\section{The emergence of the global justice movement}

As noted in the introduction, by the late 1990s there was a sense in most corners that capitalism, liberal democracy, and the free market had defeated all comers. State socialism as a serious alternative had collapsed, and the social movements of the late 1960 s and 1970 s seemed to be settling into a comfortable pattern of contention, making demands upon elites without challenging the fundamental structure of the liberal democratic state. The 1999 protests in Seattle overturned this sense of complacency, calling attention to a new phenomenon-the GJM. As protest followed protest, the movement evolved, and commentators called attention to its roots in the Global South. The GJM was recognised as manifesting not just in Seattle, or even Prague, Geneva, Edinburgh, Melbourne, and other cities that played host to meetings of the World Economic Forum (WEF) and WTO, but also in Chiapas, in Porto Alegre, in Mumbai, in millions of smaller protests, communications, websites, tiny flickers well below the radar screens of mainstream political science and international relations studies. The GJM did not come out of nowhere-it has a long lineage, and is built on decades of organising in both the Global South and the Global North.

During the late 1960s and early 1970s, a number of protests gained international attention. In 1968 a small group of students occupied the University of Nanterre, in France, protesting changes to university funding and course structures. The police tried to re-take the university, and it was eventually shut down by its administration. Other university students in the Sorbonne began to protest against the presence of police in universities and against arrests carried out during protests and meetings. Other sections of society joined in-many professors showed their support for students and local residents assisted demonstrators. On May 13 a general strike began and protests were held against the government's "internal imperialism" and for the rights of students and workers (Feenberg \& Freedman 2001, 5-30). These events, and the strikes and protests which followed, attained a "mythic proportion" for the Left in France and elsewhere (Feenberg \& Freedman 2001, $\mathrm{Xv}$ ). At the same time, 1968 saw protests in other parts of the developed world. Dubcek, under public pressure, began a series of reforms in Czechoslovakia, including greater freedom of speech and an opening up of the political system. 
The Soviet Union responded by sending in the tanks, and many people demonstrated against the occupying force, protesting and putting up graffiti and posters (Glenn 2003; Davies 2007). In the US, a range of social movements were also having a significant impact on the political landscape, including the anti-war movement and the feminist movement. Protests elsewhere in the Global North contributed to the sense that change was in the air.

By the 1980s, social movement theorists had come to see the movements that had emerged in the late 1960s as constituting a new phase in collective action, and Alberto Melucci had coined the phrase "new social movement" to describe them (Melucci 1996, 5). Melucci, Touraine, Offe, Habermas, and others working within the new social movements perspective on social movement studies argued that these events were a sign that post-industrial societies were no longer concerned with the materialist goals of traditional leftist movements. The "old left" was, many theorists argued, associated with social democracy and communism, with class conflict, trade unions, conventional lifestyles, and modernist views that embraced technological progress (Hunt 2003, 14). NSMs were differentiated from the "old left" through not only their goals, but also their rejection of prevailing avenues for change, their disregard for seizing state power, their focus on cultural and social rights as well as struggles over material goods and resources, and a membership composed of the new middle class as well as those marginal to the labour market (Burgmann 2003, 18-19; Della Porta \& Diani 1999, 12). The environmental, queer, and feminist movements are prime exemplars of NSMs.

The new social movement perspective has come under criticism for a number of reasons. One of these is its failure to recognise the continuities between NSMs and previous movements (Hunt 2003), while another is the tendency to see NSMs as "unitary empirical objects" (Melucci 2006, 5). Others criticise the perspective for paving the way for a postmodernist attack on a critical, collectivist, confrontational and campaigning impetus and encouraging the shift towards a politics of identity (Burgmann 2003, 22). Similarly, new social movement theory was seen as implying a value judgement between "old" and "new" movements, with the replacement of class-based movements by identitybased movements valorised as a positive and necessary development 
(Burgmann 2003, 19). Finally, the new social movements perspective has been charged with neglecting the insights that could come from closer attention to Southern movements, as has most social movement theory (Foweraker 1995). Each of these criticisms is valid, to an extent, and introduces complexities to our understanding of the movements that emerged during the 1960s and 1970s, which I will continue to refer to as NSMs.

Several aspects of NSMs should be emphasised at this point, and it is important to note gaps and problems with new social movement theory. NSMs show many continuities with their predecessors. Both "old" and "new" social movements make identity claims, become involved in institutionalised politics, have both hierarchical and decentralised organisational components, and mobilise the middle class as well as other sections of the population (Pichardo 1997, 414419). As is the case with other social movements, NSMs are heterogeneous, and the characteristics that define them are not necessarily shared by, or limited to, all groups within a designated NSM. As well as concerns with the categorisation of NSMs, the new social movements perspective (along with social movement scholarship more generally) has at times become bogged down in abstract and introspective discussions that have little application to the world of activism (Flacks 2005, 7-9). Both the European and the North American scholarship on social movements have neglected and continue to neglect Southern movements, with Latin American movements being the major exception (Edelman 2001, 291-294). These problems, to a greater or lesser degree, are acknowledged throughout the literature.

Nevertheless, it is true to say that after the late 1960s many existing movements began to display the characteristics of NSMs listed above, and new movements emerged that fit this categorisation. The GJM owes much to these movements, and shares many of the characteristics attributed to NSMs, including anarchic organisational structure, novel protest methods, and (to a lesser extent) post-materialist aims and an active middle-class membership. However, the key difference between NSMs as they are conventionally categorised and the GJM is that the latter has a much broader scope, both in terms of the issues that it addresses and in terms of its geographical reach. The evolution from NSMs to the GJM was aided by three interrelated factors: the 
linkages made between increasingly transnational NSMs and Southern movements, the rise of neoliberalism, and the ICT revolution.

From the 1960s onward, large parts of the Global South were experiencing massive upheavals. On October $2^{\text {nd }} 1968$, in La Plaza de las Tres Culturas in Mexico City, a student demonstration against government attacks on civil liberties and university autonomy was broken up by the police. Around 300 students were killed, and around a thousand arrested. Many involved in the student movement fled the city and went into the country to carry on the fight, influenced by Che Guevara and Mao (Rubin 2002, 40-41). National liberation and anti-colonial struggles were taking place throughout the Third World, as it was then known, many of which involved attempting to redefine women's rights and status. Gail Omvedt (1998) argues that a range of social movements that emerged in the 1970s in India, including dalit and anti-caste movements, women's movements, environmental movements, and farmers movements, should also be seen as NSMs. These movements are just as important to the history of the GJM as predominantly western NSMs, if not more so.

Throughout the last three decades of the twentieth century, many groups and movements have built links and networks that crossed the divide between the Global North and South. These networks have intensified and expanded connections that have been present even in movements during nineteenth and early twentieth century, including movements against foot-binding in China and against circumcision in Kenya (Keck \& Sikkink 1998, 39), Chilean activism against the Pinochet regime, and later attempts to have General Pinochet tried for human rights violations spread from Chile around the world (Khagram, Riker \& Sikkink 2002, 3). NGO and church groups began to build networks around debt and structural adjustment issues in the 1970s, and by the 1990s transnational networks in the US and Europe were strengthening ties with groups in Latin America, Asia, and Africa (Donnelly 2002, 158-159). During the 1990s, activists' attempts to prevent the building of the Narmada Dam in India built an international campaign, forging connections with organisations based in the United States, Europe, and Japan (Kothari 2002, 236-237). These, and numerous other campaigns and movements, were precursors to the protests at Seattle. 
A number of transnational social movement networks and organisations have grown out of or have a substantial base in the Global South, many of which have been instrumental in forming the backbone of the GJM. These include People's Global Action (PGA), which is not a formal organisation and therefore has no official headquarters, and Via Campesina, which has an "international operative secretariat" in Indonesia. PGA self-identifies as an instrument for coordinating social movements' activism, and has been involved in organising worldwide Global Action Days, Caravans, and regional conferences since its creation in early 1998 (Desmarais 2003, 37; People's Global Action 2007). Via Campesina, an international peasant farmers' union, has been described as "one of the most extraordinary examples of the movement's capacity for international networking" (Notes from Nowhere 2003b, 28). Created in 1993, it currently claims members in 56 countries throughout the world, and defines its struggle as being against neoliberalism and injustice worldwide (Via Campesina 2009). These coalitions and others like them, including the Third World Network, played a role in creating international networks in the lead-up to Seattle, and continue to do so today.

Movements in the Global South have also played a key role in developing the strategies and tactics adopted by those within the GJM. Graeber notes that "[m]any, perhaps most, of the movement's signature techniques-including mass non-violent civil disobedience itself-were first developed in the global South" $(2004,207)$. The Ejército Zapatista de Liberación Nacional (EZLN), more commonly known as the Zapatistas, are seen as having reinvented the radical political imagination of the world, providing a blueprint for a new movement (Notes from Nowhere 2003b). This group owes much to the the ideas and the activists of the 1968 wave of protest in Mexico, but has changed considerably over time and developed a new language and form (Rubin 2002). As well as using what Notes From Nowhere, a collective of global justice activists, calls "a quite different language of resistance-of land, poetry, indigenous culture, diversity, ecology, dignity" (2003b, 23), the Zapatistas have helped to bring the GJM into being through online and face-to-face meetings, in particular the 1996 Encuentro Against Neoliberalism and For Humanity (Milburn 2004, 473). The 
contributions of Southern movements to the formation of the GJM, and to its growth and activities, have been significant.

At the same time, the increasing transnationalisation of predominantly western NSMs has been an important factor in the emergence of the GJM. Many social movements, including those that preceded the NSMs, have had an international or transnational element to their analysis and/or their organisational structure. In addition to the examples discussed above, Keck and Sikkink (1998) point out that both the abolitionist and woman suffrage movements involved extensive communication between activists in different countries, while the labour movement of the $19^{\text {th }}$ and early $20^{\text {th }}$ centuries was "originally conceived of as international in structure and internationalist in aim" [emphasis in original] (Waterman 1998, 17). The transnationalisation of social movements picked up speed in the 1980s and 1990s; even before the 1999 Seattle protests scholars were starting to comment on the increasing transnational nature of activism. Hegedus argued in 1989 that the 1980s had seen a shift from the local to the global in the understandings and orientations of supporters of western social movements (in Cohen \& Kennedy 2000, 299), while Kreisberg (1997) noted the increasing proliferation of transnational social movement organisations (TSMOs) during the 1980s and 1990s. These TSMOs, and the increasingly transnational analysis of many NSM participants, gradually increased their links with Southern movements and TSMOs.

One of the most commonly cited reasons for the increase in transnational connections over recent decades is the rise of neoliberalism and the growth of economic globalisation. With the growing reach of the institutions and processes of neoliberal globalisation, participants in struggles around the world began to recognise commonalities under its aegis. Many of these commonalities centre around recognition of a common enemy, as "different groups find themselves facing the same global corporations, international institutions, and market-driven race to the bottom" (Brecher, Costello \& Smith $2000,15)$, as well as environmental degradation that stretches across national boundaries. One story from the movement explains the coming-together of different struggles as a result of their common oppression: "For struggling for a better world all of us are fenced in, threatened with death. The fence is 
reproduced globally. In every continent, every city, every countryside, every house" (Marcos 2003, 0). There is a significant body of academic, activist, and journalistic writing that addresses and critiques this view of the GJM as a response to neoliberalism. Here it is enough to note that both a common goal (a better world) and a common threat (described here using the metaphor of the fence, which separates people from each other, from the spaces of decisionmaking, from the resources that they need to live well) have played a role in the formation of the GJM.

There are also more pragmatic aspects to this story. How are fences broken? How do "[t]he rebels search each other out", "walk towards one another", "find each other and together break other fences" (Marcos 2003, 6-7)? In a literal sense, much of this was, and is, achieved through the same networks and flows that have facilitated the restructuring of capitalism and the emergence of neoliberalism, ICTs being particularly important. As well as the dominant networks of trade, finance, and capital, other international networks are growing in importance, as "ordinary people not only move across national boundaries but take advantage of cheap transportation and communication to sustain new transnational communities" (Evans 2000, 39). As the Notes from Nowhere Collective put it, the emergence of the GJM meant that,

[c]apital's dream of super fast networks that will spread consumerism across the planet was turned on its head. [...] People were using the global communications infrastructure for something completely different - to become more autonomous, to get the state and corporations off their backs, to live in a more healthy way. To talk to one another (2003b, $65)$.

ICTs, particularly the Internet, and other global flows provide the material means for activists to communicate with each other and non-participants, to organise, and to engage in the activities which together form a global web of activism.

This, then, provides some understanding of how and why the GJM has emerged, but further discussion is required as to how to define the GJM. There have been numerous attempts to theorise the GJM, each of which understands 
it in slightly different terms. Proponents of neoliberalism tend to portray it as an "anti-globalisation" movement, reactionary and opposed to all forms of globalisation (Venter \& Swart 2002a, 116). However, as hinted at above, to the extent that the movement is against globalisation it is against neoliberal globalisation, and both relies on and encourages many other forms of globalisation (Jordan \& Taylor 2004, 43). Almost all commentators recognise the heterogeneity of this global web of movements, and it is often referred to as a, or even the, movement of movements (della Porta et al. 2006; Klein 2004), although there are slightly different interpretations about what defines it and what it is calling for. Starr, for example, sees it as a network of anti-corporate movements confronting (economic) globalisation (2006), while others understand it as primarily an anti-capitalist movement (cf. Callinicos 2003), a movement for globalisation from below (Brecher, Costello \& Smith 2000), an alterglobalisation movement, or even a globalisation movement (Graeber 2004, 204). Each of these labels brings with it a slightly different understanding of the movement, a different setting of boundaries.

For brevity's sake, I will mainly refer to this movement of movements as the global justice movement, although I use other terms at times. The "global justice movement" label takes precedence because it is in frequent use by activists. While this should not be the only determining factor in social scientists' use of particular terminology, it is an important consideration. Secondly, and on a related note, this term avoids typecasting the movement as purely reactionary, unlike the "anti-globalisation" epithet. Finally, it defines the GJM through its aim - justice on a global scale-while leaving room for the many ambiguities of the movement. However, I wish to emphasise that labels used by other authors each capture an element of the movement, which is at times anti-capitalist, anticorporate, a movement for globalisation from below, and so on. Each of these are avatars of the movement. At the same time there are other networks of movements involved in other struggles that overlap with and flow through the GJM.

The GJM is made up of a wide variety of actors who drift in and out of involvement, including individuals, smaller movements, and organisations of various sorts. Few of these actors are pursuing a goal primarily defined as 
"global justice", or even opposition to neoliberal globalisation. Rather, they are involved in struggles over issues which feed into the end goal of a more democratic, diverse, and sustainable world. Additionally, actors within the GJM pursue their goals through quite different strategies, spanning "both normal/institutional and non-normal/non-institutional political action" (Fisher et al. 2005, 104). The movement contains many contradictions, including conflicting interests and groups that were previously, or remain, hostile to each other (Brecher, Costello \& Smith 2000, 16). It therefore seems legitimate to ask what, if anything, holds the movement together.

A number of overlapping and interconnected strands form the warp and weft of the GJM. As in a tapestry, none of these issues and struggles can, alone, define the movement. It is the fact of their interconnectedness that makes the GJM what it is. The first of these is the attempt by global justice activists to critique our existing relationship to nature and offer alternatives. Such an attempt is exemplified by the International Forum on Globalization's report on Alternatives to Economic Globalization, which lists "ecological sustainability" as one of ten core principles for societies that offer an alternative to neoliberalism, as well as drawing on ecological ideas in their discussion of other principles such as "the precautionary principle", "food security and safety", "diversity", and a "common heritage" (Anderson et al. 2004, 77-100). GJM activists are engaging in many different struggles, but the desire for sustainability is a common theme throughout the movement.

A second strand which is notable within the movement is the commitment to exploring more direct forms of democracy: activists argue that elections alone are not enough, and that decisions should by made by those who will bear the consequences (Anderson et al. 2004, 79). The commitment to direct democracy is also embodied in the lived practices of the movement itself, which activists proudly describe as being "without leaders [...] without clear organizational structures, [and] without a command and control centre" (Notes from Nowhere 2003c, 64). There is no single blueprint for a political system that will meet the requirements of direct democracy within the GJM. Rather, the movement is the site of repeated negotiations, discussions, and experiments with and surrounding the ideals of direct democracy. 
A third strand running through the GJM is the critique of capitalism, which has both radical and reformist expressions. Activists within the reformist sections of the movement have focused much of their critique on the growing power of corporations and international financial institutions, arguing that these should be reined in by governments. Others argue that what is needed is a more serious challenge to the existence of both capital and the state (Graeber 2004, 202). This has also been linked to critiques of the enclosure of the commons through privatisation, which has taken on both radical and reformist guises, as when Klein writes that, "Thousands of groups today are all working against forces whose common thread is what might broadly be described as the privatization of every aspect of life, and the transformation of every activity and value into a commodity" $(2004,220)$. Each of these three strands are present to a greater or lesser extent throughout the movement, and are manifested in a wide variety of local and transnational struggles.

Finally, it must be emphasised that diversity is at the heart of the GJM. The authors of Alternatives to Economic Globalization argue that diversity "is key to the vitality, resilience, and innovative capacity of any living system. So too for human societies" (Anderson et al. 2004, 89). They argue for the importance of cultural diversity, economic diversity, and biological diversity, contrasting these with what they see as corporations' attempts to "reduce costs and increase market control through cultural homogenization, economic specialization, and elimination of unprofitable species" (Anderson et al. 2004, 89 \& 94). Diversity is also valued within the movement, evident in the many proud proclamations that the movement is "resonating across borders of nation, class, race, gender, [and] age" (Notes from Nowhere 2003a, 312) as well as in the frequent recounting of the wide range of struggles that constitute the movement (Graeber 2004, 205; Notes from Nowhere 2003b, 21). The movement's ability to weave together different visions of how to build a more sustainable and democratic world is strongly tied to the value placed on diversity. Attempts to preserve and nurture diversity are a continuing strand within the movement, but are also more than that: diversity is at once the basis of the movement's structure, a tactic, and an end-goal. 
These strands stretch across many different struggles and many parts of the world. Della Porta defines the movement as "the loose network of organizations [...] and other actors engaged in collective action of various kinds, on the basis of the shared goal of advancing the cause of justice (economic, social, political, and environmental) among and between peoples around the globe" $(2007,6)$. It is essential to acknowledge that there are multiple versions of what constitutes justice on a global scale, and it is useful to bear in mind the call by movement participants for "one world with room for many worlds" (Marcos 1997), or for the emergence of new stories rather than a single dominating ideology (Notes from Nowhere 2003b, 23). Actors within the movement may be pursuing highly localised and specific goals (that nevertheless are consonant with, and often framed within, the concept of global justice), but they are tied to the broader movement by communication with other activists, an analysis that recognises the links between their own struggles and others around the world, and shared participation in movement activities such as protests and WSFs. It will be obvious that this definition encapsulates a large proportion of contemporary activism, although it does not include all activism around the world. Arguably, one of the most remarkable and significant aspects of the GJM is that it has knit together movements from the Global North and Global South to produce a heterogeneous and fluid, but nevertheless interlinked, network of activism and communication.

\section{The global justice movement and knowledge systems}

Struggles over knowledge are important to the GJM because many of the most fundamental characteristics of the movement rely on participants' access to ICTs, and particularly to the Internet. An influential RAND study, Networks and Netwars (Arquilla \& Ronfeldt 2001), argues that there are fundamental links between the use of networked forms of organisation, doctrine, strategy, and technology. The use of particular technologies, strategies, and organisational forms is not merely a pragmatic choice, but is also fundamentally tied to the movement's ideology. In fact, we can take this one step further and argue that the movement does not have an ideology in the traditional sense; rather, its ideology is written in the practices of the movement itself (Croeser 2006; Graeber 2004). As with the NSMs that preceded it and which thread through it, 
participants within the GJM attempt "to use activism itself, rooted in the actual experience of ordinary people, as a form of governance" (Wapner 1995, 336), as a way to express and experiment with ways of bringing "one world with room for many worlds" into being. The movement's project is therefore inextricably linked to its actions and structures, and in turn to the ICTs upon which these are built.

Firstly, the structure of the movement is in large part dependent on access to the technologies of the Information Age. A key aspect of the movement's organisational structure is its networked form. While there are innumerable gatherings, manifestos, and organisations associated with the movement, it remains a network of networks, in which sub-networks are simultaneously overlapped and overlapping, not the tree-like hierarchy of the traditional organisation but rather what the Zapatistas call a desmadre: a big mess (Froehling 1999, 174). While earlier movements, particularly NSMs, were composed of horizontal networks rather than hierarchical structures, this has arguably been taken to a new level within the GJM. As well as leading on from previous social movements, the mix of autonomy and connection expressed in this "loosely connected global network", composed in part by smaller subnetworks, in which different actors mobilise together and interact while at times seeming to remain quite separate (Venter \& Swart 2002b, 197) also has echoes of the way in which websites are linked by hypertext. Just as sites on the Internet are connected by key hub websites (Barabasi 2002), the movement is connected by a network of "nodal organisations [that] are typically in touch, on a horizontal and spreadeagled basis, with many other initiatives and groups, which are themselves in touch with other initiatives, groups, and individuals" (Keane 2003, 61). The similarity is more than incidental, as the World Wide Web provides a space and a template for the global web of activism.

These networks are built on ICTs, not just the Internet but a host of other communicative media, as well as on face-to-face communications enabled by relatively cheap international travel. Numerous accounts of the early days of the GJM, for example, emphasise the importance of the Zapatistas' 1996 Encuentro Against Neoliberalism and For Humanity (cf. Graeber 2004, 204; Milburn 2004, 473; Burbach 2001, 145). This Encuentro was itself both an 
outcome and a validation of the importance of networks. The Zapatistas had been significantly strengthened by the emergence of a web of international supporters who were able to act swiftly on their behalf, which would not have been possible without the Internet (Froehling 1999). The Internet also played a major role in the rapid organisation of the first Encuentro, which attracted about three thousand participants from 42 countries (Froehling 1999, 169). At the Encuentro, the leader of the Zapatistas read out a vision for an "intercontinental network of resistance" which emphasised the decentralised and transnational nature of the movement (Graeber 2004, 204-205), a vision which must have owed much to the Zapatistas' own experience of the possibilities of networks. Elsewhere, other sections of the movement communicate and organise through websites, mailing lists, mobile phone communication, and at gatherings like the Encuentros and the WSF, forming networks that cross not only borders, but also the hazy boundary between online and offline space.

These networks are not merely a strategy or side-effect of the movement's activities, but rather form an integral part of its mindset, with many movements within it being marked by "a cross-border mentality" in which there are "links and chains of non-governmental solidarity and contestation spanning vast spaces stretching to the four corners of the earth" (Keane 2003, 61). These networks bring with them strategic benefits, such as the ability to facilitate cross-border flows of information and resources, but they also encourage and are dependent on another important and frequently-cited aspect of the movement, "a way of looking at the world not so much in terms of fragmentation-as many Marxists tend to do-but of possibilities for coalitions" (Escobar 1999, 49). This network of networks is built on and through a recognition of the value of diversity. It is also reliant on access to ICTs and other tools that allow swift, cheap, communication within and between countries.

The GJM is constituted of struggles from all parts of the world, many different ideologies and analyses, different perspectives on tactics and end-goals. The movement itself is built through diversity, as are movement events: "demonstrations actually comprise a convergence of hundreds of smaller protests, occurring at the same time and place, against a common enemy, but for many different reasons" (Venter \& Swart 2002a, 121). As already noted, 
movement participants and organisations come from all over the world: the Zapatistas in Chiapas, Indian farmers, refugee advocates from Australia, landless workers in Brazil, and so on. Maintaining a movement this diverse requires a flexible master frame, which the vision of one world with room for many worlds and the idea of justice on a global scale provides, but it also requires much discussion and communication (della Porta et al. 2006, 62-73). The networks discussed above play a large role in allowing discussion and debate and connecting different local struggles. The GJM's ability to incorporate diversity - and thus to exist in its current form—would not be possible without access to the knowledge systems that enable these networks.

Secondly, the ability to access, analyse, and disseminate knowledge effectively is a vital tool for GJM activists. If we are indeed entering a new phase of capitalism in which production "has come to mean controlling complex systems of information, symbols, and social relations" (Melucci 1996, 100), the ability to use information effectively will be key to the future success or failure of the movement. In fact, "through their creation of conditions that allow information to act in viral-like ways, the complex communication systems of advanced capitalism create lacunae or dark spots where institutional control becomes increasingly difficult", opening up new areas for resistance (Jordan \& Taylor $2004,20)$. These dark spots for control range from the personalised networks and cells associated with terrorism through to online peer-to-peer networks, and change their location and operations as attempts are made to bring them under control. Given this, creation of and access to alternative information channels is inherently political. This makes the bi-directional nature of information flow on the Internet doubly important, which was made clear in statements from media consultant Doug Miller in the wake of anti-Nike activism, in which he declared that board members were becoming increasingly scared that their corporate reputations could be blown away in two months by the Internet (Bennett 2003, 162). While the activism against Nike may have emphasised the role of the Internet in the swift dissemination of information, it also demonstrates the importance of creativity, symbolism and novelty.

A key strategy within the GJM is the use of emotive, novel, or amusing ways of transmitting activists' messages. While those in both the Global North and the 
Global South increasingly have access to huge amounts of information, it seems probable that "the capacity of individuals [particularly in the developed world] to process, sort, select and use appropriate information may have been diminished", in part because of the sheer volume we receive each day (Schultz 1994, 113). Facts about sweatshop wages are easily submerged among pictures of famine in Africa, local news, ever-present advertisements and the barrage of popular culture. Gaining attention, then, not only relies on the construction of "causal stories" to explain facts and prompt action (Keck \& Sikkink 1998, 17), but also the ability to dramatise these stories and provide emotional handholds. Jonah Peretti's correspondence with Nike, in which he requested that they stitch the word 'sweatshop' onto his shoes, rapidly spread around the world over email primarily because it was entertaining (Peretti 2001). Information about Nike's abuse of workers' rights was vital to the groundswell of opposition Peretti's emails helped to build, but it was carried along by the humour and novelty of the exchanges. While access to the Internet and other ICTs is not essential to GJM activists in spreading their message, Peretti's story illustrates the effectiveness of the Internet in rapidly spreading well-constructed, amusing, or emotive messages. As people throughout the world, including in the Global South, increasingly access the Internet through their mobile phones, such messages may spread even more quickly and widely.

Culture jamming is a particularly effective way of both intervening in mainstream culture and creating engaging messages that spread swiftly online. Culture jamming is "the practice of parodying advertisements and hijacking billboards in order to drastically alter their messages" (Klein 2001, 310), and has crept from the world of billboards onto the Internet with parody sites such as those set up by the "Yes Men" (Ollman et al. 2003). Klein argues that although culture jamming and related forms of activism never dry up entirely, in recent years they have been in the midst of a revival, "focused more on politics than on pranksterism" (2001, 314). This is a politics that is heavily influenced by its prankster past and simultaneously on the lookout for new ways in which to stimulate action. Books such as Days of War, Nights of Love (Maul et al. 2001) and websites such as Fuck for forest (2009) and sniggle.net: The Culture Jammer's Encyclopedia (2009) blur the line between reportage, analysis, incitement, entertainment and even pornography. Pranksterism's effectiveness 
at reaching an audience is demonstrated by one of the Yes Men's latest stunts: when they posed as US Chamber of Commerce officials on October $19^{\text {th }}, 2009$, searches for the Yes Men on Google increased by about three times the average rate of the last twelve months in the days that followed (Google Trends 2009). Such pranksterism, when combined with the power to disseminate information rapidly, is vital to the movement, giving activists the ability to capture attention and support in a world of sound bites.

Finally, knowledge systems are important to the GJM because activists are in a position of weakness relative to elites when it comes to having their analyses and arguments recognised as authoritative. GJM activism therefore requires, at least in part, a questioning and rethinking of how knowledge is produced and whose knowledge is considered to be legitimate. As discussed above, the entanglement of the language of scientific rationality with neoliberal capitalism plays a part in sustaining support for the current system. As long as it is seen as the only system that is realistic_-as, in fact, the only possibility-all attempts to build widespread change will fail. This implies that in order to achieve their goals, GJM activists must gain spaces in which their analyses of the problems with neoliberalism, as well as of viable alternatives, are recognised as legitimate.

The importance of this work is highlighted by the frequent claim by critics that the movement is irrational or uninformed. Proponents of neoliberal globalisation have repeatedly argued that western activists may, perhaps, be wellintentioned, but they do not understand the situation. Norberg's In Defense of Global Capitalism, for example, is positioned as an attempt to help those who are confused mend the error of their ways. Take the following:

Much of the criticism of globalization is based on portraying it as something big and menacing. Often such criticism is not reasoned argument, but flat statements of fact. Critics may say, for example, that 51 of the world's biggest economies are corporations or that something like $\$ 1.5$ trillion are moved around in financial markets every day, as if size itself were intrinsically dangerous and terrifying. But that is arithmetic, not argument (Norberg 2003, 11). 
Defining movement participants as producers of legitimate knowledge is therefore not only a part of the struggle for global justice, but also a part of the movement's struggle to change the field of possibilities open to activists and the power structures which limit or facilitate their work.

This is one of the reasons why the Indian movement discussed in the following chapter has such resonance within the GJM, although there are others of comparable importance. One of the main claims of the movement opposing GM crops is that the scientific research referred to by economists and agricultural scientists in support of GM crops is far from unbiased. Movement participants use a range of techniques to destabilise these claims. Some of these techniques involving working within the dominant scientific paradigm, by, for example, the production of "unbiased" scientific studies while claiming that elite studies are biased. Other techniques involve questioning the scientific paradigms which GM proponents work within: activists, for example, have argued for a more spiritual and holistic approach to agriculture, and to science. In unsettling the legitimacy of pro-GM science, they assert their own claims to authoritative knowledge. In a broader sense, the Indian movement contributes to the GJM's project, and to social movement participants' need to be accepted as legitimate speakers, by establishing the legitimacy of situated, grassroots knowledge.

The project of rethinking and redefining knowledge systems is therefore an integral part of the movement's struggle. From participants' ability to propose meaningful alternatives to neoliberal globalisation through to the organisation of the GJM itself, the shape of the GJM's project is defined by how people think about knowledge. Additionally, particular technological systems, most notably the Internet, continue to play a key role in facilitating communications within the movement and between the movement and outsiders, as well as enabling the movement's decentralised, networked structure. The spaces and technologies opened up by globalisation and the Information Age have played a vital role in building new movements and allowing a linkage of the local and the global; however access to these spaces and technologies is not a given. 


\section{Section four: the ongoing struggle to control knowledge}

As the spaces and technologies of the Information Age become sites through which established elites are challenged, elites seek to gain control of these spaces. Even as activist and other anti-establishment actors explore the possibilities that new knowledge systems offer and work to redefine the way in which we produce and access knowledge, governments, corporations, and other elites seek to maintain their dominance over the same systems. This is true at a variety of levels, from individual technological artefacts through to the way in which we define science. The model of collective, peer-based knowledge production embodied in indigenous knowledge systems and online endeavours such as F/LOSS has repeatedly been refused legitimation or been threatened by established actors, ranging from the Encyclopaedia Britannica through to universities through to the World Intellectual Property Organization (WIPO). Similarly, governments and corporate actors have been exploring and developing the potential of Information Age technologies to further surveillance and commercial interests. This section does not attempt to exhaustively catalogue the variety of struggles over knowledge that have been precipitated by and interlinked with the emergence of new technologies and scientific knowledge, but rather to emphasise the contested nature of knowledge by outlining a few important battles.

It must be recognised that different actors have vastly different interests that they are trying to further in their attempts to control knowledge. Political elites may be motivated to engage in data collection about citizens by concerns of efficiency in service provision. They may wish to protect vulnerable sectors of the population, particularly children. They may also wish to secure crucial networks or data, control internal dissent, or raise barriers to external threats. Many attempts are currently underway by established economic elites to preserve existing business models, but this is not the only motivation for elites' attempts to control knowledge. Industries, corporations, and even individuals within the business world are driven by the desire to open new markets as well as to be able to access important research or information. Often, the interests of these different actors clash. Within government, as well as within the business world, competing interests complicate any simple reading of elite attempts to control knowledge. Nevertheless, there are a number of broad trends that have 
emerged in recent years that are worth noting: a second enclosure of the commons, increased surveillance, and resistance to peer-produced knowledge systems.

\section{Enclosure of the commons}

Interest in the concept of enclosure has been growing in a number of fields, and within activist circles, since the 1980s. The term refers to the privatisation of public commons: the first period of enclosure is usually seen as being the era that began in the late 1400s in England and continued throughout the following centuries, during which common land used by the poor became private property owned by the rich (Patel 2007, 76). The question of whether we are facing a new period of enclosure or a new phase in an ongoing process is debatable. The concept has been applied to a wide variety of processes by those within the GJM, ranging from environmental degradation in the Global South (Midnight Notes Collective $1990,1-2)$ through to the spread of advertising into public spaces and the patenting of genes (Klein 2004, 220). Significant attention has also been paid to extensions to copyright terms and other infringements of the public domain of culture, most notably by Lessig (2001; 2004) and Boyle (2008). Finally, Benkler has also used the term to refer to attempts to control the development of hardware and software design, as well as of the structure of the Internet $(2006,385)$. Some of these processes are only indirectly related to struggles over knowledge. For the purposes of this thesis, there are three broad areas of enclosure that are important: enclosure of genetic diversity, enclosure of the public domain of culture, and enclosure of the digital commons. Each of these will be discussed in more detail in following chapters.

Developments in biotechnology have opened up a number of new possibilities over previous decades, including the ability to sequence genes and to modify living organisms at the level of individual genes, rather than through the slower processes of plant breeding and animal husbandry. There are many different directions that biotechnology research could take, and different responses to current technologies. Bollier has argued that current research has been driven by the tendency towards agricultural systems based on monocultures, the consolidation of the seed industry, and the search for "a more market-friendly product" $(2002,76)$. For this reason, and because biotechnology research has 
been largely driven by private interests (Benkler 2006, 332 \& 337), biotechnology research and the context in which it takes place has tended to cement and extend corporate control over agriculture, and to extend the reach of commercial interests into new arenas, such as indigenous medicine systems.

One aspect of this process of enclosure which will be discussed in more detail in the following chapter is "bioprospecting", also called "biopiracy" by its critics. This is the conversion of cultural knowledge and biological resources into marketable products, as in the case of the production of a treatment for Hodgkinson's disease from Madagascar's rosy periwinkle. Examples of this process range from the Merck pharmaceutical company's purchase of around 10,000 genetic samples from Costa Rica through to the ownership claims made over the gene pool of isolated populations in Tonga and Iceland and over genes expressed in a family with a rare congenital illness (Bollier 2002, 79-81). This enclosure of biological and genetic diversity has been facilitated by the extension of intellectual property law, through both national and international institutions.

Over the last three decades, a number of key court cases and international institutions have expanded corporate control over genetic diversity. In the 1970s, the US provided expanded formal intellectual property protection for the private sector via the Plant Variety Protection Act (Falcon \& Fowler 2002, 199). In 1980, in Diamond vs Chackrabarty, the US Supreme Court distinguished between products of nature and a patentable genetically modified bacterium, and ruled that live, genetically modified organisms are patentable (Rhoten \& Powell 2007, 351). In 1987, the US Patent Trade Office ruled that patents were allowed on "non-naturally occuring non-human multicellular living organisms, including animals (USPTO in Rhoten \& Powell 2007, 351). These shifts allowed increased scope for patents in the areas of genetics and biotechnology, and consolidated the US view of equivalence between discovery and invention (Rhoten \& Powell 2007, 352). Effects of these shifts reach beyond the borders of the US, in large part because of the recent drive towards "harmonisation" of intellectual property law through international regimes. 
Harmonisation of intellectual property law at the international level has a tendency to involve shifts towards the most expansive interpretations of intellectual property law. International institutions that regulate the control of genetic resources used in agriculture, medicine, and other applications reflect this tendency. The WTO agreement on Trade-Related Aspects of International Property Rights (TRIPS), which came into effect in 1995, contains a clause which requires WTO members to provide for the patenting of "non-biological and microbiological processes" (WTO 1994). The clause, Article 27.3(b), allows members to exclude plants, animals, and essential biological processes from patentability, but members must provide patents or other protections for plant varieties. This article remains controversial as it requires that member states allow patents on life. Other international institutions and agreements have had similar effects, extending the control that states and private interests have over genetic resources. For example, the Convention on Biological Diversity, completed in 1992 with the intention of protecting biodiversity, has had the effect of encouraging national legislation which prioritises restrictions on access to biodiversity resources (Falcon \& Fowler 2002, 209). The international intellectual property regime surrounding genetic resources has expanded considerably over previous decades, and in combination with changes to national legislation in many states has radically increased the framework for control of genetic resources.

The expansion in intellectual property regimes has also had effects on cultural content, acting to counter the tendencies encouraged by ICTs. Whereas research and development in biotechnology has tended to support tighter control over genetic resources, the ICT revolution has tended to make the sharing and distribution of cultural content between peers easier. Elites, from large content industries such as those represented by the Recording Industry Association of America (RIAA) to governments, have found it more and more difficult to control the flow of music, movies, documents, and other information. The expansion of intellectual property rights and development of protection mechanisms for these rights has been one way in which elites attempt to regain lost control. US corporations, in concert with the US government, have been at the forefront of efforts to develop these mechanisms. The extension of copyright terms in 1976, 1998, and again in 2003 has played an important role in limiting 
the public domain in the US; as a report from the Tomales Bay Institute notes, one effect of these extensions has been that while Disney has based many of its films and characters on stories taken from the public domain, none of its works have been returned to this domain $(2003,19)$. Other expansions of intellectual property rights in the US, such as the Digital Millennium Copyright Act (DMCA) of 1998, accompanied these copyright extensions, adding new provisions; the DMCA, for example, makes it illegal to circumvent technological protection measures that limit access to content.

"Harmonisation" of intellectual property law at the international level has, as in the case of genetic resources, tended to expand rather than reduce the scope of intellectual property rights over cultural content. At times, the US has also attempted to create more expansive intellectual property protections nationally by working through international regimes, as the Clinton administration seemed to do in the mid-1990s through their involvement in WIPO (Samuelson 1997, 3). As well as working through international intellectual property regimes, the US has entered into a number of bilateral trade agreements over the last few years which have prioritised intellectual property rights, overcoming trading partners' aversion to stronger property rules by exchanging concessions in other areas (Fink \& Reichenmiller 2006). The effect of US government activism in expanding international intellectual property regimes has been significant, and more restrictive understandings of content ownership have taken a firm hold in the international system.

\section{Surveillance}

ICTs, and their widespread adoption throughout everyday life by those in the Global North, have vastly increased the ease with which governments can watch and listen in on citizens' activities. The most well-known example of the surveillance enabled by new technologies is London's closed-circuit television (CCTV) network; around 500,000 CCTVs blanket London, with a growing organisational infrastructure for their use by police (Schneier 2008; Bowcott 2008). Other examples abound, from the bill passed in 2008 in Sweden that will allow law enforcement and intelligence agencies to monitor international telephone and electronic communications (Goodin 2008; Montgomery 2008) 
through to the 2007 confirmation that AT\&T had facilities capable of copying and analysing substantial amounts of US Internet traffic (Singel 2007), through to the 2008 discovery that the Chinese government was archiving millions of text messages sent through Skype (Leonard 2008). While the Internet and other communications networks decrease the cost and difficulty of communication for grassroots actors, they also make it easier and more tempting for governments to surveille their citizens and those in other states. However, government surveillance is facilitated not just by the availability of technological means, but also by enabling legislation and willing (or at least accepting) publics.

\section{Resistance to peer-produced knowledge}

The final aspect of struggles over knowledge to be discussed here are attempts to delegitimise or otherwise resist peer-produced knowledge systems that have been enabled or affected by new technologies. This struggle has numerous dimensions; it is reflected in the claims that indigenous oral knowledge does not constitute prior art that have been prevalent in patent disputes over neem and turmeric, as well as in responses to the emergence of Wikipedia. For example, the rebuttal issued by Encyclopaedia Britannica to a Nature article that compared it with Wikipedia emphasised the fact that Wikipedia "allows anyone, regardless of knowledge or qualifications, to write and edit articles on any subject", and referred to it as a "database" rather than an encyclopaedia (2006, 1). Attempts by political, economic, and academic elites to maintain their hold on authority by determining the terms by which knowledge should be considered legitimate are by no means new, although new battles have begun to be fought over recent decades. These struggles, as well as those discussed previously in this section, will be discussed in more detail in coming chapters.

Each struggle discussed here, and throughout this work, involves the overlapping deployment of legal, technological, and cultural strategies for exerting control. In the case of biotechnological research, the technological ability to sequence and manipulate genomes would not be enough in itself to expand private control over genetic resources. The expansion of patent and copyright law, and the creation of a cultural discourse that is willing to accept the extension of this law to cover genes or organisms, have also played a vital 
role. Similarly, the convergence of technological protection measures, changes to national and international intellectual property regimes, and a discourse that frames the sharing of content as piracy have also played a role in elites' attempts to gain control over the emerging realm of digital content. The first section of this chapter emphasised the interlinkage of science and technology with other power structures. This interlinkage is ever-present in struggles over technology and its effects; actors with competing interests may prioritise action in one area, but ultimately strategies that attempt to gain control purely through the development of new technologies (or new legal regimes, or through another such single dimension) are unlikely to succeed.

As these struggles shift between the local, the national and the global level, they are also heavily influenced by the many inequalities that are written throughout the international system. Historically, the North has relied extensively on the Global South for food crop varieties and raw resources. Today, new international intellectual property regimes have made it easier for corporations in the North to lay claim to the South's genetic resources (Falcon \& Fowler 2002, 208-209). Similarly, struggles over knowledge tend to privilege knowledge-systems associated with western science, with indigenous knowledge systems either being rifled through and incorporated in research (often by corporations) or dismissed. Concerns over national security and increasing surveillance, while affecting citizens throughout the world, have disproportionately affected those from the Global South, and ethnic and religious minorities within the North which have roots in the Global South. From the micro- to the macro-level the effects of new technologies and struggles over how they will develop and be used are linked to other power structures.

\section{Conclusion}

The first section of this chapter outlined a critical approach to knowledge. This approach sees science, technology, and access to information as closely related and overlapping, and as inherently and always affected by and constitutive of other power structures. These power structures, from gender to economic systems to the mechanisms of government, shape the way in which we define, develop, and access systems of knowledge, and are at the same 
time shaped by such systems. Further, while some systems of knowledge may encourage certain tendencies-as, for example, the Internet facilitates decentralisation-these tendencies are never fixed. As new branches of science or new technologies develop and begin to be used, the process of contestation which shaped them continues. In the case of the Internet, this is manifested in attempts by political and corporate elites to gain tighter control over how the Internet is used. In the case of biotechnology, groups around the world are attempting to lever control of key technologies and genetic resources from the hands of private interests. These struggles will, in turn, have political effects.

The second section of this chapter discussed the various ways in which new forms of knowledge have both enabled shifts in capitalist production and been harnessed and shaped by capitalist elites. At the same time, as the third section of this chapter showed, shifts in knowledge systems have facilitated the emergence of the GJM, which is struggling to create more democratic, sustainable, and diverse forms of globalisation. The contest over the form of globalisation takes many forms, and is taking place throughout the world. Struggles over knowledge make important contributions to this contest.

As I will discuss in greater detail in following chapters, struggles over knowledge are likely to have direct and far-reaching effects on the GJM's work. Neoliberal capitalism and the GJM are both deeply integrated with new forms of knowledge, using the technologies of the Information Age not just as useful tools, but also in ways which affect their inherent character. Activists within the GJM therefore have a strong interest in directly contesting measures taken by elites to gain a firmer grasp on knowledge systems. The work, and very existence, of the GJM relies in many ways on retaining, or further expanding, democratic control over knowledge.

Many activists today are intensely aware of these issues and have been heavily involved in struggling for more democratic visions of science and technology. Some of these activists are working outside the various networks that make up the GJM, as is the case with participants in the digital liberties movement. Attempts by activists to collaboratively design software and to retain a relatively accessible structure for the Internet have not yet gained wide attention within 
the GJM, despite the tactical and strategic importance of each of these projects to GJM activism. Intellectual property, on the other hand, has become a hot topic within the GJM, particularly as it applies to living beings. This is both a result of, and a factor in, the prominence given to anti-GM struggles throughout the world, and particularly in India. It may not be immediately apparent, but these struggles are part of the same project. The chapters that follow will explore the ways in which these struggles over knowledge contribute to the broader work of the GJM. 


\section{Chapter Two}

\section{Opposition to genetically modified crops in India: who knows best when it comes to agriculture?}

\section{Introduction}

Biotechnology is just as vital to the emerging Information Age as developments in other ICTs. The ability to sequence and modify genes, and even to create new life forms, has the potential to radically transform the world in which we live. This possibility is increasingly likely as biotechnological measures are proposed as possible solutions to the problems caused by climate change, ranging from enhanced carbon-fixing trees to crops adapted to new conditions. The direction in which biotechnology will develop is not fixed. As with other technologies, there are a number of different models emerging. Research into use of the bacillus thuringiensis (Bt) toxin in pest control exemplifies this; $B t$ has been inserted into the genes of cotton, tomato, and corn and marketed by private agrochemical corporations, but it has also been used extensively in what is usually considered to be organic farming in Cuba, and in China development of $B t$ varieties has been predominantly by public institutions. In each of these cases, the model of scientific research, aims, and dissemination of results have been radically different. In part, the shift towards research models that produce technological solutions, including GM crops, has been linked to an increasingly close relationship between biotechnology and ICTs. Biotechnology relies heavily on increased computing power, and biological metaphors such as resilience and evolution are increasingly used to develop computing and networking capabilities. Most notably, research into and use of biotechnology, as with other ICTs, is fraught with questions relating to what has come to be known as intellectual property, as well as with the inclusiveness and accessibility of the research process.

This chapter examines the debate over biotechnology in India, focusing in particular on activism within the Indian state of Karnataka (see map below). Although the most well-known Indian opponents of GM crops are based in the 
north of India, Karnataka has been the site of some of the largest mobilisations around GM crops. As with all social movements, the movement opposing GM crops in India is heterogeneous and fluid, made up of groups and individuals with varying perspectives and levels of involvement. The Karnataka Rajya Raitha Sangha (Karnataka State Farmers' Association, KRRS) was particularly instrumental in mobilising farmers around $B t$ cotton, which was opposed as part of a broader resistance to neoliberal globalisation. At the same time, there has been a growing movement within India working to promote organic and traditional agriculture, much of which overlaps significantly with the anti-GM movement. Through activism inside India as well as international connections (which will be discussed further in the fourth chapter), this movement has been working to redefine the debate over GM crops.

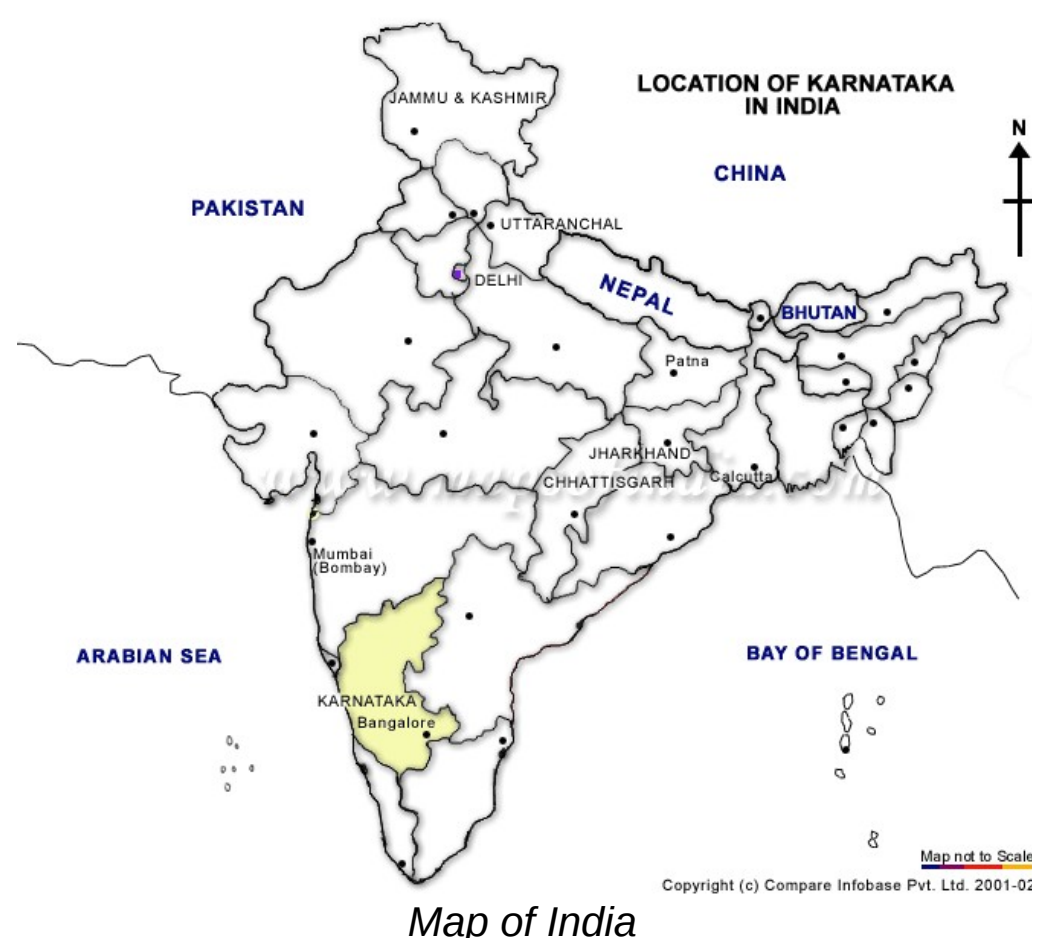

This chapter discusses the movement in two parts, the first of which has been primarily involved in opposing GM crops, while the second has been promoting alternatives to GM crops and the input-heavy monocultures associated with Green Revolution agriculture. Each section of the movement is roughly associated with a particular set of actors and analytical frameworks, and engages in distinct activities. Separating discussion of the movement into two sections therefore allows a certain structural and analytical clarity that is 
necessary given the range of issues involved. However, it must be emphasised that the movement is messy; many groups and individuals fit into both sections of the movement, and frames that I have associated with one section of the movement are called upon on occasion by the other.

The first section of this chapter focuses on the opposition to GM crops. The nature of the GM crop first introduced to India, Bt cotton, and the strength of pre-existing social movements encouraged the take-up of the issue by farmers' groups, rather than environmentalists. The KRRS has been the most important of these groups, focusing attention on the issue through mass mobilisations and direct actions. The involvement of the KRRS and other such groups has led to the debate being predominantly structured in terms of GM crops' effects on farmers, rather than their potential to cause harm to the environment or to human health. Opposition to GM crops has been approached through frames already adopted by the KRRS and other farmers' groups, such as Gandhian discourse about swadeshi (village-level self-sufficiency), a conceptual distinction between rural and urban India, and the emerging opposition to neoliberal globalisation. This section of the movement has, through these frames, argued that GM crops (like commercial hybrids) are expensive, unprofitable, and make Indian farmers dependent on MNCs.

The second section of this chapter focuses on those participants who are promoting alternatives to GM crops. This part of the movement has largely gone unrecognised by those studying the opposition to GM crops, perhaps because participants' activities tend to be small-scale, highly localised, and nonconfrontational, and therefore have received little media attention. The work within this part of the movement centres on preserving and promoting traditional crop varieties and agricultural techniques, and is often framed within an ecofeminist or development discourse. While many of those involved in this work actively oppose GM crops, it is part of a broader opposition to agricultural techniques associated with the Green Revolution, including monocropping and the use of purchased seed and chemical pesticides and fertilisers. Participants have continually worked to establish the benefits of traditional agricultural systems, including traditional knowledge developed by rural communities. They 
have also resisted the enclosure of the commons associated with commercialisation of Indian plant varieties.

The third section of this chapter addresses some of the more problematic aspects of this movement's work, including some of the unintended consequences of their framing of the debate. While the ecofeminist discourse of some movement leaders, particularly Vandana Shiva, has gained a wide audience overseas, it seems not to have gained a foothold in India. This has a number of implications, possibly the most important of which is that the opposition to GM crops within India has been framed almost entirely by arguments that do not oppose GM crops for their inherent qualities. The debate over GM crops has not primarily been framed in terms of the possible harms or moral qualities of genetically modified organisms, but rather on the basis of the traits, costs, and other characteristics of particular GM crops, including $B t$ cotton. Arguments that GM crops are unprofitable, instruments of foreign domination, or part of a system of chemical-based agriculture are necessarily open to debate, as has been amply demonstrated by dissenting voices within and in opposition to the movement, as well as by those engaged in widespread pirating of $B t$ cotton. This pirating, and the lack of effective government response to it, suggest that opponents of GM crops may have already lost the battle in India. GM crops have gained a firm foothold, and several such crops have a significant following among farmers in some areas. However, their interventions into the debate have made a significant impact on the national and international discourse surrounding biotechnology.

\section{Section one: the opposition to genetically modified crops in India}

In the West, opposition to genetically modified organisms (GMOs) has usually rested on their potential to cause damage to the environment, or harm consumers. For example, an Australian government report noted concerns raised by "consumer and community groups" about GMOs' potential impacts on food safety and the environment (Anderson \& Lee 2005, 1), while stating that any reticence to adopt GM crops on the part of farmers is due to concerns over 
access to GMO-free markets such as Japan and Europe (Anderson \& Lee 2005, 13). Resistance to GMOs in the West has been dominated by consumer and environmental groups, particularly Greenpeace, with limited involvement of producers $^{6}$. Effects on food safety and the environment are highlighted, and there is little discussion of potential damage to producers. A representative antiGMO pamphlet reads,

GM foods on the market have not undergone adequate testing to ensure that they are safe to eat and safe for the environment. [...] GM foods are released into the environment without proper understanding of their wider ecological effects or control requirements (Campaign to keep Western Australia GM Free 2008).

While the pamphlet discusses the high royalty charges for farmers, it is clear that the pamphlet is aimed at consumers, who are asked to "[r]emind a farmer about the benefits of staying GM free". The framing of GMOs as a Pandora's Box that will expose consumers and the environment to unforeseen damage refers back to the precautionary principle, which is in outlined in Principle 15 of the Rio Declaration (1992): "Where there are threats of serious or irreversible environmental damage, lack of full scientific certainty should not be used as a reason for postponing measures to prevent environmental degradation." As it applies to GMOs, this principle is used to argue that the potential impact of GMOs on the environment is vast, unknowable, and irreversible. Essentially, these concerns cannot be addressed by the scope of any foreseeable study or by changes to how GMOs are developed. The speed with which radical changes can be made to an organism using GM technology, and the difficulties involved in isolating GMOs from other organisms in the food chain and ecosystem, mean that these arguments leave little room for future acceptance of GMOs.

In India, the situation is significantly different. Although opposition to GMOs in India is heterogeneous, arguments against them predominantly position them

$6 \quad$ There are several Canadian farmers who have been actively involved in the opposition to GM crops (Greenpeace Australia Pacific 2009), but this activism remains limited in scope. 
as the extreme form of pre-existing trends, and highlight effects on farmers. "Threats to human health," writes Herring, have "figured only secondarily, in contrast to the European opposition," which he argues may be due to "the reality of some Maslovian hierarchy of needs in a poor country" $(2001,2)$. The argument that Indians do not care about possible health consequences of GMOs because they cannot afford to is beguiling, but it is not the whole story. In the West, concern over health consequences of GMOs has largely been the outcome of years of concerted activism. In India, activists have drawn upon other oppositional discourses in order to frame the debate. Existing opposition to changes to Indian agriculture made during the Green Revolution (the shift towards monocropping, chemical-intensive agriculture, the use of hybrid crop varieties, dependence on commercial seed, and entry of foreign agrochemical companies into the Indian seed market) have been extended to include GM crops. Similarly, critiques of the commercialisation of indigenous plant varieties from the Global South and the accompanying body of international intellectual property (IP) law have been developed in tandem with and extended to cover the critique of GM crops. Although there are exceptions, Indian arguments against GMOs tend to rest on the particular crops, legal regimes, and research models involved, rather than being built on inherent critiques of genetic engineering.

The first GM crop to be introduced to India was Bt cotton, a transgenic crop variety based on the insertion of the Cryla gene from the bacterium Bacillus thuringensis, which makes the plants resistant to the boll weevil, a common cotton pest. The first $B t$ cotton seeds were imported to India for research purposes in 1995 by Mahyco in partnership with Monsanto ${ }^{7}$, and field trials began in 2000. In 2002, the Genetic Engineering Approval Committee (GEAC) gave permission for $B t$ cotton, marketed as Bollgard, to be sold commercially. However, Bt cotton was grown commercially in India before 2002; in 2001 it was discovered by Mahyco that cotton planted over thousands of hectares in Gujarat contained the Bt gene. This cotton seems to have appeared in around 1999, and was traced back to Navbharat-151, sold by the Navbharat seed company

\footnotetext{
${ }^{7}$ Mahyco is India's largest seed company, and Monsanto bought a 26\% stake in it in order to link in to Mahyco's distribution network. Mahyco Monsanto Biotech (India) Pvt Ltd is a joint venture marketing company created in 1998 in order to market $B t$ cotton.
} 
(Stone 2007a, 85). The head of Navbharat claimed that the company had not been aware that there was a Bt gene in its seeds. GEAC ordered that Navbharat-151 seeds, and crosses bred from them, be burned, but did not have the capacity to effectively enforce the decision (Herring 2008, 134). As a consequence, both legal and illegal $B t$ cotton varieties are now common in many parts of India.

The fact that it was cotton that led the way for GM crops in India is significant. While other GM crops have since been introduced, much of the debate continues to focus on cotton. Cotton is a key crop within India, and as well as being vital to the economy it was a powerful symbol of protest against British colonialism during the struggle for Independence (Ramamurthy 2004, 751). Gandhi encouraged Indians to spin and weave their own cotton, khadi, and official rules stipulate that the Indian flag be made of khadi. As well as the symbolic associations attached to cotton, the use of a cash crop rather than a food crop as the vanguard entry to the Indian market undermined use of the pro-poor discourse associated with GM cassava in Africa and Golden Rice, both of which are food staples. Cotton is not grown by subsistence farmers, as it needs a minimum level of investment. Growing cotton requires inputs, most of which must be purchased: seeds, irrigation, fertilisers, pesticides. At the same time, it must be emphasised that the majority of farmers growing cotton in India are not well off. Further, it is worth noting that cotton yields in India are relatively low in India by global standards ${ }^{8}$ (Gruère, Mehta-Bhatt, \& Sengupta 2008, 10). In contrast to Australia, where farm sizes are over 360 hectares on average (Cotton Australia 2008), and the US, where an increasing amount of cotton production takes place on large family farms earning over US\$500,000 a year (Macdonald et al. 2006), a large farmer in India might plant around 20 acres of cotton. The average cotton farm size in India is between 2.4 and 5 hectares (Gandhi \& Namboodiri 2006, 9). At the time of Bt cotton's entry to India, suicide rates in rural areas had reached epidemic proportions, and the main victims had been cotton farmers, especially small and marginal farmers (Stone 2002a). Given the context, it is unsurprising that the entry of GM crops into India was

8 It is also important to recognise that cotton consumes about 45 per cent of pesticides used in Indian agriculture, placing cotton farmers in a particularly vulnerable position due to dependence on the price of pesticides (Gruère, Mehta-Bhatt, \& Sengupta 2008, 10). 
primarily framed as an issue affecting farmers, rather than consumers or the environment.

It is also notable that while there have been a number of prominent environmental movements in India, particularly the Chipko movement, environmental activism in the south of India has been limited. Muzaffar Assadi argues that although many groups in the South have taken up environmental causes, particularly since the 1980s, these struggles remained specific to certain areas or local cultures, and Karnataka has not developed a comprehensive environmental movement $(2004,199)$. Over the last decade, a number of environmental NGOs have established themselves in Karnataka, including Greenpeace and the ESG, but as yet it remains difficult to identify a comprehensive environmental movement within the state. It may be, however, that environmental movements in Karnataka will take on a different form from those in the West. This may result in part from the work of groups that address environmental issues through the prism of other frames, such as ecofeminism, swadeshi, or opposition to economic globalisation, as will be discussed below.

Karnataka has also seen limited anti-GM activism on the part of consumers, particularly the middle-class activism that has been associated with anti-GM activism in the West ${ }^{9}$. Divya Raghunandan, the manager of Greenpeace India's anti-GM campaign between 2005 and 2007, attributes this in part to the uneven benefits of development:

Middle class activism has been low, and there's a clear distinction between those who benefit from the development paradigm and those who don't. And it's those who don't who've always been mobilised, and the farmers' groups also, they've been mobilised, any mass mobilisation you see in India are those groups. The middle class has really not done that much. (2006, pers. comm., Feb 7)

\footnotetext{
9 It is frequently claimed that anti-GM activism in the West is predominantly a middle-class issue (cf. Life Sciences Network 2003; O'Neill 2003). There is some evidence for this. For example, Hall and Moran $(2006,32)$ find that Scottish anti-GM survey respondents were significantly more highly educated than the general population. However, more research is needed if this claim is to be confirmed.
} 
This lack of middle-class activism is in part responsible for a frame that prioritises effects of GM crops on farmers. This has been changing over recent years. In January 2009, a blog was set up to publicise anti-GM activism (GM Free Karnataka 2009). The shift towards blogging as a medium for activism, the use of English, and the blog's consumer-focused slogan, "What will they test on you next?", all suggest an emphasis on trying to mobilise a middle-class audience. These efforts, however, are still in their infancy.

In contrast to the limited presence of environmental and consumer activism, farmers' movements have had a notable presence in India, and Karnataka, at intervals since the colonial era. Peasant movements emerged in the early nineteenth and twentieth centuries, but the most important movement Karnataka has seen in recent times has been the KRRS. The KRRS was part of a wave of farmers' movements ${ }^{10}$ that emerged in India during the 1960s and peaked in the 1980s (Brass 1995a). Brass argues,

it is impossible to ignore or underestimate the powerful effects the farmers movements have had on local, regional and national politics in India throughout the last decade. Their impact extends from demonstrations, blocking the food transportation systems, denying officials access to villages, refusing to pay outstanding bills...and withholding crops from local markets (which results in price rises) to an important role in the overthrow of Rajiv Gandhi's Congress government in the 1989 elections (1995a, 3-4).

As is the case with other social movements, the influence of the KRRS has waxed and waned over time. In its early years, says one farmer, "the green towels [worn over the shoulder as a sign of membership in the KRRS] became a menacing symbol for the authorities and for bureaucrats" as farmers pressed their demands and various large agitations were carried out (Tippanna 2006, pers. comm., Feb 15). Demonstrations in the early 1980s gained "widespread

10 The KRRS and other farmers' movements exist in the space between social movements and more formally structured organisations. Nanjundaswamy describes the structure of the "organisation" as highly decentralised, but in the same place he emphasises that the KRRS is a movement (1998b, 155). 
and spontaneous sympathy" and some protests were supported by students, lawyers, and political parties (Assadi 1997, 55-56). Over time, partly as a result of the splitting of the movement into separate factions, its influence decreased. Even at the peak of its power, it was difficult to gauge popular support and involvement; Nanjundaswamy estimated at one point that KRRS membership stood at around ten million (1998a, 152), but when the KRRS put candidates up for election support was limited-in 1994 only one candidate was elected to the State Assembly (Assadi 1997, 83). Despite the limited political support for the KRRS, leaders from a range of political parties still continue to visit Karnataka's Dharwad and Gadag districts, which are associated with the farmers' movement, to pay tribute to the two farmers whose deaths sparked the birth of the KRRS (Mohan 2003), and the KRRS remained a powerful actor in Karnataka in the 1990s, when GM crops were introduced to the state.

Consequently, the KRRS has played a significant role in the opposition to GM crops, not only within Karnataka but also nationally and, to an extent, internationally. The KRRS "constituted the core of organized opposition" in India during the 1990s (Herring 2001, 7), but other farmers' movements have also played a significant role, and there are signs that others may take over the central role once played by the KRRS. Farmers' movements have also been among those calling most vocally for access to GM crops, which will be discussed below. Farmers' movements have been tremendously significant actors in this debate, and it is necessary to understand something of the history of the KRRS and the way in which their changing analysis and focus have been brought to bear on the opposition to GM crops. The KRRS has, roughly, followed a similar pattern to social movements elsewhere, moving from a predominantly class-based analysis to a new social movements model in which social and "post-materialist" issues were addressed and, over the last decade, to a global justice frame. This history has been reflected in the framing of GM crops.

During the early years of the KRRS its focus, like that of other farmers' movements of the era, was primarily on economic issues affecting farmers. The focus on remunerative prices is seen as a characteristic feature of this wave of 
farmers' movements, as were demands for lower costs for inputs and higher returns for outputs (Brass 1995b, 36; Assadi 1994, 215). The water levy protests that sparked the formation of the KRRS and introduced an element of militancy to the movement were a case of direct demands being made for economic concessions from the state government (Mohan 2003). The KRRS during the 1980s was primarily a protest movement focusing on agricultural issues, including terms of trade unfavourable to agriculture, declining per capita income and purchasing power of farmers, increasing cost of input prices, low prices for agricultural crops, increasing poverty, growing indebtedness, and an urban-biased state policy (Assadi 2004, 205). This concern with farmers' economic conditions has been an ongoing focus within the movement.

While left-wing political theorists such as Lohia were influential in movement leaders' analysis of the relationship between farmers and the Indian state during this period, it is the Gandhian discourse of Bharat's oppression by India that has been most significant to the farmers' movements' discourse. The distinction between "Bharat" and "India" is a vital part of Indian politics and has played a significant role in this discourse. Sharad Joshi, leader of the Shetkari Sanghatana farmers' movement in Maharashtra, contrasted Bharat, "the vernacular name denoting the ordinary, the rural, the little tradition, the "real" country of small peasants and agricultural labourers, with [India,] the Western, urban, industrial, internationally oriented, modern nation-state" (Gupta 1998, 80). The KRRS has taken up the concept with enthusiasm, positioning itself as a village movement built on the Gandhian concept of swadeshi: national self reliance firmly rooted in the idea of rural reconstruction (Assadi 1994, 218). Nanjundaswamy has written that the final objective of the KRRS is the "Village Republic" and that this determines the organisation of the movement itself, with the basic unit of organising being the autonomous village unit (Nanjundaswamy 1998b, 155). This vision of Bharat conjures up images of an undifferentiated peasantry, a harmonious agricultural society that is threatened from without but with a unity of interests within ${ }^{11}$. The Bharat/India distinction and the associated

\footnotetext{
11 Talking to Somalingiah, one of the oldest members of the KRRS, I asked how he felt about the inequalities that have traditionally existed between men and women and as a result of the caste system. He replied that "The question is mostly between the city and upper class, in the lower classes [in the villages] there is mostly equality. No more no less" (Somalingiah \& Prasad 2006, pers. comm., Feb 23).
} 
Gandhian framework have continued to play a large part within the discourse of the KRRS.

At the same time as the movement has deployed this uniquely Indian discourse, it has also used language and protest repertoires frequently linked with the NSMs that emerged in the 1960s and 1970s in other parts of the world. Several scholars of Indian farmers' movements have argued that farmers' movements are also NSMs. Banaji, for example, argues that these movements display several features that distinguish them from earlier, class-based movements, including "a relatively articulate leadership, extraordinary skills in holding the attention of the media [...] and [innovative] agitational methods", as well as involvement in the 'post-material' and social issues associated with NSMs (1994, 228). Nanjundaswamy, the charismatic leader of the KRRS (and, after its split, of one faction of the movement) has been vocal in support of non-dowry and inter-caste marriages, women's rights (Assadi 1994, 213), language movements (Kannada, the local language, is seen as an embattled and vital aspect of Kannadigan identity), and other struggles that go beyond the direct expression of farmers' class interests. Arguably, the adoption of the language of NSMs intensified during the late 1990s as the KRRS began to participate in international activist networks. Nanjundaswamy's (1998b) descriptions of a movement committed to cultural change, challenging patriarchal structures, direct democracy, decentralised organisation, nonviolence, and ecological approaches is a model NSM. However, this rhetoric seems to largely have been confined to movement leaders, and has had a limited influence at the grassroots level.

The shift towards a critique of neoliberalism has been far more significant amongst movement participants. Until the mid-1990s, the movement had analysed India's position within the international system within the framework of a variant of Third World dependency theory that saw Indian capital as exploited and oppressed by western or international capitalism (Assadi 1994, 220). The shift towards a critique of neoliberal globalisation first began to manifest in the early 1990s as the Indian government increasingly became a party to neoliberal globalisation. At first the KRRS focused on MNCs, particularly those based in 
the US, as the agents of neoliberalism (Assadi 1995, 193), but later neoliberalism as a whole came under fire. Within the movement this shift is attributed to Nanjundaswamy's leadership. Somalingiah, a member of the KRRS since its inception, and Prasad, a current member, say that after the Dunkel Draft ${ }^{12}$ came out Nanjundaswamy analysed what was happening and "presented it step by step, and it was clear". This helped to begin a mass movement against neoliberal globalisation, convincing farmers of the need for action (Somalingiah \& Prasad 2006, pers. comm. Feb 23). Assadi argues that in fact the shift came as the movement began to contest neoliberalism from within a domestic framework and thus came into contact with organisations and individuals also opposing the Dunkel Draft within an anti-neoliberal framework, particularly Vandana Shiva, Suman Sahai, Vanaja Ramprasad, and BK Keayla (Assadi 1995, 193). The KRRS's involvement in the international opposition to neoliberalism helped to shape their response to GM crops.

This critique of neoliberalism has not replaced the previous Gandhian discourse. Rather, the notion of a Bharat under attack from urbanised India was expanded to include a frame that positioned Indian farmers as under threat not only from national policies skewed against them, but also from developments in the international arena that the Indian government was entering into. The movement equated neoliberal globalisation with a new era of colonisation where national resources, production and consumption were to come under control of MNCs (Assadi 2004, 206). Opposition to MNCs such as KFC and Cargill was framed within a Gandhian discourse of resistance to foreign domination, particularly the attack on KFC in 1996, which took place on January $30^{\text {th }}$, the anniversary of Gandhi's death. Swadeshi was positioned as not only an alternative to morally corrupt city life, but also extended to the international level; the KRRS spoke of linking with other movements and Southern nations to form a "Khadi curtain" in opposition to neoliberalism (Assadi 1997, v). This synthesis of Gandhian discourse and opposition to neoliberalism has proved to be tremendously resilient and resonant within the Indian context.

12 The Dunkel Draft was a draft put together by Arthur Dunkel, director-general of the GATT, in an attempt to produce an acceptable compromise between Northern and Southern interests in the wake of the Uruguay Round of trade negotiations. 
Large demonstrations against GM crops began in 1998 with the Cremate Monsanto campaign, also called "Monsanto, Quit India". The campaign was launched on August $9^{\text {th }}$ by a coalition of NGOs (Shiva 1998), and the KRRS began its part of the campaign in November (Nanjundaswamy 1998a, 152). Although the campaign focused on Monsanto, Nanjundaswamy said that the KRRS and other groups involved wanted all "corporate killers like Monsanto, Novartis, Pioneer etc" involved in biotechnology to leave the country (1998a, 152). As well as targeting companies other than Monsanto, Cremate Monsanto mentioned a number of key issues that extend beyond the actions of biotechnology companies_slogans for the campaign included not only "Stop genetic engineering" and "No patents on life" but also "Bury the WTO". From the beginning, the debate over GM crops was clearly framed within the overlapping discourses of swadeshi and opposition to neoliberalism.

The Cremate Monsanto campaign invoked the Independence movement and Gandhi's legacy at various points. Even the alternative name, "Monsanto, Quit India", explicitly echoed the "British out of India" of the Independence struggle (Zwick \& Zwick 2000; Shiva 2000). The framing of resistance to GM crops has been a continual theme in the Indian movement, often conceived as part of the KRRS's wider role as a second Independence movement. Somalingiah explains this role as an opposition to the Indian government instead of the British, again to defend the villages:

In my younger days I was part of the Independence movement. In the same, I am continuing my work for self-sufficient villages, Gram Swaraj, local self-sufficiency, the Indian old system in the villages. [...] After Independence Gandhi was killed and then the movement was stuck. The continuation of democracy was stopped by the bureaucracy, the villages were not self-sufficient. The farmers' association, the KRRS, is a continuation of the Independence movement, against the government [which is] anti-village, anti-people (Somalingiah \& Prasad 2006, pers. comm., Feb 23). 
The positioning of anti-GM activism within an anti-colonialist context stretches back to the opposition to the power of foreign seed companies in India, most notably the Beeja (Seed) Satyagraha launched India-wide in 1992. The Beeja Satyagraha was described at the time as a second Salt Satyagraha ${ }^{13}$, and it was declared that, "If the charka [the Indian spinning wheel] was the symbol of Indian Independence, the seed is the symbol of the protection of this independence and the farmers' culture" (KRRS in Assadi 2004, 208). Cremate Monsanto was therefore part of a broader set of actions that placed opposition to GM crops within the framework of a second Independence movement.

At the same time as Cremate Monsanto positioned opposition to GM crops within the context of the Indian Independence movement, it also situated it within the contemporary resistance to neoliberal globalisation. This was partly because of the clear continuity with the KRRS's earlier actions against MNCs; while direct actions against field trials of GM crops were significantly less confrontational than their destruction of Cargill's depot (Scoones 2005, 35), they were both positioned and interpreted as part of the same anti-MNC campaign. The two frames-opposition to GM crops as anti-colonialist and opposition as anti-neoliberal-are in many respects complementary, but they serve different strategic purposes and at times come into conflict, as will be discussed further in the fourth chapter. To a large extent, the emphasis that each frame receives in the movement is a matter of the arena in which actors are speaking. When speaking within India, a Gandhian frame can be a more effective way of building opposition to GM crops. In international arenas, however, a frame that clearly positions the struggle within Karnataka as part of a global resistance to neoliberalism may be more useful.

Common to the framing of GM crops within both Gandhian discourse and the opposition to neoliberalism is the positioning of GM crops as the extension of an existing trend, the commercialisation of seed in the form of hybrids. In both frames of resistance, commercial seeds are seen as part of a shift away from local sovereignty. Anti-neoliberal discourse emphasises the specifically US

13 The campaign of civil disobedience begun by Gandhi, where Indians illegally produced salt to avoid British salt taxes. 
origin of GM seeds, objecting not just to the fact that seeds are genetically modified but primarily to the entry of foreign (particularly US) firms into the Indian seed market. Similarly, within the Gandhian notion of swadeshi there is significant opposition to buying seeds—genetically modified or otherwise-from outside the village. Purchases outside the village are seen as diminishing the power of farmers, and making them economically dependent on and inferior to the city:

Local seeds-I will not purchase seed, I will not purchase fertilizer, insecticide, pesticide, tractors, I will not purchase anything which can be prepared or made in my village. [...] Globalisation wants to bring the farmers to purchase in the cities. It saw that villagers, the local village produced only 6 to 8 quintals per acre. So they thought that they would give varieties that would give multiple yields. So you would come to buy this, and money would come to the city from the village. [...] So you will purchase the seed, and you will purchase fertiliser, and money will come from the village to the town (Palekar 2006, pers. comm., Feb 19).

Whether GM seeds are framed as part of MNCs' erosion of Indian sovereignty, or as part of the shift of power from Bharat to India, resistance is primarily linked to the fact of their commercialisation rather than the fact of their being genetically modified.

The primary method for differentiating GM crops from hybrid varieties has been through the "terminator technology" frame. Terminator technology was originally developed as a "technology protection system", part of a class of Genetic Use Restriction Technologies (GURTs), and was intended to be a way of stopping the re-sowing of seed by producing sterile seed. The technology was initially developed by Delta \& Pine Land in 1998, which was subsequently acquired (along with its patents) by Monsanto in 2006. Activists reframed the technology, resisting attempts by Monsanto and others to argue that it was an effective way of preventing the spread of GMOs into the environment (Mooney 2007, pers. comm., Feb 22; Stone 2002b, 613). Instead, they argued that it removed farmers' access to seed, firmly cementing corporate control over life itself. 
The furore surrounding terminator technology was vocal, and continues to this day. The apocalyptic tone of discussions is exemplified by Shiva's claims that "the possibility that the terminator may spread to surrounding food crops or to the natural environment is a serious one. The gradual spread of sterility in seeding plants would result in a global catastrophe that could eventually wipe out higher life forms, including humans, from the planet" $(2000,83)$. In large part because of pressure from activists within and outside of India, Monsanto announced in October of 1999 that they would not use terminator technology (Shiva 2000, 85). Additionally, the Indian government banned the use of terminator technology in 2001, as part of the Protection of Plant Varieties and Farmers' Rights Act. Nevertheless, many Indian farmers, activists, and others in both the West and India continue to believe that terminator technology is in use (Stone 2002b, 613; Herring 2008, 130). In part, this may be because movement leaders make oblique references to seeds that "cannot be saved and resown", as Vandana Shiva did during a talk I attended at the Nairobi WSF in 2007. These references rarely make it clear that barriers to seed saving are mostly legal and, in the case of hybrids, are because the characteristics of secondgeneration seed make it undesirable to save and re-sow, rather than because seeds will not germinate. When I spoke to a journalist actively involved in researching and writing on GM crops in India, and with a critical attitude to movement perspectives, he repeatedly referred to a "terminator gene" and seeds that could not be saved (Bhat 2006, pers. comm., Feb 28). The terminator technology frame therefore continues to play a significant role in antiGM activism, both within India and internationally.

It is difficult to gauge the effect that the terminator technology frame has had on farmers, but there are signs that it may not have had much resonance, primarily because many farmers who are above subsistence level buy new seed each season anyway. It is also clear that some farmers have experimented with GM seed, including Shankarikoppar Mahalinga, one of the farmers whose land was used for a test plot, and have found that it germinates (Herring 2008, 138). Farmers' concerns tend to hinge more on the cost and profitability of GM varieties, and this has therefore been a key concern within the KRRS. There are 
ongoing debates about the profitability of Bt cotton, many of which focus on the cost of seed. Prasad, an activist with the Nanjundaswamy faction of the KRRS, said in an interview that farmers in districts of Karnataka using Bt seeds were finding that the cost of production was too high, as 450 gram packets of $B t$ cotton seeds cost around Rs1,600 (2006, pers. comm., Feb 20). Concerns over the high cost of seed were echoed by a number of those I interviewed (Bhat 2006, pers. comm., Feb 28). Given the links made between farmer indebtedness and rural suicides, these concerns have played a large part in the debate.

The discussion of pesticides has also played a significant role in this debate, as $B t$ crop varieties are advertised as reducing the need for pesticide application. The cost of pesticides is high, and cotton in many parts of India has been increasingly vulnerable to pest infestations (Ramamurthy 2004, 752). As well as the financial costs involved in purchasing pesticides, the health effects of applying several rounds of pesticide to crops are high, especially for farm labourers. The promise of cotton varieties that can effectively resist pest outbreaks is therefore extremely attractive to farmers, as was seen in the case of the Navbharat variety's resilience and widespread adoption in Gujarat. Much of the debate around $B t$ crops therefore turns on how effective the protection against pests they offer is, and whether pest populations will build up resistance to $B t$ toxins. The KRRS and other groups emphasise the ultimate ineffectiveness of $B t$, pointing to the need to continue use of pesticides as well as the possibility of future resistance.

As well as concerns about the effectiveness of Bt cotton's ability to deal with pest outbreaks, questions that apply to any other cotton variety are equally important with $B t$ varieties. The insecticidal Cry $1 \mathrm{~A}(\mathrm{c})$ gene expressed by $B t$ crops has been bred into a number of different cotton varieties, each of which has its own requirements in terms of inputs (such as fertilisers and water) and yields. This has muddied the debate by creating difficulties in evaluating the effects of $B t$ cotton, as there has been considerable variation in the performance of different Bt cotton varieties (Herring 2008, 136). However, it has 
not stopped blanket claims about the value (or lack of value) of $B t$ cotton by both proponents and opponents of $B t$ crops.

By necessity, opponents of GM crops in India have spent much of their energy debating these concerns with yields and high seed and other input costs. As Omvedt (1998) points out, "[f]armers may love the land they work on and their animals [...] But they are people who are trying to scratch out a living, who want a better life for their children and for whom farming is a source of income and not a very good income". Activists must focus on these issues, and therefore frequently frame their discussions with farmers in terms of practical arguments surrounding seed and input costs, yield sizes, and related concerns. However, these arguments are open to debate, and proponents of GM crops can answer them with studies that show lowered seed or input costs, or with the production of new, better-performing GM varieties.

Similarly, arguments that GM crops make farmers dependent on foreign agrochemical companies apply equally to hybrids, or indeed to any seeds and other inputs purchased from MNCs. Gail Omvedt (1998) has argued that use of $B t$ cotton is compatible with swadeshi farming, as farmers already rely on hybrid seeds, and Mahyco is an Indian company with a long and reputable history. Further, Indian governments, and Karnataka's government in particular, have shown great enthusiasm for developing Indian biotechnology along a similar path to information technology (Scoones 2007). There is therefore a reasonable expectation that India will soon be developing its own GM crops. Effectively, both the discourse of swadeshi and arguments that GM crops are too expensive provide only a temporary and contingent basis for opposition.

\section{Section two: "there is no resistance without alternatives"}

There is a significant overlap between activism within the opposition to GM crops which focuses on resistance to GM crops and activism promoting organic and traditional agriculture. As MD Nanjundaswamy wrote, "there is no sense in dividing resistance and alternatives, since none of them can take place without the other" $(1998,157)$. However, this aspect of the movement has received 
relatively little attention amongst scholars, perhaps because the activities it carries out are less visible. As well as my own work in the area (Croeser 2007), Scoones' study of anti-GM activism in India, Brazil and South Africa is a notable exception in its recognition that, "anti-GM activists have linked up with those working on small-scale sustainable agriculture [as] a positive story is seen as key, where the rhetoric of activists can become a reality on the ground" (2005, 35). While the actions against GM crops have often been deliberately symbolic and aimed at gaining media attention, much of the work for alternatives has occurred at the grassroots level and has been far less dramatic. This work has framed the debate around GM crops primarily within development or ecofeminist perspectives. Despite the lack of scholarly attention to these groups, the perspectives they espouse have gained a wider audience internationally than those put forward by the KRRS and others working within the swadeshi frame.

There is a wide range of data to support the claim that groups working on sustainable agricultural development are part of the movement against GM crops. As discussed in the first chapter, there are a number of problems with attempts to exactly map and describe social movements, which have shifting boundaries and fluid membership. It is nevertheless possible to show links through self-identification with movement goals and with the movement as a whole, participation in movement actions, and organisational links. For example, during a survey of anti-GM activist organisations in Bangalore, Scoones found that several organisations primarily addressing sustainable agriculture, seed saving and biodiversity actively identified themselves as having an explicitly anti-GM stance, including the Genetic Resource, Energy, Ecology, and Nutrition (GREEN) Foundation, AME Foundation, Honey Bee Network and the Organic Agriculture Network $(2005,21)$. These organisations also take part in movement events, as in the case of an open letter written in 2008 to the chairman of the National Biodiversity Authority in protest against his statements in favour of GM crops. This letter was signed by the GREEN Foundation and Sahaja Sumruddha (an umbrella organisation for sustainable agriculture practitioners), as well as by a variety of related organisations based outside Karnataka. 
Organisations promoting sustainable agriculture are deeply integrated with the movement against GM crops.

There are a number of different groups involved in efforts to promote sustainable agriculture. Vandana Shiva's high profile internationally means that the group she founded, Navdanya, is relatively well-known. Navdanya, which promotes domestic crop biodiversity through work with small farmers, is based primarily in the north of India (Navdanya 2008). Gene Campaign, which also works in the northern part of India, has also received some international attention, in large part because of the work of Suman Sahai. In Karnataka, there are a number of organisations and individuals promoting organic, sustainable, or traditional agricultural techniques. The GREEN Foundation and ICRA are both working with marginal farmers on these issues, while speakers such as Subhash Palekar have been holding workshops for farmers in partnership with the KRRS and other organisations.

These groups should be distinguished from the KRRS and other farmers' movements. Navdanya, Gene Campaign and the GREEN Foundation more closely fit the NGO model, with governing boards, formalised leadership structures and role allocation, and clearly-defined activities. While it is difficult to gauge the exact extent of participation in either farmers' movements or NGO activities, the targeted projects carried out by Gene Campaign, GREEN Foundation and Navdanya would seem to inherently limit the breadth of their support base. GREEN Foundation works with 3245 farmers at last count (GREEN Foundation 2008c) and Gene Campaign has several hundred members, each working with local coalitions (Gene Campaign 2008). Navdanya claims a significantly higher support base of 70,000 farming families (Navdanya 2008). Despite the undeniable influence of these organisations, their involvement has often been primarily through specific developmental projects and contributions to debate at the elite level (such as attempts to influence government policy and statements to the media) rather than through expansive mobilisation of opposition at the grassroots level. 
Activities carried out by these groups fall into three broad categories. The first category of work focuses on developing rural communities through a range of projects, including providing training in traditional and organic agricultural techniques and helping to establish seed banks and marketing systems for village produce. The second category of work provides a research base for the first category; groups document local crop varieties and how they are grown and used, and research traditional agricultural techniques that may be falling into disuse. Finally, each of these groups also engages in what is usually called advocacy: promoting the importance of organic and traditional agriculture, and of crop biodiversity. This advocacy is often aimed at a policy-making audience, but is also directed at urban audiences at times. While those promoting alternatives to GM crops occasionally take part in the large protests and direct actions that have gained groups such as the KRRS and Greenpeace so much attention, their work tends to be less visible.

The difference in activities carried out by those promoting organic agriculture and those vocally opposing GM crops is strongly tied to the frames adopted by each. While those discussed in this section employ some of the same frames as the KRRS, their discourse tends to fit more easily within the language of development and ecofeminism than Gandhian or global justice discourse. Navdanya, Gene Campaign and GREEN Foundation all link ecological issues to social justice concerns; while Navdanya highlights effects on and involvement of women, Gene Campaign specifically targets adivasi communities ${ }^{14}$ and the GREEN Foundation focuses on landless and marginal farmers.

The development work done by these groups is frequently framed in terms of food security. Promotion of local crop varieties is primarily justified in terms of their high nutritional content and suitability for local conditions. For example, GREEN Foundation's kitchen garden programme makes extensive use of local legume and vegetable varieties. Kitchen gardens are seen by GREEN Foundation as both "a repository of diversity in vegetables", and as a means of

\footnotetext{
${ }^{14}$ Adivasis are indigenous peoples who have historically been marginalised within India. Many adivasi communities depend heavily on forest produce, and the process of colonisation and enclosure of the forests that began formally with the 1864 Forest Act and was extended by legislation in the post-colonial period left them with few formal rights over forest resources (Bijoy 2003).
} 
ensuring nutritional security (2009c). Preservation of crop biodiversity, similarly, is seen as a way of ensuring a varied and nutritious diet for rural communities. Seed banks are a way of not only preserving local crop varieties, but also ensuring that farmers have access to seed. While this is conceived of as an alternative to GM crops, and more generally to the purchase of commercial seed, it is usually framed in such a way that food security is highlighted, rather than a more confrontational anti-GM message.

The ecofeminism ${ }^{15}$ espoused by Shiva has gained more visibility in oppositional communities, particularly within the GJM. Shiva is frequently called upon in both activist and academic spaces to speak for the Global South ${ }^{16}$, and her analysis tightly interweaves a critique of the ecological effects of GM crops and other commercial farming methods with discussion about their consequences for the poor. Shiva also draws on other intellectual traditions, including Marxism and post-colonial studies. Brass describes Shiva's position as one that advocates human rights and democratic resistance, "and celebrates endogeneity/difference/diversity/decentralisation", while opposing "development/progress/class/modernity as unacceptable universal categories associated exclusively with a western 'colonial' Enlightenment project" (1995b, 41). While Shiva uses a variety of different terms throughout her work, her position remains consistently rooted in ecofeminist critiques of contemporary capitalism.

Shiva's ecofeminist perspective associates Indian spirituality with a more caring and nurturing approach to nature. For example, in one interview Shiva connected Indian perspectives with those of American Indians, saying, "Just like Chief Seattle talked about being in the web of life, in India we talk about vasudhaiva kutumbkam, which means the earth family. Indian cosmology has never separated the human from the non-human-we are a continuum" (in Van Gelder 2003). Throughout the Third World, Shiva argues, life is sacred (Shiva

15 Ecofeminism is a stream of political philosophy and activism that links the domination of woman with the domination of nature. As with feminism and environmentalism more broadly, there are a number of variations of ecofeminism thought and practice.

16 For example, in Genetically modified organisms in agriculture, a voluminous publication that aims to provide "an overview of the gamut of GMO issues" (Nelson 2001, 4), Shiva's is the sole perspective from the Global South, although there is another about the Global South. 
2000, 98). GREEN Foundation and related groups use traditional rituals and festivals in order to promote local crop varieties and agricultural techniques, and see these rituals as embodying and reproducing traditional knowledge. GREEN Foundation's website, for example, mentions the importance of "technical, social, and spiritual dimensions" of traditional knowledge (GREEN Foundation 2009a). This willingness to reference and work within Hindu spirituality, as well as to engage with spirituality in a more general sense, distinguishes many groups within this section of the movement from the KRRS, which has been criticised for its avoidance of religious symbolism (Assadi 1994, 214).

The projects that these groups are undertaking are important and meaningful, especially for the communities which they work with. However, the inevitably localised nature of the work makes it difficult to tell how significant its impact will be on the landscape of Indian agriculture. Similarly, it remains to be seen whether a significant proportion of farmers will make use of indigenous seeds in preference to commercial seed. Seed banks certainly make a vital contribution to the movement opposing GM crops, keeping alive the possibility of alternatives to GM crops and the "high-yielding" seed varieties developed during the Green Revolution. It is important to note that it is not only local seed varieties that must be preserved, but also the body of agricultural knowledge that accompanies them; which seeds should be planted under which conditions, what different varieties are useful for, which seed to save, and how to preserve seeds.

The major contributions made by these groups may be not so much in terms of specific projects, but rather their contributions to the debate over the future of Indian agriculture. One aspect of this has been their focus on seed sovereignty, also adopted to a lesser extent by the KRRS and groups focusing on opposing GM crops, and more generally the opposition to foreign ownership of Southern biodiversity. This has been most clearly expressed through the development of the concept of biopiracy.

During the 1990s, biopiracy remained a disputed concept. Even in 2000, a report on the concept listed the industry viewpoint on biopiracy as being, "the 
unauthorized use, multiplication or copying of privately owned innovations that are protected by patent or plant breeders' rights." The industry perspective was that the application and enforcement of "intellectual property rights" is vital to protect the rewards of innovation and hence encourage further research (Crucible II Group 2000, 22). Activism around a number of key cases changed that. In the wake of attempts to patent extracts from neem and turmeric, and to patent a variety of Basmati rice, activists have managed to firmly redefine biopiracy as the enclosure of (mostly) Southern biodiversity by (mostly) Northern MNCs for commercial gain. There are varying degrees of critique of the application of intellectual property laws to animal and plant life, ranging from perspectives that see it as permissible, but skewed towards MNCs, to those within the movement opposing GM crops who see any patent on life as impermissible (Shiva 1997; Nanjundaswamy 1998a, 125). Neither the court cases that have been rallying-cries for activists nor the arguments made have focused on GM crops, but GM crops are frequently positioned as the extreme form of the existing trend towards patenting and commercialisation of indigenous plant varieties.

These claims have disrupted the increasing naturalisation of intellectual property within international legal regimes, and have been instrumental in the creation of laws protecting the rights of people in the South over their natural biodiversity. As discussed in Chapter One, there is a significant body of work that traces the development of intellectual property and explores the relatively recent emergence of claims that authors, inventors, artists, and so on have a natural right to have exclusive control over their work (Boyle 2008, 29 on). As biotechnology has become an increasingly lucrative domain of research, and in order to expand and cement the profitability of biotechnological research, claims that link intellectual property with natural and unassailable rights have been extended to cover research that deals directly with living organisms. The incorporation of protections for these "rights" into international institutions such as the WTO has further contributed to shaping a global discourse that naturalises intellectual property rights over biotechnological research. 
The struggle over biopiracy as a concept and a legal definition is tightly interlinked with attempts to change the terms of the debate by gaining acknowledgement and legitimacy for indigenous and traditional knowledge systems. During the turmeric court case, those arguing that there were examples of prior art had to deal with a legal system skewed against oral and community-based knowledge (Shiva 2000). Activists throughout the Global South, and their allies in the North, have worked to gain recognition for grassroots knowledge, as Darrell Posey did in the case of the Declaration of Belém (1988). They have also had to establish that intellectual property, insofar as it exists, is something that can be possessed by communities, and held in common, and that it is not just a source of revenue but also the lifeblood of many communities.

Attempts to gain legitimacy for alternative ways of knowing have been expressed in a number of other ways. One of these is the insistence on a more holistic, networked, and contextualised model of scientific research. Shiva has argued that GM technology is the result of an "engineering paradigm" which "offers technological fixes to complex problems, and by ignoring their complexity, generates new ecological problems which are later defined away as 'unanticipated side effects' and 'negative externalities'" (2001, 191). A concrete example of this is the claim that Green Revolution crop varieties are superior to indigenous varieties. Shiva (2000) argues that rather than evaluating crops across only a single dimension (yield), they should be seen as part of an interlinked system. Indigenous varieties, she argues, may produce less yield, but also produce fodder for animals, or building materials. They may be more drought-resistant, or require fewer expensive inputs. Often, they are grown with a number of other crops, so that the soil fertility is maintained and a range of nutrients are available. This focus on crops as part of a system, rather than stand-alone components, is echoed in the work of GREEN Foundation (GREEN Foundation 2008a) and Gene Campaign.

This more holistic and grounded science is usually explicitly associated with traditional knowledge by its advocates. This trend is especially evident in the case of groups that promote organic farming as an alternative to GM and Green 
Revolution agriculture, although it is not limited to these groups. Somalingiah, one of the oldest members of the KRRS, said that a key movement aim is to translate the traditional Indian system into the modern age, emphasising the links between traditional life and a holistic, ecological perspective: "Our village system is an ecological system" (Somalingiah \& Prasad 2006, pers. comm., Feb 23). Shiva highlights the interconnectedness of "indigenous agriculture, for example, cropping systems include a symbiotic relationship between soil, water, farm animals and plants" (1991, 69). In each of these examples, traditional knowledge and practices are not conceived of as opposed to science, but rather as a more rooted, holistic, and effective form of science.

Other attempts to change the terms of the debate by redefining science have worked within the dominant scientific paradigm, but have claimed the higher ground by arguing that pro-GM studies are biased by commercial interests. Activists argue that the current institutional environment is not conducive to unbiased evaluations of GM technology. In large part, this is seen as a result of the disproportionate involvement of the private sector in biotechnology, as compared to the larger role played by the public sector during the first Green Revolution. Divya Raghunandan sees the Indian Council of Agricultural Research, the apex body for agricultural research in India, as facing a huge crisis not only in terms of funding, but also in terms of decision-making about the future direction for research. Under these circumstances, GM technology is being offered up as a solution, and with it massive funding and advantageous public-private partnerships (2006, pers. comm., Feb 7). Activists' perceptions of pro-GM bias within the Indian public agricultural research sector were further evidenced by numerous references to an academic at the University of Agricultural Sciences, Bangalore, who was "supporting this [movement] from the back side" (Bhat 2006, pers. comm., Feb 28), as he was worried that direct criticism of GM crops would lead to him losing his job (Babu 2006, pers. comm., Feb 22; Bhat 2006, pers. comm., Feb 28). For many activists, researchers in both the public and private sectors have little basis for claims to scientific objectivity and neutrality. 
These critiques of bias within the current research environment do not remain within the movement; they are frequently voiced, and have reached audiences within governments and academia, affecting the research environment internationally, if not within India. Disrupting the dominant discourse is also important within Indian rural communities, and activists have attempted on numerous occasions to counter what they see as misinformation put out by agricultural companies. A large part of Greenpeace India's work on the GM issue has focused on countering "aggressive and unethical" marketing of GM seeds to farmers, which frequently make assurances of increased yields (Raghunandan 2006 pers. comm., Feb 22; Greenpeace \& CSA 2005). Greenpeace India researched these claims, and another NGO then placed this research in the form that the initial advertisements had taken in order to reach farmers (Raghunandan 2006, pers. comm., Feb 22). Given the intense marketing of GM cotton this is an important part of the movement's work.

Participants within the movement offer up their own studies, implicitly or explicitly claiming that these are scientifically purer, unbiased by the self-serving motives of Monsanto and other MNCs. For example, Greenpeace India, working with NGOs from several other cotton-growing states, set up the Monitoring and Evaluation Committee in order to study the use of $B t$ cotton in the field. Greenpeace India also provided GEAC with briefing papers on high-protein varieties of Indian potatoes in 2002, filling in the gaps that they felt were left by pro-GM research in the approvals process for GM potatoes (Raghunandan 2006, pers. comm., Feb 22). So far, those within the movement seem to have had some success in undermining claims to neutrality by supporters of GM crops, but have had limited success in gaining legitimacy for their own position. There is a widespread sense that both sides have exaggerated, if not lied, and that non-partisan views are difficult to come by (Scoones 2005; Stone 2002).

\section{Section three: complexities and contradictions}

There are unintended consequences to all actions. While the Indian movement opposing GM crops (including those sections providing alternatives) has managed to bring significant attention to bear on the GM issue, it seems likely 
that they have lost the battle when it comes to GM crops. This is partly a result of the regulatory and policy-making environment surrounding GM crops. On the face of it, India's federal system provides substantial regulation of GM crops at the national level. The first main instrument within the national framework regulating GM crops is the Environment Protection Act 1986. Amendments to the Environment Protection Act made in 1989, the Rules for the Manufacture, Use, Import, Export and Storage of Hazardous Micro Organisms, Genetically Engineered Organisms or Cells 1986 (or "Rules"), set up a framework for regulating possible "environmental pollutants", and gave the main responsibility for implementation to India's Ministry of Environment and Forests. The Department of Biotechnology also has a mandate to "Evolve Bio Safety Guidelines", and situates its work within the context of the Environment Protection Act (Department of Biotechnology). The Rules set up a number of regulatory bodies, including the previously-mentioned GEAC, whose roles include reviewing developments in biotechnology, enforcing biosafety, and investigating and taking punitive action in case of violations of statutory provisions. In addition to the 1989 modifications to India's Environment Protection Act, the Seed Policy 2002 contains a section (Section 6) explicitly addressing GM crops. This section states that, "[a]ll genetically engineered crops/varieties will be tested for environment and bio-safety before their commercial release, as per the regulations and guidelines of the Environment Protection Act (EPA), 1986". This provision was reinforced in Section 15(1) of the draft Seeds Bill 2004. Taken together, this legislation provides what is, potentially, a rigorous structure for the approval, review, and containment of GM crops.

In reality, however, both the national implementation of legislation and state policy regarding GM crops have been disappointing for anti-GM activists. While it is possible for existing national legislation to provide mechanisms for a rigorous approach to the review of GM crops, the political will to do so has not materialised. This can, in part, be explained by the focus on biotechnology as an area of development for India's "new economy". This focus is exemplified by the Department of Biotechnology's website, which describes the Department's mandate being to: "Promote large scale use of Biotechnology", "Support R\&D 
and manufacturing in Biology", and "Promote University and Industry Interaction", as well as the brief mention of biosafety. This focus has also been replicated at the state level. While some states have at least temporarily banned $B t$ cotton, the focus on biotechnology as an area of development has been echoed in state-level policies, particularly in Karnataka. This has been highlighted by the government of Karnataka's increasing support for biotechnology since 1999, which has resulted in plans for Bangalore Helix, a biotech business cluster, Bangalore Bio, an annual national event that began in 2001, and an increasing number of biotechnology degrees offered at state tertiary institutions (Scoones 2003; Scoones 2007; Bangalore Bio 2009; The Hindu 2008). Despite the possibilities offered by existing legislation, the overall policy framework has not been conducive to activists' attempts to restrict the entry and spread of GM crops into India.

There is a consensus within sections of the Indian state and national governments, as well as within at least some agricultural communities, that any attempts to regulate the spread of GM crops are likely to fail, and may be ultimately undesirable. This has been demonstrated most clearly in the case of unauthorised sowings of Bt cotton in Gujarat which, as noted above, were not burnt once discovered. In part, this was because of pressure on the government by farmers. Gujarat's Minister of Agriculture argued that if farmers wanted the technology, it must be the pesticide lobby that was opposed to $B t$ cotton, while the consensus within state and national governments, and eventually GEAC, was that "farmers' interests" should not be harmed by preventing access to $B t$ cotton (Herring 2008, 133). Activists' assessments are that the reality has been that, "there's no political will to regulate, and it's incapable, the government is completely incapable of regulating crops" (Raghunandan 2006, pers. comm., Feb 7). Stone's ethnographic accounts of farmers' decisions about seeds in Warangal, Andhra Pradesh, confirm that farmers were concerned about the quality of illegal seeds, but had no concerns about legal issues (2007a). Even given the political will to enforce what would be an unpopular decision, it seems doubtful that the Indian government would have the resources necessary to prevent the spread of unauthorised GM crops, or recall GM crops that had been previously authorised. 
Faced with strong governmental support for biotechnology, the movement seems not to have established a basis for widespread opposition among farmers themselves. Research by Scoones suggests that there are occasional channels open for changing policy on biotechnology by mobilising rural constituencies around elections. However, anti-GM activists, and the KRRS in particular, have not managed to mobilise the numbers necessary to gain leverage through these channels. In fact, Scoones argues that farmers most likely to be part of the KRRS are also those most likely to experiment with $B t$ cotton $(2003,23-24)$. It is possible that this partly explains the inability to gain significant policy changes on GM crops. Additionally, it is possible that some of the more successful frames of opposition leave open significant space for adoption of GM crops.

Ecofeminist perspectives which configure genetic engineering as an affront to the sanctity of life leave no room for the adoption of GM crops, as they provide an inherent objection to GMOs. While it is difficult to gauge exactly the extent to which ecofeminism has gained a foothold in India, there are several reasons for considering its influence to be limited. Firstly, although several large farmers' movements have mobilised a discourse with some similarities to ecofeminism, radical outcomes of this discourse have often been contained and limited by their articulation within the framework of Hindu nationalism. For example, although Sharad Joshi has explicitly aligned Shetkari Sanghatana with "women's power", this is done without critiquing "naturalized social roles and hierarchies of the traditional patriarchal Hindu family" (Roy \& Borowiak 2003, 70). Secondly, to the extent that ecofeminist discourse is picked up by farmers' movements, it seems to be maintained only while useful. Sharad Joshi's alignment of Shetkari Sanghatana with "women's power" did not prove a barrier to the movements' adoption of a pro-GM stance. Organisations such as Navdanya and GREEN Foundation have a firmer commitment to ecofeminist principles, but in comparison to farmers' movements their support base is limited, as is their political power. While ecofeminism has been a significant theme within the anti-GM movement in India, the Gandhian idea of swadeshi 
and opposition to neoliberal globalisation remain the backbone of the movement.

These frames do not provide a basis for inherent opposition to all GM crops. Even some of those within the movement, for example, talk about their opposition to GM crops not in terms of a fundamental disagreement with the use of GM technology, but rather in terms of the need for an Indian-controlled seed industry. One journalist involved in reporting on GM issues who spoke at the 2006 South Against Genetic Engineering conference, Harishchandra Bhat, said of Bt cotton seeds, "[w]hy should you depend on what Monsanto produces? ... Instead we need to have our own [biotechnology]" (Bhat 2006, pers. comm., Feb 28). Those who take this position frequently emphasise the need for Indian universities to take the lead in developing new seed varieties, including GM seeds. This is often positioned within a sovereignty discourse, as a matter of India having control over vital aspects of its economy. The lack of visibility of this perspective within the movement can perhaps be attributed more to its distastefulness to movement leaders than to it being a position held by few movement participants, although this is hard to gauge without more extensive research in the field.

The most stunning example of the flexibility of swadeshi discourse, and the associated Bharat/India distinction, in relation to GM crops was seen in the actions of Shetkari Sanghatana, the farmers' movement led by Sharad Joshi. As noted above, massive illegal plantings of $B t$ cotton were discovered in Gujarat in 2001. When the national government ordered that the plants be uprooted and burnt, Shetkari Sanghatana held a large rally and Joshi declared that, "They will have to walk over our corpses to destroy this crop. This is our satyagraha" (Joshi in Herring 2004, 212). Even once the government promised to pay for crops before they were burnt, Shetkari Sanghatana continued to oppose the move, positioning it as a matter of urban bias: "[d]evelopment should not be locked up in the cities. The marvel of technology should reach the villages", declared Joshi (in Herring 2004, 212). The KRRS and other anti-GM groups contested these claims, but Joshi's claims were nonetheless effective and had a resonance that is clear from the spread of pro-Bt protests to other states 
(Herring 2004, 212). Other farmers' groups, such as Khedut Samaj from Gujarat, have also begun calling for the legalisation of black market, Indianbred, Bt seeds (Herring 2008, 140). The ease with which swadeshi discourse incorporates calls for Indian-produced GM crops has already become problematic for the movement opposing GM crops, and may become more so in the future.

While the cotton plantings that Shetkari Sanghatana were defending were, it seems, not known to be GM cotton when they were planted, since 2001 there has been widespread and deliberate pirating of $B t$ cotton. It is difficult to gauge the exact extent of adoption of pirated cotton, but information obtained by Herring in 2005 indicated that at the time 34 per cent of all cotton seeds sold in India were transgenic, and of these approximately 73 per cent are pirated, or "stealth", seeds. Herring notes that these figures only include packaged and branded seeds. If loose seeds are included, the figures may be much higher (2008, 135). These pirated and packaged cotton seeds are often linked to legitimate Bt varieties by names such as "BesT cotton" (Herring 2008, 134). Adoption of GM cotton is not a one-way process; some years there will be adoption amongst almost all farmers in an area, while in other years GM cotton will be dropped (Stone 2007). All of the evidence seems to be that farmers pirating seed are doing so for pragmatic reasons, and that they see GM cotton as part of the same continuum as non-GM hybrids; GM seeds are subject to the same cost-benefit analyses as other seeds.

In some cases, it might be possible to attribute this attitude to a lack of information about GM crops. At least among some farmers, understanding about what is involved in GM technology seems limited. One group of farmers from near Darwhad, around 430 kilometres North of Bangalore, who had a long history of involvement with the KRRS knew about Bt cotton, although it is not commonly used in the area. However, they consistently referred to it as a "hybrid" rather than as transgenic, even upon further questioning about GM varieties. These farmers have not only worked with the KRRS, but also watch television and listen to the radio, and familiarise themselves with government policies (Tippanna 2006, pers. comm., Feb 15). Stone's research in the 
Warangal district of Andhra Pradesh confirms that farmers treat GM crops as simply another, albeit more highly regulated, hybrid variety (2007a). This suggests that their particular status as transgenic is either not fully understood or is considered to be of minimal importance. So far little research has been done into the extent to which farmers understand the difference between GM and non-GM hybrids, and make their choices according to this information. This research would be an important and valuable contribution to the field, especially when discussing the effectiveness of grassroots knowledge as it applies to this issue.

The pirating of $B t$ cotton has become a controversial issue in the debate over GM crops. As Herring (2008) notes, it disrupts claims by opponents of GM crops that farmers know best. If farmers' holistic, grounded, grassroots agricultural practices lead to widespread adoption of $B t$ cotton, it creates a serious problem for claims that grassroots knowledge should be preferred over "MonsantoKheti", as Shiva calls the science of genetic engineering (Van Gelder 2003). It also further destabilises the already-precarious legitimacy of movement leaders' speaking position; arguments that leaders are not in touch with farmers, and that they do not understand farmers' needs and preferences, are further strengthened by farmers' willingness to adopt GM crops.

This piracy has been pointed to by some, most notably Ronald Herring, as an example of farmers subverting attempts by Mahyco-Monsanto to extract monopoly rents in the form of patent charges. As noted above, the cost of legal $B t$ cotton seeds is very high. However, this is not solely guaranteed by patent protection. Mahyco-Monsanto is able to charge these prices because they are the only supplier of $B t$ seeds that have gone through GEAC's accreditation process. Pirated Bt seeds (which have not undergone environmental field trials) cost considerably less: they were selling for Rs 250-700 per packet in Gujarat in 2005, while second-generation Bt seed packets were selling for as low as Rs 10 per packet (Herring 2008, 135). Farmers' use of black market Bt cotton allows them to gain the benefits of $B t$ without paying high prices. It often means using, or even reviving, seed-saving and breeding skills, as at times $B t$ seeds have been in short supply (especially in 2001, after the banning of Navbharat) 
(Herring 2008, 134). There are some signs that seed piracy is getting farmers more involved in the process of breeding seeds (Stone 2007a, 87), regaining control over seeds from large MNCs.

On the other hand, there is evidence that suggests that this optimistic reading of the situation is not entirely justified. Research in a different part of India, Andhra Pradesh, suggests that the widespread adoption of pirated Bt cotton is not necessarily the outcome of farmers' application of a practical cost-benefit analysis, and is not associated with increased control over seed. A study carried out by Stone (2007a) suggests that at least in some areas, mass adoption of particular cotton varieties (including Bt varieties) is based on very little real evidence, and cotton farmers have lost many skills associated with the choice and conservation of seeds. In Andhra Pradesh, Stone has found, farmers adopt $B t$ cotton because of advertising, or because influential farmers have adopted it. They often do not know key characteristics of the varieties that they plant (such as boll size), and do not engage in experimentation with seeds, preferring novel varieties to those that are tried and tested. Stone sees this as largely an outcome of an uncertain seed market, in which seed quality may vary widely and reliable information is hard to come by. Bt cotton is not the cause of deskilling, argues Stone, but it is likely to exacerbate the problem as variations in its performance across brands contribute to the general uncertainty over the performance of different seeds $(2007 a, 85)$. While it is possible that in some areas Bt cotton, and specifically the illegality of unregistered varieties, will contribute to a greater involvement of farmers in seed saving and breeding, Stone's research makes it clear that this is unlikely to be the case in all areas. Further, as more varieties of GM cotton (and other crops) undergo the GEAC registration process, the incentive to save and breed seed under the radar is likely to diminish.

Nevertheless, the debate sparked by piracy of $B t$ cotton and the arguments put forward by those opposing GM crops in India may prove important in coming years. The genie is out of the bottle in terms of the adoption of GM crops in India, but the role of farmers, NGOs, and other movement participants in the decision-making process about agricultural development is far from settled. The 
movement opposing GM crops has managed to bring significant attention to bear on the issues surrounding GM crops, including their environmental impacts and questions of how they will affect Indian farmers' access to seeds. While some of the consequences of the movement's activities have been far from what participants would have hoped, it is nevertheless the case that a range of questions are being asked and approaches considered that might otherwise have fallen by the wayside. Each of these forefronts different aspects of the struggle over knowledge.

The first way in which the movement has forefronted struggles over knowledge is through attempts to change the terms of the debate by questioning both the neutrality of the scientific studies used by proponents of GMOs, and the model of science itself. As noted previously, anti-GM activists have repeatedly criticised the methodology and interpretation of $B t$ cotton trials, as well as trials of other GM crops. Greenpeace India has not only produced analysis of other studies, but has also produced competing studies (Scoones 2005, 33-34; Raghunandan 2006, pers. comm., Feb 7). In addition to this, activists have introduced, or emphasised, alternative frameworks for analysing the success or failure of agricultural systems. Where agricultural companies emphasise the potential profitability of GM crops, particularly in the case of GM cotton, activists have attempted to define a successful agricultural system in terms of one or more of the following: village and/or national sovereignty, food sovereignty, preservation of crop biodiversity, environmental sustainability, and/or preservation of cultural traditions. Doing so has frequently involved putting forward an alternative vision of science, as Shiva does when she calls for "'.Sitakheti" [...] a woman centred - nature - centred agriculture" (1998). These critiques are valuable from a scientific viewpoint, as they lead to close examinations of methodology, the interpretation of results, and the generation of hypotheses.

Perhaps more importantly in terms of the movement's work, however, they reframe the debate in ways which lever open a space for increased input from farmers, women, agricultural labourers, activists, and other groups that may currently be excluded. In critiquing the bias of corporate studies of GM crops, 
activists destabilise assumptions that large-scale, well-funded tests are necessarily more legitimate and authoritative than those produced by NGOs on small budgets. This case study reinforces the argument made in Chapter One: in highlighting links between public research and the corporate sector, Indian activists question the assumption that political and economic power have no influence over academic research, refusing any claim that scientists know best and can make neutral evaluations for the good of all. Activists argue that farmers (and by extension activists) must therefore be part of the decisionmaking process. Finally, calls for a paradigm of scientific research that sees agricultural systems as systems must, by necessity, place those who make their living through agriculture firmly in the picture as decision-makers, researchers and experimenters rather than as the passive recipients of agricultural technology.

Secondly, activists have disrupted the dominant discourse by refusing attempts to naturalise the application of intellectual property law to biodiversity. In part, this has been through the overlap between the anti-GM movement and activists taking part in specific battles, as in the case of neem, turmeric, and basmati. On a deeper level, however, activists in the Indian anti-GM movement have worked to frame the global understanding of intellectual property. Perhaps the largest contribution here has been the effective framing of the patenting of life as biopiracy, flying in the face of attempts to configure it as merely the newest Information Age growth industry. The work of Indian activists in opposing the patenting of life has also been instrumental in the creation of a global discourse that runs counter to the neoliberal narrative of intellectual property. This counterdiscourse sees communities, rather than corporations, as the subjects. The object is not biotechnology, but rather biodiversity. The verb is not "to own", but "to care for". This counter-discourse has not necessarily triumphed, but it has had an influence on debates throughout the world and on international institutions, including the Convention on Biological Diversity.

Thirdly, activists within the anti-GM movement in India have built their arguments on the foundation of a strong claim for the free flow of information. There are two aspects of this. Firstly, if we see seeds as vessels for the 
transferral and reproduction of genetic information, a definition which many activists may no doubt find overly reductive, arguments for seeds to remain beyond the purview of intellectual property law are arguments for the ability to share (and remix) genetic information. Secondly, activists have repeatedly called for research into GM technology to be carried out in a more open and accessible way. Greenpeace India have attempted to open the debate on "the whole morality issue of how information needs to be out in the public domain, both for farmers and for consumers", and have made extensive use of India's Right to Information Act as part of their campaigns (Raghunandan 2006, pers. comm. Feb 7). In pursuing their struggle, Indian activists have repeatedly argued that knowledge needs to remain accessible, especially for marginalised communities.

Each of these aspects of the struggle over knowledge is at the same time an expression of the movement's claims, and a strategy for bolstering the movement's position. They have implications for the kinds of argument that the movement can make, and for the shape of the movement itself. For example, in claiming a space for farmers' knowledge as potentially less biased than that provided by corporate research, activists are simultaneously making an argument about GM crops and reinforcing their own reliance on links with the grassroots for legitimacy. This link may also give activists, observers, and critics reason to approach the movement's arguments with some caution, and to ask about the extent to which arguments for a new kind of science or the open flow of information are based on activists' desires to strengthen their own position. Herring (2006) has argued that activists' framing of science, and of the potential risks of GM crops, has far more to do with attempts to build broad coalitions and gain support than with the real interests of farmers. This is by no means the only reading of the situation, and my research provided numerous examples of committed and informed activists who have firm grassroots support. Nevertheless, the use of arguments that centre on how knowledge should be defined and disseminated can cut both ways, opening the movement up to criticism as well as creating new spaces for activists' voices to be heard. 


\section{Conclusion}

The changes wrought by GM crops in India are yet to be seen. If critics of GMOs are right, the massive release of GM crops into the Indian agricultural system and natural environment should be cause for considerable concern. While it is still conceivable that this release is reversible, it is incredibly unlikely, given the scale of GM crops' adoption and the lack of resources and political willingness the Indian government has to deal with the issue. This is not to say that the work of the movement is over. Participants still see value in preventing the entry of new GM crops into India, and in holding the government to account in terms of their adherence to biosafety procedures (or lack thereof). The movement against GM crops has managed, in concert with other movements worldwide, to maintain critiques of genetic engineering and prevent it from becoming a stable and widely-accepted technology. They have simultaneously argued against claims that GM crops are technically better, and have argued for the inclusion of non-technical issues in the debate.

Hope for anti-GM activists may also come in the form of a higher visibility for the debate over GM crops. Research by Stone (2007), Jewitt (2000), and Gupta and Chandak (2005) has indicated that farmers' agricultural knowledge is spotty. In some areas, responses to Bt cotton have been marked by a context of considerable deskilling (Stone 2007), while in others farmers have made use of plant-breeding skills to derive significant gains from Bt cotton (Gupta \& Chandak 2005). The debate over Bt cotton, and by extension GM crops more generally, has gained significant coverage in a range of media, including radio and the agricultural press. It has also stimulated more research and activism related to farmers' agricultural knowledge. One possible outcome of the attention to these issues may be increasing recognition among policy-makers and academics of the importance of farmers' agricultural expertise. Another may be a growing awareness of possible risks of GM crops among farmers. Whatever the outcome of the debate over farmers' agricultural knowledge and how this relates to use of GM crops, it is notable that the debate is taking place at all. That even proponents of GM crops have attempted to legitimise their position by pointing to farmers' use of $B t$ cotton (and pirating of $B t$ cotton) may even be 
seen as a promising sign, insofar as it places a premium on farmers' knowledge and experience.

As well as contributing to the debate within India over GM crops, activists within this movement have been part of a global struggle to redefine how knowledge is produced, who owns knowledge, and who should have access to it. While this case study has focused on the local context of Indian activism, and particularly on the southern state of Karnataka, it is important to remember that activists have both drawn on and contributed to global discourse about intellectual property, biotechnology, and what should constitute legitimate knowledge. At times this has been overt, as was the case when activists protested against provisions for patents on life in TRIPS. At other times activists' contributions have been less visible: when activists' critique the bias of corporate research and lever open a space for their own contributions to the debate, this space is also opened for other marginalised groups around the world.

The movement therefore contributes to the broader project of globalisation in two ways: through direct links with the global justice movement, which will be discussed in more detail in the fourth chapter, and through activists' participation in local, national, and global debates over knowledge. The latter has taken three main forms. Firstly, in undermining the legitimacy of corporate and academic research, Indian activists have contributed to attempts underway throughout the world to establish grassroots actors as legitimate producers of knowledge. Activists have also strengthened the position of others working towards globalisation-from-below by arguing for a more holistic scientific paradigm, one which is rooted in local realities and therefore places value on the knowledge and experience of grassroots actors. Secondly, activists have contributed to the global movement by refusing the naturalisation of the neoliberal approach to intellectual property, in this case the claim that genes can be owned. Given the opposition to the enclosure of the commons that is a recurring theme within the global justice movement, this is a significant contribution to the global struggle to retain spaces outside the reach of corporate control. Thirdly, activists have reiterated the importance of the free flow of information, be it research data or the genetic information encoded in 
seeds. Activists within the global justice movement have a particular interest in information remaining free, as they do not have the resources to pay for access to information. They also rely on the ability to disseminate their messages widely and effectively. The movement discussed in this chapter may be firmly rooted in India, but its contributions spread beyond India's borders, feeding into the wider struggle for globalisation-from-below.

These contributions have links and echoes with struggles throughout the world. The most obvious analogues are in the struggles underway in other parts of the Global South, such as those discussed by Scoones (2005) in his comparison of anti-GM struggles in India, Brazil and South Africa. However, there are also movements emerging from more surprising quarters that address many of the same issues as those discussed here. As we will see in the next chapter, activism is now emerging around information technology, rather than biotechnology, that draws on many of the same themes as the anti-GM struggle in India. This activism is similarly opposed to corporate domination, to claims that only elites can produce legitimate knowledge, to monocultures, and to barriers to the free flow of information. 


\section{Chapter Three}

\section{The digital liberties movement: the digital is political}

\section{Introduction}

This chapter discusses the digital liberties movement (DLM), which is attempting to highlight the political dimensions of decisions about digital technologies and how they are used. As is the case with the previous case study, this struggle is about particular technologies and issues, but it is also in a broader sense about knowledge: who has a right to access knowledge, and whose knowledge is recognised as legitimate. For a number of reasons, including the relatively recent emergence of the movement and the differences between it and more traditional social movements, it has received little attention within mainstream social movement scholarship. Much of this chapter therefore focuses on providing a comprehensive outline of the movement's history, goals, analysis, tactics, and participants. In doing so, it will also be necessary to address some of the conceptual issues that are involved in studying the movement, including a discussion of "virtual" and "offline" spaces, emphasising the close relationship between the two and the material effects of choices and actions taken online.

The first section of this chapter provides a brief outline of the DLM, outlining the argument for considering it a coherent movement. This argument draws on social movement scholars' work in order to map the DLM, focusing on participants' emerging collective identity and the movement's network structure. This section gives a framework for returning to an exploration of the context from which the DLM has emerged, which is necessary for a deeper understanding of the issues that the DLM is addressing and the communities which it is built from.

The second section of this chapter discusses the context of the DLM's emergence. Revisiting and extending arguments from Chapter One, it examines the extent and nature of technological change that has been associated with the 
revolution in ICTs. The path of technological development has been dependent on historical, geographical, and political factors, including US technological and political predominance. Its future also remains open to the influence of a variety of actors, including elites and those striving to achieve globalisation from below. We are now at a critical point in the development of the networked era. Various elites, including governments (particularly the US government) and entrenched industries, are attempting to gain tighter control over the spaces opened up by ICTs and the uses to which they are put. In some cases, these attempts have relied on deploying technological or legal measures of control. However, in the case of certain kinds of knowledge, there has been a largely successful attempt, led by corporate interests and supported by many governments in the Global North, to fundamentally rewrite the political framework used to determine who should have access to and ownership over certain information. The naturalisation and extension of IP law has severely curtailed the freedom to access and disseminate a wide range of cultural content. Together, these developments have led to significant restrictions on the freedom that is potentially afforded by the ICT revolution.

The third section returns to the development of the DLM, tracing both its history and its current incarnation. While the DLM takes some inspiration from movements that have more traditionally fallen under the purview of social movement scholars, its roots are in communities and subcultures that are largely based online. These roots have shaped the DLM, feeding into and overlapping with it. They have contributed ideas, participants, and tactics. The emergence of the DLM has resulted both from the evolution of these movements, and from the reaction to trends discussed in the second section. While the DLM is still in its infancy, a number of battles have served as rallyingpoints, bringing attention to the movement's claims and helping to forge the networks that sustain it. Out of these battles, and the everyday communications that all movements rely upon, the DLM is slowly building into a recognisable movement. 


\section{Section one: defining the digital liberties movement}

The DLM has emerged partly in response to elite attempts to (re)gain control of ICTs, and partly through merges of and changes within communities that have existed for decades, including the F/LOSS movement, the hacker community, and the yippies, that use, tinker, and develop ICTs. This background will be further explored in the following sections. This section provides a brief outline of the DLM and the grounds for considering it a coherent movement in order to situate the discussion that follows.

As I pointed out in the first chapter, it can be difficult to exactly define what constitutes a social movement, and even more difficult to draw the boundaries around a particular social movement. This problem becomes more acute in the case of movements which have not yet received significant attention in the media or within academia, as even their existence is nebulous, and may be disputed. It should be noted that the characteristics and boundaries of the DLM as they are described here remain fluid. While it is undeniable that a movement is emerging, one could easily posit its locus and membership differently.

There are a number of organisations and individuals which form the core of the movement, and in each case one could dispute whether "digital liberties" are really the focus of their activism. Cory Doctorow has been involved in activism around these issues for a number of years now, and is one of the authors of a group blog, BoingBoing, that regularly addresses copyright, civil liberties, online surveillance, and other matters at the heart of the movement's work. Lawrence Lessig has also played an important role through his academic work and advocacy. As well as being involved in key court cases relating to US copyright law, Lessig's The Future of Ideas (2001) and Free Culture (2004) have proved highly influential within the movement, and Lessig has been involved in setting up FreeCulture.org, which has a number of student chapters around the world. Yochai Benkler, Lawrence Liang, Wendy Seltzer and Jessica Litman are some of the other visible activists in the field, many of them working within academia and the legal profession. There are, as in any other social movement, thousands of unsung movement participants whose activities remain largely unseen. Organisations involved in the movement include the EFF, Public 
Knowledge, Piratbyrån ${ }^{17}$, Foundation for a Free Information Infrastructure (FFII), the Free Software Foundation (FSF), and many others. Some of these actors position themselves as involved in IP research and activism, others in civil rights advocacy or other areas.

It is possible to see these actors as involved in other movements, and indeed to see the DLM not as one movement but rather as several overlapping movements. This is, however, not an conceptual problem limited to the DLM. As I argued in the first chapter, social movements are inherently multifaceted, fluid, and messy. Even those as well-established as the feminist movement or the environmentalist movement can be seen as a kaleidoscope of other movements, with participants flowing in and out of various overlapping movements. The DLM has been influenced by ideas, and is composed of activists, from the F/LOSS movement, the creative commons movement, the anti-copyright movement, civil liberties movements, appropriate technology movements, opposition to software patents, and hacker culture, among others. Yet at the same time there is significant evidence that it is more than simply the sum of these parts.

One justification for considering the DLM to be a single movement is that ideas, activists, and frames, are increasingly cohering to tie together issues as wideranging as online civil liberties, F/LOSS, digital rights management (DRM), and intellectual property rights (IPR). At first glance, it is difficult to see the connection between these issues, and in many cases their political dimensions are unclear. Establishing that there is a connection, and framing these issues as political, constitutes a large part of the movement's work. The frame that ties the DLM together, and which we will discuss in more detail below, is the attempt to build an understanding that citizens/users (rather than corporations or governments) should control ICTs and online spaces, tying this control to democratic principles and ideals of personal freedom. In coming years, it is likely that this work will not only gain more visibility, but will help activists to gain a more durable and cohesive sense of their place in the struggle which they are engaged in.

17 The Piratbyrån disbanded in June 2010, stating that this was partly because they felt their work was done and partially because of the death of one of the founding members (BBC News 2010). 
As noted in the Introduction, a social movement is defined as "a sustained, organized public effort making collective claims on target authorities" that uses a particular repertoire of tactics on behalf of a group of people that claim to be worthy, united, numerous, and committed (Tilly 2004, 3-4). In addition to this, some scholars have argued for the importance of network structures (della Porta \& Diani 1999, 159) and collective identity (della Porta \& Diani 1999, 24) as defining features of social movements. This provides a useful starting point from which to examine the emergence of the DLM and sketch its defining characteristics.

Currently, the requirement for a collective identity and a proclamation of unity outlined in Tarrow's definition of a social movement is perhaps the most problematic aspect of my claim that a movement has emerged around digital liberties. There are a number of terms currently in use by media, scholars, and participants themselves to identify movement participants, including "infoanarchists", "online civil libertarians" (Schwartz \& Cha 2000; Borland 2001), "pirates" (Engström 2007, pers. comm., July 27), "(anti-)intellectual property activists" (Brown 2005) and "copyfighters" (Farivar 2008). However, each of these terms tends to address only a single aspect of the movement's work, and none has yet gained wide currency. No single term is used to describe either the movement or participants. I have adopted the label "digital liberties" because it encapsulates both the grounds of battle (including hardware, software, and online spaces) and the general disposition of the movement (which highly values individual autonomy, and is inclined towards libertarian principles), both of which will be discussed in more depth below. While a fullyfledged collective identity has not yet been developed by movement participants, adoption of the above-mentioned terms by activists do point towards a nascent sense of collective identity.

Similarly, the network structure of the movement is still developing, and communication and dialogue between different actors within the movement are growing. There are several organisations that form nodes in this nascent network structure. One of the most important of these is the EFF, which was founded in 1990 and fights for "our freedoms in the networked world" (EFF 
2008). Public Knowledge, also based in the US, is "a Washington, D.C.-based public interest group working to defend citizens' rights in the emerging digital culture" (Public Knowledge 2008). In Europe, key organisations include the FFII and the Piratbyrån, or Piracy Bureau, a Swedish organisation engaged in "reflection over questions regarding copying, information infrastructure and digital culture" (Piratbyrån 2007). Given the DLM's deep roots in online spaces, mapping the links between organisations' websites provides at least a rough indication of the emerging network structure. The cluster map shown on the following page was built using a tool called Issue Crawler, which tracks and displays links between websites. 


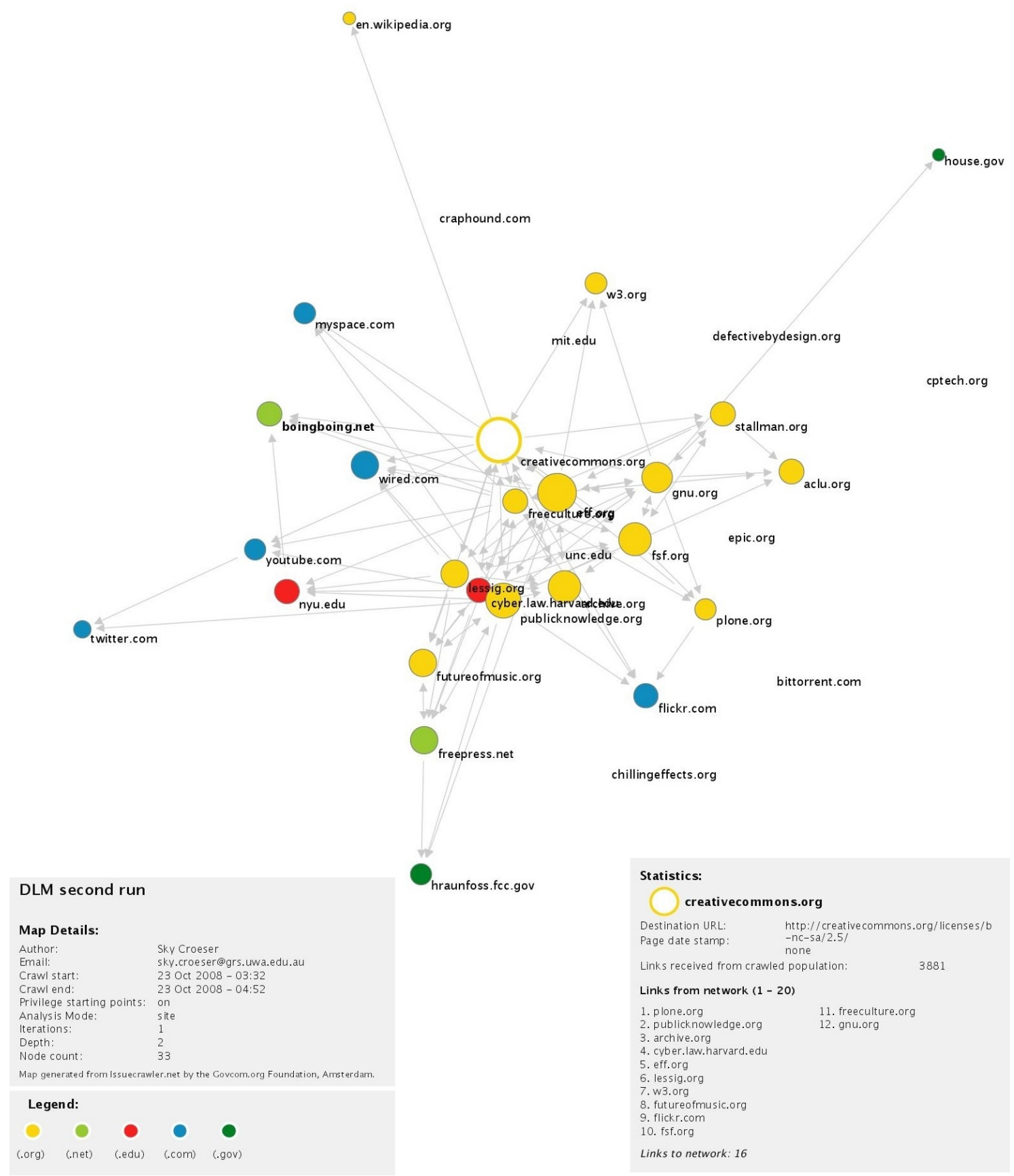

Cluster map illustrating the DLM, Issue Crawler

These links could represent either organisational ties (links to organisations involved in a coalition or campaign) or common interests (links to articles or other content on related issues). Grey arrows represent links; an arrow from one site to another shows that the former linked to the latter. While the nodes of this map have intentionally been limited for the purposes of clarity, it is illustrative of the links between organisations active around different issues within the DLM. For example, there are strong links between Free Press (freepress.net, active on media reform) and The Berkman Centre for Internet 
and Society (cyber.law.harvard.edu, which assesses the role of law in regulating cyberspace). F/LOSS organisations, including the Free Software Foundation (fsf.org) and the $\mathrm{GNU}^{18}$ project (gnu.org) are also linked to groups active on civil liberties (aclu.org, eff.org), copyright issues (creativecommons.org), and the regulation of cyberspace (cyber.law.harvard.edu). This map shows a network in which organisations involved in a range of issues relevant to the DLM are tightly interlinked.

As well as the activism that these organisations engage in, they are also sometimes involved in what could be considered network building activities. These activities include organising and promoting conferences and discussions, as well as more informal gatherings such as dinners. Events such as these are often conceived of primarily as spaces in which activists develop strategies for action, but they are also important in order to build links, coalitions, and a sense of movement identity, as has been demonstrated by the many discussions and debates over the purpose of the WSFs (cf. Whitaker 2004; Teivainen 2004). Although the development of network structures and movement identity is rarely a stated goal of such events, at least in the case of the DLM, they provide a space for the movement to grow and cohere.

While gatherings in geographically- and temporally-specific locations are important to the construction and development of social movements, ICTs have become increasingly useful in helping movement participants to build and maintain networks. Participants in environmental, feminist, and other such movements that have garnered more thorough attention within social movement scholarship take part in discussions about their activist identities online, and use these spaces to build and maintain connections both through ICTs and face-toface communications. For the DLM, the World Wide Web and email have played a major role in the emergence of the movement. Boingboing, a group blog, and Slashdot, "news for nerds", are pre-eminent in this regard. While Boingboing has a clear set of bloggers who post, and Slashdot has a cadre of developers, editors, and official authors, both include mechanisms for readers to suggest items, and there are comment threads attached to each post in which readers can hold discussions. For this reason, it is useful to think of these

$18 \mathrm{GNU}$ is an operating system developed as a free software alternative to Unix, hence the name: "GNU's Not Unix". 
websites as discussion forums, rather than in terms of the more traditional oneto-many media model. As Kreimer notes, the interactivity of the Internet allows "information to blend into recruitment and mobilisation" (2001, 131). Both readers and authors/developers/editors become part of a community, and have an impact (albeit unequal) on the tone and content of the sites.

The communities that surround these sites are slowly building an understanding of how the issues covered by the DLM are interlinked, and a sense of involvement in a common struggle. In part, this happens through the news items posted: both Boingboing and Slashdot regularly post items related to developments in IP regimes and enforcement, F/LOSS, online surveillance and rights violations, and other topics relevant to the DLM. Tags and categories help to frame these issues; Boingboing authors regularly tag items related to copyright and IP with "copyfight", while many posts relating to the use of ICTS for surveillance or information-gathering on citizens are tagged "civlib". On Slashdot, items are divided into categories such as "linux" and "politics", as well as being assigned tags such as "netneutrality", "p2p", "privacy", and "antimicrosoft"19. Authors' commentary, similarly, positions and interprets issues within the movement's frames, and readers add to this by reinforcing, reframing, or contesting authors' interpretations. One post about Walmart's removal of a server that allowed customers to listen to music bought online attracted both favourable comments and counterarguments, including a complaint from user STANFROMBROOKLYN that Walmart's actions are no excuse for illegal downloading. Overall, there were 78 comments on this post, which was only one of many posts for the day (Doctorow 2008b). The importance of these sites was emphasised in an interview with Christian Engström, then Vice Chairman of the Piratpartiet, or Pirate Party, a Swedish political party that is part of the DLM. He not only attributes his early involvement in the FFII to following discussions about software patents on Slashdot, but also says of the Piratepartiet, "we were born out of Slashdot, people reading Slashdot" (2007, pers. comm., Jul 27). Slashdot, Boingboing, and a host of smaller websites function as spaces in which movement participants discuss issues and build a common analysis, creating the movement as they do so. These spaces have become key sites in

\footnotetext{
19 Slashdot readers can assign their own tags, which means that they are sometimes contradictory. For example, an article on US voter registration was tagged with both "stuffthatmatters" and "whocares", as well as the more conventional "politics", "today", "news", "usa" and "story" (kdawson 2008).
} 
the resistance to elite attempts to (re)gain control over ICTs, which are discussed in the following section.

\section{Section two: (re)taking the digital}

In Chapter One, I discussed some of the ways in which new technologies are being used by participants in the global justice movement. The previous chapter built on this by examining various ways in which participants in the Indian antiGM movement fight for control of knowledge: not only access to knowledge, but also a legitimate role for themselves as producers of knowledge. Echoing Chapter Two, this chapter examines a movement concerned with the control of knowledge. As in the case of the Indian movement, the DLM seeks to preserve and to continue pre-existing traditions (in this case, the freedom and generativity of digital technological systems). It is also attempting to combat emerging threats to participants' control over knowledge. This section of the chapter outlines the context in which the DLM has emerged, focusing particularly on developments that movement participants see as threatening. Currently, the DLM is defined in large part through its opposition to elite attempts to (re)gain control over ICTs. It is therefore necessary to understand these attempts in more detail.

To begin with, we must briefly revisit the changes to the technological landscape that are tied to these threats. The latter part of the twentieth century saw a range of interconnected developments in ICTs that have had far-reaching effects on the world. Castells, while by no means the first to analyse these developments, has nevertheless produced some of the most comprehensive examinations of the $\mathrm{ICT}^{20}$ revolution and its effects on society. Castells argues that the ICT revolution is "at least as major a historical event as was the eighteenth-century industrial revolution", and has transformed our world to a digital one $(2000,29)$. As Castells' voluminous explorations of the ICT revolution's effects imply, the consequences of these developments have been significant and multifaceted. However, for the purposes of this chapter, there are three interrelated aspects of recent developments that are particularly

20 Castells refers to the "information technology revolution" in his work. However, I prefer to write of the "information and communications technology revolution", as I feel this term more fully encapsulates the nature of the technologies involved. 
important: the digitisation of information, the increasing interrelationship between online and offline spaces, and a nascent shift in how we produce knowledge.

\section{The digital revolution}

Firstly, the ICT revolution is linked to a radical change in our ability to share information. Digital information can be gathered, shared, and processed far more easily than information in analogue form. Much has been made of the social and political consequences of the development of the Gutenberg press and the subsequent democratisation of knowledge. However, even with the relatively accessible printing enabled by movable type (and other developments in printing in following centuries), the information contained in printed material remains difficult to share. The invention of photocopying technology, video cassette recorders, and many other copying technologies of the 1980s and 1990s made it easier to pass on information, but the costs of sharing content still remained non-trivial, and depended on the creation and transportation of physical artefacts. The shift from analogue to digital storage of information has opened new possibilities for collation and processing of information on a broad scale, and has radically lowered the barriers to copying and sharing information, in many cases making the cost of sharing of material trivial.

Castells argues that this is part of the embedded logic of the new technological system. While he acknowledges the influence of the context of the system's emergence, he sees it as fundamentally "characterized by the capacity to translate all inputs into a common information system, and to process such information at increasing speed, with increasing power, at decreasing cost, in a potentially ubiquitous retrieval and distribution network" (2000, 32). Information can be readily transferred between formats and devices; movies, books, articles, photographs, and music can be copied innumerable times and moved from computers to flash drives to iPods to mobile phones. The authors of a 2000 report on these issues, The Digital Dilemma, argue that a trio of technological advances have led to these radical shifts in the economics of information: "(1) information in digital form has changed the economics of reproduction, (2) computer networks have changed the economics of 
distribution, and (3) the World Wide Web has changed the economics of publication" (Samuelson \& Davis 2000, 7). Prior to the digitisation of information, the knowledge economy was one of scarcity. Now, at least for those with access to computers, the costs of copying and sharing information are minimal.

The effects of this have been wide-ranging. Castells draws on the work of Melvin Kranzberg and Carroll Pursell to argue that, as was the case with prior technological revolutions, the ICT revolution has been characterised by "pervasiveness, that is by [its] penetration of all domains of human activity, not as an exogenous source of impact, but as the fabric in which such activity is woven" (2000, 30). Developments in ICTs do not only affect us through our direct use of technologies such as computers and the Internet. As Castells argues in The Rise of the Network Society, they have also created significant shifts in the economy, work, employment, and culture (2000). People of different classes, people from different parts of the world, are affected differently, but they are all affected. For some workers, particularly but not exclusively so-called knowledge workers based in the Global North, a large part of both work and leisure time has come to be structured around ICTs of one sort or another. The ICT revolution has also changed how we experience space and place, creating new spaces and changing how we experience familiar places.

\section{The relationship between the real and the virtual}

Secondly, it must be emphasised that while it may once have been possible to distinguish between the real and the virtual, between offline space and cyberspace, it is increasingly difficult to do so. During the early era of the Internet, a mythology was built up around cyberspace. Cyberspace was seen as disconnected from the material world, a space where people could be anyone and do anything. This mythology was built in part on the imagined cyberspaces of authors like William Gibson who were writing during the early days of the World Wide Web and shaped the way in which people pictured it and its future (Kneale 1999, 206). The habit of thinking of the World Wide Web, and the Internet more generally, as a space separate from the material world remains common. As Berry $(2004 a, 324)$ notes, the ontological status of the Internet 
remains undetermined, with some researchers treating it as a space in itself, while others treat it as a textual repository or as something else entirely. However these deeper ontological questions are settled, it is at the very least necessary to interrogate and disrupt assumptions that the real exists separately from the virtual.

The notion of online interactions taking place in an immaterial space must be abandoned. Sterling writes that "[a]lthough it is not exactly "real," "cyberspace" is a genuine place. Things happen there that have very genuine consequences" (1992). Even this reminder is not enough, as it reinforces the idea of cyberspace as a separate place, another loosely connected layer of reality. It is necessary to put aside, at least at one level, this idea of the virtual. At the most fundamental level, the Internet is not virtual, but rather is built upon a material infrastructure: users' computers and servers and fibreoptic lines and satellites launched into space. The reality of cyberspace is underscored by a 2007 report that found that the ICT industry was responsible for approximately two percent of global carbon emissions (Gartner 2007). At the level of user experience, too, it must be emphasised that claims that online "I have no body and neither does anyone else" (Miller 1995, 54) should not be accepted at face value. Our online interactions do not leave our embodied reality behind-the socialisation that comes with a gendered body, the economic realities that accompany our geographical locations, the educations we have been afforded, the constraints of time zone and language...none of these can be sloughed off and left behind when we are "online". There are several good reasons for refusing to accept the fiction that cyberspace is separate from offline space.

It is important to remember, also, that the spaces we think of as offline are heavily enmeshed with the digital. Mobile phones are increasingly pervasive, even (especially) in the Global South. Sterling (1992) called cyberspace "THE PLACE BETWEEN the phones"; with mobile phones, we message, talk, send and receive photos, use the Internet, all while "offline", carrying this place between the phones into the world with us. Surveillance technologies also crisscross offline space-many cities are heavily surveilled by CCTVs, which not only record these spaces but also shape behaviour within them. We (especially in the Global North) leave a digital trail as we use credit cards, global 
positioning systems, mobile phones, and radio frequency identification (RFID) cards. Satellites gather data for governments, and projects like Google Maps and Google Street View provide detailed data on supposedly offline places. In countless ways, large and small, offline and online spaces are merged.

In addition to this, it is important to recognise that the ICT revolution has been heavily shaped by its roots in particular places, as has the ongoing struggle about the future of ICTs. Castells argues that the rapid development of ICTs in the 1970s was clustered in the US, and particularly in California, as a result of "the autonomous dynamics of technological discovery and diffusion, including synergistic effects between various key technologies", rather than because of social characteristics of the US. However, the way in which the ICT revolution developed was "decisively shaped by the historical context in which it expanded" $(2000,60)$. Over the last three decades, this has continued to hold true: US attitudes towards government regulation, as well as US trade and military imperatives, have played an important role in shaping the development of ICTs. More generally, the geographic and strategic realities of place continue to play a role.

The importance of the US in the context of ICTs is manifested in a number of areas. In terms of vital infrastructure, the Internet Consortium of Assigned Names and Numbers (ICANN), which makes key decisions about domain names, remains at least to some extent under the control of the US Department of Commerce (Vaidhyanathan 2004a, 36-37). In addition to this, a 2001 study found that the US acts as a "central switching facility" for international connections, carrying a significant proportion of intraregional Internet traffic (Townsend 2001, 1701-1702). While the US's role has decreased since 2001 with the growth of other nations' infrastructure, it is estimated that a quarter of all traffic still passes through the US (Markoff 2008). The US has also had a dramatic effect on the international use of ICTs through the "War on Terror": related US legislation such as the PATRIOT Act has been used as a model for the expansion of government surveillance within many of their allies' borders. The US has also been hugely influential in the development of international IP regimes, not only through their involvement in intergovernmental organisations such as the WTO and WIPO, but also through bilateral agreements such as the 
free trade agreement with Russia (Samuelson 1997). Whilst actors around the world have been taking part in the struggle for control over the future of the Internet and other ICTs, the US continues to play an important role both through elite attempts to control ICTs and as a site of growing resistance.

\section{Shifts in knowledge production}

Thirdly, the ICT revolution has had profound impacts on knowledge: how we access it, how we produce it, and what we consider to be legitimate knowledge. Some of these effects are quantitative rather than qualitative. As discussed above, information in digital form can be shared more widely, and at a much greater speed than information bound within books, particularly when shared online. On a qualitative level, however, the ICT revolution has also led to shifts in how we think about the production of knowledge. Projects such as Wikipedia, a user-edited encyclopaedia, have opened up new possibilities for the production of relatively reliable knowledge by people who are not officially accredited, through a relatively decentralised process. Crowdsourcing, "a new web-based business model that harnesses the creative solutions of a distributed network of individuals through what amounts to an open call for proposals" (Brabham 2008, 76), opens up similar possibilities for distributed, decentralised knowledge production that does not rely on accredited experts. The ICT revolution has led to qualitative, as well as quantitative, shifts in knowledge production. Changes in our understanding of who produces legitimate knowledge, and how they do so, are likely to continue in coming years.

\section{(Re)gaining control over information and communications technologies}

The first chapter of this dissertation explored some of the ways in which ICTS have added to activists' toolboxes, allowing qualitative and quantitative changes to how participants in the GJM organise and pursue their goals. The rapid changes of the last few decades have led to a high level of openness in how technologies have been used. Sclove argues that technologies are more open in the early stages of their development; "the flexibility associated with a given technology [...] tends to diminish with time," as "owing to the accompanying evolution of supporting custom, entrenched interest, and various sunk costs, it 
is often difficult to achieve radical design alterations once an initial decision has been implemented" $(1995,19)$. It is not only this growing institutional inertia that solidifies the uses to which technologies can be put, but also the ways in which different groups within society react to and shape emerging technologies-the attempts that are made to bring new technologies under control by established elites. As we saw in the final section of Chapter One, elites have been making attempts in a number of areas to gain tighter control over how knowledge is produced and disseminated.

Just as in other areas, governments, corporations, and other elites have been seeking to (re)establish their dominance over the Internet and related technologies, even as social movements and other actors have explored their liberatory or disruptive possibilities. It should be emphasised here, as it was in the first chapter, that the motivations behind government and corporate attempts to regain or strengthen their control over these spaces and systems vary. In some cases, the shutting-down of these spaces of dissent has been part of a campaign waged by authoritarian states against internal actors working directly or indirectly against the government, as in China, Burma and Iran. In democratic states, the same process has been at least overtly motivated by a desire to protect vulnerable sections of the population, as with censorship of child pornography sites in European states. The ongoing "War on Terror" of the last few years has also played a significant role, with increasing government surveillance of citizens and non-citizens. The use of surveillance technologies has also been justified by references to more traditional law and order concerns. While there have been some signs that elites are directly concerned with activists' use of ICTs, such as the inclusion of "anti-globalisation hackers" in a US military training scenario (Caldwell \& Hunter 2002), on the whole social movements have not been the direct target for these measures.

Campaigns waged by governments to bring the technological systems of the Information Age under their control have not been waged purely to secure the national interest in a traditional sense, but have also been closely linked to corporate interests. Corporations have a variety of motivations for attempting to develop the way in which information age technologies are used and develop, 
primarily their desire to prevent "theft" of "intellectual property" in order to secure or increase their profits from commercialisation of particular technologies.

\section{National security, law and order, and surveillance}

The same technologies that allow social movement participants an unprecedented ability to communicate with each other and their audiences also vastly increase governments' ability to watch their own citizens (Graham \& Wood 2003). One example of this is the use of cheap cameras and computational analysis of digital communications, license plates, and facial recognition systems. Additionally, spaces of digital communication are themselves coming under increasing surveillance. This is well-recognised in the case of authoritarian states, where online communications and publications have been monitored and activists and journalists have been jailed or otherwise punished for their work. One of the most frequently-discussed examples of this is China's extensive content control system, in which large teams of paid government officials monitor blogs and other websites. All Chinese Internet users must sign in with their real names whenever they go online, even in Internet cafés (Fallows 2008; Chinese Human Rights Defenders 2009). However, it is important to recognise that this surveillance is by no means absent from democratic states. In the United States, whistle-blowers have brought attention to widespread surveillance of digital communications, including mobile phone communication, by government agencies, particularly the National Security Agency. In 2006 Mark Klein, a former AT\&T technician, brought to light evidence that AT\&T had built "spy rooms" that had the capacity for surveillance and analysis of Internet content on a massive scale (Singel 2007). Subsequently, the United States Senate under Bush voted to legalise such operations, and granted amnesty to telecommunications companies that had been involved through amendments to the Foreign Intelligence Surveillance Act (Singel 2008). This move has been supported by the Obama administration and by Judge Walker of the US District Court for the Northern District of California (Electronic Frontier Foundation 2009). The scale of this surveillance, as well as United States government responses when it was brought to light, gives reason to suppose that it is likely to continue, if not to escalate. 
Such surveillance is also taking place in other democratic nations, although usually on a smaller scale. The most radical example so far is Sweden's 2008 bill allowing the National Defence Radio Establishment to monitor international telephone and electronic communications. The bill was passed with revisions which allowed for some independent oversight, but numerous concerns remained, including the possibility that the bill would enable the monitoring of domestic, as well as foreign, traffic (Goodin 2008; Montgomery 2008). Reports in 2009 also indicated that the UK government was developing facilities for more widespread surveillance of a range of communications data, although the home secretary at the time, Jacqui Smith, denied that such a plan existed (Leppard \& Williams 2009). Laws such as these may affect not just citizens living in the states concerned, but all Internet users, as the structure of the Internet means that information often travels across the globe before reaching its destination.

Surveillance of citizens and non-citizens by governments has also been justified through law and order concerns, as is the case with London's extensive program of CCTVs (McCahill \& Norris 2002, 6). Many police programs relating to the Internet can also be seen as an adaptation of existing law and order concerns to cover new technologies. For example, investigations into child pornography rings or the blocking of child pornography websites extend existing efforts to curb child pornography, rather than introducing new concerns. Government attempts to curb "piracy" online have an uneasy relationship to these extensions of traditional law and order concerns. On the one hand, they do fit in with pre-existing copyright enforcement, which was predominantly aimed at large-scale producers of pirated material. On the other hand, they extend government enforcement (often hand-in-hand with private entities such as Internet service providers (ISPs) or the RIAA) to cover small-scale violations of copyright on an unprecedented scope. The future of these initiatives will depend upon the technical feasibility of carrying out large-scale monitoring of Internet use, as well as on responses by sections of the DLM and other concerned actors. 


\section{Corporate surveillance}

While government-mandated surveillance is worthy of significant concern, various companies are also accumulating highly personal information about those who use their services. Google, Amazon, and Yahoo, for example, all hold extensive databases on users for months, if not years. For companies which have control over a broad swathe of email services, photo management accounts, social networking sites, and blog hosts, this information can provide a detailed picture of users' lives and activities. Such databases have occasionally been accidentally breached, as in the case of America Online's release of identifiable search strings in 2006 (Kawamoto \& Mils 2006). The recent shift towards cloud computing, in which data is stored online rather than on users' computers, vastly increases the power that corporations providing such services will have to gather, store, and process information about their customers (Andrejevic 2007). Whilst the motivations for this data-gathering predominantly centre on customer service and targeted advertising, users have raised a number of concerns, including the loss of privacy associated with data breaches.

There are also serious concerns about the overlap between data-gathering by corporations and government surveillance in both democratic and authoritarian states. In 2003 and 2006, Yahoo handed over data on Li Zhi and Shi Tao to the Chinese government, which led to the subsequent arrest and jailing of the two bloggers (Blakely 2006). In the US, data gathered by a third party, for example email stored on Gmail, Google's mail service, can be requested by intelligence services under section 215 of the PATRIOT Act. Whereas a warrant is usually required to access data stored on one's own computer, the target of surveillance may be entirely unaware that their data has been accessed, as any party served with a section 215 order may neither disclose nor appeal the order (Zittrain 2008, 186). Those who use online email services, calendars, blogs, and photo services expose much of their life to such breaches of privacy. Additionally, national borders provide limited protection, as users may be subject to surveillance originating in the state where their service provider is located, as well as the state in which they live. 


\section{Protecting "intellectual property"}

The most vocal opposition has been directed at a range of measures taken to protect intellectual property. These measures have escalated in recent years, largely in response to the emergence of peer-to-peer technologies, but they are by no means new. In the 1970s, the music industry ran a campaign against cassette-taping that featured a cassette-shaped skull and the caption "Home taping is killing music" (Lessig 2004, 314). When the VCR was made available in the 1980s, Motion Picture Association of America (MPAA) president Jack Valenti said that it was "the Boston Strangler of the American film industry", and attempted to have it banned (Lessig 2004, 76). As noted above, the digitisation of culture allows copying and sharing on a far greater scale than music cassettes or VCRs ever did. Not only can an unlimited number of copies be made of any digital content, but if that content is put online it can be accessed by a wide audience. It is unsurprising, then, that the music and movie industries have increasingly sought ways to control the flow of content. As well as technical barriers to copying and sharing content discussed below, corporate lobby groups have, in tandem with some governments, made efforts to consolidate and expand existing regimes surrounding such content.

There has been a significant expansion of copyright legislation's coverage in many countries, particularly the United States. Lessig (2004, 136-139) provides an analysis of various changes to copyright legislation in the US since its first inception in 1790, including the extension of copyright to cover derivative works. Perhaps the most far-reaching changes to US domestic legislation are embodied in the DMCA, enacted by the US Congress in 1998. The DMCA was part of the Clinton Administration's attempts to ensure that the National Information Infrastructure was "made safe" for digital content, which needed to be protected from unauthorised copying and distribution (Benkler 2006, 413). The DMCA was a voluminous document with numerous provisions, among which are laws which make it illegal to circumvent technical protection mechanisms (discussed below) and laws which required online service providers to immediately remove materials deemed to be infringing copyright upon request by copyright holders (Samuelson \& Davis 2000; Benkler 2006, 414). Siva Vaidhyanathan argues that these provisions are replacing "a humanbased, democratically generated system with misplaced faith in cold, blunt 
technology" (2004a, 87). The DMCA has been the most extreme case of what Benkler calls "paracopyright" legislation (2004, 383), but the European Union and other developed states have also enacted similar legislation.

There has also been an extension of international IP regimes that were developing prior to the shift to digital media. In the 1980s the US government, along with several other leading trading nations, began to see IP as a new basis of comparative advantage, a way to meet the challenges raised by the gradual erosion of competitiveness in some traditional areas of production (Subramanian 1991, 945). Halbert follows Alford in arguing that the prioritisation of IP as a trade issue during the 1980s was a result of US government attempts to provide "a clear answer to why the United States was having difficulties in the world market" $(1999,81)$. By focusing on foreign piracy, the White House was able to place the blame for the growing trade deficit on external sources, and to simultaneously address the frustration at both piracy and legitimate competition expressed by US exporters dependent on IP (Alford in Halbert 1999, 81). The US has increasingly pushed for strong international IP protection, and has been largely responsible for the inclusion of IPR in international institutions such as the General Agreement on Trades and Tariffs (GATT), as well as bilateral agreements, such as the United States-Canada Free Trade Agreement (Halbert 1999, 79). Samuelson (1997) provides extensive documentation of the US' relatively successful attempts to incorporate its concerns into the 1996 WIPO conference's agenda, while also noting the power that TRIPS gives to firms. This incorporation of IPR into international and bilateral agreements has continued to play a large role in US trade policy. It also reflects back into US domestic legislation: instruments such as the DMCA are described by supporters as being necessary for meeting commitments made in WIPO meetings (Benkler 2004, 414), as well as being used to justify further extensions of international IP regimes in the name of harmonisation.

Several scholars have argued that current changes to national and international IP regimes do not merely represent a quantitative shift in the extent of copyright. Rather, they represent a qualitative shift in how we conceive the ownership and control of cultural content (Vaidhyanathan 2004a; Lessig 2004; Halbert 1999). When copyright and related laws were developed in Europe, and later in the 
United States and other nations, they were a way to grant a limited monopoly to "creaters, inventors, discoverers or marketers" in order to offer an incentive for innovation. Balanced against this limited monopoly was the idea that new discoveries and creative works should enter the public domain after a limited time (Vaidhyanathan 2004a, 88). The term intellectual property is a relatively new one, originating only in the last century (Vaidhyanathan 2004a, 87). Copyright and patent law were significantly different, and their incorporation under the umbrella concept of intellectual property is a relatively recent development.

The narrative that has been constructed around IP is a significant revision of the idea of copyright as a temporary monopoly. This narrative equates intellectual property with private property in its traditional sense, removing it from the realm of the public domain. In this narrative, "sharing becomes stealing. Creative work becomes private property" (Halbert 1999, 101). One of the clearest demonstrations of this was the MPAA's (2004) You Wouldn't Steal A Car advertisement, in which a voiceover says, "You wouldn't steal a car. You wouldn't steal a handbag. You wouldn't steal a mobile phone. You wouldn't steal a movie. Movie piracy is stealing. Stealing is against the law. Piracy. It's a crime." Advertisement campaigns such as this one have been accompanied by lobbying and other attempts to build the idea of creative work as private property into an unproblematic and widely accepted cultural and legal framework for IP.

As well as attempts to control the spread of creative content through legal means, industries with an interest in protecting IP have been attempting to build technological systems and devices that limit the range of uses to which they can be put. Digital rights management ${ }^{21}$ technology, software which prevents users from accessing, copying or distributing certain content, is one example of this. So, for example, if you buy a CD with DRM, you may not be able to make a copy of it on your computer or music player. If you buy a copy-protected DVD in Asia, you may not be able to play it in the US. Trusted computing, an initiative currently under consideration by sections of the music, movie, and computer

${ }^{21}$ Opponents of DRM refer to it as "digital restrictions management", but this term has not entered wide usage. 
industries, would extend the idea behind DRM to computers as a whole, stopping users from installing unauthorised software (Anderson 2003). Technical protection measures such as these are significantly strengthened by domestic and international legislation against the circumvention of copyprotection technology, including the DMCA. In addition to the ongoing development of DRM technology, there has been a shift towards "tethered appliances" which place more control in the hands of their makers than their users (Zittrain 2008), and an ongoing struggle over which corporate interests will be prioritised when it comes to the workings of the Internet itself.

\section{Controlling knowledge}

On one level, these struggles focus around particular technologies or laws. On another level, they are far-reaching and fundamental attempts that are being made to control the democratising possibilities of new technologies. Changing notions of IP, DRM, and the DMCA all work in concert to define who is considered to have legitimate access to certain information, and under what conditions. As noted in Steal This Film II (The League of Noble Peers 2007), knowledge and information has always been controlled-before the time of the Gutenberg Press, books were not only produced in limited numbers but also sometimes guarded and chained. To control others' access to this information, you only had to control their access to the actual physical artefacts that contained it. With the advent of ubiquitous digital content, it is increasingly easier to transfer information between devices. The measures discussed above limit people's ability to transfer information in an uncontrolled way, but on a more fundamental level the concept of intellectual property, as well as specific national and international IP regimes, shape the extent to which people are considered to have a right-ethically and legally-to access and share information. Debates about the conditions under which citizens should be able to access intellectual property have been largely separated from debates about government and corporate data-gathering. However, these questions belong within the same broad framework: what power do different kinds of knowledge bring, and who should have access to that power? 
Interwoven with attempts to control access to information are attempts to uphold certain groups as legitimate producers of knowledge in the face of democratising trends. The concept of "users" is important here. Benkler argues that the idea of a "user" implies "a new category of relationship to information production and exchange" $(2006,138)$. Rather than being either a consumer or a producer of software, for example, a user switches between roles, contributing to development as well as "consuming" the product. The emergence of the idea that laypeople can be producers of knowledge has been lauded in some corners and heavily criticised in others. Establishing the necessity of user access to information and control over technology requires, at some level, an understanding that users have valuable contributions to make. Activists within the DLM must continually reinforce the idea that the videos, source code, music, mashups, and so on that are produced by amateurs are worth saving, despite the harm that it may cause to more well-established producers (including academics, the movie and music industry, journalists, and other accredited sources). Benkler argues that today, "proprietary, market-based models of information production compete with those that are individual, social, and peer produced" (2006, 382). For example, Microsoft's Windows and Encyclopaedia Britannica compete with Linux and Wikipedia. Is accepted knowledge-be it a line of software code or an encyclopaedia entry-to be decided by companies, by small groups of experts, or by peer review? Lessig (2004) provides another way of thinking about this: as a struggle between a mode in which the ability to produce and distribute cultural content (such as films, music, software and novels) is controlled by an oligopoly, and one in which everyone has the right to do so.

As is the case with many of the issues addressed by social movements, governments play a contradictory role, being appealed to by both activists and entrenched elites. As discussed above, the US government has primarily aligned itself with the interests of established industries, and has sought to cement its own control over ICTs in a number of ways. However, it has at times supported activists' positions, as when President Obama declared that he "remain[s] firmly committed to net neutrality [discussed below] so we can keep the Internet as it should be-open and free" (2009). The EU has also taken 
some steps which activists may find heartening, including the development of an Open Source Observatory to support open source software development (Battistoni 2008). Governments in the Global South also have a complex role in relation to these issues. While on the one hand many have shown a willingness to use ICTs for censorship and surveillance (as have many democratic states), their stance on copyright has been more complex. Some states, such as Iran, have refused to join international IP regimes, while others have been unwilling or unable to enforce IPR. The role of national governments in the struggle over ICTs therefore remains contested, with multiple forces within and outside of government attempting to shape their approach to the issues discussed in this chapter.

\section{Section three: the emergence of the digital liberties movement}

This section returns to a more detailed discussion of the emergence of the DLM, exploring its roots in previous movements and communities and landmark struggles. Many of the values and ideas which define the DLM show a clear lineage from hacker communities, the free culture movement, and the F/LOSS movement. These values and ideas include an emphasis on the importance of user control over technology and on freedom (predominantly defined with reference to the US political system). These communities and movements overlap with the DLM, and have contributed leading digital liberties activists to the DLM. After exploring the roots of the DLM, this section moves on to outline landmark struggles in the emergence of the DLM, explaining the ways in which these struggles have defined the movement.

\section{Roots in previous movements and communities}

The DLM, like many other movements, has been created from the enmeshment of various other movements, organisations, campaigns, and individuals. These include free culture groups, the F/LOSS community, hacker culture, (online) civil liberties groups, media activists, and others. It also includes a great number of people who have participated in a single action, or in a few scattered actions. Academics have played a significant role within the movement, as they do in many social movements either in a capacity separate from their academic work 
or through this work itself. Although there are methodological difficulties in ascertaining to what degree this is the case, my sense is that academics play an even larger role in the DLM than they do in most other movements. This is in part because the movement's focus on the technical infrastructure of computers and the Internet, and on IP, invites participation from those with tertiary qualifications in either law or computer science, and those with the time and resources to research these issues. Additionally, academics have a vested stake in debates over access to information and debates about how knowledge is produced, as both "producers" and "consumers" of research.

As noted in the Introduction, this needs to be taken into account in analysing the movement. For example, Lessig's Free Culture is a scholarly work by a respected academic, and can be studied from that perspective. In the context of Lessig's activism, however, including the battle over the Sonny Bono Copyright Extension Act that he describes in the book and played a key role in, it is simultaneously a piece of movement literature which aims to convince and involve the reader. Similarly, Vaidhyanathan writes that he is an activist with specific goals in mind: "I want to keep these [online peer-to-peer music-sharing] channels open and the music flowing, and I want to change the terms of the conversation that has dominated the accounts of the phenomenon" (2004a, 61). Additionally, as Vaidhyanathan notes, academics who take part in filesharing and are part of the DLM have a privileged status, in that their work is to debate and think about issues $(2004 a, 62)$. Academics are skilled at phrasing their arguments, and academic careers these days are geared towards a constant stream of publications. As such, academics have a privileged position not only in terms of having the time and skills to formulate their arguments on topics like filesharing, but also in that they are well positioned to take on a public role as chief propagandists for the movement.

Although civil liberties activists, academics, and artists play a significant role in the movement, its background in the F/LOSS community and hacker culture has probably been most formative, and hence requires some further exploration. Many of the participants, values, and organisational strategies of the DLM have either come from or overlap with hacker culture and the F/LOSS 
movement. Understanding the DLM therefore requires some understanding of hacker culture, as well as of the F/LOSS movement.

\section{Hackers}

There are many myths that surround hacker culture, and even the word hacker has different meanings in the context of computer culture, law, and other fields. It is not my intention to get into the minutiae of either the history of hackers and hacking, or the debates that surround this history and the activity itself ${ }^{22}$. It has become almost mandatory to protest against association of hacking with malicious and illegal online behaviour, including computer crime and computer intrusion, labelled "cracking" rather than hacking by many (Jordan \& Taylor 2004, 5; Castells 2001, 41; Himanen 2001). As Sterling notes, hackers "come in a variety of odd subcultures, with a variety of languages, motives and values" (1992), and I do not intend to get into an ethnographic classification of hacker subcultures. These communities, behaviours and identities overlap, and such a dissection is not relevant to this work. What is important is the way in which ideals and norms developed in the hacker community have carried through from this culture into the DLM.

It is relevant, in building an understanding of hacker culture and its influence on the DLM, to trace its emergence back to the movements of the 1960s and 1970s, which it grew out of and co-evolved with. Sterling argues that "the genuine roots of the modern hacker underground can be traced to a now muchobscured hippie anarchist movement known as the Yippies", a movement led (insofar as it had a leader) by Abbie Hoffman whose "basic tenets were flagrant sexual promiscuity, open and copious drug use, the political overthrow of any powermonger over thirty years of age, and an immediate end to the war in Vietnam, by any means necessary, including the psychic levitation of the Pentagon" (1992). The Yippies began their involvement with the world of hacking by making extensive use of the phone system for agitation work, and argued that by denying the federal government the tax charged for phone calls they were engaging in civil disobedience, refusing to support the US government's war in Vietnam (Sterling 1992; Jordan \& Taylor 2004, 13). From

\footnotetext{
${ }^{22}$ For a classic history of the topic, see Levy's Hackers (1984).
} 
here, the Yippies moved towards a more radical and thorough engagement with the telephone system.

This was done in large part through publications that made hacks of the phone system more widely available. In 1971 the Youth International Party Line newsletter, an underground publication put out by those associated with the Yippie movement, changed its name to the Technological American Party $(\mathrm{TAP})^{23}$, and began to provide "detailed technical information, predominantly about how to phone-phreak (obtain free phone calls through the technical manipulation of the phone system)" (Jordan \& Taylor 2004, 14). Over time, TAP shifted towards a technical, rather than political, focus, and when it ceased publication in 1984 its mantle was taken up by the "phone-phreak/hacker magazine 2600" (Sterling 1992; Jordan \& Taylor 2004, 14). In some senses, what was once an overtly political movement transformed into a movement that revelled in technical power. However, traces of the Yippie influence and a political stance remained. For example, the pseudonym adopted by 2600's editor, Emmanuel Goldstein, is the name of the protagonist in Orwell's 1984 (Jordan \& Taylor 2004, 14). This background is important, not only for the political overtones the association bought to the movement, but also because it helps in understanding that hacking is not necessarily something that only takes place on computers, or on the Internet.

There are many competing definitions of who should be considered a hacker. Jordan and Taylor get around the issue by defining a hacker as anyone who performs "hacks"- uses of technology that are "original, unorthodox and inventive", building on Turkle's description of hacks as uses of technology that are "simple, masterful and illicit" (Jordan \& Taylor 2004, 6). This is the original use of the term hacker, from the early days of computer use at American universities, particularly MIT. This use of the terms hack and hacker remains in common use. MAKE magazine's online blog, for example, frequently refers to ways to "hack" children's toys, coffee machines, baby perambulators and other non-computer technologies in order to perform unusual feats with them, or in order to circumvent prescriptive limits put in place to intentionally "cripple" them. MAKE's Owner's Manifesto declares that "If you can't open it, you don't own it"

23 Or Technical Assistance Program, according to Sterling (1992). 
(Mr. Jalopy), which has a conscious resonance with the traditional hacker perspective.

Hacker communities have made a number of important contributions to the DLM. The first of these is the idea that users should have control over the technology which they use, rather than technology controlling users. Activists within the DLM apply this to a wide range of technologies and spaces, as we will see below. Secondly, communities and individuals heavily involved in hacking have played a role in forming the DLM and continue to be active within the movement. Richard Stallman, one of the founders of the free/libre software movement discussed below and a paradigmatic hacker, contributed the idea of the copyleft license, and remains active and influential within the movement. Similarly, one attendee at the last Hackers on Planet Earth Conference noted that the hacker community present at the conference displayed an interest in issues related to digital liberties, including "copyright [...] The Freedom of Information Act (FOIA), censorship, [and] the Digital Millennium Copyright Act (DCMA)", and were interested in developing links with other communities (Abbott 2008). There are also a number of other threads common to hacker culture that run through the DLM, including an oppositional attitude towards corporations.

\section{The free/libre and open source software movement}

Many scholars of and participants in online cultures see the F/LOSS movement as a subset of hacker culture, or as an overlapping movement or community. Either assessment is fair, depending on how each is defined. The F/LOSS community centres around the development and dissemination of free/libre or open source software, in opposition to proprietary, non-free or closed software. The Windows operating system is an example of proprietary software. You have to buy it, it is illegal to copy to it, and you cannot legally see or modify the source $\operatorname{code}^{24}$ on which it runs. In the case of proprietary software, you are

\footnotetext{
${ }_{24}$ Machine code is the most basic level of code, and is expressed digitally and numerically. It is very difficult and time consuming to write or read, although in the early years of hacking programming was done directly with machine code. Source code is a step above machine code-it is written in a variety of "highly abstracted languages [which] use a formalized syntax and are usually constructed around simplified English keywords. Together with symbols and punctuation, programs are written in a structured syntactical style made up of statements, loops and conditionals to construct the logical operation of the program." Source code needs to be compiled into machine code to be read and executed by a computer.
} 
supplied with an "executable"-a file with a exe extension-that is not in the more easily comprehensible form of source code. Although it is possible to reverse-engineer the source code from this, "it is complex, time-consuming, and usually illegal" to do so (Berry 2004, 67). In contrast, F/LOSS is licensed under the GNU General Public License (GPL) and other copyleft ${ }^{25}$ licenses which allow users to see the source code and change it, and to use and redistribute the software for free. This attempt to describe F/LOSS may give some hint as to why the movement has, until recently, been the province of hackers and others comfortable with computing technology and jargon.

In recent years, however, there has been a move towards making F/LOSS more accessible, adding to its significant popularity in technical circles. While the spread of F/LOSS for specialised uses such as web servers is notable (Moody 2001, 129; Wheeler 2005), the use of F/LOSS in ubiquitous software is likely to be more important. For example, several F/LOSS web browsers have been developed, and are gaining popularity. Mozilla's Firefox has made significant inroads into the browser market, having over 20 per cent of the usage share as of May 2009 (Wikipedians 2009c). Open Office, a F/LOSS alternative to Microsoft Word, was estimated to have 11 million active users in the US alone in March of 2009 (Asay 2009). Linux ${ }^{26}$, which in 2001 could reasonably be described as "too complicated to use" for most individual users and without a simple (graphical) user interface (Castells 2001, 46), now comes in several user-friendly flavours ${ }^{27}$, most notably Ubuntu, the motto of which is "Linux for human beings". Additionally, the development of a child-friendly, Linux-based operating system for the One Laptop Per Child (OLPC) project, intended for distribution in the Global South, has been an important milestone. Although the OLPC project has foundered somewhat in recent years, it inspired a number of low-cost netbooks which cost under AU\$500 and frequently run on customised flavours of Linux that lower costs. While users and institutions may often adopt

Source code files also frequently contain explanatory notes written by programmers to allow others to understand their work (Berry 2004, 67).

25 A term coined by Richard Stallman to denote a license that is "more anti-license than anything else", enforcing sharing of code rather than its restriction (Wayner 2000, 5).

26 Linux is referred to as GNU/Linux by Stallman and the FSF, who argue that Linux's base in the GNU operating system should be recognised in its name. I use the term "Linux" for simplicity rather than to indicate any partisanship on this issue.

27 Different versions of Linux are usually known as "flavours". 
F/LOSS for pragmatic reasons, as adoption grows it frequently brings with it exposure to some of the ideals behind the F/LOSS movement.

The distinction between free software and open source software is based on what some see as a relatively minor ideological difference, while for others it is a major point and a centre of vociferous disagreements. A common phrase in the F/LOSS movement is that free software is "free as in speech, not free as in beer". The GPL specifies that licensees may not prevent others from accessing their products for free, but may charge a fee to cover the costs of distribution (Chiao 2003, 3). Richard Stallman's GNU Manifesto sets out four freedoms for free software (Stallman in Wayner 2000, 84):

Freedom 0: The freedom to run the program, for any purpose.

Freedom 1: The freedom to study how the program works, and adapt it to your needs.

Freedom 2: The freedom to redistribute copies so you can help your neighbour.

Freedom 3: The freedom to improve the program, and release your improvements to the public, so that the whole community benefits.

This emphasis on "free as in speech", with all the associations attached to the word "free" (particularly in the US context) is something that Stallman and the FSF have deliberately clung to.

For Stallman and other proponents of free software, the meanings attached to "free" reinforce their commitment to free software for reasons that are political and moral, not merely technical. To those on this side of the free versus open debate,

The word "free" is ... about a way of life. The folks who write the code throw around the word in much the same way the Founding Fathers of the United States used it. To many of them, the free software revolution was also conceived in liberty and dedicated to certain principles like the fact that all men and women have certain inalienable rights to change, 
modify, and do whatever they please with their software in the pursuit of happiness (Wayner 2000, 78).

For some, this approach is absolutely vital to a meaningful commitment to free software. For others, it adds an unnecessary political dimension to an essentially technical issue.

Those who support the open source software position emphasise the technical, rather than moral and political, benefits of F/LOSS. Torvalds writes:

there are enormous benefits to be gained by opening up one's technology and making it available under the same terms as Linux and a host of other inventions. To get a glimpse of those benefits, all you have to do is just look at the comparatively low standards of quality of any closed software project. The GPL and open source model allows for the creation of the best technology. It's that simple (Torvalds \& Diamond 2001, 194).

Eric Raymond puts it this way:

Perhaps in the end the open-source culture will triumph not because cooperation is morally right or software "hoarding" is morally wrong (assuming you believe the latter, which neither Linus [Torvalds] nor I do), but simply because the closed-source world cannot win an evolutionary arms race with open-source communities that can put orders of magnitude more skilled time into a problem $(2000,23)$.

Open source programming is better, according to this viewpoint, simply because it produces better software, measured against technical standards.

Despite the occasional sniping from either side, advocates of both approaches, including the 'grandfather' of free software and Linux's 'benevolent dictator', stress their willingness to cooperate with each other. Stallman writes: 
The relationship between the Free Software movement and the Open Source movement is just the opposite of that picture [of a conflictual relationship]. We disagree on the basic principles, but agree more or less on the practical recommendations. So we can and do work together on many specific projects. We don't think of the Open Source movement as an enemy. The enemy is proprietary software (Stallman 2005).

While Linus Torvalds does not entirely agree with Stallman's perspective, he does say that Stallman "deserves a monument in his honor for giving birth to the GPL" (Torvalds \& Diamond 2001, 194). Open source advocates also frequently, if not necessarily consciously, demonstrate a political or ethical reasoning for their support for open source software, as in the case of Torvalds' equation of the open source software model with democracy (Torvalds \& Diamond 2001, 230). While it is therefore useful to take note of the difference between the free software and open source software positions, it is important to bear in mind that the boundaries between the two are blurry.

The F/LOSS movement overlaps with and feeds into the DLM, and has inspired many of its activists. For example, Lessig writes in the preface to Free Culture that much of the inspiration for the book came from the work of Richard Stallman and the Free Software Foundation; "Indeed, as I reread Stallman's own work [...] I realize that all of the theoretical insights I develop here are insights Stallman described decades ago" (2004, xv). There are four important aspects in which the values of the F/LOSS movement are reflected and reinforced in the DLM. The first of these is the priority placed on users' access to and control over the technologies that they use, in this case software. The GPL emphasises not only the ability to access software, but also to adapt it where necessary. The second important aspect is the value placed on peer evaluation of knowledge and the contributions of amateurs. While most F/LOSS is nominally controlled by a developer team, or an individual who decides which suggested improvements to include in future versions, anyone can critique and develop the source code. F/LOSS advocates argue that this is ideologically and/or technically preferential to a model of software development that relies on accredited experts. Thirdly, there is a strong sense of both the importance of the individual and the value of community. The freedom repeatedly referred to is 
heavily influenced by the US model of liberal democracy and its individualist ideals. At the same time, the GPL embodies an acknowledgement that individuals benefit from and have a responsibility to contribute to the community. Finally, the split between the the free/libre perspective and the open source approach is illustrative of a broader tension within the DLM between approaches that prioritise technical considerations and those that are more willing to engage with debates about the political consequences of technology.

\section{Landmarks in the emergence of the digital liberties movement}

Movements are built both through the slow process of dialogue and networking, and through the connections made through protest. There have been a number of issues that have served as rallying points for the DLM. Some of these have involved protracted campaigns, while others have been swift protests which were resolved rapidly. These cases illustrate the key modes of contention employed by digital liberties activists. While in most of these struggles activists have relied heavily on institutionalised modes of contention, particularly lobbying and legal challenges, direct action has been used repeatedly and effectively. These cases provide multiple examples of activists using technological solutions to sidestep legal barriers to sharing information. Following a brief outline of each landmark case, I will use these examples to explore recurring themes within the movement in more detail, including the importance of user control over technology, the need to protect amateur production, and the links made between democratic principles and issues related to copyright and code.

\section{Eldred vs. Ashcroft}

In 1998, the US Congress extended the terms of existing copyright for the eleventh time in 40 years, by 20 years. Eric Eldred, who had been planning to publish various works that were due to enter the public domain, announced that he would publish as planned, despite the extension of copyright on these works. His intentions were stymied by the passing of the 1998 No Electronic Theft Act by the US Congress, which meant that publishing would have made Eldred a felon (Lessig 2004, 215). Lawrence Lessig was among those who decided to challenge the Sonny Bono Copyright Term Extension Act (CTEA) on the basis 
that repeated extensions of US copyright act created a perpetual copyright, rather than the limited copyright specified in the US Constitution.

Ultimately the case was lost, but despite this it has become an important moment in the history of the DLM. Lessig's description of the case in the latter part of his 2004 book, Free Culture, emphasises the breadth and depth of support that the team drew on. As well as support from academics, libraries, five Nobel Prize-winning economists, and lawyers of various stripes, the team also garnered assistance from Hal Roach Studios and the Eagle Forum (Lessig 2004, 231-233), a conservative and pro-family group (Eagle Forum 2008). Lessig recognises the importance of the case, writing that, "[t]he night before the argument, a line of people began to form in front of the Supreme Court. The case had become a focus of the press and of the movement to free culture. Hundreds stood in line for the chance to see the proceedings" (2004, 237-238). The case's importance is also emphasised by others within the DLM, including Vaidhyanathan (2004b). Unlike in the cases of the DeCSS code, the 09F9 key, and the Grey Album, discussed below, this fight was decisively lost. There is, however, a sense within the movement that while the CTEA was upheld, the larger struggle over copyright terms continues.

\section{DeCSS}

In 2000, a small group of hackers created a program that would allow users to circumvent the content scrambling system (CSS), a form of DRM that was created to prevent unauthorised access to DVDs. The program, called DeCSS, or Decrypt Content Scrambling System, allowed the hackers to play DVDs on their computers, which ran Linux. 2600: The Hacker Quarterly published several articles on DeCSS, and included the code in the text. After complaints from the movie industry, 2600 was forbidden from publishing information on DeCSS. Instead the editor, Corley, writing as "Emmanuel Goldstein", linked to other sites that ran the code. The judge followed by issuing an injunction against such linking. The court eventually ruled that the right to free speech was not sufficient to protect Corley and he was not allowed to publish the code or links to the code (Lievrouw 2003, 8; Vaidhyanathan 2004a, 70-72). At least in court, the battle was over by 2001. 
Activism around the DeCSS code took a number of forms. Corley's willingness to publish the code and defend himself in court was notable, but perhaps more important was the surge of support that rapidly built up around him. The DeCSS code was disseminated around the web and through peer to peer networks. It remains available at the time of writing. Reasoning that works of art are covered by First Amendment speech protections, David Touretzky (2000) and other supporters of Corley set up on online gallery of works incorporating the code. The gallery features versions of the code represented within haikus, t-shirts, dramatic readings, songs, and yearbook pages. While the court was successful in banning publication of the code in 2600 , they were completely ineffective in preventing the spread of the code and easy access to it.

\section{Diebold Election Systems vs. the Internet}

In 2003, an activist researching electronic voting machines, Bev Harris, found a site that stored thousands of files on how the Diebold electronic voting machines worked. These files provided information that allowed Diebold machine passwords to be bypassed, which was worrying given the use of the machines in US elections. Harris published her findings in an online magazine called Scoop, and later published an analysis of the discussions that had taken place around the files. A large number of internal emails were also leaked from Diebold to Wired magazine, as well as to Harris, who published them on her website. Diebold responded by claiming that the emails were under copyright, and demanding that Harris, her ISP, and a number of other sites remove them, an order which was complied with. University students throughout the United States began storing and analysing the emails, and continued to do so until they, too, were required to remove them by Diebold's invocation of provisions of the DMCA (Benkler 2006, 227-229). As in the case of the DeCSS code, it rapidly became clear that it would not be possible for Diebold to put the cat back in the bag. 
Benkler recounts the multipronged campaign that the students then engaged in:

First, they kept moving the files from one student to another's machine, encouraging students around the country to resist the efforts to eliminate the material. Second, they injected the materials into FreeNet, the anticensorship peer-to-peer publication network, and into other peer-topeer file-sharing systems, like eDonkey and BitTorrent. Third, supported by the Electronic Frontier Foundation, one of the primary civil-rights organizations concerned with Internet freedom, the students brought suit against Diebold, seeking a judicial declaration that their posting of the materials was privileged. They won both the insurgent campaign and the formal one $(2006,31)$.

The success of this campaign is clear: the materials remained online throughout the case, and ultimately the legal case was won.

\section{Grey Tuesday}

In 2004 Brian Burton, working as DJ Danger Mouse, created a mashup of the Beatle's White Album and Jay-Z's Black Album, called the Grey Album. Jay-Z had offered up a capella versions of all of his tracks on vinyl for remixes, but EMI/Capitol, which owns the rights to the White Album, was less open to experimentation and served Burton with a cease-and-desist order (Mason 2008, 97). Burton has said that he did not undertake the project with intentions of making a statement about copyright law, but was just trying to "make an art project" (Rimmer 2007, 133). This explains his rapid cooperation with EMI/Capitol. This cooperation was not enough to get Burton off the hook: Sony, which owns the Beatles' composition rights, also threatened legal action (Mason 2008,97 ). Burton may have been willing to cooperate with the demands made by these companies, but a number of activists (and hitherto uninvolved individuals) were less malleable.

On February $24^{\text {th }} 2004$, thousands of users were involved in a protest called Grey Tuesday, in which they defied the cease-and-desist letters by downloading the Grey Album. At least 170 websites hosted the album for download, and 
many of the owners kept the album online despite receiving cease-and-desist letters themselves (McLeod 2005, 80). Downhill Battle, a music activism project, organised the protest, and set up a website to publicise it. On the site, Downhill Battle (2008) argue that "the attempt to censor this record is one of the most clear-cut examples of what's wrong with current sampling rules", and that major record labels "use copyright in a reactionary and narrowly self-interested manner that limits and erodes creativity". Activists were protesting the fact that copyright law was being used to prevent amateurs from sampling and remixing music. This activism has ensured that the Grey Album has remained available, as well as a number of similar remixes inspired by Grey Tuesday.

\section{F9}

In 2007 there was another highly visible protest around DRM, this time about the sharing of an encryption key known as 09F9 that facilitated the breaking of restrictions on sharing high definition DVD content. Digg, a popular website for aggregating users' website recommendations, received a cease-and-desist letter from the Advanced Access Content System Licensing Authority and the MPAA demanding that Digg take down links to sites with the 09F9 key. Users immediately revolted, repeatedly posting the key to the front page of the site (Felten 2007b). The key was also posted to other sites in numerous forms, including on t-shirts and as songs (Felten 2007a). Digg founder Kevin Rose capitulated but, as in the case of the DeCSS code, the 09F9 key remains available.

\section{Net Neutrality}

Unlike in the case of the Grey Album, DeCSS code, and the 09F9 key, the campaign around Net Neutrality is long-running and ongoing. Currently, the Internet has been designed so that most of the processing involved in the network is done by computers accessing and (re)transmitting information, rather than by the infrastructure at the heart of the network, and all packets of information are treated equally. Those in favour of Net Neutrality argue that this model should be protected, and that ISPs should not be allowed to prioritise some users' traffic over others'. Their opponents argue that it should be up to ISPs to decide what kind of service to provide, and that the government should 
not "restrict innovation" by regulating the Internet (NETCompetition.org Q\&A). There have been a number of important legislative moments in this debate, including the 2002 US Federal Communications Commission (FCC) classification of Internet services as "information services", meaning that certain non-discrimination requirements would not apply to cable Internet services (Esbin 2008, 1), and the 2006 inclusion of the Net Neutrality concept by the FCC in the agreement that allowed AT\&T to buy BellSouth (Public Knowledge 2008). Each of these moments have been accompanied by significant lobbying by both opponents and proponents of Net Neutrality.

There are a number of groups working on the Net Neutrality campaign at the moment, and there has also been significant activism by individual Internet users. Public Knowledge is involved in activism around the Net Neutrality issue, as well as in copyright activism. Their involvement includes providing a list of relevant US legislation, including draft bills, listing important court cases underway, assisting in such court cases through amicus briefs, providing campaign material (such as information sheets and press releases), and filing briefs (Public Knowledge 2008). The Save the Internet coalition engages in similar activities, and their website encourages visitors to donate, sign petitions, call members of Congress, and spread awareness (Save the Internet 2008). The Open Internet Coalition engages in lobbying, issues press releases, and provides educational resources for site visitors (Open Internet Coalition 2008). A wide variety of others have also been involved. The Ask A Ninja website, for example, produced a popular video in 2006 that (roughly) explained the concept of Net Neutrality, and encouraged viewers to visit the Save the Internet website to find out more and get involved. Both the formal lobbying and more informal grassroots organising and awareness-raising have played important parts in this ongoing campaign, and seem to have achieved some success. In September 2009, President Obama's appointee to the chair of the FCC, Julius Genachowski, announced that legislative steps needed to be taken to preserve the open nature of the Internet (Genachowski 2009). The principles outlined by Genachowski, and his appointment itself, are promising signs for Net Neutrality activists. 


\section{Anti-Clean Feed activism in Australia}

In mid-2008, the Australian federal government declared that it was looking for ways to make the Internet "safer, particularly for children" (Conroy 2008), delivering on pre-election promises to "take the lead on cyber-safety" (Electronic Frontiers Australia 2008). Although the details were unclear at that stage, initial trials of a filtering system by the Australian Communications and Media Authority covered material that was "inappropriate", as well as illegal. Activism around the issue began swiftly, with a number of organisations and individuals joining the fray.

Activism against an Australian Clean Feed took a variety of forms. Established civil liberties groups, particularly Electronic Frontiers Australia, which established the No Clean Feed campaign. The website for this campaign encourages visitors to contact the Minister for Broadband, Communications and the Digital Economy, Senator Stephen Conroy, as well as to contact other Members of Parliament and ISPs. The website also urges visitors to sign a petition. Other organisations have engaged in similar protests, including Australians Against Internet Censorship, which offers guides to letter-writing and petitions as well as links to protests, t-shirts, posters and flyers. More unconventional tactics have also been used, including NetAlarmed's satirical site, the creation of two Twitter feeds, the defacement of the Federal Government Classification Board's website (Moses 2009), and the creation of the Digital Liberty Coalition, which aims to oppose the Clean Feed through the use of "direct action and guerrilla marketing" (Digital Liberty Coalition 2009). A number of Australian and international bloggers have also written about the feed and posted buttons protesting it on their sites.

While the activism around the Clean Feed has certainly played a role in raising the profile of the issue, problems with implementation may ultimately end up being the deciding factor in scuppering the idea. Targeted content has come under repeated criticism, as the Clean Feed blacklist has at various times included a dentist's website, photography by artist Bill Henson, pro-euthanasia websites, and anti-abortion websites (Moses 2009). There are also technical issues with the plan, including doubts as to whether it could effectively target 
the most egregious material and whether implementation of the plan would degrade performance for Australian Internet users (Electronic Frontiers Australia 2009). There are now signs that Senator Conroy is backing down on the plan, including his recent statement that if it is implemented it may be voluntary (Colley 2009).

\section{Pirate Bay trial}

In February 2009, Swedish prosecutors filed charges against four people involved in The Pirate Bay: Gottfrid Svarthold Warg, Peter Sunde, Fredrik Neij, and Carl Lundström. The four were charged with "promoting other people's infringements of copyright laws" (Kravets 2008), as The Pirate Bay website makes links available to torrent files of copyrighted material. Some of the charges laid against the defendants were dropped swiftly, but in April 2009 they were found guilty of the remainder of the charges and sentenced to one year in jail and a total of SEK30 million, or around AU\$4.8 million, in fines. Both the defendants and the prosecutors appealed the verdict, and these appeals are currently being processed.

Activism around the trial has been so intense that many commentators have called the initial guilty verdict a Pyrrhic victory (Kiss 2009; Thompson 2009). The most notable demonstration of support has been the increase in support for the Swedish Piratpartiet, which has 49,841 members at the time of writing (Piratepartiet 2009), up from around 15,000 before the trial began (Sjoden 2009). While the Pirate Bay and the Piratpartiet have no official relationship, the Piratpartiet was at the time the only political party taking a strong stance on filesharing. The increased support for the Piratpartiet in the wake of the Pirate Bay trial enabled the party to win their first seat in the European Parliament in the 2009 elections. There were also other manifestations of support, including distributed denial of service ${ }^{28}$ attacks on the website of the International Federation of the Phonographic Industry, which supported the trial, and a "pizza delivery attack" (multiple pizza delivery orders) on their headquarters (illunatic 2009; Leyden 2009). Hundreds of people protested in cities around Sweden

${ }^{28}$ Distributed denial of service attacks are repeated attempts to access a website from multiple computers at the same time, which overwhelms the server and temporarily shuts down the website. 
against the guilty verdict (Nordstrom 2009). Information on other forms of protest against the trial is being collected on The Pirate Bay's blog, including calls for people to return all their music and videos to companies and promise not to buy any more (Kopimi 2009). As well as failing to slow either the Pirate Bay or filesharing more generally, this trial served to increase activism around the issue.

\section{Common themes}

The focus in each of these cases has largely been on IP law and the technological means of enforcing it. Activism is also emerging around issues of surveillance and censorship, not only in the cases discussed here but also in the UK, Denmark, Sweden, Iran, China, and other countries. However, the struggles mentioned here have played a particularly emblematic or formative role. DeCSS was one of the first widespread revolts against DRM, and in combination with the 09F9 protests and Grey Tuesday illustrates one of the movement's primary tactics: the use of the Internet and peer-to-peer networks to ensure access to information, often illegally. The analysis and dissemination of material on Diebold Election machines not only provided a clear connection with the mechanisms of democracy, but also demonstrated the potentially stifling effects of the DMCA. Eldred vs. Ashcroft has been a rallying-point for free culture groups around the world. The Australian campaign against the Clean Feed and the Swedish Pirate Bay trial have both showed emerging nonUS loci of activism. The benefits of the Swedish trial for the Piratpartiet have pointed to emerging links between the DLM and conventional politics, as happened with the environmental movement and Greens parties in previous decades. Finally, the issue of Net Neutrality may be the most important in determining the future of the Internet. Analysis of these struggles allows us to draw out some common threads which tell as more about the DLM as a whole.

Most of the above-mentioned protests have attempted to highlight the political aspects of an issue previously conceived of as primarily technical in nature. In the case of the 09F9 revolt, Edward Felten notes that people participated in part as a reaction to what they saw as censorship, a concept which a decade ago may have seen as absurd when applied to a number (Felten 2007b). On the 
DeCSS gallery, the issue of access to the code is framed in terms of freedom of speech, with the curator writing that the gallery was put together in order to highlight "the absurdity of Judge Kaplan's position that source code can be legally differentiated from other forms of written expression" (Touretzky 2000). Similarly, activists involved in Grey Tuesday framed their protest in terms of protecting freedom of speech-preventing the censorship associated with DMCA takedown notices, as well as freedom to "cut and paste" existing cultural content into new messages (Downhill Battle 2008). In the case of the Diebold machines, activists took what was considered to be an uncontroversial upgrade to voting procedures and turned it into a debate about citizen oversight into the voting system. Lessig (2004) spends much of his analysis of Eldred vs. Ashcroft lamenting his approach to the case, arguing that his focus on the US Constitution's provision for limited terms of copyright lost the case, where a clearer focus on the political harms done by copyright extension (which he believed were obvious) would have been more effective. Finally, Net Neutrality activists continually highlight the political aspects of the Internet's structure; the Save the Internet coalition argue that an open and non-discriminatory structure is "the reason why the Internet has driven economic innovation, democratic participation, and free speech online" (Save the Internet 2008). Together, these protests and campaigns have been part of the DLM's attempt to understand, publicise, and shape the political effects of information technology.

These cases also highlight the value placed within the movement on the contributions of amateurs and the need to protect access to ICTs for those with relatively few resources. In the case of Eldred vs. Ashcroft, digital liberties activists were fighting for the right of those outside large content industries to publish and build on the stock of work that composes our culture. Those who participated in Grey Tuesday were arguing that amateurs and musicians working outside the bounds of big record labels needed to be able to draw on samples of other music in order to create remixes, mashups, and other new work. Finally, the fight for Net Neutrality emphasises the importance of equal access for all to the Internet, including those without the resources to pay for higher visibility or quicker load-times for their web pages. A vital part of the DLM's work is the attempt to preserve spaces and resources for amateurs and others with limited resources to make their voices-and music-heard. 
The ways in which the DLM carries out this work is frequently surprising. Analysis of these protests also reveals an unexpected development in the movement's contentious repertoire. The movement's gestation through websites, the technical skills of many participants, and the orientation towards online activities would suggest the adoption of hacktivism of the sort described by Jordan and Taylor (2004) and Wray (1998) as a key tactic, but this has not, on the whole, eventuated. Instead, many of the movement's most visible protests have predominantly taken place through the authorised channels for democratic dissent. Many of the above-mentioned struggles have involved lawsuits, and in the case of the more protracted campaign over Net Neutrality, visitors to the Save the Internet website are urged to call their members of Congress. The focus on institutionalised dissent is not particular to the protests and campaigns mentioned here; regular calls to action on Boingboing, for example, request that Boingboing readers contact their local representatives (Doctorow 2009a, Doctorow 2009b). Similarly, the EFF, FFII, and Public Knowledge are all involved in lobbying and lawsuits, rather than direct action. As with all social movements, the DLM encompasses actors that engage in both institutionalised and more radical forms of dissent.

DLM participants do take part in a number of protests and direct actions, although these do not always take forms that would be familiar to scholars of social movements. On the more familiar end of the spectrum, there have been a number of marches and protests, although these have tended to gain little attention in the media and have not garnered significant participation. Less recognisable is the ongoing mass campaign of civil disobedience, in which movement participants break copyright, share files, remix cultural content, and modify their hardware or software in order to sidestep restrictions on the uses to which it can be put. Outside of the movement, these activities are rarely understood as civil disobedience, in part because they do not follow the model of recognised forms of civil disobedience, such as Rosa Parks' refusal to move to the "coloured" section of the bus or the Gandhian satyagraha that was central to the Indian Independence struggle. However different filesharing or posting a few numbers and letters to a site may appear to be from the protests of the 
American civil rights movement and the Gandhian satyagrahis, it is clear that it can be (and is) understood as a new incarnation of this familiar tactic.

Many of those who engaged in the 09F9 revolt and other movement protests clearly vocalised their moral objections to the laws concerned, and framed their activities in terms of civil disobedience. Felten writes that in addition to the desire to resist censorship, Digg users posted the 09F9 key because "Giving a private party ownership of a number seems deeply wrong to people versed in mathematics and computer science" (Felten 2007c). Kembrew McLeod, an academic-activist who took part in Grey Tuesday, writes that he "engaged in this act of copyright civil disobedience" in order to promote dialogue on these issues $(2005,80)$. Some of those involved in filesharing also situate their activities within the framework of civil disobedience, as commenter "mb_webguy" does on The Pirate Bay's blog:

Some call use "pirates", but we're not villains. We simply recognize that communication is natural, and that information cannot be contained. We may be criminals, but only in the light of unjust laws. We continue to act according to our consciences in civil disobedience of these unjust laws, in the tradition of Gandhi and Martin Luther King, Jr., until the day that our governments see the futility and foolishness of intellectual property laws. Vive le résistance! Vive le Pirate Bay! (mb_webguy 2009).

No doubt many would dispute this argument, noting important differences between filesharing and more familiar forms of civil disobedience, including the frequent anonymity of filesharers. Nevertheless, claims by users that they are engaging in civil disobedience, and the debates that frequently follow, are part of the process of adapting civil disobedience to the use of new technologies, and developing a wider understanding of what the DLM is and how it will pursue its goals.

The array of different strategies, tactics, individuals and organisations involved in these struggles is a concrete illustration of the diversity of the DLM. All social movements are made up of actors with differing affiliations, ideologies, and contentious repertoires. This is no less true of the DLM, which is made up of 
communists, anarchists, libertarians, and a number of participants who would be reluctant to identify with any political ideology at all. However, there are a number of recurring themes and frames within the movement. On the one hand, many of these struggles place a high premium on the freedom of the individual, either conceived in terms of freedom to tinker with the technologies of everyday life (as in the case of the DeCSS and 09F9 codes) or in terms of freedom from government surveillance and censorship. This theme owes much to the movement's roots in hacker culture, with its fierce individualism. On the other hand, the DLM does not entirely eschew collective solutions. The movement makes repeated claims on the state, including demands that the state hold to the promises of liberal democracy and calls for protection from the power of corporations (as in the case of the struggle over Net Neutrality). Many activists are also involved in building projects that have echoes of collectivism, including F/LOSS and books, music, and even films licensed under creative commons licences. The complexities of the DLM's ideological positioning, and the implications of this positioning for its involvement in and relationship with the global justice movement, will be discussed in more detail in the following chapter.

\section{Conclusion}

The matter of the DLM's emerging network structure, collective identity, and contentious repertoire have been discussed at length here in order to clearly position the movement within the context of social movement scholarship. Researchers have been relatively quick to recognise shifts towards the use of new technologies and online spaces by traditional social movements, and even to posit a move towards a new way of organising and acting. Work on the Zapatistas has been a catalyst for this; both Cleaver's (1999) paper on 'Computer-Linked Social Movements and the Global Threat to Capitalism' and Arquilla and Ronfeldt's (2001) Networks and Netwars have been influential studies that cite the Zapatistas as a turning-point in the area. However, as Froehling argues, the Zapatistas are in many ways similar to previous social movements, and use of the Internet was at least at first confined to their supporters (1999). The emergence of social movements that organise predominantly through the use of ICTs, and that address issues related to new 
technologies, is a phenomenon that movement scholars have proved less wellequipped to deal with.

This movement will prove to be an important one in coming years, and the issues that it addresses will have effects on the work of other social movements throughout the world. The DLM is struggling to retain user control over the devices and networks that allow widespread communication and rapid access and dissemination of information. They are also working to (re)establish the legitimacy of the amateur as a producer of knowledge in the face of elite attempts to undermine the growth of amateur content production. At the heart of their work is a continual questioning of claims that technology is apolitical, and a commitment to highlighting the effects of new technologies on democracy. While the movement is increasingly linking issues of user control of technology with critiques of corporate and government power, the movement's development of an overarching frame to link these concepts will be vital in coming years. This aspect of the movement's work remains underdeveloped.

The next chapter will examine some of the resonances between the DLM and the Indian movement discussed in Chapter Two. Each is concerned with user control over the technologies of everyday life, grassroots access to knowledge, and the legitimation of the grassroots/amateurs as producers of knowledge. At the same time, there are some strong barriers to communication between these movements, and indeed between the DLM and many other movements in the global justice movement. There is evidence that the DLM, or at least sections of it, overlaps with the global justice movement, but this overlap is currently small and uncertain. Understanding the relationship between the DLM, the Indian movement against GM crops, and the GJM gives an insight into some of the reasons why struggles over knowledge are so vital to the GJM's work. 


\section{Chapter Four}

\section{The global justice movement and struggles over knowledge}

\section{Introduction}

This chapter synthesises analyses of the DLM and the Indian movement opposing GM crops in the context of their contributions to the GJM's struggle for globalisation from below. In the first chapter I argued that knowledge is an important site of political contestation, and that struggles over knowledge are vital to the GJM. The following chapters examined two such movements, arguing that each is involved in struggles to control particular technologies and redefine knowledge. In many cases, these struggles serve as the focus of the movements concerned, as for example in the case of the Indian anti-GM crop movement's attempts to promote the value of traditional agricultural practices. At the same time, such struggles frequently reinforce the position of movement activists: promoting traditional agriculture improves the position of activists as producers of knowledge relative to scientific or political elites. This chapter looks at the contributions that both movements are making to the GJM's attempts to build globalisation from below, including points of agreement and areas in which there are disjunctures.

In the first section of this chapter I argue that both the DLM and the Indian opposition to GM crops have a complex relationship to the global web of activism. While the Indian movement has come to play an emblematic role within the GJM, Indian activists' ability to build connections with other groups and movements throughout the world has been hampered by limited resources, and by organisational forms in which leaders retain control of international communications. In contrast, the DLM has a relatively open structure and most members have access to the resources necessary to build connections at the local and international level. Despite this, the overlap between the DLM and the GJM remains limited, and digital liberties activists have not attained a high level of visibility within the GJM. Few studies highlight the difficulty of drawing boundaries around social movements, and the question of boundaries and 
movement membership remains under-examined within social movement scholarship. These examples highlight the difficulty of definitively mapping the borders of movements, particularly the GJM. Nevertheless, while claims that either the Indian opposition to GM crops or the DLM are contained within the GJM are problematic, there are reasonable grounds for seeing both case-study movements as partially overlapping with the GJM.

The most important argument put forward in this chapter is that despite the limitations on each movement's connection with the GJM, both the DLM and the Indian opposition to GM are making vital contributions to the GJM. The second section outlines four important respects in which both the DLM and the Indian opposition to GM crops are contributing to the work of the GJM. The first of these is their contribution to establishing the validity of grassroots, situated, and peer-based knowledge systems. Secondly, both of the case-study movements discussed in previous chapters are working to preserve diversity in the face of homogenising forces. This provides support to the attempt to build the "one world with room for many worlds" imagined by GJM activists. Thirdly, both of these movements are working against the privatisation of the commons. Again, the ideological function that this serves is supportive of the project of building globalisation from below, while in practical terms it means that vital resources remain accessible. Fourthly, each movement is helping to gain or retain democratic control over key technologies. These contributions are at the heart of each movement's work and are, like many other struggles throughout the world, vital to building globalisation from below. These case studies illustrate important ways in which local struggles, or struggles over particular technologies, feed into a larger, loosely-connected, effort, often in unexpected and under-recognised ways. This discussion also illustrates the importance of struggles over knowledge, giving concrete examples of the contributions that such struggles make to the GJM. 


\section{Section one: mapping the movements}

Each of the movements discussed in preceding chapters has a complex relationship to the broader GJM. Mapping these relationships is difficult, in large part because of the inherently fluid and informal nature of social movements. In the case of the GJM, attempts to map the movement are further complicated by the range of issues and networks, and the geographical spread of the actors, that constitute the movement. Few, if any, struggles, organisations, or activists fit neatly within the borders of the GJM. Instead, the GJM is composed of many overlapping actors and movements, most of which refuse easy categorisation. Close examination of the DLM and Indian opposition to GM crops reveals many points of connection, but it also reveals the problematic nature of any simplistic positioning of either movement within, or in relation to, the GJM.

\section{The Indian opposition to genetically modified crops and the global justice movement}

Claims that the Indian opposition to GM crops is part of the GJM are unlikely to be controversial. While the movement does not have the same iconic place within the GJM that the Zapatistas have attained, it is frequently cited in movement publications and has a high level of visibility within the GJM. We Are Everywhere (Notes from Nowhere 2003f), a publication written by GJM activists to chronicle the movement's work, includes several references to the Indian movement, including in discussions of Peoples' Global Action (de Marcellus 2003, 99), and of solidarity and sabotage as tactics (Notes from Nowhere 2003d, 456). Several of their struggles are also marked in the timeline of "moments of resistance and rebellion" (cf. Notes from Nowhere 2003, 81 \& 131). They are mentioned by José Bové, a French farmer and activist with a prominent position in the GJM, as part of the growing network of international solidarity between farmers (Bové 2004, 142). Patel cites the KRRS as amongst those with dissenting voices and visions of agriculture $(2007,42)$, and the group is described in an NGO account of La Via Campesina as providing some of the earliest and largest displays of farmer opposition to neoliberal globalisation (Desmarais 2003, 13). London activists discussing the KRRS also described it as an organisation with its "credentials in tact" [sic] (Townes 1999). Mentions of Vandana Shiva are also frequent within texts about the GJM, as is praise for her work (cf. Bello 2004, 64; Starr 2006; Achbar \& Abbott 2004). Groups and 
individuals from the Indian movement are certainly seen as belonging to the GJM, and are often referred to as inspirational examples.

Many of the participants in the Indian movement also identify with the GJM. For example, Chukki Nanjundaswamy, leader of one faction of the KRRS, said in 2006, "[w]e feel that our voices have been part of the international antiglobalisation movement. And we feel that our views are the same and we have a common enemy. Since our enemy has globalised, we must also globalise our struggle" (2006, pers. comm., Jan 19). Leo Saldanha, member of an Indian NGO that has been involved in the opposition to GM crops, the Environment Support Group, said,

I don't know if we are part of the left but I think certainly in most positions we are taking we're anti-globalisation. Because the way we see globalisation, it's also imperialist. [...] See, the problem with globalisation is that it's quite a right-sounding name, but when you look into what the mechanisms of it are it works through consumerism, it works through trade barriers, it works through taking control of resources [...] So they're taking control away from the people, so we are for control which is located locally, not in abstract, remote sense. Therefore I think we're also anti-capitalist in that sense, that makes sense for anti-globalisation also (2006 pers. comm., Jan 25).

This discussion also demonstrates an engagement with long-running debates within and surrounding the GJM about the movement's orientation and goals.

In addition to identifying with the aims of the GJM, activists from the Indian antiGM movement have engaged in a number of events that serve as links with the broader GJM. One of the most important of these was the Intercontinental Caravan, which took place in May and June of 1999. This was an event in which several bus-loads of farmers from the Global South travelled through Europe and engaged in what one participant called "perhaps the most ambitious attempt yet to connect up different traditions of struggle, North and South" (Ainger 2003, 169). Participants included activists from the Bangladeshi landless people's movement, human rights and environmental activists from 
Nepal, Zapatistas, Black community movement activists from Columbia, Rainbow Keepers from Ukraine, and activists from Brazil and Chile (Assadi 2004, 210). During the Intercontinental Caravan, solidarity between the Indian farmers' groups and European groups and movements was strengthened by identifying "common enemies", and taking part in actions and campaigns that activists from both North and South could support (Featherstone 2003, 407). The activists protested "with local people against the world economic system, gene technology, war and the nuclear threat", drawing these issues under the banner of "regain[ing] control over countries, communities and the future colonised by transnationals" (Assadi 2004, 210). The Intercontinental Caravan was an important moment in the history of the Indian struggle against GM crops, and it both required and reinforced connections between Indian activists and those in other countries.

As well as participation in the Intercontinental Caravan, Indian anti-GM activists have been involved in a range of significant GJM events. Vandana Shiva, the most prominent internationally active member of the Indian opposition to GM crops, spoke at the first WSF in 2001, the 2004 Mumbai WSF (and at Mumbai Resistance, a parallel forum held at the same time), the 2007 WSF in Nairobi, and at other world, regional, and local social forums. She has also participated in other GJM events, such as the September 2000 protests against the World Economic Forum Asia-Pacific Summit. Scoones notes that Vandana Shiva has become one of the GJM's "stars", used to provide "a sense of occasion to an otherwise average protest event, garnering publicity and media coverage along the way" $(2008,327)$. MD Nanjundaswamy played a similar role within the GJM, albeit far more briefly. Over the course of the KRRS's adoption of a global justice/anti-globalisation frame he "increasingly moved in international activist circles, and was revered as a 'southern' farmer leader, a voice from the poor and marginalized" (Scoones 2008, 327). MD Nanjundaswamy and others within the KRRS have also participated in a number of protests against international financial institutions, including protests against the WTO in 1999 and 2001.

The KRRS's involvement in the WSF has been more complex. The KRRS was part of the steering committee for the 2003 Social Forum to be held in Senegal, but was not satisfied with the process or the direction in which the Forums were 
heading. In a series of letters between MD Nanjundaswamy and Bernard Cassen of the Association for Taxation of Financial Transactions in Order to Aid Citizens (ATTAC), MD Nanjundaswamy outlined several issues that the KRRS had with the upcoming Forum, including "dissatisfaction about the way in which the ASF [Asian Social Forum] is being launched by NGOs little known to the people of India" (KRRS in Farrer 2004, 174). KRRS members also questioned Cassen's objections to Fidel Castro's participation in the Forum:

[Cassen said] that Fidel Castro's participation will split the global movement. So, our demand from the organisers in Mumbai was that Fidel Castro should inaugurate the World Social Forum because he is the voice of the anti-globalisation movement at the international level and if his participation splits the movement his absence would also split the movement and the Indian farmers' movement would not take part in the WSF (C. Nanjundaswamy 2006, pers. comm., Jan 19).

Members of the KRRS subsequently split from the WSF process. When the 2004 WSF was held in Mumbai, the KRRS was involved in organising a parallel forum called Mumbai Resistance (C. Nanjundaswamy 2006, pers. comm., Jan 19). These debates and splits do not necessarily imply a split from the GJM, but rather different tendencies within it.

The Indian movement has also been heavily involved in several international coalitions and networks that are central to the GJM. The KRRS is a member of Via Campesina, an international movement of "peasants, small- and mediumsized producers, landless, rural women, indigenous people, rural youth and agricultural workers" (Via Campesina 2009) that is central to the GJM. Via Campesina was formed in 1993, and was intended to form a bridge between Northern and Southern peasants and farmers. It has held numerous protests and conferences throughout the world, including many that directly targeted global financial institutions such as the WTO (Desmarais 2003). Involvement in PGA has also been important to the KRRS. PGA, an outcome of a "Zapatistainspired 'Encuentro'" in Spain in 1997 (Townes 1999), has focused on coordinating Global Action Days in response to neoliberal globalisation, taking the form of decentralised protests surrounding meetings of international 
financial institutions (Peoples' Global Action 2007). PGA's second conference was held in Bangalore, with significant involvement by the KRRS. The KRRS were also represented at the PGA's first conference in 1998, with one participant describing MD Nanjundaswamy's speeches around Switzerland as inspiring radical anti-WTO groups to spring up in his wake (de Marcellus 2003, 99). The KRRS's involvement in these networks is a manifestation of their involvement in the broader GJM.

In analysing social movements, there is a tendency to default to discussing NGOs and other organisations, which are more visible and more readily mapped than the fluid chaos that constitutes the full range of social movement participation. Similarly, it is relatively easy to use the KRRS as a stand-in for the Indian opposition to GM crops as a whole. However, the overlap is not complete. As noted in Chapter Two, some members of the KRRS are not opposed to GM crops, or at least are not opposed to all GM crops. Many others are opposed in theory, but do not in practice take part in anti-GM crop activism, or activism promoting organic and traditional farming. There are also many participants in the Indian opposition to GM crops who are not members of the KRRS or other large organisations, but who nevertheless play a role in building and maintaining links with other parts of the GJM. These efforts are often limited by a lack of access to the resources associated with NGOs, but they nevertheless play a role in integrating activism on a local scale with international networks of resistance.

The Indian movement is integrated with the GJM through a wide variety of alliances and communications, through Indian activists' self-identifications and through other activists' perceptions of the Indian movement. However, it is useful to question the straightforward claim that the Indian movement is part of the GJM. Membership of any social movement is fluid and often indeterminate. It is most easily mapped by looking at movement organisations, and at snapshots of particular movement events. A comprehensive analysis of social movements needs to look beyond these moments of clarity and encompass the uncertainties and contradictions that are inherent to social movements. While the previous discussion supports claims that the Indian opposition to GM crops is tightly interlinked with the GJM, there are also a number of important 
disjunctures between the Indian movement and the GJM, and there are significant limitations to the extent to which the Indian movements can network internationally.

Research into transnational social movements and related transnational networks recognises the difficulties involved in cross-border organisation. For example, Bandy and Smith recognise the substantial obstacles to building and maintaining networks of activism across "gaps in power, wealth, ideology, culture, strategic interests, and organizational forms" (2000, 231). Attempts to build transnational coalitions are also, Bandy and Smith $(2000,233)$ argue, more likely to succeed when they include NGO participation from the North, as these NGOs have significantly greater access to resources such as specialised knowledge, financial resources, and organisational capacity. Bandy and Smith (2000, 241) also draw on the work of McAdam, Tarrow and Tilly (2001) in noting the crucial role of brokers in developing and sustaining cross-border coalitions. Both the need for access to resources and the crucial role of brokers play important roles in limiting the extent of connections between the Indian anti-GM movement and the GJM.

The first limitation is that of resources. The constituent-base claimed for the Indian opposition to GM crops, and particularly of the KRRS, is predominantly made up of relatively poor farmers. When it comes to travel and involvement in international events, participants are limited not only by their lack of money, but also by other factors such as the difficulty of obtaining visas (Ainger 2003, 165; Featherstone 2003,412$)^{29}$. In one account of a protest against GM crops held in Bangalore, even the train fare from the rural areas to Bangalore is seen as potentially problematic, a cost that the KRRS must pay to ensure or induce attendance (Biewen 2000). Attendance at international protests against the WTO and other international financial institutions, and at world or even regional social forums are well out of the reach of most movement participants.

Resource constraints also feed into and magnify other obstacles to direct engagement with transnational activism. Language is an enormous barrier;

29 Ironically, insofar as participants were able to surmount financial obstacles in order to attend events, this is seen by some to detract from claims that they are truly a mass movement for poor farmers (cf. D'Monte 2000). 
even within India, the number of different languages spoken inhibits the ability to form national movements, although this is to an extent eased by the number of people who speak several languages as well as their first language. During my fieldwork, I encountered few movement participants who spoke and read English other than urban, middle-class professionals, many of whom were working for NGOs rather than in the less organised sections of the movement ${ }^{30}$. Language barriers do not only inhibit direct communication between activists, they also limit the ability of movement participants to present their viewpoints and access information in international media, including online.

The role of brokers is vital in sustaining international connections. Effectively, movement leaders often become the only movement participants who are capable of making and sustaining cross-border linkages. In the international sphere, the only activists to have garnered significant visibility are the late MD Nanjundaswamy and Vandana Shiva, although others (including Suman Sahai and Devinder Sharma) have had moments in the spotlight. These leaders become the nodes that connect different groups and movements. As one KRRS member said, "in terms of designing the global movement, for example, Professor Nanjundaswamy was the founder of Via Campesina in India, and he brought together many farmers' movements in the Asian countries, and he initiated the Via Campesina in Asia" (Chandrashekar 2006, pers. comm., Feb 4). While this description undoubtedly glosses over the contributions of many other members, it does highlight MD Nanjundaswamy's importance in building and maintaining those connections. The highly personalised nature of these connections increases their fragility, as was seen during the organisation of the Intercontinental Caravan when Shiva and Nanjundaswamy entered into an acrimonious debate about the venture (Featherstone 2003, 413). The KRRS's split added to this. With the split into the Nanjundaswamy and Puttanaiah factions, there was a deep division between those focusing on local issues and those who saw these issues as part of global problems (Assadi 2004, 210), with the Puttanaiah faction predominantly focusing on the local sphere. This meant that when MD Nanjundaswamy died in 2004, the KRRS's involvement in transnational coalitions and protests tapered off, as well as its role in the Indian anti-GM struggle (Raghunandan 2006, pers. comm., Feb 7). Nanjundaswamy's

30 I do not mean to privilege English as the language of activism, but it is the international language most likely to be spoken by Indian activists. 
daughter, Chukki Nanjundaswamy, took the reins of the Nanjundaswamy section of the KRRS after his death, and at the time that I interviewed her she remained the only one within the organisation with regular access to the Internet (C. Nanjundaswamy 2006, pers. comm., Jan 19). As long as international connections continued to be channeled through one or two movement leaders in this way, they are likely to remain fragile, easily broken by the incapacitation of movement leaders or personal disagreements.

Finally, it should be noted that as well as resource limitations, the frames deployed by Indian anti-GM activists have contradictory effects. In many cases, the movement's framing of their issues serves to reinforce their links with other movements in the Global South, and with the GJM as a whole. As we saw in Chapter Two, since the 1990s the KRRS and other groups that constitute the movement have framed their struggle as part of the broader opposition to neoliberalism. Even those activists whose focus is on local projects and preservation of indigenous farming techniques frequently refer back to global movements. The opposition to globalisation has, however, been framed in a uniquely Indian manner. As previously discussed, the Indian opposition to GMOs has frequently called upon the discourse of swadeshi, the Gandhian notion of village-level self-reliance. This framing does not necessarily contradict a master frame of opposition to neoliberalism. Rather, it positions the exploitation of Indian farmers as part of a new era of globalisation, in which national resources, production, and consumption are all controlled by multinational corporations (Assadi 2004, 206). This frame fits neatly within the rhetoric of the GJM, emphasising the importance of the local in the face of neoliberal globalisation.

At times, however, this tendency towards nationalism has worked to exclude others and alienate Indian activists from others within the GJM. This was particularly the case during the Intercontinental Caravan, possibly one of the few times in which movement activists other than leaders well-versed in the language and ideals of the GJM interacted in an unstructured way with European activists and others from the Global South. One account describes an Indian activist approvingly discussing the links between Hitler's nationalism and Hindu tradition: 
On the very first day, an Indian guy got up and started talking about how wonderful Hitler was...how the swastika symbolises a maize mill which functions by getting rid of the bad parts of the maize and keeping the good parts...Hitler "defended the German nation state when it was in crisis, by getting rid of the problem elements, and now India has to do the same" (Do or Die 1999)

Featherstone $(2003,414)$ also mentions opposition from members of the Indian delegation to Nepalese participants speaking at events, claiming that it was an "Indian not a Nepalese Caravan". Mahendra Singh Tikait, a farmers' leader from the North of India, was also accused of imperialism by Nepalese participants (Madsen 2001, 3741). While incidents such as these are by no means the rule, they do undermine claims to a unitary solidarity between Indian activists and movements of the oppressed from other parts of the world.

Framing the opposition to GM crops within a nationalist discourse facilitates and contributes to the already problematic relationship between local movements and international activism. For a range of movements in the Global South, including feminist and environmental movements, links with international organisations and movements are attacked by critics. This is particularly the case when it comes to links with organisations and movements from the Global North. One journalist covering agricultural issues, Harishchandra Bhat, noted that 'there are people who blame them [farmers' and anti-dam movements] [...] and say that these people are foreign-funded, funded by foreign agencies to prevent development in India" (2006, pers. comm., Feb 28). This is an issue that movement leaders and NGO members are aware of. Some international organisations avoid approaching local groups with funding in order to avoid such accusations, and movement leaders often take care to emphasise their grounding in local communities and concerns. While these issues do not preclude involvement of local movements in the GJM, they do complicate the process and provide additional difficulties that must be navigated.

The point of this examination of the Indian movement's involvement with the GJM is to complicate the image of the GJM as having a strong and unified core 
membership and a less well-integrated periphery of other participants. Even those movements which are assumed to be at the "centre" of the GJM, as the Indian movement is, are not fully integrated with the movement. They are not contained within the GJM, but rather overlap with it. Their struggle is at times explicitly positioned as part of the GJM, but more often activists are addressing issues with a local focus. Nevertheless, as we will see in the following section, these movements make vital contributions to the GJM. This is possible because, as we saw in Chapter One, the GJM is by its very nature constituted from diverse and decentralised struggles on a wide range of issues and in many different parts of the world.

\section{The digital liberties movement and the global justice movement}

Activists within the DLM do not face the same resource constraints as Indian anti-GM activists. By definition, they have access to the Internet. Many of them are highly educated, well-paid, and mobile. If anyone exists in the space of flows (Castells 2005), it is them. Yet, in contrast to the Indian movement, links between the DLM and the GJM are few and far between. Again, it is difficult to quantify this exactly given the blurry nature of social movements and the problems with clearly delineating their boundaries. The difficulty is compounded by the ephemeral nature of connections between movements. Personal communications, fleeting involvement in joint actions, references in movement texts and other such linkages are easily overlooked. Absences are hard to map, but there are at least some signs of this absence of connection between the two realms of activism. Movement texts from the GJM tend to make scant reference to F/LOSS, online civil liberties, file sharing, and other issues dear to the DLM. When they do mention digital liberties activism and issues, it is usually within a discussion of hacktivism as a tactic (cf. Starr 2006, 77-78; Jordan \& Taylor 2004). Participation of digital liberties activists in GJM events is also limited, although again this is difficult to prove conclusively. This claim is predominantly based on my experience of the Nairobi and Pakistan WSF, as well as the lack of information on activists and groups from the DLM in accounts of GJM events.

Omission of these movements may, however, be due to a reporting bias. There is a possibility that activists from other movements and scholars who are writing 
about the GJM do not see the issues addressed by the DLM as important, or do not have the conceptual framework to recognise digital liberties activism. For example, F/LOSS activists set up computers with Linux for the Nairobi WSF (Tectonic 2007), yet this is omitted from most accounts of the Nairobi WSF. Articles on the top two activist websites provided when a Google search is carried out for coverage of the Nairobi WSF, Globalise Resistance (2009) and Choike (2009), make no mention of Linux. There is some support for the thesis that activists do not necessarily see digital liberties issues as important in discussions of the use of free software at the Mumbai WSF:

For some IWC [Indian Working Committee] and IOC [Indian Organising Committee] members the knowledge management software used was of marginal interest. Some viewed FS [Free Software] as a way to claim self-reliance against mega-corporations but they still saw it as a technical issue (Juris, Caruso \& Mosca 2008, 102).

Given such attitudes, it is unsurprising that F/LOSS and related digital liberties activists' involvement may be under-reported in activist coverage of GJM events. Similarly, while there has been some academic analysis of the use of F/LOSS at various WSFs (cf. Smith \& Smythe 2008; Juris, Caruso \& Mosca 2008), this work remains at the periphery of the discipline. Lack of interest on the part of GJM activists and academics working in the area, as well as their ignorance of digital liberties activism, must therefore be taken into account in analysing the DLM's relationship with the GJM.

Some academic research does exist that links the DLM with global justice activism, although the links found are weak. Starr's (2006) research is notable here. In mapping connections between anti-corporate movements, Starr notes that "the cyberpunk movement" is one of the few which shares only limited connections with other movements $(2006,161)$. The cyberpunk movement, which she locates as centred around the ideas contained in early 1980s cyberpunk novels, is shown to have an emerging connection with peace and human rights movements, a weak link with anarchist movements, and a strong link with Zapatismo (2006, 73 \& 160). Given the centrality of the Zapatistas to the GJM, the strong link between the cyberpunk movement and Zapatismo 
would seem to imply at least the possibility of a growing connection between the cyberpunk movement and the GJM. However, Starr's research does not provide enough information to adequately map the movements' relationships with each other, because she has defined a connection as "a public embrace of each other's ideology and/or projects" $(2006,161)$. A connection between movements as defined here does not necessarily imply communication, organisational links, or involvement in common projects. While Starr's work provides a valuable starting-point, these issues and the lack of information as to which groups are involved in the cyberpunk movement make it impossible to define the extent to which the digital liberties and cyberpunk movements overlap.

There are two different starting points for examining the apparent gulf between the DLM and the GJM. The first of these is to take it as unproblematic, to assume that there is no reason for these movements to be connected, and the gulf between them therefore requires no explanation. The second starting-point, which I will take as the basis of the following discussion, assumes that this gulf does require an explanation. In a world where social movements are increasingly cooperating and communicating across borders, isolation is the exception rather than the norm. Participants in the DLM have access to significant resources, and are in a strong position to know about the work of the GJM. Further, as discussed below, many of the values central to the DLM are shared by the GJM, including a commitment to diversity, decentralised power, and direct democracy, and an opposition to excessive corporate power and the enclosure of the commons. Given this, the reasons for the lack of integration between the GJM and the DLM is worthy of analysis.

The first and most obvious reason is the relative youth of the DLM. As discussed in Chapter Three, the DLM has emerged relatively recently. Its oldest direct antecedents, hackers and Yippies, are only a few decades old, and the sense of a cohesive and unified DLM is still developing. Without this, and lacking a clear collective identity, it may be difficult for movement participants to see the necessity, or possibility, of creating strategic alliances with other social movements. Similarly, the lack of visibility associated with the youth of the DLM inhibits participants in other movements from seeking alliances. However, these factors cannot fully explain the relative isolation of the DLM: there is sufficient 
self-awareness within the movement and sufficient access to resources to expect a greater degree of networking and cross-movement integration to have occurred by now. Further, the GJM itself has only emerged over the last two or three decades, and other movements have successfully developed crossmovement links in this time.

Arguably, the reason that the DLM has remained relatively isolated from the global web of activism that constitutes the GJM is the dominance of frames and ideology within the DLM that do not mesh well with those of the GJM. While the GJM is constituted of participants with a broad range of ideological affiliations, it is dominated by those with left-wing anarchist and socialist tendencies. Activists within the movement show a consistent hostility towards the valorisation of the market as the primary mechanism for the allocation of resources, and towards the associated growth in corporate power. This tendency is exemplified in many of epithets applied to the movement by both activists and scholars, including "anti-corporate" (Starr 2006; Juris 2005) and "anti-capitalist" (Callinicos 2003). One of the main tensions within the GJM, evident at WSFs and in many internal movement debates, is between activists with centralist tendencies and those who eschew formal and hierarchical structures (Farrer 2004). Debate over the power of capital, on the other hand, is limited. While individuals and organisations within the movement may differ in the extent to which they advocate reform of or revolution against capitalism, resistance to the power of corporations and to the use of the market as the primary mechanism for allocating resources is taken for granted within the GJM.

In contrast to this, participants within the DLM are frequently reluctant to associate their work with leftist projects. While participants in the DLM have on occasion been described as communists and/or socialists (Kelly 2009; Stallman 2008; Himanen 2001), many within the movement have been quick to distance themselves from these labels. Lawrence Lessig, one of the leading proponents of creative commons licences and a key figure within the DLM, responded immediately to Kevin Kelly's (2009) claims that digital culture was experiencing a "New Socialism". Lessig (2009) writes that "none of the things that Kelly (and I) celebrate about the Internet are 'socialist"' because they are based on freedom, rather than coercion. In the same piece, Lessig objects to Mark 
Helprin's Digital Barbarism (2009), complaining about the "mushiness in thinking" involved in Helprin's "incessant Red-baiting - the suggestion that the movement of which I am a part is a kind of warmed over Marxism from the 1960s" (Lessig 2009). While Richard Stallman, a prominent free software advocate, does not object to the label with such vehemence, he does write,

[a]nyone who criticizes certain business practices can expect to be called "communist" from time to time. This is a way of changing the subject and evading the issue. If people believe the charges, they don't listen to what the critics really say. (It is much easier to attack communism than to attack the views of the free software movement.) (Stallman 2008).

These sentiments are representative of the mood within most of the movement, which eschews left-wing and anti-capitalist ideologies.

Attempts to outline the DLM's politics are complicated by the expressed disavowal of any political stand by many of those within the movement, which should be seen more as a rejection of traditional political divisions than as evidence of a true rejection of political projects. Leaders of the Swedish piratpartiet, for example, explicitly argue that it is neither left- nor right-wing, and that its members come from both sides of the political spectrum (Engström 2007, pers. comm., Jul 27), yet it is at the same time obviously engaged in a political project. When it comes to F/LOSS advocates, Wayner writes,

[t]o some extent, the politics of the free and open source movement are such a conundrum that people simply project their wishes onto it. John Gilmore told me over dinner, "Well, it depends. Eric Raymond is sort of a libertarian but Richard Stallman is sort of a communist. I guess it's both." The freedom makes it possible for people to mold the movement to be what they want $(2000,140)$.

Anthropological research by Gabriella Coleman supports this. Coleman notes that "FOSS ${ }^{31}$ developers would suggest that it is unacceptable to claim that FOSS has as one of its goals anti-globalization, or for that matter any political

\footnotetext{
31 Note that "FOSS" and "F/LOSS" refer to the same constellation of practices and software.
} 
program" $(2004,507)$. This insistence that all sides of the political spectrum are represented, or that none are, is common within the movement.

Despite this insistence, there are a number of common themes that define the politics of the DLM. The first of these is a resistance to the centralisation of power, particularly within government but also in the hands of corporations. The opposition to government power is exhibited in the repeated campaigns fought by digital liberties activists to resist expansion of government powers and surveillance, including those conducted against the changes to Swedish law regarding wiretapping, against the development of government databases in a range of states (including the UK and Israel), and against the use of RFID chips in passports and other government documents. It was also shown in the rush by digital liberties activists to provide tools to Iranian protesters enabling them to evade government Internet filters and surveillance (Anonymous Iran 2009; Haystack 2009). Digital liberties activists' aversion to corporate power and attempts by established industries to consolidate their hold on power have also been demonstrated in activists' regular campaigns against and/or complaints about the RIAA, Microsoft, AOL Time Warner and other large corporations. Activists have also identified and protested against numerous instances of collusion between corporate interests and governments. For example, Cory Doctorow (2009b) linked to a list of "corporate lickspittles" that were allowed access to the Obama administration's secret copyright treaty on Boingboing, and Xeni Jardin (2009) noted Iranians' boycott of Nokia after reports that it collaborated in surveillance of Iranian citizens during the 2009 protests against the alleged rigging of the elections. The latter blog post was followed by further calls for boycotts of Nokia in the comments section. This rejection of centralised power meshes well with the more anarchistic tendencies within the GJM.

While this firmly places the DLM on the anti-authoritarian side of the freedom/authority axis of the political spectrum, digital liberties activists have far more faith in market solutions and the outcomes of capitalism than most activists within the GJM. Ultimately, this positions the DLM closer to liberal and libertarian politics than the predominantly anti-capitalist/anti-corporate GJM. In part, this is due to a common (although not universal) assumption within the DLM that capitalism leads to an effective allocation of resources and 
encourages innovation, as long as the bloat of corporate monopoly is avoided. Pekka Himanen's discussion of "the hacker ethic" which informs much of the DLM notes that hackers recognise that "in a capitalist society it is very difficult to be completely free unless a person has sufficient individual capital" $(2001,54)$. Activists within the GJM often propose that the solution to this problem is to escape from, dismantle, or radically reform capitalism (cf. Jordan 2004, 10; Notes from Nowhere 2003a, 107; Porto Alegre II 2002). In contrast to this, Himanen explores examples of hackers who have chosen "capitalist hackerism" after deciding that "if one is the empowered capitalist, one can make one's own life decisions" (Himanen 2001, 54). This individualist solution calls for no structural change, and undermines the critique of capitalism that it answers. By making a commitment to "capitalist hackerism", hackers at least implicitly concede the possibility of achieving their goals within the system.

The DLM is also characterised by a pervasive commitment to American ideals, particularly "freedom", primarily defined negatively (as freedom from control) rather than positively (as freedom to access opportunities or resources). This is demonstrated by the politics expressed by Lawrence Lessig and the Free Culture groups. Lessig comes from a liberal, reformist perspective. Neither he nor his argument is revolutionary. Lessig argues that the current system of intellectual property rights in the United States has become skewed too far in the direction of existing cultural industries, particularly the large record and film studios. If America is to continue to be a centre for cultural innovation, if it is to preserve its tradition of "free culture", it needs better intellectual property law. Lessig's description of "free culture" makes his perspective clear through the concepts that he associates with the "free" of free culture: "'free" as in "free speech," "free markets," "free trade," "free enterprise," "free will," and "free elections"' (2004, xiv). Throughout Free Culture, Lessig repeatedly emphasises that he has faith in the American system, and is trying to preserve its best features rather than challenge it. Many others working within the DLM take a similar position. Yochai Benkler, a lawyer and academic who has worked with Lessig on open content licences and has published a voluminous work on The Wealth of Networks (2006) similarly sees the "Internet revolution", 
as a dimension of individual freedom; as a platform for better democratic participation; as a medium to foster a more critical and self-reflective culture; and, in an increasingly information-dependent global economy, as a mechanism to achieve improvements in human development everywhere $(2006,2)$.

There are hints here at a politics that rejects, or at least critiques, capitalism and representative democracy, but the basic faith in the market and the value of freedom and democratic participation are far from radical.

As in any social movement, a range of perspectives are represented within the DLM. While more centrist movement participants frame issues through the language and ideas of liberal politics, libertarianism also has a strong presence within the movement. In part, this may be a result of the politics of online culture that emerged in the early days of the Internet. Tim Jordan relates this to a view of the Internet as an "an electronic frontier where pioneers meet beyond the interference of government and bureaucracy" $(2001,2)^{32}$. Jordan argues that because of the experience of Internet users who enter cyberspace alone, and must "confront their singularity before building a sense of others in the electronic world", political ideologies that emphasise individual liberty and the right to self-government tend to prevail $(2001,8)$. To the extent that today's Web is an intensely social one in which many users' online and offline communities are interconnected (cf. Lenhart et al. 2007), we might question the relevance of Jordan's research to users' current experiences. However, when speaking of the cultures within long-running (by Internet standards) communities founded in the early days of the Internet, Jordan's research remains relevant.

This is borne out by the self-identification with libertarianism espoused by a significant number of high-profile members of the DLM. Libertarians within the movement include Jimmy Wales, founder of Wikipedia, who has declared himself a follower of Ayn Rand (Zittrain 2008, 143) and Eric S. Raymond, who wrote one of the founding texts on open source software. Similarly, John Perry Barlow, co-founder of the EFF, has described peoples' online experiences as creating a "small 'l' libertarian" culture, as people experience functional, large-

32 The metaphor of cyberspace as a frontier, and its implications for women, is expanded upon by Miller (1995). 
scale anarchy (Jordan 2001, 8). Barlow has said that "I personally don't believe in the nation-state", and has been described as both an anarchist and a cyberlibertarian (Barlow 1997; Wikipedians 2009b). While Cory Doctorow has resisted attempts to label him a libertarian, his activism and books have been adopted with great enthusiasm by libertarians, particularly Little Brother (2008), which won the Prometheus Award for libertarian science fiction in 2009. Those within the movement rarely make a clear distinction between libertarianism and anarchism, but the faith in market mechanisms and individualism frequently expressed by movement participants distinguishes the libertarian tendencies of the DLM from the more collectivist and anti-capitalist anarchism that runs through the GJM.

The gap between the left-wing and frequently radical politics of the GJM and the more liberal and/or libertarian politics of the DLM is one possible explanation for the current dearth of links between the GJM and the DLM. The different political orientation of each movement would explain, in part, why the DLM does not seem a natural ally for GJM activists to turn to. Another possible explanation would be that digital liberties activists' framing of digital spaces and technologies as key areas of contestation has not yet fully been accepted by external audiences, including GJM activists. Linking back to the earlier discussion of possible under-reporting of digital liberties activists' involvement in GJM activities, it is possible that GJM activists remain unaware or unconvinced that struggles to (re)gain control over these technologies are necessary and urgent. Conversely, the liberal and libertarian politics that run through the DLM are unlikely to be conducive to seeking alliances within the GJM, particularly given the dominant representation of GJM activists within mainstream media as violent, disruptive, "fringe characters", who are uninformed about economic and political realities (Boykoff 2006, 205). Although most digital liberties activists have the resources to seek alternative sources of information on the GJM which portray the movement in a more positive light, they do not necessarily have incentives to do so. There are therefore significant barriers to activists within either movement seeking greater connections with the other.

Just as in the case of the Indian opposition to GM crops, however, the relationship between the DLM and the GJM is not simple to map. While, as I 
have argued above, the evidence of connections between digital liberties activism and the work of the GJM is limited, there is also evidence that the gulf between the movements has been bridged and that connections between them are growing. For example, several prominent digital liberties activists have taken steps towards acknowledging the GJM's work, and activists from within the GJM have begun to make links with digital liberties activism. BoingBoing has occasionally covered GJM events, including police violence at London's anti-G20 protests, framing the story in terms favourable to the GJM activists (Doctorow 2009c), and "indigenous anti-globalization protests" from Eucador (Jardin 2006). From the other direction, Vandana Shiva, a key figure within the GJM, has compared open source software to "open" seeds, saying that open source software is "a way of spreading prosperity and knowledge in society" in the same way that saving and swapping seeds is (Shiva in Elsedoudi et al. 2009). The video of this discussion was then posted online to Red Hat Magazine $^{33}$ along with a link to Navdanya, the organisation Shiva works with. Discussion of digital liberties issues by GJM activists, and vice versa, is not necessarily common. It does exist, however, and may be instrumental in developing and extending the frames of each movement in order to incorporate issues addressed by the other.

There are also tantalising glimpses of projects emerging that cross the divide between digital liberties issues and GJM activism. One example of this is the One Big Torrent website, which uses peer-to-peer technology to share "material that deals with or is relevant to issues of social justice, progressive and radical politics, independent media, ecology" (One Big Torrent 2009). There are also a variety of organisations that provide information and communication technology (ICT) support services to GJM activists, including the Resist! collective in Canada (Resist!ca 2009), riseup.net (2009), and Bangalore's Janastu. Kate Milberry argues that examples such as these, as well as the use of F/LOSS for the Indymedia site, demonstrate that the GJM "has broadened to include a new brand of activism, one that moves beyond simply using technology toward particular ends to include the modification and transformation of technology itself" (2006a). This would seem to indicate that some digital liberties activism is becoming incorporated into the GJM, and that the DLM overlaps in part with the

33 Red Hat is a prominent open source software company. 
GJM. However, the available data leaves this question open as the scale of collaboration between digital liberties activists and the GJM remains limited. Moreover, Milberry has not yet provided enough data to determine whether there is a distinction between activists who fall within the scope of the DLM and those who are, in contrast, tech-savvy GJM activists.

Attempts to map the relationship between the GJM and the DLM are further complicated by the difficulties involved in mapping rapidly shifting ground, and by the informality of many movement connections. As I noted in the previous chapter, the DLM is still emerging, and as such is in a state of transition. Connections and overlaps between digital liberties activism and activism in other movements are therefore still developing. Connections may also exist at the level of informal relationships and cross-movement participation or overlap. Relationships such as these are not likely to be visible to researchers of social movements unless researchers are able to conduct in-depth participant observation. Even in such cases, the range of informal relationships that become visible will be highly localised and depend greatly upon the activists with which researchers are working. It will therefore require both more time and more research before a better understanding can be developed of the relationship between the DLM and the GJM. For now, I posit that the DLM is one of the innumerable movements that overlaps with and helps to constitute the GJM, but the extent of the overlap is as yet unclear.

Both the DLM and the Indian movement against GM crops have a complex relationship to the GJM. While the Indian movement can be reasonably placed within the bounds of the GJM on the basis of its adoption of GJM frames and involvement in key GJM organisations and events, its connection to the broader movement is, arguably, fragile. The link between the Indian movement and the GJM depends in large part on the ability and willingness of movement leaders to sustain and nurture international connections. This link also depends on frame contestation within the movement, as global justice frames occasionally come into conflict with other frames, including nationalism. The DLM, as defined in Chapter Three, has not adopted the politics of the GJM, and digital liberties activists have not been heavily involved in GJM events. Nevertheless, some connections exist between digital liberties activists and the GJM, and activism 
contesting the structure of ICTs is, as Milberry (2006a; 2006b) argues, taking place within the GJM. Drawing a firm line between the GJM and the DLM is not, therefore, as simple as it first appears. One way to deal with this would be to call for firmer theoretical models for conceptualising and mapping social movements. Another, which I prefer and have attempted here, is to accept the amorphous and fluid nature of social movements as inherent, and to highlight it rather than attempting to define it away.

This means that it is vital that we evaluate the contributions that struggles over knowledge make to the GJM in a way which recognises the structure and diversity of the GJM itself. The GJM, as argued in Chapter One, does not have a centralised structure, and has no single manifesto or plan of action, nor is there a blueprint for the world which GJM activists are struggling to create. Activists working to further the goals of the GJM are not directed from a central point, and their contributions take diverse forms. The GJM's work, therefore, must be understood as growing from a great many actions, small and large, distributed throughout the world.

It is, to an extent, important whether particular activists, groups, or movements, are linked to the GJM. Such links help to establish whether actors see their work as part of the GJM's project, and whether they are informed by the discussions and debates that flow through the GJM. However, the connections between struggles at the local level and the GJM as a whole may be less important, in the end, than the extent to which such struggles fit with and support the GJM's vision of a better world. The following section therefore focuses on the myriad ways in which each of the case-study movements contribute to the GJM's project.

\section{Section two: struggles over knowledge and contributions to the global justice movement}

Both the Indian movement against GM crops and the DLM make vital contributions to the GJM's project, despite the complexities of each movement's relationship with the GJM. The multifaceted nature of the GJM is such that the movement's work is underway in multiple spaces around the world, through local struggles and international networks, legal actions and direct action. The 
celebration of diversity that runs through the GJM, discussed in Chapter One, is conducive to the emergence of a movement of movements that does not require individual actors to sign up to a single manifesto or become part of an overarching organisation in order to support the movement's work. The struggles that constitute the GJM take many forms throughout the world. Similarly, struggles over knowledge take many forms throughout the world. Those working to retain democratic control over knowledge are doing so in many different ways, and many different spaces. The case studies discussed here each make vital contributions to the GJM through their own work, without this work necessarily being framed as part of the GJM's project. This is because, as outlined in Chapter One, knowledge systems play a vital role in sustaining the movement's structure and work, and in gaining legitimacy for GJM activists' arguments. The DLM and the Indian movement opposing GM crops are contributing to the GJM through their attempts to (re)gain democratic control over key technologies, to build peer-based knowledge systems, to preserve and develop diversity, and to resist enclosure of the commons.

\section{Democratic control over key technologies}

As I argued in the first chapter, Information Age technologies play a vital role in the structure of the GJM and as tools in its work. More generally, however, control over technology is important because it is central to the lives of the individuals and communities that constitute the GJM. Both the Indian movement against GM crops and the DLM are involved in attempts to retain, or regain, user control over important technologies. In the case of the Indian movement, the struggle is focused around seed as a symbolic reference and a basic need. As described in Chapter Two, the launch of the Beeja (Seed) Satyagraha was an important moment in the history of the movement against GM crops. The alienation of seeds from Indian farmers, and indeed farmers throughout the world, has been underway since the Green Revolution: farmers came to depend more and more on purchased hybrid seed, which did not perform well if resown. The Beeja Satyagraha attempted to work against this trend, declaring that control over seeds was as symbolic of India's current struggles as the spinning wheel had been during the Independence struggle (Assadi 2004, 208). Parallels were also drawn with the Salt March resisting British taxes on salt. The 
KRRS said that the only difference between the two was that the Beeja Satyagraha was part of the "second Independence movement" (Assadi 1995, 199). Movement activists have continued to assert that as seeds are a necessity for life, and as seeds are at the centre of farmers' lives and work, farmers must have access to them.

Practically, this has meant that the movement has resisted attempts to create legal barriers to the sharing and saving of seeds. While some of this activism has been directed at national governments, activists from the Indian movement have also been instrumental in raising awareness of the effects of international institutions surrounding IPR. In 1993, for example, in the leadup to India's accession to TRIPS, five hundred thousand farmers rallied in Bangalore in protest (Borowiak 2004, 520). Protests such as these have politicised the application of IPRs to seeds, and to indigenous knowledge systems more generally. Movement activists have also worked to reconfigure the language of rights, arguing that they "reserve the right to punish those who are guilty of pirating the common intellectual property rights, reversing thereby the burden of proof" to require that MNCs prove that they have any rights over agricultural knowledge. This was also demonstrated by the movement's creation of the day of "Reaffirming the Common Intellectual Property Rights of the Peasants" on August 151993 (Assadi 1995, 203). The work of the Indian movement, as well as that of other peasants' and indigenous peoples' movements throughout the world, has been vital in preventing the wholesale privatisation of agricultural knowledge in the Global South, although this is a battle that is still very much under way.

The development of seed banks and research into the knowledge associated with traditional seed varieties has also been an important part of this struggle. Several of the organisations discussed in Chapter Two have made community seed banks a centrepiece of their work, including Navdanya, Gene Campaign, and the GREEN Foundation. These seed banks focus on in situ seed conservation, in which seeds are used by farmers, who then harvest and return seed to the bank. Ex situ seed conservation, such as the Svalbard Global Seed Vault in Norway, preserves seed varieties as "back ups" in case of biodiversity loss or as static libraries to be drawn on for research (Ministry of Food and 
Agriculture 2009). In contrast to this approach, in situ conservation focuses on seeds as part of an interdependent system. GREEN Foundation emphasises the importance not only of access to seed, but also the preservation of seed selection, and when and under what conditions to sow. Women's role as custodians of this knowledge is highlighted (GREEN Foundation 2008b). All three organisations have focused their efforts on crop and medicinal varieties used locally, such as millets and rice varieties that are integral to food sovereignty. They also prioritise access for marginalised sectors of the community, including women and dalits. These seed banks provide access to seeds, as well as to the knowledge necessary to use them well, ensuring the continued existence of alternatives to commercial seed (including both GM and "high-yielding" varieties).

As the need for preserving knowledge associated with seeds makes clear, the Indian movement discussed here is concerned with far more than the seeds themselves. Those opposing the use of GM crops are concerned not just with the type of seeds sown, but also with the agricultural systems in which they are used. The emphasis on agriculture as a system is clear throughout the movement, from Shiva's insistence on indigenous agricultural cropping systems' "symbiotic relationship between soil, water, farm animals and plants" $(1993,39)$ to the KRRS's linkage of "the colonization of the seed through the myth of miracle seeds, destruction of genetic diversity and ecological stability through the Green Revolution and Monoculture, soil toxicity and soil erosion due to heavy fertilizer use and HYVs [high yielding varieties]" (KRRS in Assadi 1995, 192). Ensuring seed sovereignty is therefore part of a larger project of building farmers' control over their means of production.

This project is often framed within a Gandhian vision of swadeshi, village-level self-reliance. Subhash Palekar, a proponent of zero-budget farming who was on a speaking tour organised by the KRRS at the time that I conducted my field work, argues that,

in the old India [...] Every village was totally self-reliant [...] whatever demands in the village, they were fulfilled by small village industries. If you want clothes, it was there. If you want oil, it was there. Each 
commodity was manufactured in the village. So the money was not taken from the village to the cities. The farmer was going to the city to sell his produce - money would come to the village from the city. So villages were prosperous (Palekar 2006, pers. comm., Jan 19).

Palekar advocates avoiding any agricultural system, including some forms of organic farming, that require buying inputs such as fertiliser, seed, pesticides or water from outside the farm. There are also other projects attempting to build, retain, or reproduce agricultural systems that require little to no inputs, ranging from permaculture to attempts to revive traditional Indian breeds of cattle (cf. Joshi 2004; Love4Cow Trust 2009). These projects all help to sustain or regain local autonomy, strengthening the position of local communities.

These struggles contribute significantly to the GJM. Work by Patel (2007), among others, provides convincing evidence that the world food system, from seed to table, is increasingly under the control of a few large transnational corporations. There are numerous ways in which activists within the GJM benefit from a decoupling of food production from this global food system. Many movements within the GJM are composed of peasants, farmers, and others who rely on agricultural production for an income, including those involved in PGA and Via Campesina. Agricultural systems that remove or decrease reliance on the market strengthen the position of those within these movements. By encouraging people to avoid relying on and contributing to corporate control over agriculture, these movements nurture alternatives to capitalism in its current form and create spaces in which the power of corporations is diminished. Most fundamentally, local control of a significant proportion of food production is vital to attempts to build a world in which local communities have meaningful autonomy.

As in the case of the Indian movement against GM crops, the DLM is working to retain control over the technologies of everyday life (albeit for rather different lives). This is expressed in a concern with preserving or establishing user control over software, hardware, and information flows. For many in the West, ICTs form the fabric of everyday life. In Australia, for example, 67 per cent of households had computers and 75 per cent had Internet access by 2008 , and 
80 per cent of households had mobile phones by 2007 (Screen Australia 2009). As the knowledge industries grow in both the Global North and the Global South, more and more people are working directly with ICTs, while even many jobs previously thought of as manual labour rely considerably on networks of ICTs. A loss of control over these technologies may not imply the same devastating economic consequences for users that Indian farmers have suffered as a result of their increasing dependence on outside inputs and prices determined by the global market. However, as many digital liberties activists have pointed out, it means losing the ability to re-cut the fabric of mainstream culture to produce critiques of dominant institutions (Gaylor 2009). It also implies a ceding of power over the technologies that we rely on to communicate, to work, to create, and to organise.

Just as the Indian movement is reviving traditional agricultural systems and experimenting with new agricultural systems that are alternatives to large-scale monocultures, the DLM is working to preserve and create alternatives to digital monocultures and elite-controlled technologies. Once again, there is no resistance without alternatives. One example of this is the development and promotion of creative commons and copyleft licences, which provide an alternative to the restrictive approach to copyright currently in ascendancy. As well as being used for a wide range of F/LOSS, these licences are also increasingly being used on content-sharing sites such as Flickr and on search engines, including Google and Yahoo. Licences such as these serve two purposes. Firstly, they give content creators a means by which they can retain some control over their work without capitulating to a system of overly-restrictive copyright. A number of publications associated with the GJM are being given copyleft licences, including books (Notes from Nowhere 2003), Indymedia websites, and online content from magazines that focus on GJM activism (such as The New Internationalist). Secondly, and more importantly, these licences provide both a critique of dominant copyright practices and alternatives to them, providing one possible model of a way to balance creators' interests with a vibrant culture open to reuse and remixing. Digital liberties activists' reformist framing of these licences will not necessarily be adopted by the GJM, but at the very least the DLM has opened a space for discussing alternatives. 
The DLM has also been instrumental in developing and promoting a range of tools, including software and peer-to-peer networks, that allow users to evade or resist government and corporate controls. Some of these may seem trivial at first: for example, the Adblock Plus Firefox extension was developed to allow users to block pop-up and side-bar advertisements from websites (Palant 2009). However, even software such as this serves an important role in resisting the privatisation of cyberspace. Wladimir Palant, creator of Adblock Plus, writes on the extension's "Frequently Asked Questions" page that "widespread adoption of ad blocking software will make intrusive ads economically inefficient until they become as rare as pop-up windows already are today", noting that this may help to make the Internet "a better place". Similarly, even explicitly nonideological open source software ${ }^{34}$ provides alternatives to the corporate hegemony of Apple and Microsoft. For those who want to avoid supporting multinational corporations or the controls on user behaviour that are attached to Apple and Microsoft's software, Linux and other F/LOSS are vital alternatives. As well as software, the creation of peer-to-peer tools such as Bittorrent and sites like The Pirate Bay create temporary autonomous zones (Bey 1991) that are relatively free of government and corporate control. Not all of these tools and spaces are explicitly designed for political reasons, or for use by activists, but they nevertheless help to resist corporate and government control over ICTs and democratise control over ICTs.

Finally, digital liberties activists also provide a number of tools that are aimed directly at activists, particularly tools designed to evade government censorship and surveillance. The most notable of these is The Onion Router, "a free software and an open network that helps you defend against a form of network surveillance that threatens personal freedom and privacy, confidential business activities and relationships, and state security known as traffic analysis" (Tor Project 2009). BoingBoing also provides a guide to getting around online censorship and surveillance which provides links to useful software, guides, and networks (BoingBoing 2009). In Little Brother, Cory Doctorow imagines an operating system called Paranoid Linux which would assume that its user was under assault from a hostile government and do everything it could to keep its user's communications secret $(2008,36)$. This idea was briefly taken up, but

34 To revisit the distinction between open source's apolitical position and the more overtly politicised position of free/libre software, see Chapter Three. 
seems to have fallen by the wayside. It may well reappear at some point in the future. Tools such as these enable activists (and ordinary people) to retain control over communication technologies, evading government attempts to censor or gather information on citizens. This is important not only for activists in authoritarian states, but also for GJM activists who may be engaged in illegal activities which they consider to be justifiable acts of civil disobedience, particularly in the context of the "War on Terror".

In summary, the Indian anti-GM movement and the DLM are both working in concrete ways to ensure that citizens control the technologies that shape their lives. In the case of the Indian movement, activists are working to retain people's control over seeds and agricultural systems in the face of increasing corporate control. In the case of the DLM, struggles to (re)gain control over ICTs support the democratisation of the technologies that many of us use to work, create, and communicate. Activists working in both of these movements recognise that it means little to have a nominally democratic political system if other factors limit citizens' ability to exercise meaningful control over their lives. They are raising awareness of some of the manifold areas in which it is necessary for people to control the means of production, as well as the means of communication, and the information and cultural content that we build our lives on and around. At their most effective, these movements are creating autonomous spaces in which corporate and government power is diminished, or even absent, in which alternatives can be explored, and strength gathered. Even when this ideal is not achieved, however, they increase the ability of activists to organise, to communicate, to build alternatives to the dominance of neoliberalism and to preserve the local and particular in the face of globalising trends.

\section{Peer-based knowledge systems}

As we saw in Chapter One, activists within the GJM benefit from shifts towards peer-based, rather than hierarchical, knowledge systems. There are a multiplicity of these systems in existence, with varying degrees of openness, ranging from indigenous knowledge systems around the world through to the peer-review academic publication system through to Wikipedia and F/LOSS's 
"bazaar" (Raymond 2000) model of development. While each of these casestudy movements is working to preserve existing peer-based knowledge systems, their projects are not merely commemorating these systems: both movements' work includes active, innovative attempts to find new ways of storing and producing knowledge in an open and accessible way.

For those involved in the Indian movement against GM crops, the politics of knowledge are vital. Shiva argues that the Green Revolution was accompanied by a shift in the whole knowledge system associated with agriculture. Peasants were no longer seen as plant breeding specialists and "custodians of the common genetic heritage", and their place was taken by "scientists of multinational seed companies and international research institutions". Plant breeding strategies also changed, shifting from a focus on "maintaining and enriching genetic diversity and self-renewability" to one on "uniformity and nonrenewability, aimed primarily at increasing transnational profits and First World control over the genetic resources of the Third World" (Shiva 1991, 63). At the same time, Shiva $(1991 ; 1997 ; 2001)$ argues, measurement of yields and productivity within what she calls "the Green Revolution paradigm" (which she also calls an "engineering" paradigm) is heavily skewed towards monocultures, ignoring the multiple outputs of indigenous agricultural systems. Through this process, Shiva argues, control over agricultural knowledge slipped from the hands of peasants and into the hands of experts in academic institutions and corporations.

The Indian movement therefore has a high stake in establishing the value of traditional and grassroots knowledge. Rebuilding the understanding of peasants and farmers as plant breeding specialists and challenging the Green Revolution paradigm is the only way in which the battle can be moved to ground that favours the movement. Shiva argues for a view of knowledge that understands all societies as having their own knowledge systems that are suited to local conditions and needs $(1993,135)$. Practically, the support given by Shiva and others to traditional knowledge systems is expressed throughout the movement in the revival or continuance of agricultural festivals, consultation with farmers who continue to use traditional farming techniques, and the preservation of cultural practices and knowledge surrounding indigenous agricultural systems. 
Experiments are also under way with new methods of organising this knowledge, such as the GREEN Foundation's collection of digital videos.

Many of the groups involved in this work are also looking at ways to develop existing knowledge. GREEN Foundation and Navdanya are just two of the many organisations within the Indian anti-GM movement that are working to rejuvenate or recover indigenous agricultural knowledge, as well as to make this knowledge available to others (GREEN Foundation, 2009c; Navdanya, 2009). These organisations draw on traditional and organic farming practices from different parts of India, as well as related practices from other parts of the world. For example, while GREEN Foundation focuses on maintaining local indigenous knowledge around agricultural systems, staff members also praised and drew on Bill Mollison's work on permaculture and organic practices drawn from other countries in their discussions with me.

This work ties into the second important aspect of the movement's attempt to strengthen peer-based knowledge systems: access to information. Since the early days of its founding, the KRRS and other actors within the Indian movement have shown concern over limits to the dissemination of knowledge. During their contestation of the Dunkel Draft, the KRRS argued that the Draft would allow for:

commercialization of research. As a consequence secrecy will prevail on the dissemination of knowledge. Knowledge, being a product of social interaction and social development, any patenting would finally impinge on the freedom of thought and expression, and finally human rights [sic] (KRRS in Assadi 1995, 197).

Throughout the movement, attempts are being made not only to preserve and develop indigenous knowledge, but also to ensure that marginalised communities retain access to it. Some of these attempts have involved large protests or legal struggles, such as the 1993 day of "Reaffirming the Common Intellectual Property Rights of the Peasants" held by the KRRS (Assadi 1995, 203) and the struggles over basmati, turmeric and neem. Others are smallscale, but nevertheless important: workshops, radio shows, and the publication 
of information in pamphlets, books, or websites. GREEN Foundation's use of creative commons licences for their Digital Green repository (2009) is a promising sign in this respect.

Some of the attempts by the movement to build grassroots agricultural systems in which farmers' knowledge is valued are, of necessity, highly localised. Even these limited, local efforts contribute to the GJM's project by preserving and developing the diversity of alternatives to large-scale, corporate-controlled agriculture. Many of these local projects connect with others, creating a web of communication through which knowledge is transferred. Local examples of successful preservation and application of indigenous knowledge are also used as inspiration for other alternatives and as counter-examples to those who claim that international experts know best. There is obviously no single local, embedded, knowledge, but each project to preserve and develop such knowledge systems, in combination with spirited defences of traditional knowledge in a more general sense, such as those written by Shiva, serve to bolster the position of GJM activists.

The peer-based knowledge systems being developed within the DLM are far removed from those that Shiva discusses in her work and, as noted in the first chapter, it would be a stretch to describe them as grassroots knowledge. Data on the digital divide shows that there are still significant gaps between and within regions in terms of Internet access. In 2009, data published by Nielsen Online, the International Telecommunications Union, and other sources showed that approximately 74 per cent of the US population had Internet access, while only around 50 per cent of those in Europe, 24 per cent of those in the Middle East, 18 per cent of those in Asia, and 7 per cent of those in Africa had Internet access (Miniwatts Marketing Group 2009). Considerable variation within regions also exists.

Within states, there are significant gaps between groups in terms of Internet access and usage. For example, Jones and Fox (2009, 3-4) found that 30 per cent of US Internet users are between 18 and 32 years old. This figure represents a disproportionate Internet presence relative to this age group's proportion of the population, which is 26 per cent (Fox \& Jones 2009, 3). Chen 
and Wellman's research suggests that digital divides based on age also exist elsewhere, and are more pronounced in some countries, including Italy, Japan, and Mexico $(2004,43)$. Chen and Wellman's research also notes several other divides, including declining, but persistent, gender divides in the UK, Japan, and China, persistent gender divides in Korea, and increasing gender divides in Germany and Italy $(2004,43)$. Digital divides based on socioeconomic status are perhaps the most important, with a declining but persistent divide based on class in the US, increasing divides in the UK, Germany, and Korea, and "huge" divides in China and Mexico (Chen \& Wellman 2004, 43). Claims that online communities or projects are open to contributions from, or accessible by, everyone, therefore need to come with qualifications.

However, all knowledge systems have limits, even those developed with the aim of being open and accessible. Developing traditional agricultural systems at a local scale will be useful to certain demographics, and developing peer-based knowledge systems online is useful to a very different demographic. Wikipedia and F/LOSS development and forums are, at least in theory, open to anyone, but in a practical sense a significant majority of the world has a limited ability to contribute to these projects. Nevertheless, the DLM makes a vital contribution to the struggle for peer-based knowledge systems by continually asserting that software, encyclopaedias, music, fiction, and other such work produced by amateurs is valuable and worth protecting. Lawrence Lessig, for example, praises the democratising effects of new technologies:

You could write an essay about the inconsistencies in the arguments of the politician you most love to hate, or you could make a short film that puts statement against statement. You could write a poem to express your love, or you could weave together a string - a mash-up - of songs from your favorite artists in a collage and make it available on the Net. [...] The technology of digital "capturing and sharing" promises a world of extraordinarily diverse creativity that can be easily and broadly shared. And as that creativity is applied to democracy, it will enable a broad range of citizens to use technology to express and criticize and contribute to the culture all around $(2004,184)$. 
This sentiment is repeated throughout the movement, whether in other defences of the value of remixes (Gaylor 2009), the many words written in praise of Wikipedia (Zittrain 2008, 133-137; Benkler 2006, 70-74), or the arguments put forward in favour of F/LOSS (Raymond 2000). In opposition to claims that the democratisation of culture has led to decreasing standards (Keen 2007; Helprin 2009), digital liberties activists argue that knowledge produced by amateurs is valuable and enriching.

Seed banks, compendia of traditional agricultural techniques, Wikipedia, and creative commons licenses are all ways of preserving and building on the knowledge of those whose contributions might otherwise be overlooked. Each challenges the idea that only formally-accredited experts can produce useful knowledge. The knowledge embodied in peer-based systems is often different from that produced by experts. Seed banks that serve local needs will contain a smaller range of seeds and a greater amount of accompanying agricultural knowledge than the Global Seed Vault. Another example of this, admitted by Wikipedians, is Wikipedia's disproportionate coverage of "trivial" subjects (such as lightsabers) in comparison to more serious subjects (such as the printing press) (Wikipedians 2009a) ${ }^{35}$. The point here is not that peer-produced knowledge is a better way of producing the same knowledge, but rather that it is a way of producing knowledge relevant to the community from which it emerges. Peer-produced knowledge systems give activists, and non-activist citizens, a chance to contribute directly to creating new understandings of the world.

These case studies also provide examples of the revival of, or experimentation with, peer-based vetting of knowledge. In the case of the traditional and organic agricultural systems promoted by the movement opposing GM crops, my observations of the GREEN Foundation and KRRS's work show that agricultural knowledge is developed and validated through a combination of reference to local traditions and practices, small-scale experimentation with new techniques by farmers, and discussion at village meetings. These processes are not without their problems, as Stone's (2007) work shows, and more research is

35 "Wikigroaning", as this practice is called, involves comparing "a useful Wikipedia article that normal people might read" to "a somehow similar article that is longer, but at the same time, useless to a very large fraction of the population". More examples can be found on the original blog entry where the pursuit was proposed (Titanium 2007). 
required into the relationship between community-level decision-making and external actors such as agricultural extension workers, NGO workers, and seed company representatives.

Many of the communities that constitute the DLM have developed intricate, selfreflexive, and rigorously documented processes for decision-making and vetting of content. Wikipedia's "Neutral Point of View" guidelines and discussion pages provide one well-known example of such a process, but Slashdot's moderation system is particularly notable. Comments are a vital part of Slashdot's peerreview system because they allow other Internet users to provide evidence or analysis that confirms, contradicts, or expands on the items posted. Slashdot has a complicated system for the moderation of such comments: the "Frequently Asked Questions" (FAQ) page (Slashdot 2009) discussing comments and moderation runs to over 7,000 words. This system is "designed to sort the gems and the crap from the steady stream of information that flows through [Slashdot]. And wherever possible, it tries to make the readers of the site take on the responsibility" (Slashdot 2009). The system works by occasionally granting registered users of Slashdot moderation points, picking from those users who read Slashdot frequently, but not obsessively. These moderation points can then be spent rating other users' comments with descriptive comments such as "informative" and a score between -1 and 5 . This system of moderation is, in turn, moderated by reference to users' "Karma", which is determined by users' activity on the site, and by a system of metamoderation (Slashdot 2009). Slashdot's FAQ shows an awareness of debate within the community about moderation, evident not only in the changes that have been made to the system but also in references to issues of fairness. For example, one heading asks "Moderation seems restrictive. Is it really necessary?", while another section addresses anonymous comments, arguing that "We think the ability to post anonymously is important. Sometimes people have important information they want to post, but are afraid to do it if they can be linked to it" (Slashdot 2009). Systems such as Slashdot's and others used within the DLM and anti-GM movement provide models by which communities can become arbiters of accepted knowledge, and do so through a dynamic process that allows debate and change. 
Attempts to build peer-based knowledge systems and to promote the value of grassroots and other peer-based knowledge are vital to the GJM. The availability of knowledge produced by and suited to the needs of local communities is an important resource for projects to build globalisation from below. This is particularly important when it comes to information on agriculture and other necessities, such as shelter and appropriate technology. In a broader sense, gaining recognition for and acceptance of peer-based knowledge shifts the power relations between elites and those who cannot call on the authority accorded by the interlinked matrices of wealth, political power, or institutional accreditation. Activists within the GJM are arguing for a more democratic world, and this claim is greatly strengthened by struggles that assert that local communities and non-elites can be knowledgeable, informed, and innovative. Such struggles undermine the idea that decisions must be made by experts from above, maintaining that ordinary people are also experts and are capable of making their own choices about how to live, how to manage resources, and how to solve local problems.

\section{Preserving diversity}

Diversity is both an end and a means in GJM activists' attempts to build one world with room for many worlds. The two case studies discussed in previous chapters provide concrete examples of the value of diversity. They are also working directly to preserve diversity in the face of homogenising and centralising tendencies. These tendencies are seen in the creation of corporate cartels in areas ranging from the global food system and the loss of agricultural crop biodiversity (Patel 2007) to the media environment, where ever-fewer umbrella corporations control an increasing proportion of the market (Gaylor 2009). Diversity of opinions, of politics, and of lifestyles are all important to the project of building globalisation from below. They represent alternatives to neoliberal globalisation, as well as being valuable in their own right.

The daily work of many activists within the Indian anti-GM crop movement is centred around preserving diversity in the face of spreading monocultures, as well as presenting arguments against the monocultures associated with the Green Revolution and biotechnology. By setting up or maintaining systems 
preserving local seed varieties and developing a multiplicity of organic and lowinput agricultural systems, activists ensure that a range of alternatives to Green Revolution agriculture exist. Those within the movement also use these systems as concrete examples on which they base their arguments against GM crops, and industrialised agriculture more generally. Activists within the movement make several interlinked arguments regarding agricultural biodiversity (GREEN Foundation 2009b; Shiva 1993). These include the importance of agricultural biodiversity for environmental sustainability and food sovereignty: retaining and developing a range of crops and agricultural systems allows farmers in different areas to adapt to local conditions, and lowers the chances that disease or bad conditions will wipe out an entire crop. As one activist on the Intercontinental Caravan put it during a discussion with the director of Nuffield, a charitable trust that published reports advocating the use of GM crops in the Global South, "[w]hat about our ecological and cultural biodiversity? When you limit seed varieties to one or two? Now we have 100 varieties. If one fails, we have many others we can use and if we have only one and it fails, all fails" (Ainger 2003, 168). Domestic crop diversity also provides farmers with food security by providing a range of nutrients in the form of varied food crops. Activists combine practical action to preserve and develop a diverse range of agricultural systems and crop varieties with attempts to highlight the value of diversity.

These arguments are also generalised by activists to refer more generally to the struggle between diversity and monocultures. Vandana Shiva's work provides the clearest example of this. Shiva's (1993) Monocultures of the Mind uses the opposition between monocultures and diversity as a framework for connecting discussions of Green Revolution agriculture, GM crops, and eucalyptus plantations to the broader issues of North-South relations, privatisation, intellectual property regimes, and imperialism. Shiva argues that, "[t]he main threat to living with diversity comes from the habit of thinking in terms of monocultures; from what I have called 'Monocultures of the Mind'. Monocultures of the mind make diversity disappear from perception, and consequently from the world" $(1993,5)$. Shiva has also linked monocultures of the mind to globalisation, arguing in an interview that, "[t]he kind of global monoculture in which everyone feels as if they have to run faster than they are running to stay 
in the same place cannot continue. I think we will become disenchanted with the glamour of globalization" (Shiva 2008). These arguments connect local struggles to the broader project of building globalisation from below.

Participants in the DLM also put forward arguments for diversity. At times, these arguments resonate with those used by the Indian movement. For example, proponents of F/LOSS sometimes draw an analogy between the software ecosystem and agricultural systems. Eric Raymond, a key proponent of the open source position, has said that he would like to see alternatives to Linux "succeed more than they are currently because mono-cultures are vulnerable. If you get a mono-culture that has just one genetic line then the first plague can wipe it out. I would like to see more diversity in the open source community", going on to describe alternatives to Linux as important to "the whole Open Source ecology" (1999). However, one of the key differences between digital liberties activists' arguments for diversity and those of the Indian activists discussed above are that the former are often (but not always) couched within the liberal language of choice. So, for example, while Stallman sees free software as an "ethical imperative" (2009), advocates of the open source approach tend to highlight the benefits of F/LOSS in the familiar terms of consumer capitalism, including "better quality, higher reliability, more flexibility, [and] lower cost" (Open Source Initiative 2007). This tendency to waver between describing diversity as a political, social, or ethical good and as a consumer good is also present in other sections of the DLM, including in discussions of the need to retain a vibrant sphere of cultural production.

At the same time, digital liberties activists are working to create a healthy digital ecosystem. This is manifested clearly in the emerging F/LOSS ecosystem: for example, as of February 2009 230,000 software projects were making use of SourceForge.net, the leading F/LOSS development website (SourceForge 2009). It is also shown in the creation of sites devoted to promoting creative commons-licensed work and making this work available for remixing, such as the "Audio" and "Legal Music for Videos" sections of the Creative Commons website (2009). More importantly, digital liberties activists have repeatedly brought attention to emerging digital monopolies. The most glaring example of this has been the critique of Microsoft's domination of the software market, 
which has long been a target for F/LOSS advocates. Eric Raymond's response to leaked Microsoft documents discussing the threat posed by Linux exemplify this critique. Raymond writes that these documents reveal "the insularity, the arrogance, [and] the obsessive drive to control both markets and customers" characteristic of Microsoft's internal culture, and goes on to say that, "[t]he real issue is that they won't leave me and my friends any safe place. They want to hijack the Internet we built with brains and sweat and blood; they want top-tobottom control of computing everywhere; they're determined to have it all, forever and ever, amen" (2004). This mistrust of monopolistic power has, in recent years, been brought to bear on Google, albeit with a more ambivalent attitude than that displayed towards Microsoft ${ }^{36}$. Digital liberties activists have raised concerns over the possibility that Google's Book Search settlement would give Google "a monopoly over the largest digital library of books in the world" (Samuelson 2009; von Lohmann 2009). Activists have also raised concerns about Google's ability to act as a gatekeeper for Internet searches, although Wikipedia co-founder Jimmy Wales' attempts to develop an open source search engine alternative to Google have foundered (ABC News 2009). Work by activists within the DLM plays a vital role in raising awareness of, and resisting, the emergence of digital monocultures.

The preservation of diversity is important to the GJM both as an intrinsic good and instrumentally. The importance of diversity has been elaborated in Alternatives to Economic Globalization (Anderson et al. 2004), a report that gathers the ideas of many activists and academics aligned with the GJM. The co-authors of this work argue that, "Diversity is key to the vitality, resilience, and innovative capacity of any living system. So too for human societies", going on to identify cultural, economic, and biological diversity as vital aspects of diversity $(2004,89)$. Instrumentally, the preservation of diversity creates spaces in which alternatives to the dominant neoliberal system can be explored. Shiva argues that "The disappearance of diversity is also a disappearance of alternatives and gives rise to the TINA (there is no alternative) syndrome" $(5,1993)$. This syndrome can be resisted through the development and presentation of alternatives, whether these are embodied in a multiplicity of agricultural systems or of operating systems. They also provide resources that may allow activists to

\footnotetext{
36 Siva Vaidhyanathan has been documenting Google's expansion and its effects on his blog,
} The Googlization of Everything (2009). 
build alternatives. In the case of the Indian movement, the availability of a diverse range of seeds that are suited to local conditions preserves a space apart from the increasingly integrated and homogenising world food system, allowing those who participate in alternative food production some autonomy. The DLM, in turn, provides resources that may be taken up by activists, including software that remains outside the control of corporate power. The value of digital diversity to the GJM has gone unrecognised. In attempting to preserve diversity online, to save spaces for the voices of bloggers and amateur coders, the DLM is also preserving space for those whose voices are underrepresented in the mainstream media and in the corridors of power.

These struggles are just two of the many which attempt to preserve meaningful diversity in a world where diversity has increasingly come to mean a choice between twenty different kinds of toothpaste. There are others, of course, including those exploring alternative ways of providing shelter (such as the cooperative housing and squatter movements), alternatives to the capitalist economy (such as those experimenting with reputation or barter economies), and alternatives to current domestic food systems (such as those experimenting with freeganism). While not all sections of the DLM would position their activism as part of the opposition to neoliberalism, their work nevertheless helps to argue for the value of diversity in the face of claims that neoliberal capitalism has the answer-and it is the same answer all around the world.

\section{Resisting enclosure}

The work of each of these movements echoes that of the other, and of the GJM's overall project, through attempts made to resist enclosure and preserve the commons. As I outlined in Chapter One, one of the unifying themes within the GJM is resistance to the privatisation and commodification of life. This resistance has the potential to serve as a basis for further alliances between the DLM and left-wing movements within the GJM. The DLM, the Indian opposition to GM crops, and the GJM as a whole have all adopted frames which highlight the importance of the commons, and projects which resist the enclosure of the commons run through each movement. Resistance to enclosure reinforces

other contributions that the DLM and opposition to GM crops make to 
globalisation from below. For example, the task of resisting enclosure within the Indian movement is closely related to attempts to preserve diversity, as monocultures in agriculture are also associated with commercialising resources previously held in common, including seeds.

The Indian movement's contributions to resisting the enclosure of the commons are manifold. Indian anti-GM activists have played a prominent role in advocating for the importance of the commons, and have provided strong arguments in support of communities' rights to hold certain resources in common. Vandana Shiva, in particular, has played a huge role in this fight. Shiva (2008) outlines the struggle against the enclosure of seeds and of traditional knowledge as having three parts, worth quoting at length:

The first step is challenging it as a moral and ethical issue-in the same way as the slave trade was challenged on the grounds that it's unethical to trade people. You can't pirate knowledge; it's illegitimate, and shouldn't be done. The second step is to develop methods of rejuvenating people's knowledge, of making sure that people regain confidence in their own knowledge so that biodiversity and knowledge is kept in the common domain. The third involves working on legal alternatives. One of the movements we have developed is to say that, just as intellectual property rights protect the inventions of individuals, common rights are needed to protect the common intellectual heritage of indigenous peoples. These are rights that are recognized through the Convention on Biological Diversity. We are working to make sure that they become foundations of our jurisprudence.

This combination of framing enclosure as a moral issue, reinvigorating the public domain, and developing common legal rights runs through the Indian opposition to GM crops.

Strategies such as those listed above by Vandana Shiva hit at the legal regimes and social attitudes that allow enclosure of the commons. There are also a number of strategies that are based on a more direct resistance to such enclosure. The most notable of these is, perhaps, "piracy" of enclosed 
resources. Shiva (2008) argues that the commercialisation of previously common resources means that, "[e]very farmer must go to the seed industry every year to buy their seed and pay an 80 percent royalty to a corporation. [...] Or, if you need a biological pest control, you can no longer use the new seed in your back yard. Instead you have to depend on the Grace Corporation [one of the large MNCs that produces pesticides] or some other entity". However, as both Gandhi's Salt Satyagraha in defiance of British salt monopolies (Shiva 2008) and the wide-scale "piracy" of GM cotton discussed in Chapter Two show, resources that are in theory under private (or government) control may nevertheless be accessed widely by others. Resistance to enclosure of traditional knowledge and seeds through open or hidden subversion of intellectual property rights has not hitherto played a significant role within the Indian anti-GM movement, presumably in large part because GM crops are seen as undesirable and patents on more desirable crops and medicinal plants have been successfully challenged in court. However, more research into this form of resistance to enclosure of the commons within the movement may provide useful results.

The DLM also places a very strong emphasis on the commons, and particularly on the public domain. Boyle argues that "the public domain is the basis for our art, our science, and our self-understanding. It is the raw material from which we make new inventions and create new cultural works" $(2008,39)$. More than this,

[o]ur markets, our democracy, our science, our traditions of free speech, and our art all depend more heavily on a public domain of freely available material than they do on the informational material that is covered by property rights. The public domain is not some gummy residue left behind when all the good stuff has been covered by property law. The public domain is the place we quarry the building blocks of our culture. It is, in fact, the majority of our culture (Boyle 2008, 40-41).

This argument is common within the DLM, and the necessity of having access to material in the public domain has been continually cited by activists as vital to democracy and to cultural innovation (cf. Lessig 2004; Gaylor 2009). Raising 
awareness of the importance of the public domain is an important part of the DLM's work.

James Boyle calls explicitly for a movement to protect the public domain, and argues that such a movement is currently at the stage that the environmental movement was at in the United States during the 1950s and 1960s. Boyle writes that activism is emerging around a number of disparate issues surrounding intellectual property, just as environmental activism emerged in the 1950s and 1960s in the US around particular areas and issues. He sees a necessity for the development of "a general framework, a perception of common interest in apparently disparate situations" (Boyle 2008, 239). I have argued in Chapter Three that this general framework is now emerging: the DLM's prioritisation of user control over the digital domain links not only disparate issues related to the public domain, but also other struggles over ICTs.

Boyle has suggested a strategy for the movement, drawing on lessons from the environmental movement. Boyle calls for a "cultural environmentalism, an environmentalism of the mind", and notes that such a movement has actually begun to emerge $(2008,241)$. This movement is beginning to perform a "semantic reorganization" of conceptions of the public domain (Boyle 2008, 242), and activists within it are working to bring attention to the importance of, and threats to, the public domain through writing, protests, lobbying, and other means. Activism around the public domain is also linked to other issues within the DLM. For example, many arguments against DRM note that technological restrictions on copying material make no allowance for fair use or for the expiration of copyright. Boyle, who is a founding member of DLM organisations Creative Commons and Science Commons, suggests adopting a strategy that works to resist the enclosure of the public domain, and this is now being adopted within the DLM.

As in the case of the Indian movement, activists from the DLM have engaged in a number of strategies that defy the enclosure of the commons in concrete ways. Creative commons and other copyleft licenses are one such example: they do not rely on changing society's perception of the public domain, nor do they require changes to the legal system of copyright. Instead, they are what 
Boyle calls "a private "hack" to produce a more finely-tuned copyright structure, to replace "all rights reserved" with "some rights reserved"', and therefore to create "a global "commons" of material [...] open to all," as long as they are willing to abide by the terms of use $(2008,183)$. Sharing copyrighted material online is another method of resisting the enclosure of the public domain within the gates of intellectual property, and is illegal rather than legal as copyleft licenses are.

Both the DLM and the Indian opposition to GM crops make important contributions to the GJM through their resistance to enclosure of the commons. Firstly, the role that activists from these movements are playing in creating support for the commons as an idea is vital. The concept of holding resources in common has been battered by neoliberal ideology, which proclaims that efficient use of resources can only be ensured by privatisation. In contrast to this, activists from the movements discussed here have argued that communities are effective at managing resources held in common, and that many benefits come from preserving some resources in common. Secondly, resources held in common are vital to building globalisation from below, including traditional knowledge and seeds. Similarly, preserving cultural content within the public domain makes a wide range of material available for activists to learn from, as well as to reuse and remix in order to spread their message.

\section{Conclusion}

Existing studies of the GJM have tended to simplify the movement, stripping away its complexities by focusing either on movement events such as protests or on NGOs within the movement. Such simplification serves an important purpose, allowing scholars to untangle the vast number of interwoven threads that make up the movement. Unfortunately, this means that important aspects of the movement are often overlooked, or passed over only briefly. I have attempted, in this chapter, to show some of the complexity that is often elided in studies of the GJM. Both the DLM and the Indian opposition to GM crops overlap with the GJM, but the relationship between each movement and the GJM is not easily mapped, nor is it stable. Nevertheless, both the DLM and the Indian movement make vital contributions to the GJM. In analysing these 
issues, I have attempted to add to the literature on the GJM, and to social movements more generally, in two important respects.

Firstly, I have highlighted the difficulties involved in studying the GJM and the value of maintaining a conceptual framework that is open to complexity and uncertainty. It would be impossible to recognise many of the contributions that these movements make to the project of building globalisation from below were we to work within a simplistic understanding of the GJM. It is only by recognising it as constituted from a wide variety of struggles, and as having blurred and shifting borders, that we can understand the role of actors at the fringes of the GJM, as well as those with clearly defined positions within the movement. The World Social Forum, the Zapatistas, anti-WTO actions, and other such spaces, actors, and events, have a well-defined role within the GJM and present objects for study that have an attractive clarity. Movements such as the two discussed here have a more unclear relationship to the GJM, and I have attempted to map this relationship without sweeping its complexity under the carpet. In doing so, I wish to emphasise the value of bringing scholarly attention to bear on more untidy elements of the GJM, and to social movements more generally, as well as those that yield to easy categorisation.

The Indian opposition to GM crops has long been a poster-child for the GJM, while the DLM has barely registered on the radar of prominent activist or scholarly accounts of the GJM. In many ways, positioning the Indian movement within the GJM is unproblematic: for example, activists within the Indian movement identify themselves as part of the GJM, GJM texts regularly refer to the Indian movement, and activists from the Indian movement take part in GJM events. Nevertheless, resource constraints and nationalist discourse separate the Indian movement from the GJM and lead to fragile connections between Indian activists and those in other parts of the world. In contrast to this, the relatively privileged demographic that makes up the DLM have the capacity to sustain international connections, but have not on the whole created the same close connections with the GJM that Indian activists have. Nevertheless, there is still a significant overlap between the DLM and the GJM, as shown by the existence of groups which provide support for GJM activists and the support 
voiced by GJM and DLM activists' for each others' projects. Both the DLM and the Indian opposition to GM crops have a complex relationship to the GJM.

Despite this, both the DLM and the Indian opposition to GM crops make vital contributions to the GJM's project. The second contribution to the literature on the GJM has been to argue for the importance of struggles over knowledge to the movement's struggle to build globalisation from below. Both case-study movements make concrete and important contributions to the GJM's project through their struggles to establish democratic control over key technologies, to preserve diversity in the face of spreading monocultures, to preserve peerbased knowledge systems, and to resist enclosure of the commons. The localised and/or issue-specific struggles carried out by the DLM and Indian movement have had wider significance, tying into and supporting the GJM's work. Struggles over knowledge are another important thread running through the GJM: they play a vital role in building globalisation from below, and they are an important part of many of the local struggles within the GJM. It is hoped that this work will encourage further scholarship examining the role of struggles over knowledge in other parts of the GJM. 


\section{Conclusion}

This thesis has argued that struggles over knowledge make vital contributions to the GJM's attempts to build alternatives to neoliberal globalisation. These contributions are not always straightforward: the GJM has no central organisation, manifesto, or blueprint for the world that GJM participants are trying to bring into being. The alternatives it presents are therefore built from the sum of many struggles, small and large, by actors distributed throughout the world. At times, these struggles are explicitly framed as part of the GJM's project. More often, they address issues that are more local or more narrow than the broad goal of "global justice". Nevertheless, these struggles are connected through a global network of activism and, most importantly, by a shared commitment to the creation of a more democratic and diverse world, in which communities, rather than corporations, control essential resources. Analysis of the Indian opposition to GM crops and the DLM has demonstrated the importance of struggles over knowledge to the GJM.

The first chapter of this thesis provided the conceptual framework for the analysis, outlining the relationship between neoliberal globalisation, the GJM, and struggles over knowledge. It began with an analysis of the connection between science, technology, and the flow of information, arguing that these are interlinked aspects of knowledge rather than separate phenomena. Knowledge needs to be understood in the context of other systems of power: knowledge is both shaped by and constitutes social, political, and economic power structures. This was demonstrated with reference to the rise of neoliberal globalisation, which has been supported in part by particular scientific narratives and technological changes. At the same time, neoliberal globalisation has shaped the development of science, technology, and knowledge more generally, supporting some knowledge systems while undermining others. The rise of neoliberal globalisation and its dominance over knowledge systems has not, however, been complete. Technological changes have also facilitated the emergence of the GJM, and GJM activists have developed strategies and structures that make effective use of ICTs. GJM activists also rely on gaining legitimacy for grassroots, embedded, and embodied knowledge systems. 
However, global elites have attempted to limit the democratising potential of changes to knowledge systems and have started to take a variety of actions aimed at regaining control over this domain, such as increasing surveillance of online communications. Struggles over knowledge are therefore linked with, and vital to, struggles to reshape globalisation.

The second chapter analysed the Indian opposition to GM crops, focusing on the southern state of Karnataka, which has been the locus of significant grassroots activism. The Indian movement has foregrounded the risks of GM crops to producers, rather than to the environment or consumers, although risks to the latter have also been discussed. This focus on producers is partly attributable to the long history of strong farmers' movements in Karnataka: the KRRS was one of the first actors to take up the anti-GM banner. The opposition to GM crops has primarily been framed through reference to swadeshi (villagelevel self-sufficiency) and the opposition to neoliberal globalisation. A significant part of the Indian anti-GM movement's work has also been directed at the need to provide alternatives to GM crops, and to Green Revolution monocropping more generally. It has also been associated with a slightly different framing of the opposition to GM crops, mobilising ecofeminist or development discourses.

While those involved in the Indian anti-GM movement have achieved limited success in their attempts to prevent the spread of GM crops in India, they have made significant contributions to the national and international debate over biotechnology and the patenting of life. Firstly, Indian activists have successfully questioned the terms of the debate over GM crops, highlighting biases in the pro-GM research and arguing for the value of alternative frameworks in assessing the success of agricultural systems. This reframing of the debate has opened up space for increased input from marginalised groups, including activists themselves. Secondly, activists have refused to allow the incorporation of biodiversity within the intellectual property framework, insisting that life cannot be patented. Thirdly, activists have argued that information-both the information contained within seeds and information about GM crops-needs to remain freely accessible to agricultural communities. These contributions have been vital interventions in debates over biotechnology and intellectual property. 
The third chapter discussed the DLM, which has received very little attention from social movement scholars. This movement is working to highlight the political aspects of digital technologies, and retain democratic control over them. The chapter began by providing evidence for my claim that a coherent movement has coalesced around these issues. It then analysed the context from which the DLM has emerged. In part, the DLM has been a response to elite attempts to gain tighter control over the spaces opened up by ICTs and the uses to which they are put. These attempts have manifested in a wide range of actions, including increased surveillance of online spaces, changes to copyright law, and the application of technological controls to particular devices. While the DLM has in part been a reaction to these developments, it has also emerged from the amalgamation and evolution of other movements and communities, most notably the F/LOSS movement and hacker subcultures. This chapter provided a definition and evaluation of an under-recognised movement that is contesting issues of extreme importance to the GJM.

The fourth chapter synthesised discussion of the Indian opposition to GM crops and the DLM with regard to the ways in which their struggles over knowledge contribute to the GJM. The chapter began by exploring the relationship of each case study movement to the GJM. Although the Indian opposition to GM crops is in many senses a paradigmatic part of the GJM, closer examination of the relationship between the Indian movement and the GJM shows that there are important respects in which this relationship is fragile and strained. The Indian movement lacks the resources to sustain international connections except at the level of movement leaders, and the nationalist framing of its struggle at times alienates it from other GJM activists. In contrast, while at first glance a wide gulf exists between the DLM and the GJM, there are grounds for believing that this has been bridged, and that connections between the DLM and GJM are growing. Analysis of the complex relationship between the case-study movements and the GJM provides a framework for understanding the way in which these movements contribute to the GJM. It also aids in developing a more nuanced understanding of the GJM as constituted from diverse struggles which are not easily mapped. Bearing this in mind, the second part of the chapter assesses the ways in which struggles over knowledge within the DLM and Indian movement contribute to the GJM. Both case-study movements aid 
the GJM's attempts to build alternatives to neoliberal capitalism through their struggles to protect peer-based knowledge systems, preserve diversity, resist enclosure, and retain democratic control over key technologies. These struggles provide vital assistance to the GJM.

\section{Contributions to the field}

The primary contribution of this thesis to existing scholarship has been to demonstrate that struggles over knowledge play a vital role in helping to support and further attempts by GJM activists to resist neoliberal capitalism and build more diverse, democratic, and sustainable forms of globalisation. Although the contexts in which the DLM and the Indian opposition to GM crops are operating are very different, there are clear and recognisable threads that run through their work. These threads play an important role within the GJM, interweaving with other struggles on diverse issues. The struggles over knowledge engaged in by the DLM and the Indian anti-GM movement support other participants involved in struggles that constitute the GJM, contributing to the creation of alternatives to the current dominant political, social, and economic systems. Without support for democratic control over important technologies, peer-based knowledge systems, diversity, and communally-owned resources, the GJM would be significantly impaired in its work. As I argued in Chapter One, control over and access to Information Age technologies and knowledge systems are vital to the work of the GJM. If these struggles over knowledge fail, there is a chance that the GJM will not be able to retain its current decentralised form, and GJM activists will lose access to many of the resources that are necessary for their work. This focus on the importance of struggles over knowledge to the GJM adds a vital dimension to existing scholarship on the GJM, and is my most important contribution to the existing literature.

The second contribution that this thesis makes to the literature on social movements and transnational social movements is the emphasis on the need to recognise that social movements have fluid boundaries that cannot be easily mapped. While this has been noted in existing literature on social movements, for example in the tendency to refer to movement "participants" rather than "members", most studies do not directly engage with the issue. Instead, the 
untidy borders of social movements are swept under the carpet either by focusing on specific events or organisations, or by simply taking movement borders for granted. This approach has its virtues, and certainly allows for a high degree of conceptual clarity. However, at times it is useful to grapple more directly with the issue.

In the case of this thesis, analysis of the complex relationship that both casestudy movements have with the GJM allows for a more nuanced understanding of the way in which the GJM is constituted from diverse struggles throughout the world. Examination of the Indian movement's relationship with the GJM has shown that even those movements considered to be at the centre of the GJM, as the Indian movement is, may not be as closely connected to the rest of the GJM as is assumed. It may therefore be useful to resist a conceptualisation of the GJM as having a strongly-connected centre and weakly-connected margins, and instead think of the movement as constituted through decentralised and often weakly-connected struggles across the world. Discussion of the DLM has reinforced this, as it has been shown that even movements that do not achieve significant visibility within the GJM may provide vital support to its work. This analysis has contributed a conceptualisation of the movement as fragmented, shifting, and consisting, in effect, entirely of margins, with no single, strong, centre.

The third contribution that this thesis has made to the existing literature is the addition of further research on the Indian movement against GM crops and the DLM. I have added to the significant body of work that already exists on the Indian movement through an in-depth analysis of the way in which activists have framed their opposition to GM crops. I have also expanded upon the existing literature by providing a deeper exploration of the relationship between opposition to GM crops and promotion of alternatives to monocropping, as well as of the relationship between the Indian movement and the GJM. My discussion of the DLM is the clearest original contribution that this thesis makes to existing literature on social movements. The DLM is bringing attention to new issues that are relevant to scholars in a variety of fields, including social movement scholarship. It displays characteristics that may provide new challenges to existing theoretical models of social movements, including the use 
of the Internet as the primary space in which the movement organises and builds collective identity. My research and analysis of the case-study movements' contributes additional analysis to scholars' understanding of these movements, as well as of how they relate the GJM.

I am hopeful that as well as contributing to the academic literature, this work will be relevant to GJM activists. In writing this thesis, I have drawn extensively on activists' analyses of their own work and the issues that they are facing. I am also deeply indebted to the Indian activists who took the time to talk to me and allowed me to observe and participate in their work, as well as to Christian Engström of the Swedish Pirate Party and to the countless WSF participants who I spoke to. The activists whose work and time I have drawn on will each disagree with some of what I have argued here, but I am also optimistic that this thesis makes useful contributions to global justice activism by highlighting the importance of struggles over knowledge to the GJM, as well as to the more issue-specific struggles being undertaken by the DLM and Indian opposition to GM crops.

Throughout this thesis I have argued that more recognition is due for the importance of struggles over knowledge to the GJM: this injunction is as relevant to activists as it is to social movements scholars, and is my most important message to GJM activists. Additionally, in highlighting the contributions that the DLM is making to the GJM's project, and the common themes that run through both digital liberties activism and the Indian opposition to GM crops, I hope to encourage a strengthening of existing links between the DLM and the GJM. Finally, I hope that my discussion of the DLM and the Indian opposition to GM crops will contribute to activists' understandings of their movements, the work they are doing and the tactics that they employ.

I hope that my research is relevant for activists because the end of history has not arrived, and we are not living in the best of all possible worlds. Although the worst effects of the global financial crisis seem to have been avoided, at least momentarily, in Australia, the latest round of financial instability has highlighted the fragility of the current incarnation of capitalism. The effects of the global financial crisis on the poorest sections of the population in developed nations 
has also reinforced the message that neoliberal globalisation does not, in fact, benefit everyone equally. For many, even in the developed nations, neoliberal globalisation has contributed to significant hardships and instability. In addition to this, the current form of capitalism (and quite possibly all forms of capitalism) are beginning to place an incredible strain upon our planet's ability to sustain the conditions which humans have adapted to. It is therefore essential that we look for alternatives to dominant political and economic systems.

Global justice activists are working to build alternatives to the current system. It is possible that the reader will not agree that the alternatives proposed by the GJM are better than what we have now, or that they are the best options available. Nevertheless, even those who disagree with the movement's work must recognise the importance of GJM activists' attempts to bring about widespread, systemic change. Given this, it is vital that scholars strive to understand how the GJM is structured, the alternatives that it is proposing, and its tactics and strategies. My work makes a significant contribution to this project in its exploration of a vital aspect of the movement's work: struggles over knowledge.

\section{Directions for further research}

More research into both the DLM and the Indian movement is required. This analysis has highlighted the important contributions that both case-study movements make to the GJM, as well as to the context in which each movement is working. The DLM continues to receive limited attention in the field of social movement scholarship, and is a crucial period of development. Given the importance of the movement's work, both in itself and in terms of how it will affect other social movements, this elision is regrettable. The Indian movement against GM crops also requires further research. As was briefly discussed in Chapter Two, 2009 saw increasing attempts to mobilise a middle-class demographic in the struggle against GM crops in Karnataka. More research into how this movement is changing, and particularly research into the involvement of educated professionals, will help to give greater insight into how social movements are affected by the processes of globalisation. While there is certainly a place for Northern researchers in this area, the importance of 
research carried out by those who understand the context and can speak the language(s) must be emphasised. Both movements are likely to change considerably over coming years, and further work will be needed to ensure that research on each movement is kept relevant and up-to-date.

As well as further research into these movements, understanding of the importance of struggles over knowledge to the GJM should be expanded by further investigation of other movements working in related areas. This analysis has shown the importance of the DLM and the Indian movement against GM crops to the GJM: these movements are not the only ones contributing to the GJM in this way. People's science movements, appropriate technology movements, freedom of information movements, and activism emerging around nanotechnology are, among many other struggles, also playing a role. Studies of the relationship of these movements to the GJM's attempts to create change are essential.

Finally, while the focus of this thesis has been on struggles over knowledge, it is the link between these struggles and material conditions that is most vital. As argued in Chapter Four, struggles over knowledge have effects on, and are affected by, very real struggles over political control that have serious and farreaching implications for the distribution of power throughout the world. Debates about intellectual property law, the structure of the Internet, or GM technology are important insofar as they relate to people's ability to access the resources necessary to have meaningful control over their own lives. It is vital, therefore, to see these struggles as always connected to the ongoing struggle over, for example, agricultural land reforms in India and the environmental and labour conditions under which electronic goods are produced. More research into the material effects of these struggles is therefore urgently required.

Struggles over knowledge are not the only important aspect of the GJM, but they nevertheless play a key role in the movement's work. The DLM and the Indian movement against GM crops are, through their struggles, strengthening the GJM and contributing to efforts by global justice activists to resist enclosure of the commons and create a more diverse and democratic world. The future of 
these movements, and of the GJM as a whole, remains uncertain. We are living in uncertain times, and each movement discussed here is opposed by a number of powerful actors and entrenched elites. Their success or failure will have important repercussions, not only for the activists involved and the issues that they are directly addressing, but also for the world as a whole. 


\section{Bibliography}

Abbott, Leala. 2008. "A librarian at the H.O.P.E (Hackers on Planet Earth) Conference." Off the Shelf. Available at: http://lealaabbott.com/wp/2008/07/20/the-librarian-at-the-hacker-conever-get-the-feeling-your-being-pwned/ [Accessed June 10, 2009].

Achbar, Mark (Director) and Jennifer Abbott (Director). 2004. The Corporation [Documentary]. Big Picture Media Corporation.

Ainger, Katherine. 2003. "Life is not business: the Intercontinental Caravan." In Notes from Nowhere, ed. We are everywhere: the irresistible rise of global anticapitalism. London and New York: Verso, pp. 160 - 170.

Anderson, Kim and Lee Ann Jackson. 2005. Global responses to GM food technology: implications for Australia. A report for the Australian Government Rural Industries Research and Development Corporation. Available from: http://www.rirdc.gov.au/fullreports/Index.htm [Accessed July 6,2007$]$.

Anderson, Ross. 2003. "'Trusted computing frequently asked questions." Available at: http://www.cl.cam.ac.uk/ rja14/tcpa-faq.html [Accessed March 2, 2008].

Anderson, Sarah et al. 2004. Alternatives to economic globalization: a better world is possible. A report of the International Forum on Globalization. eds John Cavanagh and Jerry Mander. San Francisco: Berrett-Koehler Publishers.

Andrejevic, Mark. 2007. "Surveillance in the digital enclosure." The Communication Review 10, pp. 295 - 317.

Anonymous Iran. 2009. "Task Force /i/ran. Electronic attack. Guidelines, tools, and links." Why We Protest - Iran. Available at:

http://iran.whyweprotest.net/help-iran-online/2310-task-force-i-ranelectronic-attack-guidelines-tools-links.html [Accessed July 16, 2009].

Arquilla, John and David Ronfeldt, eds 2001. Networks and netwars: the future of terror, crime, and militancy. RAND Corporation. Available at: http://www.rand.org/pubs/monograph_reports/MR1382/ [Accessed February 12, 2008].

Asay, Matt. 2009. "Does OpenOffice have 11 million active U.S. users?" CNET News. Available at: http://news.cnet.com/8301-13505_3-1019584516.html [Accessed June 9, 2009].

Ask a Ninja. 2006. "Special Delivery 4 "Net Neutrality"." Available at: http://askaninja.com/node/585 [Accessed December 8, 2008].

Assadi, Muzaffar. 1994. "'Khadi Curtain', 'Weak Capitalism' and 'Operation Ryot': some ambiguities in farmers' discourse, Karnataka and 
Maharashtra 1980-93." In Tom Brass, ed. The Journal of Peasant Studies, Special issue on New Farmers' Movements in India, 21 (3 \& 4), pp. $212-227$.

Assadi, Muzaffar. 1995. "Dunkelism and peasant protest in Karnataka: a view from within." Social Action, 45, pp. $191-205$.

Assadi, Muzaffar. 1997. Peasant movement in Karnataka 1980 - 94. Delhi: Shipra Publications.

Assadi, Muzaffar. 2004. "Social movements in Karnataka." In John Desrochers and Paulson V. Veliyannoor, eds Poverty, marginalisation and empowerment in Karnataka. Bangalore: KRCR - JPC Publications, pp. $197-215$.

Bae, Young Ja. 2003. "Information technology and the empowerment of new actors in international relations." Journal of International and Area Studies 10(2), pp. $79-92$.

Banaji, Jairus. 1994. "The farmers' movements: a critique of conservative rural coalitions." The Journal of Peasant Studies, 21 (3/4), pp. 228 - 245.

Bandy, Joe and Jackie Smith. 2005. "Factors affecting conflict and cooperation in transnational movement networks." In Joe Bandy and Jackie Smith, eds, Coalitions across borders: transnational protest and the neoliberal order. Oxford: Rowman and Littlefield Publishers, pp. 231 - 252.

Bangalore Bio. 2009. "Bangalore Bio 2009-India's Biggest Biotech Show." Available at: http://www.bangalorebio.in/ [Accessed June 2, 2009].

Barabasi, A. L. 2002. Linked: the new science of networks. Cambridge, Massachusetts: Perseus.

Barbrook, Richard, and Andy Cameron. 1995. "The Californian ideology." The Hypermedia Research Centre. Available at:

http://www.hrc.wmin.ac.uk/theory-californianideology.html [Accessed April 14, 2007].

Barlow, John Perry. 1997. "Internet underground: the John Perry Barlow interview." Disinfo.com. Available at:

http://www.disinfo.com/archive/pages/article/id1959/pg1/index.html [Accessed July 17, 2009].

Battistoni, Marco. 2008. "Mission statement." Open Source Observatory. Available at: http://www.osor.eu/breaking-news/mission-statement [Accessed June 9, 2009].

Bauchspies, Wenda, Jennifer Croissant, and Sal Restivo. 2006. Science, technology, and society: a sociological approach. Malden: Blackwell Publishing.

BBC News. 2010. "Pirate Bay Founding Group Disbands." BBC News. Available 
at: http://news.bbc.co.uk/2/hi/10433195.stm [Accessed July 5, 2010].

Bello, Walden. 2004. "The Global South." In Tom Mertes, ed. A movement of movements: is another world really possible? London and New York: Verso, pp. 49 - 70.

Benkler, Yochai. 2006. The wealth of networks: how social production transforms markets and freedom. New Haven and London: Yale University Press. Available at: http://www.benkler.org [Accessed February 27, 2007].

Bennett, Lance W. 2003. "Communicating global activism: strengths and vulnerabilities of networked politics." Information, Communication \& Society 6(2), pp. 143 - 168.

Berry, David M. 2004a. "Internet research: privacy, ethics and alienation: an open source approach." Internet Research 14(4), pp. 323 - 332.

Berry, David M. 2004b. "The contestation of code: a preliminary investigation into the discourse of the free/libre and open source movements." Critical Discourse Studies 1(1), pp. $65-89$.

Bey, Hakim. 1991. "The Temporary Autonomous Zone, ontological anarchy, poetic terrorism." Available at:

http://www.hermetic.com/bey/taz_cont.html [Accessed May 22, 2006].

Biewen, John. 2000. "Story: reporter's notebook." American Radio Works. Available at:

http://americanradioworks.publicradio.org/features/gmos_india/reportersn otebook.html [Accessed June 1, 2005].

Bijoy, C.R. 2003. "The adivasis of India: a history of discrimination, conflict and resistance." People's Union for Civil Liberties. Available at: http://www.pucl.org/Topics/Dalit-tribal/2003/adivasi.htm [Accessed August 9, 2008].

Blakely, Rhys. 2006. "Yahoo in second Chinese blogger row." Times Online. Available at:

http://business.timesonline.co.uk/tol/business/industry_sectors/media/arti cle728898.ece [Accessed December 11, 2008].

Boing Boing. Available at: http://boingboing.net/ [Accessed June 10, 2009].

BoingBoing. 2009. "Boing Boing's guide to Defeating Censorware." BoingBoing. Available at: http://www.boingboing.net/censorroute.html [Accessed July 22, 2009].

Bollier, David. 2002. Silent theft: the private plunder of our common wealth. New York and London: Routledge.

Borland, John. 2001. "Free speech victory for DVD crackers." ZDNet.co.uk. Available at: 
http://news.zdnet.co.uk/emergingtech/0,1000000183,2098494,00.htm? $r=1$ [Accessed December 11, 2008].

Borowiak, Craig. 2004. "Farmers' rights: intellectual property regimes and the struggle over seeds." Politics \& Society 32(4), pp. 511 - 543. Available at: http://pas.sagepub.com/cgi/content/abstract/32/4/511 [Accessed June 26, 2009].

Bové, José. 2004. "A farmers' international?" In Tom Mertes, ed. A movement of movements: is another world really possible? London and New York: Verso, pp. 137 - 151.

Bowcott, Owen. 2008. "CCTV boom has failed to slash crime, say police." The Guardian. Available at: http://www.guardian.co.uk/uk/2008/may/06/ukcrime1 [Accessed May 5, 2009].

Boykoff, Jules. 2006. "Framing dissent: mass-media coverage of the global justice movement." New Political Science 28(2), pp. 201-228. Available from EBSCOhost [Accessed July 20, 2009].

Boyle, James. 2008. The public domain: enclosing the commons of the mind. New Haven and London: Yale University Press.

Brabham, Daren C. 2008. "Crowdsourcing as a model for problem solving: an introduction and cases." Convergence: The International Journal of Research into New Media Technologies 14(1), pp. 75 - 90.

Brass, Tom, 1995a. "The new farmers' movements in India." In Tom Brass, ed. New farmers' movements in India. England: Frank Cass, pp. 3 - 26.

Brass, Tom, 1995b. "The politics of gender, nature and nation in the discourse of the new farmers' movements." In Tom Brass, ed. New farmers' movements in India. England: Frank Cass, pp. 27 - 71.

Brecher, J., T. Costello, and B. Smith. 2000. Globalization from below: the power of solidarity. Cambridge, Massachusetts: South End Press.

Brown, Gordon. 2006. "We need to be more fair; Labour's heir apparent on what he and Blair and the world can all agree upon." Newsweek. Available at: http://www.newsweek.com/id/45598 [Accessed November 19, 2006].

Brown, Kenneth P. 2005. "Intellectual property—Left? Considerations regarding unchallenged infringement in public domain software development." Alexis de Tocqueville Institute. Available at: http://www.adti.net/ip/laches.050405.pdf [Accessed December 11, 2008].

Burbach, Roger. 2001. Globalization and postmodern politics: from Zapatistas to high-tech robber barons. London, Sterling, Virginia and Kingston, Jamaica: Pluto Press and Awarak Publications.

Burgmann, Verity. 2003. Power, profit and protest. Crows Nest, Australia: Allen 
\& Unwin.

Caldwell, French, and Richard Hunter. 2002. “'Digital Pearl Harbor: defending your critical infrastructure." Gartner. Available at: http://www.gartner.com/pages/story.php.id.2727.s.8.jsp [Accessed December 10, 2008].

Callinicos, Alex. 2003. An anti-capitalist manifesto. Cambridge: Polity.

Castells, Manuel. 2001. The Internet galaxy: reflections on the Internet, business, and society. Oxford: Oxford University Press.

Castells, Manuel. 2000. The rise of the Network Society. 2nd ed. Oxford: Blackwell Publishing.

Castells, Manuel. 2005. "Grassrooting the space of flows." In Louise Amoore, ed. The global resistance reader. New York: Routledge, pp. 363 - 370.

Chen, Wenhong and Barry Wellman. "The global digital divide-within and between countries." IT \& Society 1 (7), pp. $39-45$.

Chiao, Benjamin Hak-Fung. 2003. "An economic theory of free and open source software: a tour from the lighthouse to Chinese-style socialism."

Proceedings of the International Conference on Open Source 2003. Available at: http://opensource.mit.edu/papers/chiao.pdf.

Chinese Human Rights Defenders. 2009. Tug of war over China's cyberspace. Available at: http://crdnet.org/Article/Class9/Class11/200903/20090318235654_14369.html [Accessed June 4, 2009].

Choike. 2009. "World Social Forum (WSF) 2007-Nairobi." Available at: http://www.choike.org/2009/eng/eventos/41.html [Accessed 26 October, 2009].

Cleaver, Harry. 1999. "Computer-linked social movements and the global threat to capitalism." Computers, Networks and the Prospects for European and World Security, Rovereto (Trento), Italy. Available at: http://www.eco.utexas.edu/homepages/Faculty/Cleaver/polnet.html [Accessed May 24, 2005].

Cohen, Robin, and Paul Kennedy. 2000. Global sociology. Houndsmills, Basingstoke, Hampshire and London: Macmillan Press.

Conroy, Stephen. 2008. "Internet filtering technology." Australian Labor Party. Available at: http://www.alp.org.au/media/0708/mscoit290.php [Accessed June 15, 2009].

Cotton Australia. 2008. "Water and Cotton Fact Sheet." Cotton Australia. Available at: http://www.cottonaustralia.com.au/facts/factsandfigures.aspx?id=17 [Accessed May 27, 2009]. 
Coleman, Gabriella. 2004. "The political agnosticism of free and open source software and the inadvertent politics of contrast." Anthropology Quarterly 77(3), pp. 507 - 519. Available at:

http://aq.gwu.edu/archive/table_summer04.htm [Accessed October 20, 2008].

Cox, Laurence and Alf Gunvald Nilsen. 2007. "Social movements research and the 'movement of movements': studying resistance to neoliberal globalisation." Sociology Compass 1(2), pp. $424-442$.

Creative Commons. 2009a. "Audio." Creative Commons. Available at: http://creativecommons.org/audio/ [Accessed July 29, 2009].

Creative Commons. 2009b. "Legal music for videos." Creative Commons. Available at: http://creativecommons.org/legalmusicforvideos/ [Accessed July 29, 2009].

Croeser, Sky. 2006. "The global justice movement: providing human security to the least secure?" ISTR Working Paper Series. Available at: http://www.istr.org/conferences/bangkok/WPVolume/Croeser.Sky.pdf.

Croeser, Sky. 2007. "Framing genetically modified crops: where do women fit into the picture?." Agenda 73, pp. $33-45$.

Croeser, S. 2008. "Contested technologies: the global justice movement and emerging constraints on activists' use of information and communications technologies." Australian Political Studies Association Conference, Brisbane, $6^{\text {th }}-9^{\text {th }}$ July. Available at: http://www.uq.edu.au/polsis/apsa2008/Refereed-papers/Croeser.pdf [Accessed August 20, 2009].

The Crucible II Group, 2000. Seeding solutions, Vol 1. Policy options for genetic resources: people, plants, and patents revisited, the International Development Research Centre, the International Plant Genetic Resources Institute, and the Dag Hammarskjöld Foundation, Rome, Uppsala and Ottawa.

Davies, Christie. 2007. "Humour and protest: jokes under communism." International Review of Social History 52 (Supplement S15), pp. 291305. Available from Cambridge Journals Online [Accessed April 15, 2009].

Declaration of Belém. 1988. International Society of Ethnobiology. Available at: http://ise.arts.ubc.ca/global_coalition/declaration.php [Accessed October 23, 2009].

de Marcellus, Olivier. 2003. "Peoples' Global Action: the grassroots go global." In Notes from Nowhere, ed. We are everywhere: the irresistible rise of global anticapitalism. London and New York: Verso, pp. 97 - 101.

della Porta, Donatella. 2007. "The global justice movement: an introduction." In 
Donatella della Porta, ed. The global justice movement: cross-national and transnational perspectives. Boulder and London: Paradigm Publishers, pp. 1 - 28.

della Porta, Donatella et al. 2006. Globalization from below: transnational activists and protest networks. Minneapolis and London: University of Minnesota Press.

della Porta, Donatella, and Mario Diani. 1999. Social movements: an introduction. Oxford: Blackwell Publishing.

Department of Biotechnology, Ministry of Science and Technology. Department of Biotechnology, Government of India. Available at: http://dbtindia.nic.in/uniquepage.asp?id_pk=110 [Accessed October 27, 2009].

Desmarais, Annette Aurélie. 2003. The WTO . . will meet somewhere, sometime. And we will be there! Ottawa: The North-South Institute/L'Institut Nord-Sud. Available at: http://www.nsi- ins.ca [Accessed April 9, 2007].

Digital Liberty Coalition. 2009. Available at: http://www.dlc.asn.au/ [Accessed June 16, 2009].

Doctorow, Cory. 2008a. Little brother. St Martin's Press. Available at: http://craphound.com/littlebrother/download/ [Accessed July 16, 2009].

Doctorow, Cory. 2008b. "Wal*Mart shutting down DRM server, nuking your music collection-only people who pay for music risk losing it to DRM shenanigans." BoingBoing. Available at:

http://boingboing.net/2008/09/26/walmart-shutting-dow.html [Accessed December 12, 2008].

Doctorow, Cory. 2009a. "Brits: act now to stop Parliament from gutting privacy protections." BoingBoing. Available at: http://www.boingboing.net/2009/03/02/brits-act-now-to-sto-1.html [Accessed June 18, 2009].

Doctorow, Cory. 2009b. "EU votes tomorrow on copyright term extension: act now!" BoingBoing. Available at: http://www.boingboing.net/2009/04/22/eu-votes-tomorrow-on.html [Accessed June 18, 2009].

Doctorow, Cory. 2009c. "London cops beating the shit out of peaceful G20 demonstrators." BoingBoing. Available at: http://boingboing.net/2009/04/02/london-cops-beating.html [Accessed July 20, 2009].

Doctorow, Cory. 2009b. "Partial list of corporate lickspittles who are allowed to know what's in the secret copyright treaty the Obama administration claims is a matter of "national security"." BoingBoing. Available at: http://www.boingboing.net/2009/03/14/partial-list-of-corp.html [Accessed 
July 16, 2009].

Donnelly, Elizabeth A. et al. 2002. "Proclaiming Jubilee: the debt and structural adjustment network." In Sanjeev Khagram, James V. Riker, and Kathryn Sikkink, eds Restructuring world politics: transnational social movements, networks, and norms, Minneapolis: University of Minnesota Press, pp. 155 - 180.

Do or Die. 1999. "The Intercontinental Caravan: a critical analysis." Do or Die (8), pp. 28 - 29. Available at: http://www.ecoaction.org/dod/no8/caravan.html [Accessed February 2, 2009].

Downhill Battle. 2008. "Grey Tuesday—free the Grey Album February 24." Grey Tuesday. Available at: http://web.archive.org/web/20080103194743/http://www.greytuesday.org/ [Accessed December 12, 2008].

Eagle Forum. 2008. "Eagle Forum—leading the pro-family movement since 1972." Available at: http://www.eagleforum.org/ [Accessed December 12, 2008].

Edelman, Marc. 2001. "Social movements: changing paradigms and forms of politics." Annual Review of Anthropology 30, pp. 285 - 317.

Electronic Frontier Foundation. 2008. "About EFF." Electronic Frontier Foundation. Available at: http://www.eff.org/about [Accessed October 8, 2008].

Electronic Frontier Foundation. 2009. "EFF and ACLU planning to appeal dismissal of dozens of spying cases." Electronic Frontier Foundation. Available at: http://www.eff.org/press/archives/2009/06/03 [Accessed June 5, 2009].

Electronic Frontiers Australia. 2008. "Labor's mandatory ISP Internet blocking plan." Electronic Frontiers Australia. Available at: http://www.efa.org.au/censorship/mandatory-isp-blocking/ [Accessed June 16, 2009].

Electronic Frontiers Australia. 2009. "Filtering fact sheets." Electronic Frontiers Australia. Available at: http://www.efa.org.au/mandatory-internet-filteringfact-sheets/ [Accessed June 16, 2009].

Elsedoudi, Islam, Kim Jokisch, and Tim Kiernan. 2009. "Video: the seeds of open source." Red Hat Magazine. Available at:

http://magazine.redhat.com/2009/03/20/video/ [Accessed July 20, 2009].

Encyclopaedia Britannica, Inc. 2006. "Fatally flawed: refuting the recent study on encyclopedic accuracy by the journal Nature." Available at: http://corporate.britannica.com/britannica_nature_response.pdf [Accessed May 4, 2009].

Environment Protection Act 1986. Government of India. Available at: 
http://dbtindia.nic.in/uniquepage.asp?id_pk=111 [Accessed October 27, 2009].

Esbin, Barbara S. 2008. "A point of view: Net Neutrality regulation in the United States." Progress \& Freedom Foundation Progress Snapshot Paper, 4(21). Available at: http://www.pff.org [Accessed October 19, 2008].

Escobar, Arturo. 1999. "Gender, place and networks: a political ecology of cyberculture." In Women@internet: creating new cultures in cyberspace, London and New York: Zed Books, pp. 31 - 54.

Evans, Peter. 2000. "Fighting marginalization with transnational networks: counter-hegemonic globalization." Contemporary Sociology 29(1), pp. $230-241$.

Falcon, W. P., and C. Fowler. 2002. "Carving up the commons-emergence of a new international regime for germplasm development and transfer." Food Policy 27(3), pp. 197-222. Available from Science Direct [Accessed April 30, 2009].

Falk, Richard. 1993. "The making of global citizenship." In Jeremy Brecher, John Brown Childs, and Jill Cutler, eds Global visions: beyond the new world order, Boston: South End Press, pp. 39 - 52.

Fallows, James. 2008. "The connection has been reset." The Atlantic.com. Available at: http://www.theatlantic.com/doc/200803/chinese-firewall [Accessed March 5, 2008].

Farivar, Cyrus. 2008. "Lessig, a copyfighter for Congress?" Salon.com Machinist. Available at:

http://machinist.salon.com/blog/2008/02/20/lessig/ [Accessed December 12, 2008].

Farrer, Linden. 2004. "World Forum Movement: abandon or contaminate." In World Social Forum: challenging empires, New Delhi: Viveka Foundation, pp. 168 - 177.

Featherstone, David. 2003. "Spatialities of transnational resistance to globalization: the maps of grievance of the Inter-Continental Caravan." Transactions of the Institute of British Geographers 28(4), pp. $404-421$. Available from JSTOR [Accessed August 3, 2009].

Feenberg, Andrew. 1999. Questioning technology. London and New York: Routledge.

Feenberg, Andrew, and Jim Freedman. 2001. When poetry ruled the streets: the French May events of 1968. Albany, NY: State University of New York Press.

Felten, Edward W. 2007a. "AACS plays whack-a-mole with extracted key." Freedom to Tinker. Available at: http://freedom-totinker.com/blog/felten/aacs-plays-whack-mole-extracted-key [Accessed 
December 8, 2008].

Felten, Edward W. 2007b. "Digg users revolt over AACS key." Freedom to Tinker. Available at: http://freedom-to-tinker.com/blog/felten/digg-usersrevolt-over-aacs-key [Accessed December 8, 2008].

Felten, Edward W. 2007c. "Why the 09ers are so upset." Freedom To Tinker. Available at: http://freedom-to-tinker.com/blog/felten/why-09ers-are-soupset [Accessed October 15, 2008].

Fernandez, Luis A. 2008. Policing dissent: social control and the antiglobalization movement. New Brunswick, New Jersey, and London: Rutgers University Press.

Fink, Carsten, and Patrick Reichenmiller. 2006. "Tightening TRIPS: intellectual property provisions of U.S. free trade agreements." In Richard Newfarmer, ed. Trade, Doha and development: a window into the issues. Washington: The World Bank Trade Department, pp. 285 - 300. Available at:

http://www.tlc.gov.co/econtent/Documentos/Publicaciones/TradeDoha.pdf \#page=292 [Accessed May 4, 2009].

Fisher, D. R. et al. 2005. "How do organizations matter? Mobilization and support for participants at five globalization protests." Social Problems 52(1), pp. 102 - 121.

Flacks, Richard. 2005. "The question of relevance in social movement studies." In David Croteau, William Hoynes, and Charlotte Ryan, eds Rhyming hope and history: activists, academics, and social movement scholarship. Minneapolis and London: University of Minnesota Press, pp. $3-19$.

Foweraker, Joe. 1995. Theorizing social movements. London and Boulder, Colorado: Pluto Press.

Friedman, Thomas. 2000. The Lexus and the olive tree: understanding globalization. 2nd ed. New York: Anchor Books.

Friedman, Thomas. 2005. The world is flat: a brief history of the globalised world in the 21st century. London: Penguin.

Froehling, Oliver. 1999. "Internauts and guerrilleros: the Zapatista rebellion in Chiapas, Mexico, and its extension into cyberspace." In Mike Crang, Phil Crang, and Jon May, eds Virtual geographies: bodies, space and relations. London and New York: Routledge, p. 164 - 177.

Fuck for forest. 2009. Available at: http://www.fuckforforest.com/ [Accessed April $21,2009]$.

Fukuyama, Francis. 1992. The end of history and the last man. London: Hamish Hamilton. 
Gandhi, Vasant P., and N. V. Namboodiri. 2006. "The adoption and economics of Bt cotton in India: preliminary results from a study." Indian Institute of Management Working Paper Series, pp. $1-25$.

Gartner. 2007. "Gartner estimates ICT industry accounts for 2 percent of global CO2 emissions." Gartner: Media Relations. Available at: http://www.gartner.com/it/page.jsp?id=503867 [Accessed November 27, 2008].

Gaylor, Brett. 2009. RiP: a remix manifesto. Eye Steel Film. Available at: http://www3.nfb.ca/webextension/rip-a-remix-manifesto/?ec=en20081015 [Accessed July 21, 2009].

Genachowski, Julius. 2009. "Preserving a free and open Internet: a platform for innovation, opportunity, and prosperity." Speech given at The Brookings Institution, Washington, September $21^{\text {st }}$. OpenInternet.gov. Available at: http://www.openinternet.gov/read-speech.html [Accessed October 29, 2009].

Gene Campaign. 2008. "Structure." Gene Campaign. Available at: http://www.genecampaign.org/Sub \%20pages/issues_structures_strategies=id2.htm [Accessed May 28, 2009].

Glenn, John K. 2003. "Contentious politics and democratization: comparing the impact of social movements on the fall of Communism in Eastern Europe." Political Studies 51(1), pp. 103-120. Available from EBSCOhost [Accessed April 15, 2009].

Globalise resistance. 2009. "WSF Nairobi 2007." Available at: http://www.resist.org.uk/?q=taxonomy/term/75 [Accessed October 12, 2009].

GM Free Karnataka. 2009. Available at: http://gmfreekarnataka.wordpress.com/ [Accessed March 15, 2009].

Goffman, Erving. 1974. Frame analysis: an essay on the organization of experience. New York: Harper \& Row.

Goodin, Dan. 2008. "World+dog ignores Sweden's draconian wiretap bill." The Register. Available at: http://www.theregister.co.uk/2008/06/04/sweden_wiretap_bill/ [Accessed December 10, 2008].

Google Trends, 2009. "yes men." Google Trends. Available at: http://www.google.com/trends? $\mathrm{q}=\mathrm{yes}+\mathrm{men} \& \mathrm{ctab}=0 \& \mathrm{geo}=$ all\&date=ytd\&sort=0 [Accessed November 13, 2009].

Graeber, David. 2004. "The new anarchists." In Tom Mertes, ed. A movement of movements: is another world really possible? London and New York: Verso, pp. 202 - 215. 
Graham, Stephen, and David Wood. 2003. "Digitizing surveillance: categorization, space, inequality." Critical Social Policy 23(2), pp. 227 248. Available from SAGE Publications [Accessed June 8, 2009].

Gramsci, Antonio. 1967. The modern prince. Translated by Louis Marks. New York: International Publishers.

Greenpeace Australia Pacific. 2009. "Canadian farmers GE-free tour." Greenpeace Australia Pacific. Available at: http://www.greenpeace.org/australia/news-andevents/events/previous/canadian-farmers-ge-free-tour [Accessed May 26, 2009].

Greenpeace India and the Centre for Sustainable Agriculture. 2005. "Monsanto's Bt cotton sold on lies and lures." Available at: http://www.greenpeace.org/india/press/releases/monsanto-s-bt-cottonsold-on-I [Accessed August 10, 2008].

GREEN Foundation. 2008a. "Case studies." GREEN Foundation. Available at: http://www.greenconserve.com/Case Studies [Accessed August 9, 2008].

GREEN Foundation. 2008b. "Community seed banks." GREEN Foundation. Available at: http://www.greenconserve.com/About\%20us.htm\#seedbank [Accessed February 15, 2009].

GREEN Foundation. 2008c. "Home page." GREEN Foundation. Available at: http://www.greenconserve.com [Accessed August 9, 2008].

GREEN Foundation. 2009a. "About us." GREEN Foundation. Available at: http://www.greenconserve.com/about.html [Accessed August 13, 2009].

GREEN Foundation. 2009b. "Agrobiodiversity." GREEN Foundation. Available at: http://www.greenconserve.com/agrobiodiversity.html [Accessed July 29, 2009].

GREEN Foundation. 2009c. "Kitchen gardens." GREEN Foundation. Available at: http://www.greenconserve.com/kitchen_gardens.html [Accessed May 28, 2009].

GREEN Foundation. 2009c. "SAP." GREEN Foundation. Available at: http://www.greenconserve.com/sap.html [Accessed July 24, 2009].

Grey, Wellington. 2007. "Science vs. faith." Miscellanea. Available at: http://miscellanea.wellingtongrey.net/2007/01/15/science-vs-faith/ [Accessed April 14, 2009].

Gruère, Guillame P., Purvi Mehta-Bhatt, and Debdatta Sengupta. 2008. "Bt cotton and farmer suicides in India: reviewing the evidence." International Food Policy Research Institute Discussion Paper 00808. Available at: http://www.ifpri.org/publication/bt-cotton-and-farmer-suicides-india [Accessed June 24, 2010]. 
Gupta, Akhil, 1998. Postcolonial developments: agriculture in the making of modern India. Durham and London: Duke University Press.

Gupta, Anil K., and Vikas Chandak. 2005. "Agricultural biotechnology in India: ethics, business and politics." International Journal of Biotechnology 7(1/2/3), pp. 212 - 227. Available at: www.sristi.org/anilg/papers/Agricultural\%20Biotechnology\%20in \%20India.pdf [Accessed June 2, 2009].

Halbert, Deborah J. 1999. Intellectual property in the Information Age: the politics of expanding ownership rights. Westport, Connecticut, and London: Quorum Books.

Hall, Clare, and Dominic Moran. 2006. "Investigating GM risk perceptions: a survey of anti-GM and environmental campaign group members." Journal of Rural Studies 22(1), pp. $29-37$.

Hård, Mikael, and Andrew Jamison. 2005. Hubris and hybrids: a cultural history of technology and science. New York and London: Routledge.

Harding, Sandra. 1991. Whose science? Whose knowledge? Thinking from women's lives. Milton Keynes: Open University Press.

Harvey, David. 2005. A brief history of neoliberalism. Oxford: Oxford University Press.

Haystack. "Haystack: a project for Iran." 2009. Available at:

http://www.haystacknetwork.com/ [Accessed July 16, 2009].

Helprin, Mark. 2009. Digital barbarism: a writer's manifesto. New York: Harper Collins.

Herring, Ronald J. 2001. "Promethean science, Pandora's jug: conflicts around genetically engineered organisms in India." The 2001 Mary Keatinge Das Lecture, Columbia University. Available at:

http://www.sasnet.lu.se/herring.pdf [Accessed December 18, 2006].

Herring, Ronald J. 2004. "Miracle seeds, suicide seeds, and the poor: GMOs, NGOs, farmers, and the state." In Raka Ray and Mary Katzenstein, eds Social movements in India: poverty, power, and politics. New Delhi: Oxford University Press.

Available from:

http://www.einaudi.cornell.edu/southasia/conference/cotton/pdf/04565ch08111.pdf [Accessed December 18, 2006].

Herring, Ronald J. 2008. "Stealth seeds: bioproperty, biosafety, biopolitics." Journal of Development Studies 43 (1), pp. 130 - 157.

Himanen, Pekka. 2001. The hacker ethic and the spirit of the Information Age. London: Secker and Warburg. 
The Hindu. "Bangalore Helix first phase almost ready." Available at: http://www.hindu.com/2008/04/25/stories/2008042550300100.htm [Accessed June 2, 2009].

Hunt, Andrew. 2003. "How new was the new left?" In John McMillian and Paul Buhle, eds The new left revisited. Philadelphia: Temple University Press, pp. 139 - 155.

illunatic. 2009. "Anon causes mischief for IFPI, calls for a media boycott." The Blog Pirate. Available at: http://www.blogpirate.org/2009/04/20/anoncauses-mischief-for-ifpi-calls-for-a-media-boycott/ [Accessed June 17, 2009].

Jardin, Xeni. 2006. "Ecuador: blogging indigenous anti-globalization protests." BoingBoing. Available at: http://www.boingboing.net/2006/03/23/ecuadorblogging-ind.html [Accessed July 20, 2009].

Jardin, Xeni. 2009. "Iranians say "no" to Nokia over reports of surveillance collaboration." BoingBoing. Available at:

http://www.boingboing.net/2009/07/14/iranians-say-no-to-n.html [Accessed July 16, 2009].

Jewitt, Sarah. 2000. "Unequal knowledges in Jharkhand, India: de-romanticizing women's agroecological expertise." Development and Change 31(5), pp. 961-985. Available from Wiley-Blackwell [Accessed May 31, 2009].

Jones, Sydney and Susannah Fox. 2009. Generations online in 2009. Pew Internet and American Life Project. Washington: Pew Research Centre. Available at: http://pewinternet.org/Reports/2009/Generations-Online-in2009.aspx?r=1 [Accessed October 7, 2009].

Jordan, John. 2004. "Our resistance is as transnational as capital." In David Solnit, ed. Globalize liberation: how to uproot the system and build a better world. San Francisco: City Lights, pp. 9 - 16.

Jordan, Tim. 2001. "Language and libertarianism: the politics of cyberculture and the culture of cyberpolitics." Sociological Review 49(1), pp. 1 - 17. Available from Open Research Online at http://oro.open.ac.uk/4903/ [Accessed February 10, 2009].

Jordan, Tim, and Paul A. Taylor. 2004. Hacktivism and cyberwars: rebels with a cause? London and New York: Routledge.

Joshi, Sopan. 2004. "Reviving the Tharparker cattle breed." Down to Earth. Available at: http://www.indiaenvironmentportal.org.in/node/29219 [Accessed July 21, 2009].

Juris, Jeffrey S. 2008. Networking futures: the movements against corporate globalization. Durham and London: Duke University Press.

Juris, Jeffrey S., Giuseppe Caruso and Lorenzo Mosca. 2008. "Freeing software and opening space: social forums and the cultural politics of technology." 
Societies Without Borders 3, pp. 96 - 117.

Kawamoto, D, and E Mils. 2006. "AOL apologizes for release of user search data." Available at: http://www.news.com/2100-1030_3-6102793.html [Accessed May 2, 2007].

kdawson. 2008. "Voters in many states must register by October 6." Slashdot. Available at: http://news.slashdot.org/article.pl?sid=08/10/06/0154218 [Accessed June 11, 2009].

Keane, John. 2003. Global civil society? Cambridge: Cambridge University Press.

Keck, Margaret E., and Kathryn Sikkink. 1998. Activists beyond borders: advocacy networks in international politics. Ithaca and London: Cornell University Press.

Keen, Andrew. 2007. The cult of the amateur: how today's Internet is killing our culture. New York: Doubleday/Currency.

Kelly, Kevin. 2009. "The new socialism: global collectivist society is coming online." Wired.com. Available at:

http://www.wired.com/culture/culturereviews/magazine/1706/nep_newsocialism?currentPage=all [Accessed July 15, 2009].

Khagram, Sanjeev, James V. Riker, and Kathryn Sikkink. 2002. "From Santiago to Seattle: transnational advocacy groups restructuring world politics." In Sanjeev Khagram, James V. Riker, and Kathryn Sikkink, eds Restructuring world politics: transnational social movements, networks, and norms. Minneapolis: University of Minnesota Press, pp. $3-23$.

Kirschenbaum, Matthew. 2008. Mechanisms: new media and the forensic imagination. Cambridge, Massachusetts and London: The MIT Press.

Kiss, Jemima. 2009. "What does the Pirate Bay verdict mean for innovation?" The Guardian. Available at: http://www.guardian.co.uk/media/pda/2009/apr/17/pirate-bay-startups [Accessed June 17, 2009].

Kleinman, Daniel Lee. 2005. Science and technology in society: from biotechnology to the Internet. Massachusetts: Blackwell Publishing.

Klein, Naomi. 2001. No logo. London: Flamingo.

Klein, Naomi. 2004. "Reclaiming the commons." In Tom Mertes, ed. A movement of movements: is another world really possible? London and New York: Verso, pp. 219 - 229.

Kneale, James. 1999. "The virtual realities of technology and fiction: reading William Gibson's cyberspace." In Mike Crang, Phil Crang, and Jon May, eds Virtual geographies: bodies, space and relations. London and New York: Routledge, pp. 205 - 221. 
Kopimi. 2009. "We recieved an email from Belgium." Spectrial. Available at: http://trial.thepiratebay.org/2009/03/03/we-recieved-an-email-frombelgium/ [Accessed June 17, 2009].

Kothari, Smitu. 2002. "Globalization, global alliances, and the Narmada Movement." In Sanjeev Khagram, James V. Riker, and Kathryn Sikkink, eds Restructuring world politics: transnational social movements, networks, and norms. Minneapolis: University of Minnesota Press, p. 231 - 241.

Kravets, David. 2008. "Pirate Bay future uncertain after operators busted." Wired.com. Available at: http://www.wired.com/threatlevel/2008/01/piratebay-futu/ [Accessed June 17, 2009].

Kreisberg, Louise. 1997. "Social movements and global transformation." In Jackie Smith, Charles Chatfield, and Ron Pagnucco, eds Transnational social movements and global politics: solidarity beyond the state. Syracuse: Syracuse University Press, pp. 3 - 18.

Kuhn, Thomas S. 1970. The structure of scientific revolutions. 2nd ed. Chicago: University of Chicago Press.

Latour, Bruno. 1987. Science in action. How to follow scientists and engineers through society. Cambridge, Massachusetts: Harvard University Press.

Latour, Bruno, and Steve Woolgar. 1986. Laboratory life: the construction of scientific facts. 2nd ed. Princeton, New Jersey: Princeton University Press.

Law, John, and John Hassard, eds 1999. Actor Network Theory and after. Oxford: Blackwell Publishing.

The League of Noble Peers. 2007. Steal This Film II. The League of Noble Peers. Available at: http://www.stealthisfilm.com [Accessed February 11, 2008].

Lenhart, Amanda et al. 2007. Teens and social media. Pew Internet and American Life Project. Washington: Pew Research Centre. Available at: http://www.pewinternet.org/Reports/2007/Teens-and-Social-Media.aspx [Accessed October 12, 2009].

Leonard, Tom. 2008. "Skype surveillance system discovered in China." The Telegraph. Available at:

http://www.telegraph.co.uk/news/worldnews/asia/china/3125179/Skypesurveillance-system-discovered-in-China.html [Accessed May 5, 2009].

Leppard, David, and Chris Williams. 2009. "Jacqui Smith's secret plan to carry on snooping." Times Online. Available at: http://www.timesonline.co.uk/tol/news/politics/article6211101.ece [Accessed June 5, 2009]. 
Lessig, Lawrence. 2001. The future of ideas: the fate of the commons in a connected world. New York: Random House.

Lessig, Lawrence. 2004. Free culture: how big media uses technology and the law to lock down culture and control creativity. New York: The Penguin Press. Available at: http://free-culture.org/get-it.

Lessig, Lawrence. 2006. Code: version 2.0. 2nd ed. New York: Basic Books.

Lessig, Lawrence. 2009. "Et tu, KK? (aka, No, Kevin, this is not "socialism")." Lessig Blog. Available at:

http://www.lessig.org/blog/2009/05/et_tu_kk_aka_no_kevin_this_is.html [Accessed July 15, 2009].

Leyden, John. 2009. "Music industry sites DDoSed after Pirate Bay verdict." The Register. Available at:

http://www.theregister.co.uk/2009/04/20/ddos_hacktivism_pirate_bay/ [Accessed June 17, 2009].

Lievrouw, Leah A. 2003. "When users push back: oppositional new media and community." In Marleen Huysman, Etienne Wenger, and Volker Wulf, eds Communities and technologies. Deventer, The Netherlands: Klower, B.V., pp. $391-405$.

Life Sciences Nework. 2003. "FAO report sounds warning for activists." Life Sciences Network. Available at:

http://www.lifesciencesnetwork.com/printpage-news.asp?ID=3429

[Accessed October 23, 2009].

Love 4 Cow Trust. 2009. Love4Cow. Available at:

http://www.love4cow.com/default.htm [Accessed July 21, 2009].

MacDonald, James, Robert Hoppe, and David Banker. 2006. "Growing farm size and the distribution of farm payments." Available at: http://www.ncifap.org/_images/Big_Farms_USDA_report.pdf [Accessed May 26, 2009].

MacKenzie, Donald, and Judy Wajcman, eds 1999. The social shaping of technology. 2nd ed. Maidenhead UK and Philadelphia: Open University Press.

Madsen, Stig Toft. 2001. "The view from Vevey." Economic and Political Weekly 36(39), pp. $3733-3742$.

Marcos, Subcomandante Insurgente. 2003. Untitled photo essay. In Notes from Nowhere, ed. We are everywhere: The irresistible rise of global anticapitalism. London and New York: Verso, pp. 0 - 7.

Marcos, Subcomandante Insurgente. 1997. "Why we are fighting: the fourth world war has begun." Le Monde Diplomatique, English edition. Available at: http://mondediplo.com/1997/09/marcos [Accessed December 19, 2005]. 
Markoff, John. 2008. "Internet traffic begins to bypass the U.S." New York Times. Available at: http://www.nytimes.com/2008/08/30/business/30pipes.html [Accessed June 5, 2009].

Martin, Emily. 1991. "The egg and the sperm: how science has constructed a romance based on stereotypical male-female roles." Signs 16(3), pp. 485 - 501. Available from JSTOR [Accessed February 20, 2008].

Maul, P. F., and Crimethinc Workers' Collective. 2001. Days of war, nights of love. Crimethinc.

McAdam, Doug, Sidney Tarrow and Charles Tilly. 2001. Dynamics of contention. Cambridge: Cambridge University Press.

Milberry, Kate. 2006a. "Reconstructing the Internet: how social justice activists contest technical design in cyberspace." M/C Journal 9(1). Available at: http://journal.media-culture.org.au/0603/10-milberry.php [Accessed July 21, 2009].

Milberry, Kate. 2006b. "Tech activism in the global justice movement: geeks, wikis and IMC." Toronto: Indymedia. Available at: https://docs.indymedia.org/pub/Global/ImcEssayCollection/Geekswikisan dIMC.doc. [Accessed July 20, 2009].

Milberry, Kate. 2009. "In defence of Wikipedia as a research source." Geeks and Global Justice. Available at: http://geeksandglobaljustice.com/?p=59 [Accessed August 28, 2009].

Miniwatts Marketing Group. 2009. "World Internet usage statistics news and world population stats." Internet World Stats. Available at: http://www.internetworldstats.com/stats.htm [Accessed October 7, 2009].

mb_webguy. 2009. "TPB FTW." The Pirate Bay. Available at: http://thepiratebay.org/blog/151 [Accessed June 18, 2009].

McCahill, M. and C. Norris. 2002. CCTV in London, Available at: http://www.urbaneye.net [Accessed October 2, 2008].

McLeod, Kembrew. 2005. "Confessions of an intellectual (property): Danger Mouse, Mickey Mouse, Sonny Bono, and my long and winding path as a copyright activist-academic." Popular Music and Society 28(1), pp. 79 93.

McLuhan, Marshall. 1994. Understanding media: the extensions of man. Cambridge, Massachusetts: MIT Press.

Melucci, Alberto. 1996. Challenging codes: collective action in the Information Age. Cambridge: Cambridge University Press.

Meyer, David S., Nancy Whittier, and Belinda Robnett, eds. 2002. Social 
movements: identity, culture, and the state. Oxford: Oxford University Press.

Midgley, Mary. 1989. Wisdom, information and wonder: what is knowledge for? London and New York: Routledge.

Midnight Notes Collective. 1990. "Introduction to the new enclosures." The new enclosures, Available at: http://www.midnightnotes.org/newenclos.html.

Milburn, Keir. 2004. "Return of the tortoise: Italy's anti-empire multitudes." In David Solnit, ed. Globalize liberation: how to uproot the system and build a better world. San Francisco: City Lights, pp. 469 - 480.

Miller, Laura. 1995. "Women and children first: gender and the settling of the electronic frontier." In James Brook and lain A. Boal, eds Resisting the virtual life: the culture and politics of information. San Francisco: City Lights, pp. 49 - 58.

Ministry of Agriculture and Food, Norway. 2009. "Svalbard Global Seed Vault." Svaldbard Global Seed Vault. Available at:

http://www.regjeringen.no/en/dep/lmd/campain/svalbard-global-seedvault.html?id=462220 [Accessed July 21, 2009].

Mohan, Madan M., 2003. "A sentimental journey that's become a ritual now." The Hindu. Available at: http://www.thehindu.com [Accessed April 16, 2007].

Mola, Ernesto López et al. 2006. "Biotechnology in Cuba: 20 years of scientific, social and economic progress." Journal of Commercial Biotechnology 13(1), pp. 1 - 11. Available from EBSCOhost [Accessed August 12, 2009].

Montgomery, Devin. 2008. "Sweden approves wiretapping bill immediately following last-minute changes." JURIST - Paper Chase. Available at: http://jurist.law.pitt.edu/paperchase/2008/06/sweden-approveswiretapping-bill.php [Accessed December 10, 2008].

Moody, Glyn. 2001. Rebel code: Linux and the open source revolution. London: Penguin Press.

Moses, Asher. 2009. "Conroy admits blacklist error, blames 'Russian mob'." Sunday Morning Herald. Available at: http://www.smh.com.au/news/home/technology/conroy-admits-tohenson-blacklist-error/2009/03/27/1237657120642.html [Accessed June 16, 2009].

Mr. Jalopy. "Owner's manifesto." makezine.com. Available at: http://makezine.com/04/ownyourown/ [Accessed December 11, 2008].

Nanjundaswamy, M. D. 1998a. "Cremating Monsanto: genetically modified fields on fire." In Notes from Nowhere, ed. We are everywhere: the irresistible rise of global anticapitalism. London and New York: Verso, pp. 
$152-154$.

Nanjundaswamy, M. D. 1998b. "An introduction to the Karnataka State Farmers Association, 1998." In Notes from Nowhere, ed. We are everywhere: the irresistible rise of global anticapitalism. London and New York: Verso, pp. 154 - 159.

Navdanya. 2008a. "About us." Navdanya. Available from:

http://www.navdanya.org/about/overview.htm [cited on 9 August 2008].

Navdanya. 2008b. "Overview." Navdanya. Available at: http://www.navdanya.org/about/overview.htm [Accessed September 9, 2008].

Navdanya. 2009. "Mission." Navdanya. Available at: http://www.navdanya.org/about/mission.htm [Accessed July 24, 2009].

Nelson, Gerald C. 2001. "Introduction." In Gerald C. Nelson, ed. Genetically modified organisms in agriculture: economics and politics. San Diego and London: Academic Press, pp. 3 - 6.

NETCompetition.org. "Q \& A One-Pager on Net Neutrality." Available at: http://netcompetition.org/index.php/go/one-page-issue-briefs/.

Norberg, Johan. 2003. In defense of global capitalism. Washington: Cato Institute.

Nordstrom, Louise. 2009. "Sweden: hundreds protest Pirate Bay conviction." Seattle Times. Available at:

http://seattletimes.nwsource.com/html/nationworld/2009074212_apeusw edenpiratebay.html [Accessed June 17, 2009].

Notes from Nowhere. 2003a. "Autonomy: creating spaces for freedom." In Notes from Nowhere Collective, ed. We are everywhere: the irresistible rise of global anticapitalism. London and New York: Verso, pp. 107 - 119.

Notes from Nowhere. 2003b. "Emergence: an irresistible global uprising." In Notes from Nowhere Collective, ed. We are everywhere: the irresistible rise of global anticapitalism. London and New York: Verso, pp. $19-29$.

Notes from Nowhere. 2003c. "Networks: the ecology of the movements." In Notes from Nowhere Collective, ed. We are everywhere: the irresistible rise of global anticapitalism. London and New York: Verso, pp. $63-73$.

Notes from Nowhere. 2003d. "Solidarity and Sabotage." In Notes from Nowhere Collective, ed. We are everywhere: the irresistible rise of global anticapitalism. London and New York: Verso, pp. 456 - 457.

Notes from Nowhere, 2003e. "Walking we ask questions." In Notes from Nowhere Collective, ed. We are everywhere: the irresistible rise of global anticapitalism. London and New York: Verso, pp. 499 - 511. 
Notes from Nowhere, ed. 2003f. We are everywhere: the irresistible rise of global anticapitalism. London and New York: Verso.

Obama, Barack. 2009. "Remarks by the President on securing our nation's cyber infrastructure." The White House Press Office. Available at: http://www.whitehouse.gov/the_press_office/Remarks-by-the-Presidenton-Securing-Our-Nations-Cyber-Infrastructure/ [Accessed June 9, 2009].

Ollman, Dan, Sarah Price, and Chris Smith (Directors). 2003. The Yes Men [Documentary]. United Artists.

Omvedt, Gail. 1998. "Peasants, dalits and women: democracy and India's new social movements." In Manoranjan Mohanty, Partha Nath Mukherji, and O. Törnquist, eds People's rights: social movements and the state in the Third World. New Delhi, Thousand Oaks and London: Sage Publications, pp. $223-242$.

Omvedt, Gail, 1998b. "Terminating choice." In The Hindu, December 14, Available from: http://www.butterfliesandwheels.com/articleprint.php? num $=50$ [Accessed January 4, 2007].

One Big Torrent. 2009. "About." One Big Torrent. Available at: http://onebigtorrent.org/about.php [Accessed July 21, 2009].

O'Neill, Graeme. 2003. "Africa needs GM crops: scientist." Australian Life Scientist. Available at:

http://www.lifescientist.com.au/article/48213/africa_needs_gm_crops_sci entist [Accessed October 23, 2009].

Open Internet Coalition. 2008. Open Internet Coalition. Available at: http://www.openinternetcoalition.com [Accessed December 8, 2008].

Open Source Initiative. 2007. "Home." Open Source Initiative. Available at: http://opensource.org/ [Accessed July 29, 2009].

Pacey, Arnold. 1983. The culture of technology. Cambridge, Massachusetts: MIT Press.

Palant, Wladimir. 2009. "Adblock plus." Add-ons for Firefox. Available at: https://addons.mozilla.org/en-US/firefox/addon/1865 [Accessed July 22, 2009].

Palant, Wladimir. "Adblock plus: frequently asked questions." Adblock Plus project. Available at: http://adblockplus.org/en/faq_project\#contribute [Accessed July 22, 2009].

Patel, Raj. 2007. Stuffed and starved: markets, power and the hidden battle for the world food system. Melbourne: Black Inc.

People's Global Action. 2007. "Brief history of PGA." People's Global Action. Available at:

http://www.nadir.org/nadir/initiativ/agp/en/pgainfos/history.htm [Accessed 
April 21, 2009].

Peretti, Jonah. 2001. "My Nike media adventure." The Nation. Available at: http://www.thenation.com/doc/20010409/peretti [Accessed October 19, 2005].

Pichardo, Nelson A. 1997. "New social movements: a critical review." Annual Review of Sociology 23(1), pp. 411 - 430. Available from EBSCOhost [Accessed April 16, 2009].

Piratpartiet. 2009. "Medlemsantal." Piratpartiet. Available at: http://www.piratpartiet.se/storlek [Accessed June 17, 2009].

Porto Alegre II. 2004. "Resistance to neoliberalism and militarism: for peace and social justice." In Jai Sen et al., eds. World Social Forum: challenging empires. New Delhi: The Viveka Foundation, pp. 102 - 105.

Public Knowledge. 2008. Public Knowledge. Available at: http://www.publicknowledge.org/issues/network-neutrality [Accessed December 12, 2008].

Ramamurthy, Priti, 2004. "Why is buying a "Madras" cotton shirt a political act? A feminist commodity chain analysis." Feminist Studies, 30 (3), pp. 734 769.

Raymond, Eric. 1999. "Eric Raymond in the cab going to the Bazaar." Available at: http://www.linuxtoday.com/news_story.php3?|tsn=1999-12-19-001-07NW-SM [Accessed July 29, 2009].

Raymond, Eric. 2000. "The cathedral and the bazaar, version 3.0." Available at: http://www.tuxedo.org/ esr/ [Accessed August 19, 2007].

Raymond, Eric. 2004. "The Halloween Documents: an appreciation." Eric S. Raymond's Home Page. Available at: http://www.catb.org/ esr/not-theosi/halloween-rant.html [Accessed July 30, 2009].

Rheingold, Howard. 1994. The virtual community: homesteading on the electronic frontier. New York: HarperPerennial.

Resist!ca. 2009. "Resist!ca | appropriate technology." Resist!ca. Available at: http://www.resist.ca/ [Accessed July 21, 2009].

Rhoten, Diana, and Walter W. Powell. 2007. "The frontiers of intellectual property: expanded protection versus new models of open science." Annual Review of Law and Social Science 3, pp. 345 - 373. Available from Annual Reviews [Accessed April 30, 2009].

Richter, Ingo K., Sabine Berking, and Ralf Müller-Schmid, eds. 2006. Building a transnational civil society: global issues and global actors. Houndsmills, Basingstoke, Hampshire and London: Palgrave Macmillan.

Rimmer, Matthew. 2007. Digital copyright and the consumer revolution: hands 
off my iPod. Cheltenham, United Kingdom: Edward Elgar.

Rio Declaration on Environment and Development. 1992. United Nations

Environment Programme. Available at:

http://www.unep.org/Documents.Multilingual/Default.asp

DocumentID=78\&ArticleID=1163 [Accessed May 26, 2009].

riseup. 2009. "riseup home." riseup.net. Available at: http://riseup.net/

[Accessed July 21, 2009].

Roy, Tania, and Craig Borowiak. 2003. "Against ecofeminism: agrarian populism and the splintered subject in rural India." Alternatives: Global, Local, Political 28(1), pp. 57 - 89. Available from EBSCOhost [Accessed May 31, 2009].

Rubin, Jeffrey W. 2002. "From Che to Marcos: the changing grassroots Left in Latin America." Dissent 49(3), pp. 39 - 46.

Rudd, Kevin. 2009. "The global financial crisis." The Monthly 42. Available at: http://www.themonthly.com.au/monthly-essays-kevin-rudd-globalfinancial-crisis-1421?page=0\%2C0 [Accessed August 28, 2009].

Rules for the manufacture, use, import, export and storage of hazardous micro organisms, genetically engineered organisms or cells. 1986. Government of India. Available at: http://dbtindia.nic.in/uniquepage.asp?id_pk=112 [Accessed October 27, 2009].

Samuelson, Pamela. 1997. "The U.S. digital agenda at the World Intellectual Property Organization." Virginia Journal of International Law 37. Available at: http://people.ischool.berkeley.edu/ pam/papers.html [Accessed November 11, 2008].

Samuelson, Pamela, and Randall Davis. 2000. "The digital dilemma: a perspective on intellectual property in the Information Age." Available at: http://people.ischool.berkeley.edu/ pam/papers.html [Accessed November 11, 2008].

Samuelson, Pamela. 2009. "Legally speaking: the dead souls of the Google Booksearch settlement." O'Reilly Radar. Available at: http://radar.oreilly.com/2009/04/legally-speaking-the-dead-soul.html [Accessed July 30, 2009].

Save the Internet. 2008. Save the Internet. Available at: http://www.savetheinternet.com [Accessed December 10, 2008].

Schneier, Bruce. 2008. "CCTV doesn't keep us safe, yet the cameras are everywhere." The Guardian. Available at: http://www.guardian.co.uk/technology/2008/jun/26/politics.ukcrime [Accessed May 5, 2009].

Schultz, Julianne. 1994. "Universal suffrage? Technology and democracy." In Framing technology, eds Lelia Green and Roger Guinery. Australia: Allen 
\& Unwin, pp. $105-117$.

Schwartz, John, and Ariana Eunjung Cha. 2000. "Clinton pledges support at anti-hacking summit." The Washington Post, February 16. Available at: http://courses.cs.vt.edu/cs3604/lib/Hacking/DOS.Clinton.wp.html [Accessed 21 November, 2009].

Sclove, Richard E. 1995. Democracy and technology. New York and London: The Guilford Press.

Scoones, Ian. 2003. "Making policy in the "new economy": the case of biotechnology in Karnataka, India." Working Paper 196. Brighton: Institute of Development Studies. Available from: http://www.ids.ac.uk/download.cfm?file=wp196.pdf [Accessed October 26, 2009].

Scoones, Ian. 2005. "Contentious politics, contentious knowledges: mobilising against GM crops in India, South Africa and Brazil." Working Paper 256. Brighton: Institute of Development Studies. Available from: http://www.drccitizenship.org/docs/publications/citizens_and_science/WP/wp256.pdf [Accessed January 4, 2007].

Scoones, Ian. 2007. "The contested politics of technology: biotech in Bangalore." Science and Public Policy, 34 (4), pp. 261 - 271. Available from Ingenta Connect [Accessed July 12, 2008].

Scoones, Ian. 2008. "Mobilizing against GM crops in India, South Africa and Brazil." Journal of Agrarian Change 8(2 and 3), pp. 315 - 344.

Screen Australia. 2009. "Media and communications devices-household penetration." Screen Australia. Available at: http://www.afc.gov.au/gtp/wnmcomphome.html [Accessed July 21, 2009].

Seed Bill 2004 (draft). Government of India. Available from: http://agricoop.nic.in/seeds/seeds_bill.htm [Accessed October 27, 2009].

Seed Policy 2002. Government of India. Available from: http://agricoop.nic.in/seedpolicy.htm [Accessed October 27, 2009].

Shipman, Alan. 2002. The globalization myth. Cambridge: Icon Books.

Shiva, Vandana, 1991. The violence of the Green Revolution: Third World agriculture, ecology and politics. Zed Books: London and New Jersey; Third World Network: Penang.

Shiva, Vandana. 1993. Monocultures of the mind: perspectives on biodiversity and biotechnology. Zed Books: London and New Jersey; Third World Network: Penang.

Shiva, Vandana. 1997. Biopiracy: the plunder of nature and knowledge. Boston, Massachusetts: South End Press. 
Shiva, Vandana. 1998. "Terminating freedom." The Hindu, December 26. Available from: http://groups.yahoo.com/group/GSN/message/508 [Accessed January 3, 2007].

Shiva, Vandana, 2000. Stolen harvest: the hijacking of the global food supply. London: Zed books.

Shiva, Vandana, 2001. "GMOs: a miracle?" In Gerald C. Nelson, ed. Genetically modified organisms in agriculture: economics and politics. San Diego and London: Academic Press, pp. $191-196$.

Singel, Ryan. 2007. "AT\&T 'spy room' documents released, confirm Wired News' earlier publication." Wired.com. Available at: http://www.wired.com/threatlevel/2007/06/att_spy_room_do/ [Accessed March 4, 2008].

Singel, Ryan. 2008. "Senate approves telco amnesty, legalizes Bush's secret spy program." Wired.com. Available at: http://www.wired.com/threatlevel/2008/02/senate-approves/ [Accessed May 2, 2008].

Sjoden, Kerstin. 2009. "Swedish Pirate Party doubles in size after Bay verdict." Wired.com. Available at: http://www.wired.com/threatlevel/2009/04/swedish-pirate/ [Accessed June 17, 2009].

Slashdot. Available at: http://slashdot.org/ [Accessed June 10, 2009].

Slashdot. 2009. "FAQ - comments and moderation." Available at: http://slashdot.org/faq/com-mod.shtml [Accessed October 9, 2009].

Smythe, Elizabeth and Peter J. Smith. 2008. "Open spaces, open sources: the World Social Forum and international communication rights in a digital world." The annual meeting of the ISA's 49th Annual Convention: Bridging Multiple Divides. San Francisco. Available at: http://www.allacademic.com/meta/p252835_index.html [Accessed October 12, 2009].

Sniggle.net: the culture jammer's encyclopedia. 2009. Available at: http://sniggle.net/ [Accessed April 21, 2009].

Snow, David A., and Robert D. Benford. 1988. "Ideology, frame resonance, and participant mobilization." International Movement Research 1, pp. 197 217.

Snow, David A., E. Burke Rochford, Steven K. Worden, and Robert D. Benford. 1986. "Frame alignment processes, micromobilization, and movement participation." American Sociological Review 51(4), pp. 464 - 481. Available from JSTOR [Accessed October 16, 2009].

SourceForge. 2009. "What is SourceForge.net." Available at: 
http://sourceforge.net/apps/trac/sourceforge/wiki/What\%20is

\%20SourceForge.net? [Accessed July 29, 2009].

Spiro, Lisa. 2008. "Is Wikipedia becoming a respectable academic source?" Digital Scholarship in the Humanities. Available at: http://digitalscholarship.wordpress.com/2008/09/01/is-wikipediabecoming-a-respectable-academic-source/ [Accessed August 28, 2009].

Stallman, Richard M. 2005. "Why "Free Software" is better than "Open Source"." Free Software Foundation. Available at: http://www.fsf.org/licensing/essays/free-software-for-freedom.html [Accessed December 11, 2008].

Stallman, Richard M. 2008. "Interview: Richard M. Stallman." Available at: http://www.gnu.org/philosophy/luispo-rms-interview.html [Accessed July 15, 2009].

Starr, Amory. 2006. Naming the enemy: anti-corporate movements confront globalization. Australia, London and New York: Pluto Press and Zed Books.

Stehr, Nico, and Bernd Weiler. 2008. "Knowledge and the law: can knowledge be made just?" In Nico Stehr and Bernd Weiler, eds Who owns knowledge? Knowledge and the law. New Brunswick and London: Transaction Publishers, pp. $1-13$.

Sterling, Bruce. 1992. The hacker crackdown. Available at: http://www.mit.edu/hacker/hacker.html [Accessed August 16, 2007].

Stone, Glenn Davis. 2002a. "Biotechnology and Suicide in India." Expanded version of original published in Anthropology News, 43 (5). Available from: http://www.artsci.wustl.edu/ anthro/research/biotech_suicide.html [Accessed December 18, 2006].

Stone, Glenn Davis, 2002b. "Both sides now: fallacies in the geneticmodification wars, implications for developing countries, and anthropological perspectives." Current Anthropology, 43(4), pp. 611 630.

Stone, Glenn Davis, 2007. "Agricultural deskilling and the spread of genetically modified cotton in Warangal." Current Anthropology, 48(1), pp. 67 - 103.

Subramanian, Arvind. 1991. "The international economics of intellectual property right protection: a welfare theoretic trade policy analysis." World Development 19(8), pp. 945 - 956.

Swidler, Ann, and Jorge Aditi. 1994. "The new sociology of knowledge." Annual Review of Sociology 20, pp. 305 - 329. Available from JSTOR [Accessed April 13, 2009].

Tarrow, Sidney. 2005. The new transnational activism. New York: Cambridge University Press. 
Tectonic. 2007. "Microsoft software banned at WSF." Available at: http://www.tectonic.co.za/?p=1345 [Accessed September 2, 2009].

Teivainen, Teivo. 2004. "The World Social Forum: arena or actor?" In Jai Sen et al., eds World Social Forum: challenging empires. New Delhi: The Viveka Foundation, pp. $122-129$.

Thompson, Bill. 2009. "Swords drawn in Pirate Bay." New Statesman. Available at: http://www.newstatesman.com/scitech/2009/05/pirate-bay-swedishfile-rights [Accessed June 17, 2009].

Tilly, Charles. 2004. Social movements, 1768 - 2004. Boulder and London: Paradigm Publishers.

Titanium, Johnny "DocEvil". 2007. "The Art of Wikigroaning." Something Awful. Available at: http://www.somethingawful.com/d/news/wikigroaning.php [Accessed July 27, 2009].

Tomales Bay Institute. 2003. "The state of the commons." Available at: http://www.onthecommons.org.

The Tor Project. 2009. "Tor: anonymity online." The Onion Router. Available at: http://www.torproject.org/ [Accessed July 22, 2009].

Torvalds, Linus, and David Diamond. 2001. Just for fun: the story of an accidental revolutionary. New York: Harper Collins.

Townes, J. "Bangin in Banga." Available at: http://www.nadir.org/nadir/initiativ/agp/new/en/pgabang2.htm.

Townsend, Anthony. 2001. "Network cities and the global structure of the Internet." The American Behavioral Scientist 44(10): 1697 - 1716. Available from Proquest [Accessed June 4, 2009].

Vaidhyanathan, Siva. 2004a. The anarchist in the library. New York: Basic Books.

Vaidhyanathan, Siva. 2004b. "The state of copyright activism." First Monday 9(4). Available at: http://firstmonday.org/issues/issue9_4/siva/index.html [Accessed December 8, 2008].

Vaidhyanathan, Siva. 2009. The googlization of everything. Available at: http://www.googlizationofeverything.com/ [Accessed July 30, 2009].

Van Gelder, Sarah Ruth, 2003. "Earth democracy: an interview with Vandana Shiva." Yes! magazine. Available at: http://www.yesmagazine.org/article.asp?ID=570 [Accessed on July 13, 2005].

Venter, Dawid, and Ignatius Swart. 2002a. "Challenging global capitalism: antiglobalisation organisation as a fourth generation people's movement 
(Part I)." Transnational Associations 54(2), pp. 110 - 126.

Venter, Dawid, and Ignatius Swart. 2002b. "Challenging global capitalism: antiglobalisation organisation as a fourth generation people's movement (Part II)." Transnational Associations 54(3), pp. 188 - 204.

Via Campesina. 2009. "Organisation." La Via Campesina: International Peasant Movement. Available at:

http://www.viacampesina.org/main_en/index.php? option=com_content\&task=blogcategory\&id=27\&ltemid=44 [Accessed April 21, 2009].

von Lohmann, Fred. 2009. "Google Book Search settlement: a reader's guide." Electronic Frontier Foundation. Available at: http://www.eff.org/deeplinks/2008/10/google-books-settlement-readersguide [Accessed July 30, 2009].

Vulliamy, Ed. 2002. "Venezuela coup linked to Bush team." The Guardian. Available at: http://www.guardian.co.uk/world/2002/apr/21/usa.venezuela [Accessed April 15, 2009].

Wajcman, Judy. 2004. Technofeminism. Cambridge, UK: Polity Press.

Wapner, Paul. 1995. "Politics beyond the state: environmental activism and world civic politics." World Politics 47, pp. $311-340$.

Waterman, Peter. 1998. Globalization, social movements and the new internationalisms. London and Washington: Mansell.

Wayner, Peter. 2000. Free for all: how Linux and the free software movement undercut the high-tech titans. New York: Harper Business.

Wheeler, David A. 2005. "Why open source software/free software (OSS/FS, FLOSS, or FOSS)? Look at the numbers!" Available at: http://www.dwheeler.com/oss_fs_why.html [Accessed August 19, 2007].

Whitaker, Chico. 2004. "The WSF as open space." In Jai Sen et al., eds World Social Forum: challenging empires. New Delhi: The Viveka Foundation, pp. $111-121$.

Wikipedians. 2009a. "Criticism of Wikipedia." Wikipedia. Available at: http://en.wikipedia.org/wiki/Wikigroaning\#Systemic_bias_in_coverage [Accessed July 27, 2009].

Wikipedians. 2009b. "John Perry Barlow." Wikipedians. Available at: http://en.wikipedia.org/wiki/John_Perry_Barlow\#cite_refGoldsmith_and_Wu.2C_2006.2C__p.17_0-1 [Accessed July 17, 2009].

Wikipedians. 2009c. "Usage share of web browsers." Wikipedia. Available at: http://en.wikipedia.org/wiki/Usage_share_of_web_browsers\#TheCounter. com [Accessed June 9, 2009]. 
Wray, Stephen. 1998. "On electronic civil disobedience." Defining Lines: $<$ Breaking Down Borders>. Available at: http://cristine.org/borders/Wray_Essay.html [Accessed October 15, 2008].

WTO. 1994. "Agreement on Trade-Related Intellectual Property Rights." Available at: http://www.wto.org/english/docs_e/legal_e/27-trips.pdf.

Youngs, Gillian. 2007. Global political economy in the Information Age: power and inequality. London and New York: Routledge.

Zittrain, Jonathan L. 2008. The future of the Internet, and how to stop it. New Haven \& London: Yale University Press. Available at: http://www.jz.org [Accessed June 9, 2008].

Zwick, Mark and Zwick, Louise, 2000. "Multinationals rob seeds of poor: Vandana Shiva and Houston Catholic workers protest patenting of life forms at RiceTec in Alvin, Texas." Houston Catholic Worker, 20 (7). Available from: http://www.cjd.org/paper/shiva.html [Accessed August 9, 2008]. 